Universidad de Lima

Facultad de Ingeniería y Arquitectura

Carrera de Ingeniería Industrial

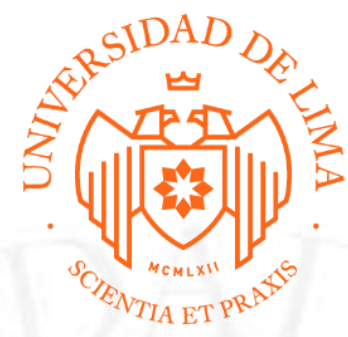

\title{
ESTUDIO DE PRE FACTIBILIDAD PARA LA \\ INSTALACIÓN DE UNA ESTACIÓN DE SERVICIO EN HUANCAYO
}

Trabajo de investigación para optar el título profesional de Ingeniero Industrial

\author{
Hanna Sheyla Alama Quinto \\ Código 20130017 \\ Marco Luis Ramos Sánchez \\ Código 20131094
}

\author{
Asesor \\ Ruth Vásquez Rivas Plata
}

Lima - Perú

Julio del 2019 


\section{ESTUDIO DE PREFACTIBILIDAD PARA LA INSTALACIÓN DE UNA ESTACIÓN DE SERVICIO EN HUANCAYO}




\section{TABLA DE CONTENIDO}

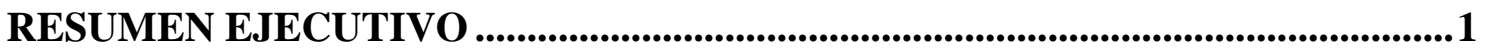

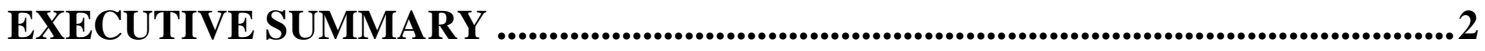

CAPÍTULO I: ASPECTOS GENERALES......................................................................3

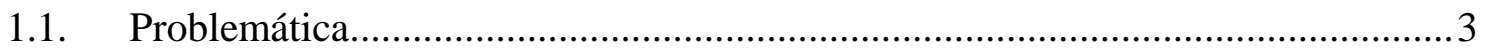

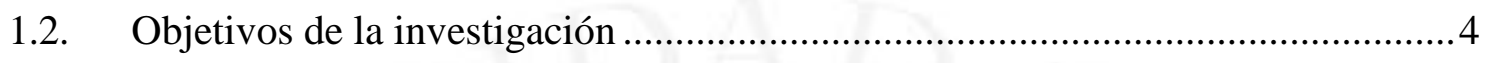

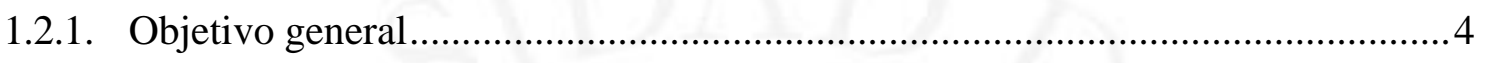

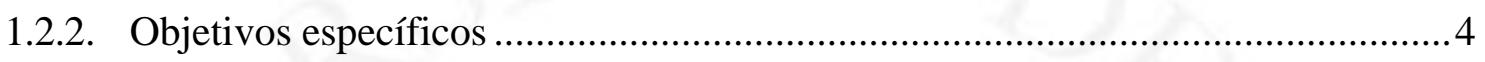

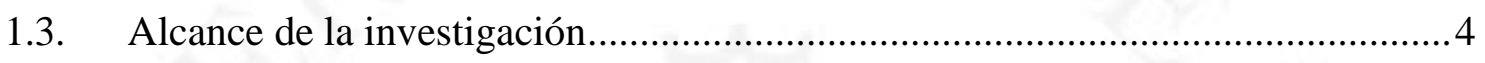

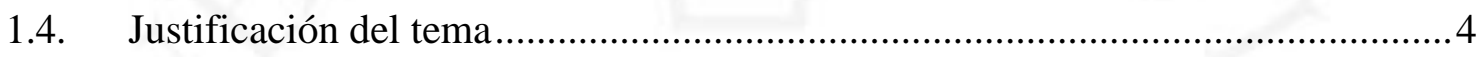

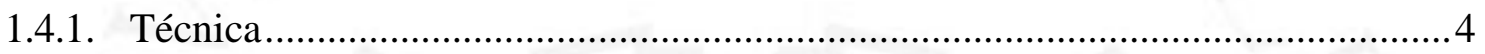

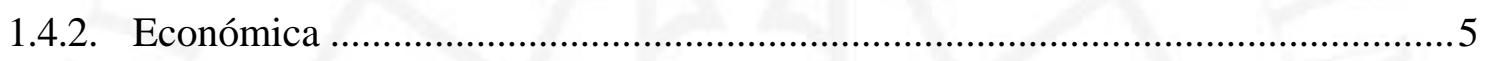

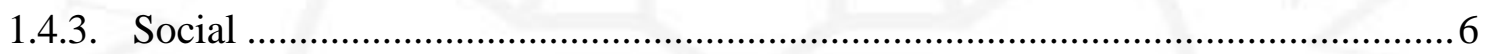

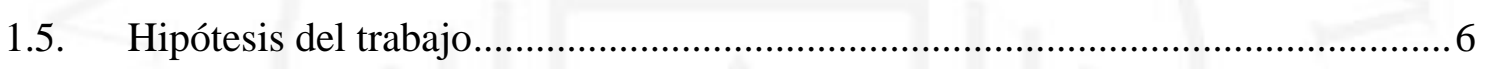

1.6. Marco referencial ................................................................................... 7

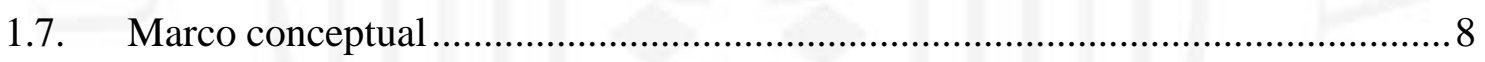

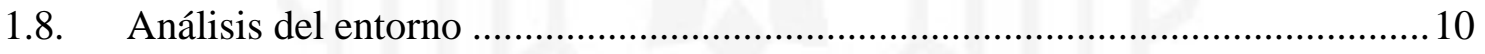

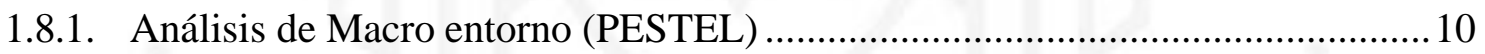

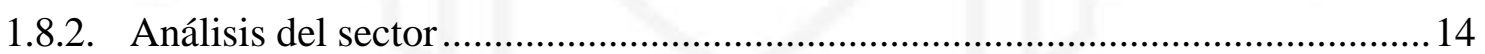

CAPÍTULO II: ESTUDIO DE MERCADO .............................................................. 18

2.1. Aspectos generales del estudio de mercado................................................... 18

2.1.1. Definición del giro de negocios del servicio y tipo de servicio ......................... 18

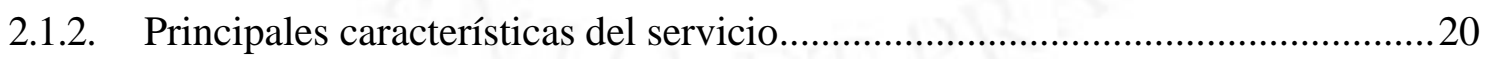

2.1.3. Definición del área de influencia del servicio.................................................22

2.1.4. Determinación de la metodología que se empleará en la investigación de

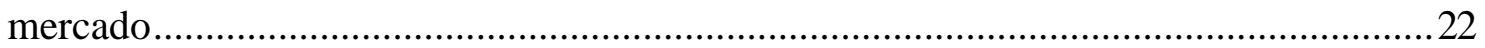

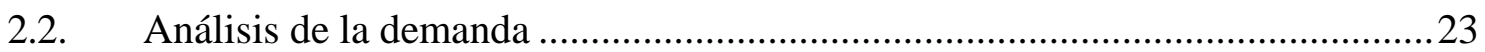

2.2.1. Cuantificación de los posibles mercados objetivo ..........................................23

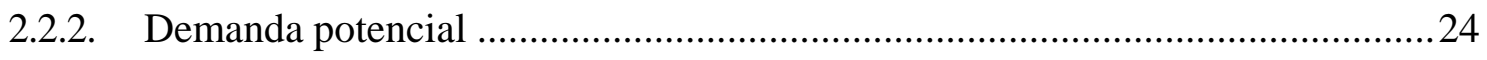

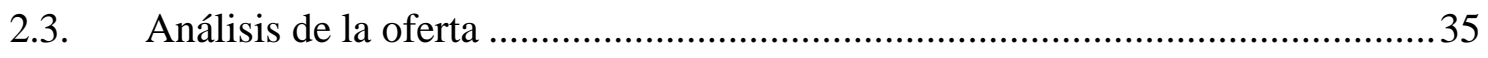

2.3.1. Análisis de la competencia. Competencia directa y sus ubicaciones. 
Participación de mercado.....

2.3.2. Descripción de las características del servicio ofertado por los principales competidores .36

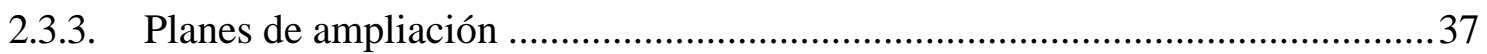

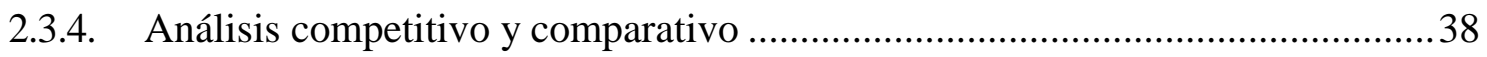

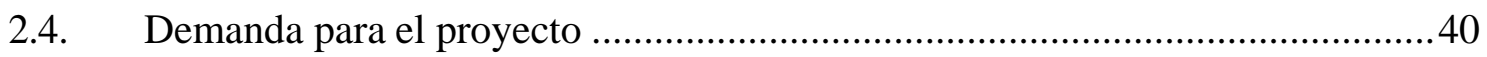

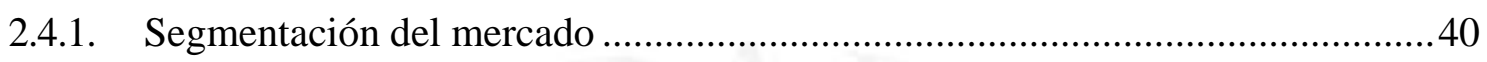

2.4.2. Selección de mercado meta............................................................................ 41

2.4.3. Determinación de la demanda para el proyecto ............................................... 41

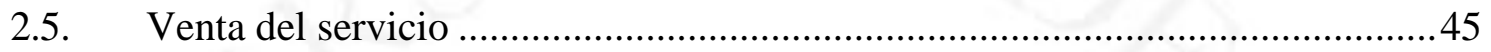

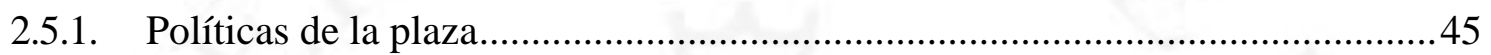

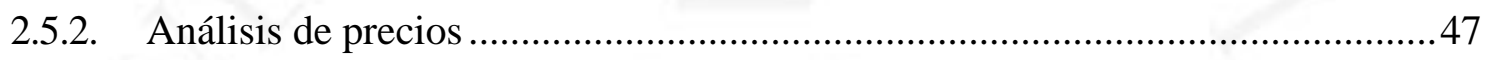

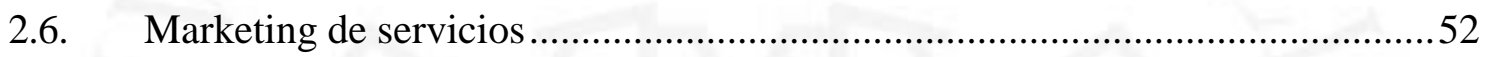

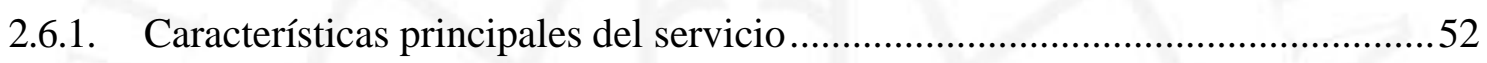

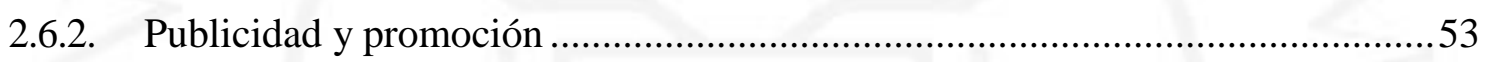

CAPÍTULO III: LOCALIZACIÓN DE SERVICIO ...................................................55

3.1. Identificación y análisis detallado de los factores de micro localización ..........55

3.2. Identificación y descripción de las alternativas de micro localización...............58

3.3 Evaluación y selección de localización..............................................................59

CAPÍTULO IV: DIMENSIONAMIENTO DEL SERVICIO...................................61

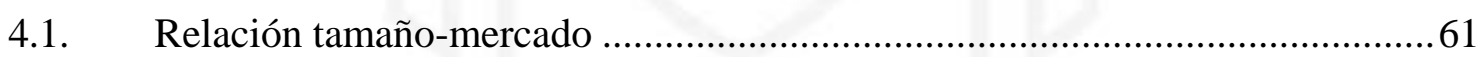

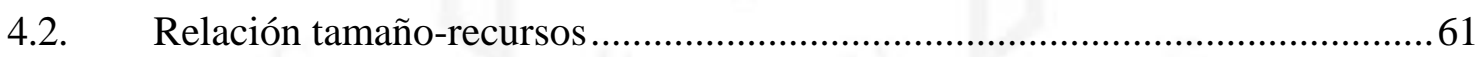

4.3. Relación tamaño-tecnología (cuello de botella de los factores críticos

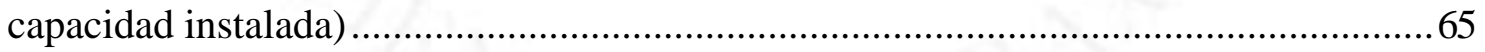

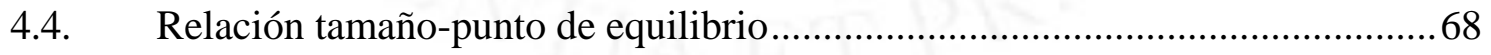

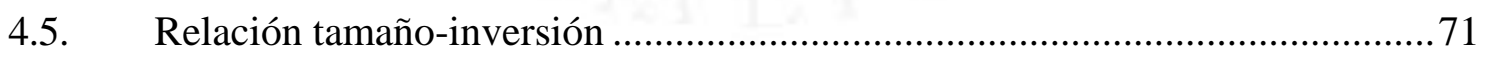

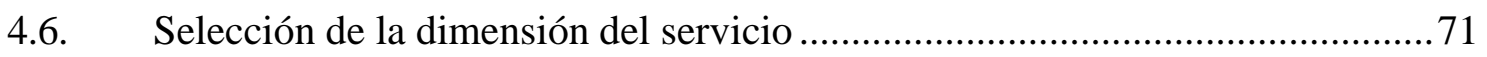

CAPÍTULO V : INGENIERÍA DEL PROYECTO.....................................................73

5.1. Definición del servicio basada en sus características de operación ...................73

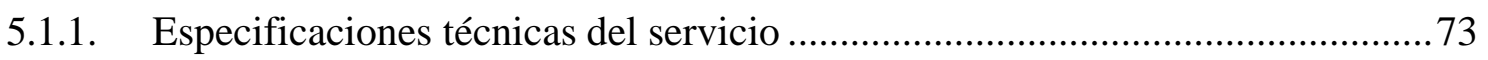

5.2. Tecnología existente y proceso de realización del servicio ..............................73

5.2.1. Descripción y selección del tipo de tecnología a usarse en el servicio..............73

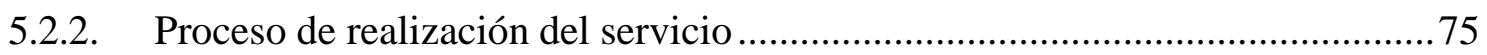

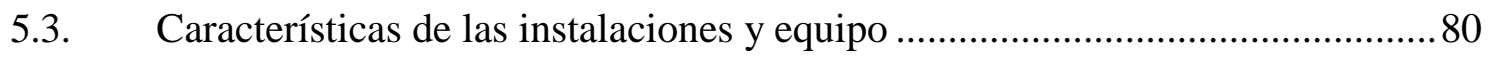


5.4.1. Identificación y descripción de los factores que intervienen en brindar el servicio (M- O. Equipo, instalaciones, tecnologías y otros) ...................................... 81

5.4.2. Determinación del factor limitante de la capacidad.......................................... 82

5.4.3. Determinación del número de recursos del factor limitante .............................. 82

5.4.4. Determinación del número de recursos de los demás factores .......................... 83

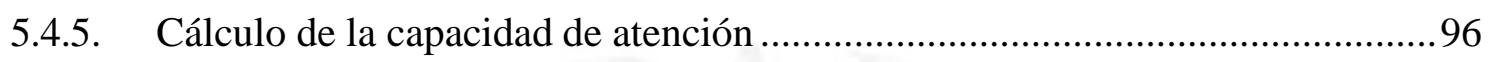

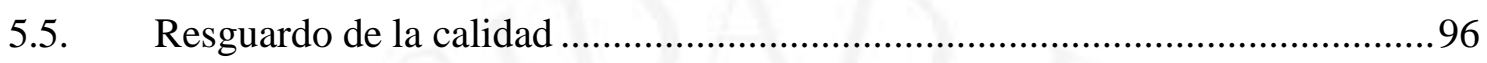

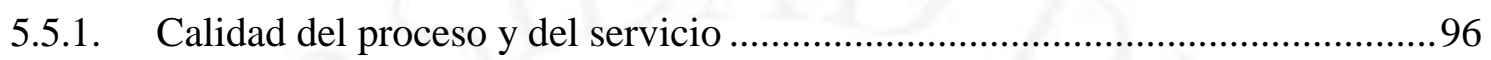

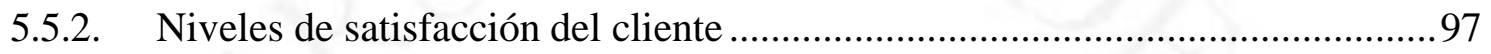

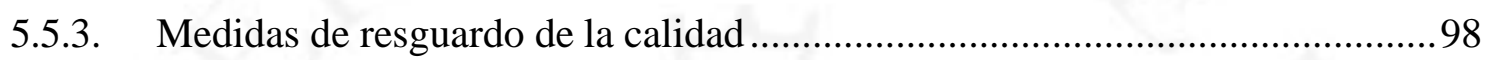

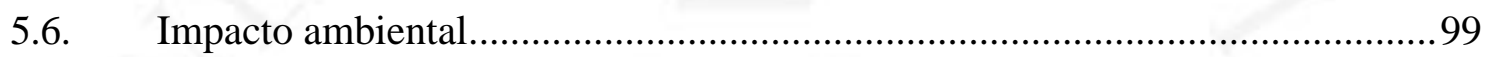

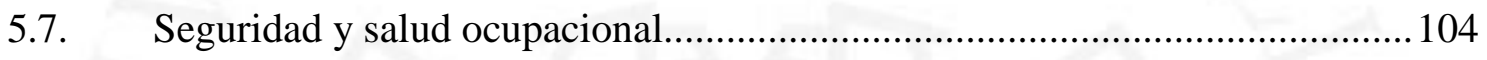

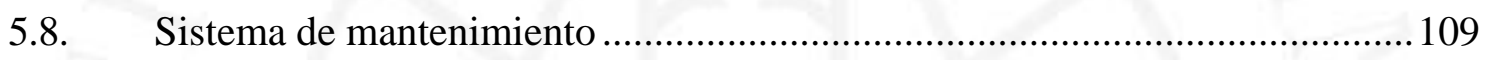

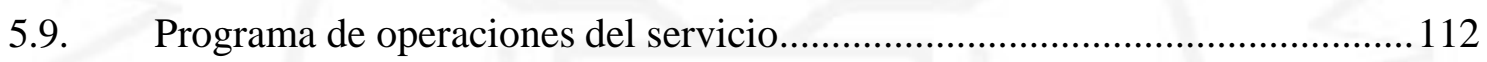

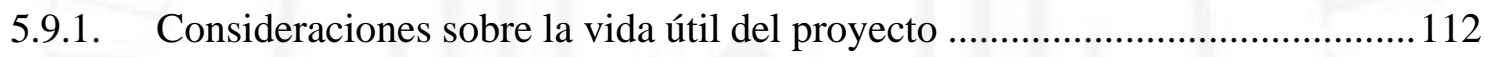

5.9.2. Programa de operaciones del servicio durante la vida útil del proyecto.......... 112

5.10. Requerimiento de materiales, personal y servicios ....................................... 113

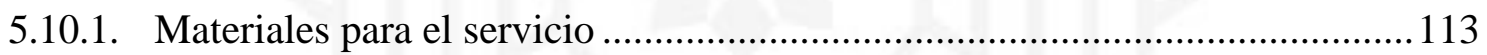

5.10.2. Determinación del requerimiento de personal de atención al cliente .............. 115

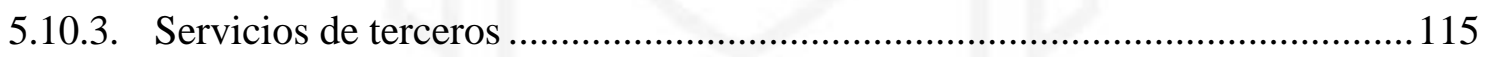

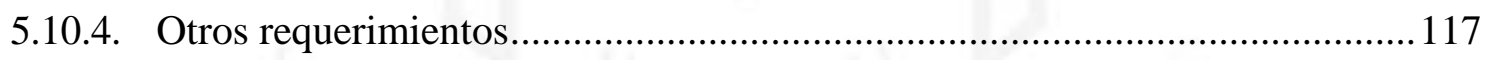

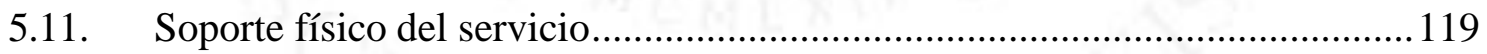

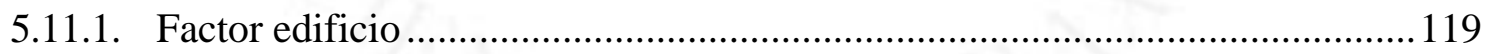

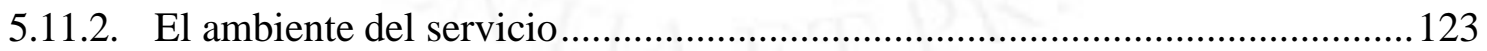

5.12. Disposición de la instalación del servicio ........................................................ 125

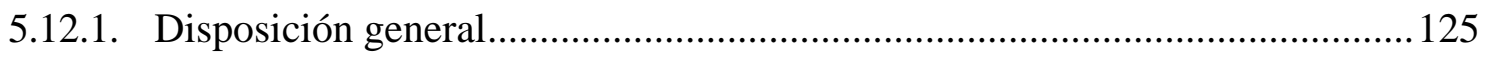

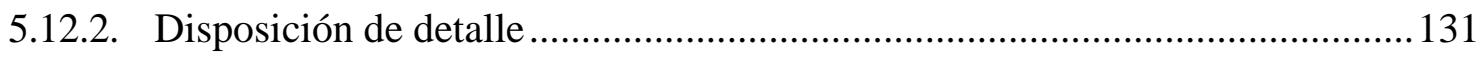

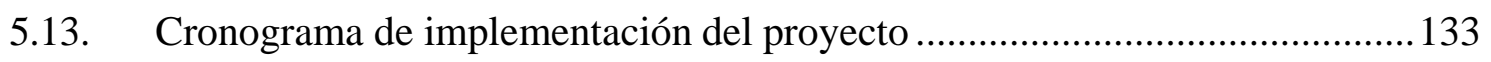

CAPÍTULO VI: ORGANIZACIÓN ADMINISTRATIVA ....................................... 134

6.1. Formación de la organización empresarial .................................................... 134

6.2. Requerimientos de personal directivo, administrativo y de servicios; y funciones $\quad$ generales de los principales puestos .................................................. 135

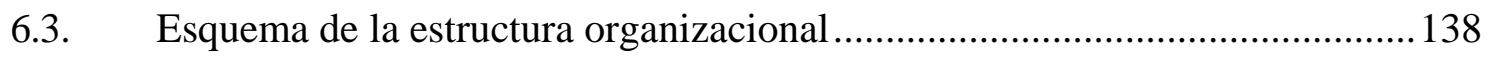


CAPÍTULO VII. PRESUPUESTOS Y EVALUACIÓN DEL PROYECTO.........139

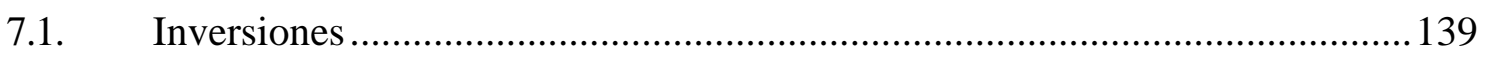

7.1.1. Estimación de las inversiones de largo plazo .................................................139

7.1.2. Estimación de las inversiones de corto plazo ................................................ 147

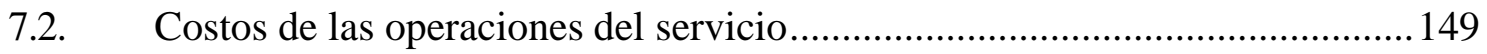

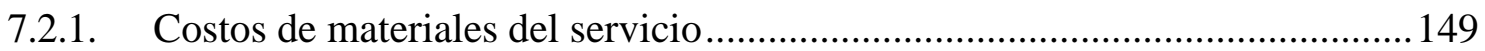

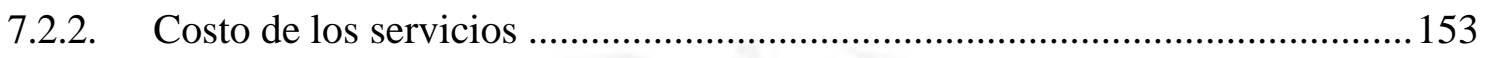

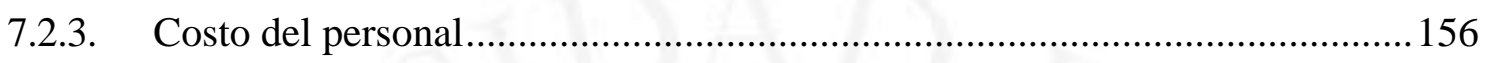

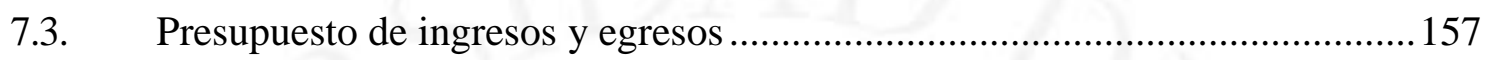

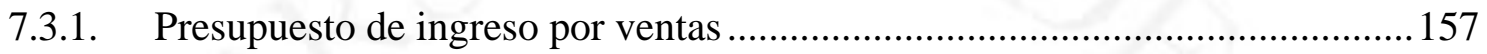

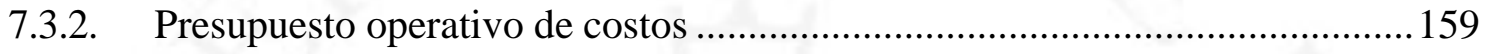

7.3.3. Presupuesto operativo de gastos administrativos.......................................... 161

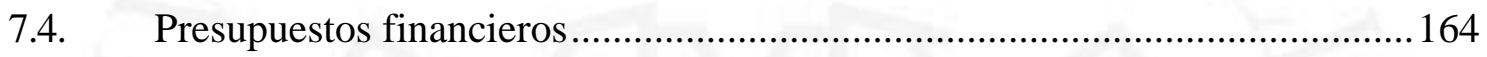

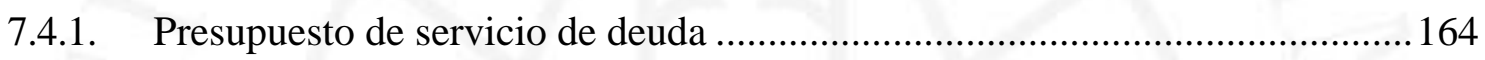

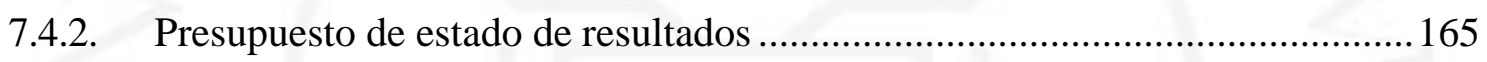

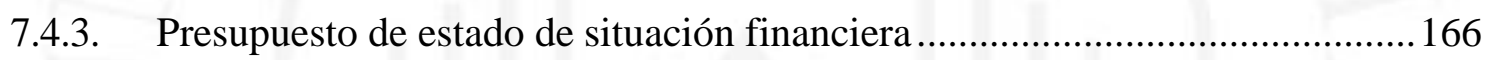

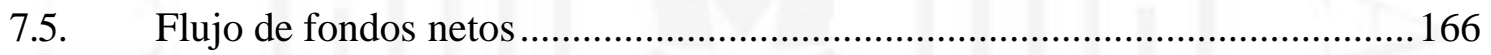

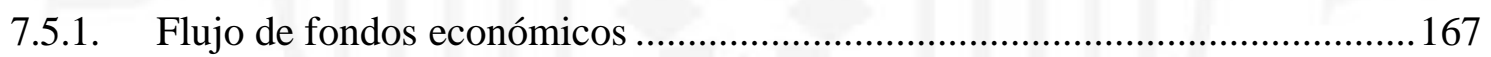

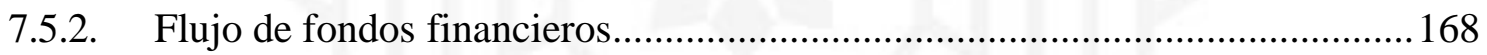

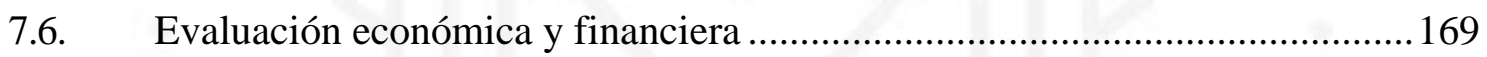

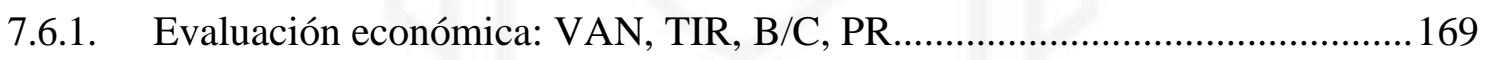

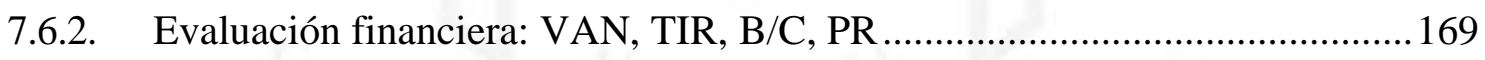

7.6.3. Análisis de los resultados económicos y financieros del proyecto .................. 169

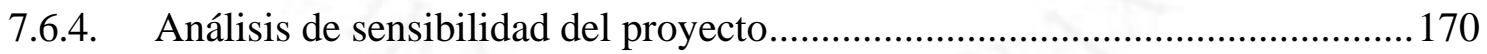

CAPÍTULO VIII. EVALUACIÓN SOCIAL DEL PROYECTO .............................173

8.1. Identificación de las zonas y comunidades de influencia del proyecto ............173

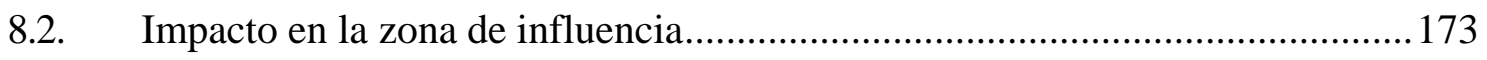

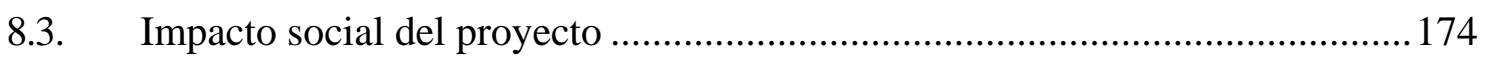

CONCLUSIONES ........................................................................................... 175

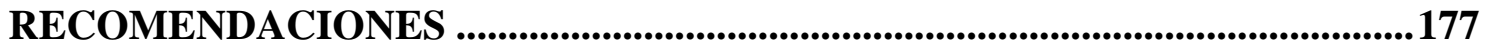

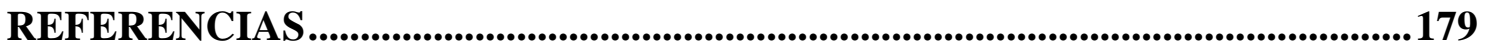

BIBLIOGRAFÍA ….....................................................................................................181

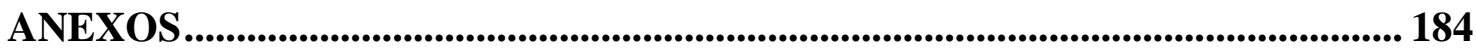




\section{ÍNDICE DE TABLAS}

Tabla 1.1 Cuadro comparativo con Plan de negocios de la empresa El Sol S.A..............7

Tabla 1.2 Cuadro comparativo con estudio preliminar para la instalación de una

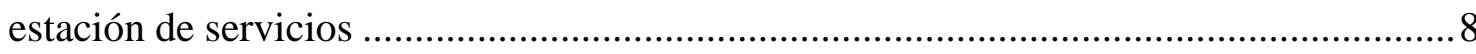

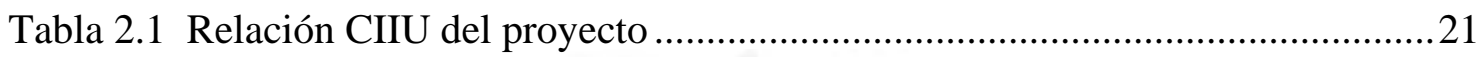

Tabla 2.3 Número de vehículos según departamentos...............................................24

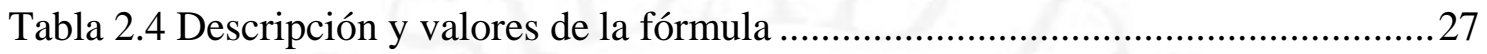

Tabla 2.5 Parque vehicular estimado para Junín, años 2007-2016 en unidades vehiculares .31

Tabla 2.6 Parque vehicular estimado para Huancayo, años 2007-2016 en unidades vehiculares 31

Tabla 2.7 Coeficiente de correlación de diferentes métodos de proyección.....................32

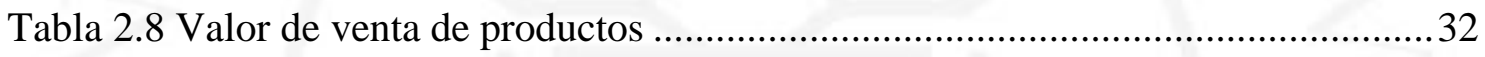

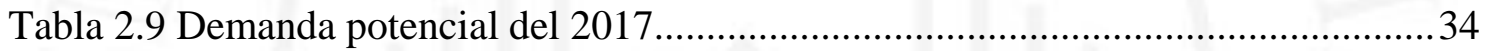

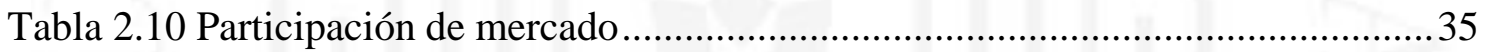

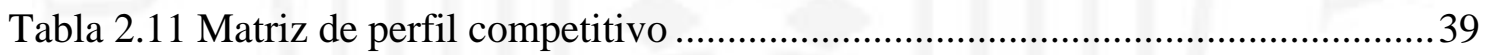

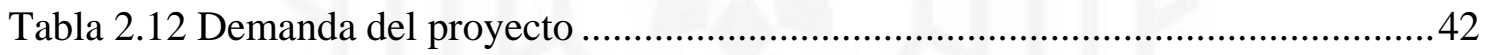

Tabla 2.13 Proporción de ingresos anuales según tipo de combustible..........................43

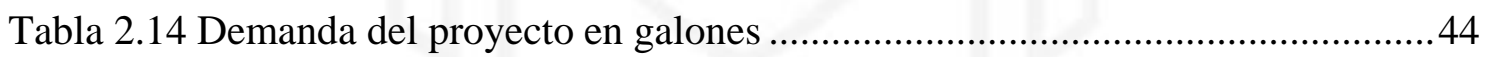

Tabla 2.15 Relación de valores de venta de Diesel B5 ................................................48

Tabla 2.16 Relación de valores de venta del petróleo Gasohol 97 ................................48

Tabla 2.17 Relación de valores de venta del petróleo Gasohol 95 ................................49

Tabla 2.18 Relación de valores de venta del petróleo Gasohol 90 ................................49

Tabla 2.19 Relación de valores de venta del GLP ......................................................49

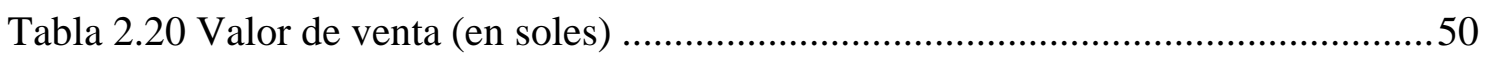

Tabla 2.21 Precio proyectado de petróleo................................................................50

Tabla 2.22 Costos proyectados de combustibles según variación de precio de materia

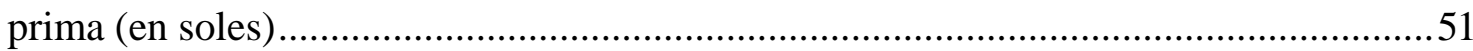

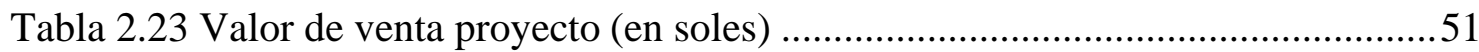

Tabla 2.24 Gasto por promoción (en soles) ...................................................................54

Tabla 2.25 Cantidad de lubricantes que se regalarán..................................................54 
Tabla 3.1 Calificación para Factor "Largo frontis"

Tabla 3.2 Calificación para Factor "Flujo vehicular"....................................................56

Tabla 3.3 Calificación para Factor "Cantidad de lugares estratégicos cercanos"............56

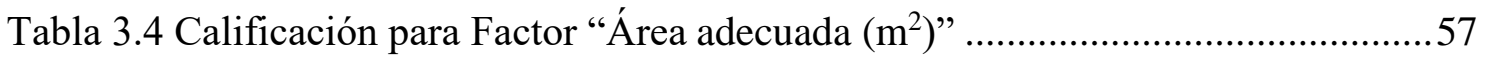

Tabla 3.5 Calificación para Factor "Costo por metro cuadrado"...................................57

Tabla 3.6 Calificación para Factor "Cantidad de cuadras de la estación más cercana".58

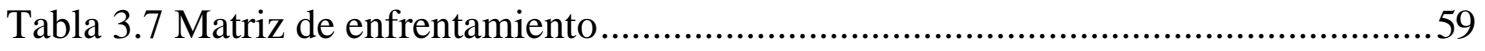

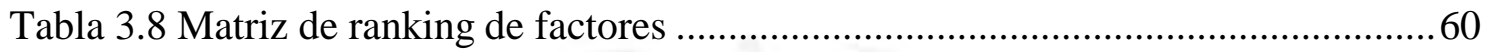

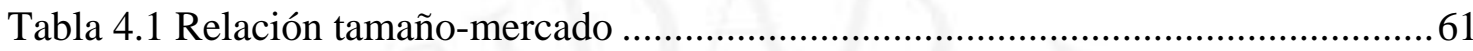

Tabla 4.2 Porcentaje de ventas de Petroperú que representa el abastecimiento del grifo

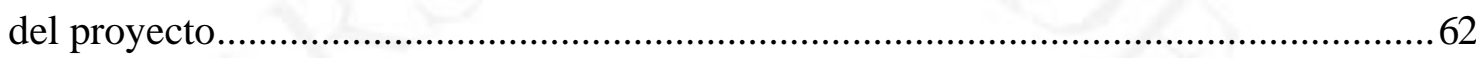

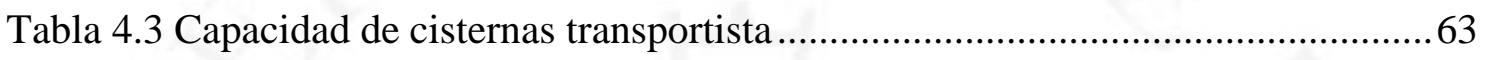

Tabla 4.4 Comparación entre capacidad transportista y demanda anual ........................63

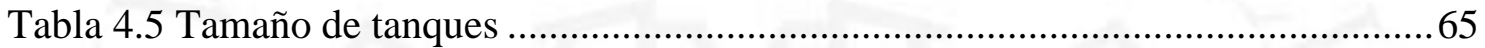

Tabla 4.6 Proporción de tiempo de abastecimiento ........................................................67

Tabla 4.7 Porcentaje de ocupación de estación de servicios en un día............................67

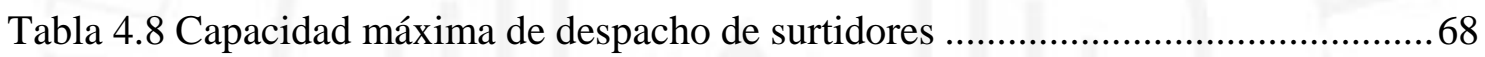

Tabla 4.9 Márgenes de contribución unitarios por galón (en soles) ...............................69

Tabla 4.10 Costos fijos anuales y mensuales del proyecto (en soles)...........................69

Tabla 4.11 Cálculo de margen de contribución ponderado total .....................................70

Tabla 4.12 Total galones punto de equilibrio ............................................................. 70

Tabla 4.13 Determinación del punto de equilibrio ..................................................... 70

Tabla 4.14 Cuadro resumen de inversión .......................................................................... 71

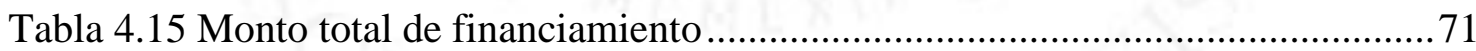

Tabla 4.16 Determinación de capacidad de proyecto ................................................... 71

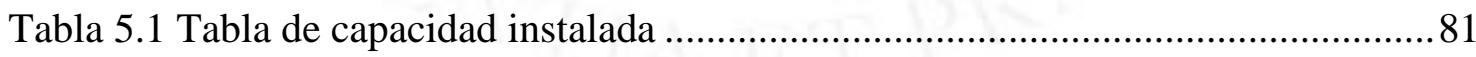

Tabla 5.2 Número de mangueras por tipo de combustible ........................................... 83

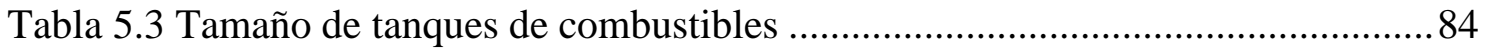

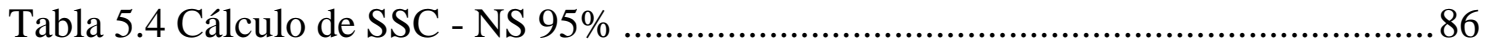

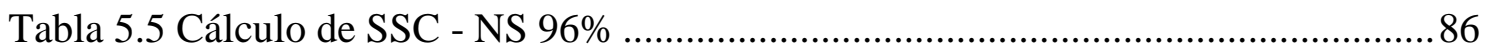

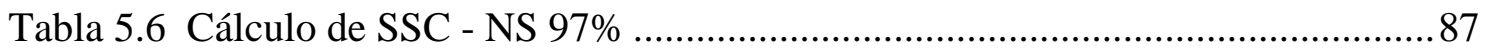

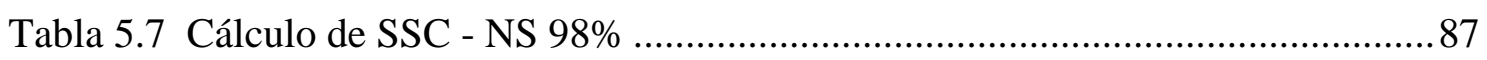

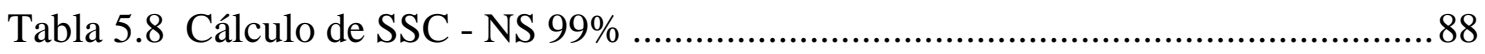

Tabla 5.9 Demanda 2028 vs tamaño tanques........................................................... 92 
Tabla 5.10 Turnos en estación de servicios según \% de ocupación .94

Tabla 5.11 Tamaño de pedidos de combustibles año 2023 .95

Tabla 5.12 Distribución de abastecimiento por compartimentos de camiones del proveedor .95

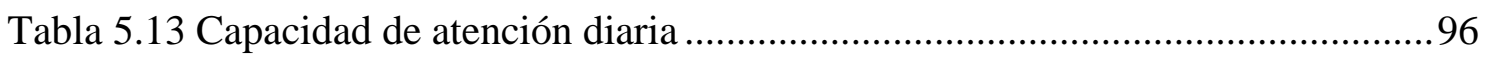

Tabla 5.14 Valoración de la magnitud del impacto para matriz Leopold ......................100

Tabla 5.15 Valoración de la importancia del impacto para matriz Leopold .................. 100

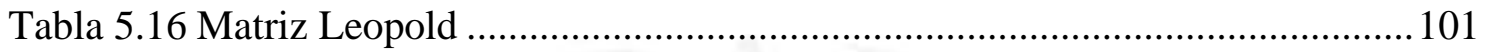

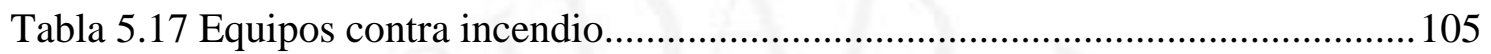

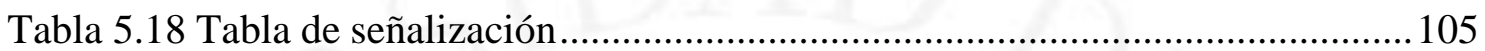

Tabla 5.19 Matriz IPERC del proceso de descargue de combustible ............................ 106

Tabla 5.20 Matriz IPERC del proceso de atención al cliente ...................................... 107

Tabla 5.21 Programa de mantenimiento preventivo .................................................. 110

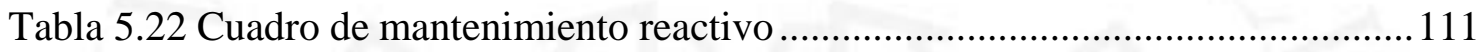

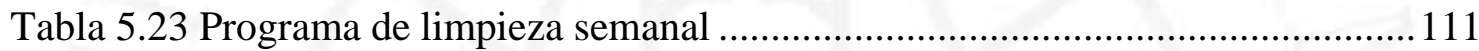

Tabla 5.24 Requerimiento de insumos para atención directa ......................................113

Tabla 5.25 Requerimiento de materiales de atención directa ..................................... 114

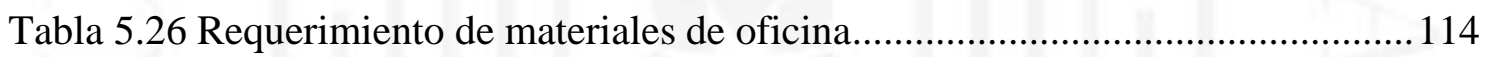

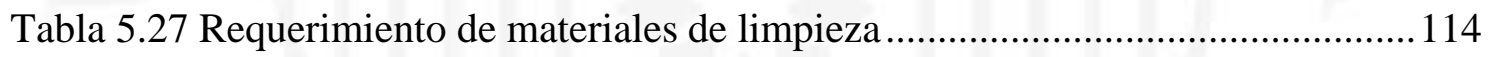

Tabla 5.28 Requerimiento de materiales para mantenimiento de máquinas ................115

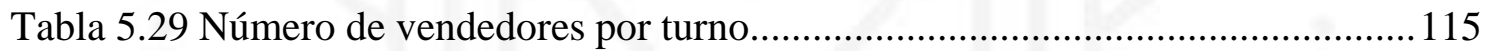

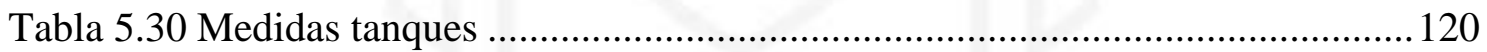

Tabla 5.31 Lista de códigos según valor de proximidad ...............................................125

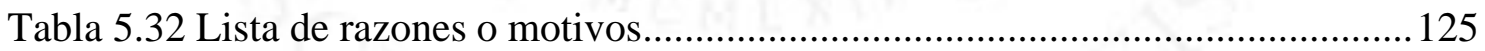

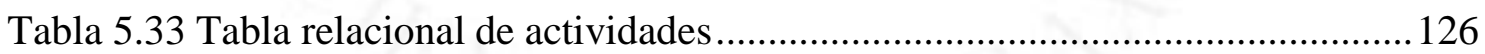

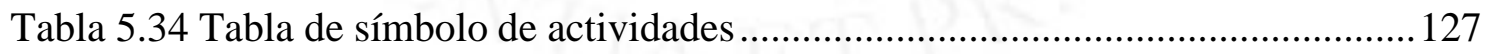

Tabla 5.35 Agrupación de las actividades de acuerdo a sus valores de proximidad .... 128

Tabla 5.36 Diagrama relacional de actividades .......................................................... 128

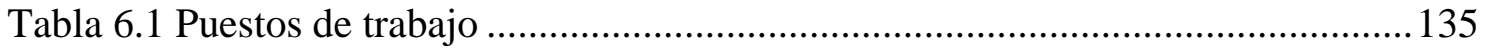

Tabla 7.1 Cuadro de resumen de inversión................................................................. 139

Tabla 7.2 Cuadro resumen de inversión en activo tangible ........................................139

Tabla 7.3 Detalle de equipo, maquinarias e implementos ......................................... 140

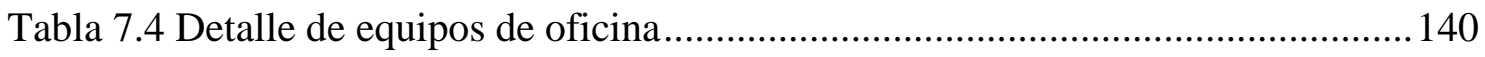

Tabla 7.5 Detalle de construcción e instalaciones generales ....................................... 141 
Tabla 7.6 Activo intangible 141

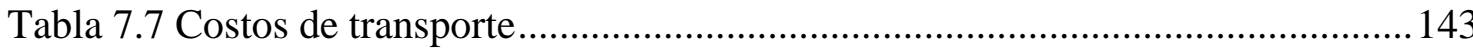

Tabla 7.8 Costos de pintura y gráficas - Parte 1 ....................................................... 143

Tabla 7.9 Costos de pintura y gráficas - Parte 2 2........................................................... 144

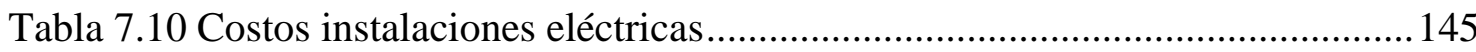

Tabla 7.11 Costos de fabricación e instalación de bienes publicitarios......................... 146

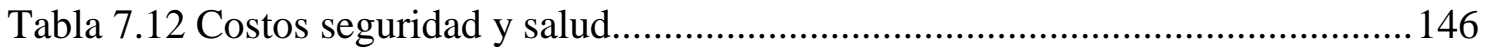

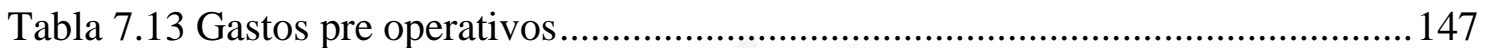

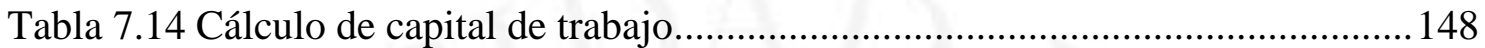

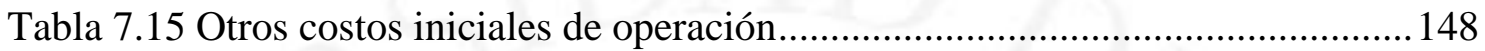

Tabla 7.16 Costo de combustibles (en soles) ............................................................... 149

Tabla 7.17 Cuadro de resumen de costos de materiales del servicio............................. 150

Tabla 7.18 Detalle de costos de materiales de limpieza .............................................150

Tabla 7.19 Detalle de costos de materiales de atención directa...................................150

Tabla 7.20 Detalle de costos de materiales de oficina ................................................... 151

Tabla 7.21 Detalle de costos de materiales de mantenimiento ......................................151

Tabla 7.22 Gastos del proyecto (en soles) .................................................................. 152

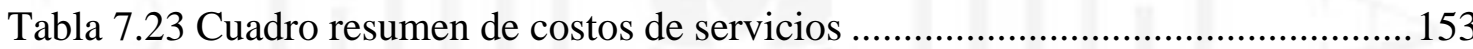

Tabla 7.24 Detalle de costo por consumo de agua....................................................... 153

Tabla 7.25 Detalle de costo por consumo de electricidad (en soles) ............................ 154

Tabla 7.26 Detalle de costo de transporte (en soles) .................................................... 154

Tabla 7.27 Detalle de costo por servicios tercerizados.............................................. 155

Tabla 7.28 Costo de servicios de terceros para mantenimiento programado ................ 155

Tabla 7.29 Costo de servicios de terceros para mantenimiento reactivo....................... 156

Tabla 7.30 Cálculo de remuneraciones de vendedores de isla (en soles) .....................156

Tabla 7.31 Cálculo de remuneraciones de personal administrativo (en soles) .............156

Tabla 7.32 Valor de venta por galón (en soles) ….................................................... 157

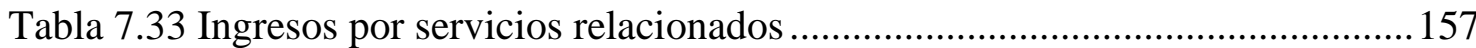

Tabla 7.34 Presupuesto de ingresos (en soles) ......................................................... 158

Tabla 7.35 Presupuesto de costos del servicio (en soles) ............................................ 159

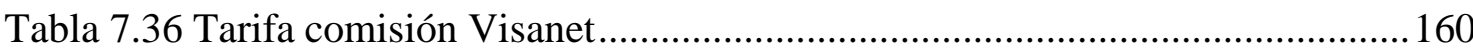

Tabla 7.37 Tarifa comisión Mastercard ........................................................................ 160

Tabla 7.38 Porcentajes de ventas con tarjetas............................................................. 160

Tabla 7.39 Presupuesto de gastos generales (en soles) .............................................. 161 


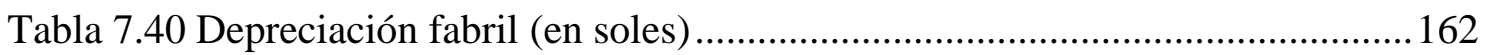

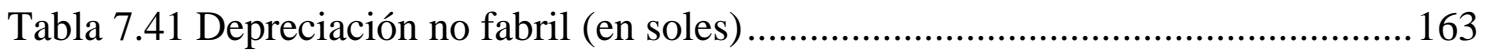

Tabla 7.42 Amortización no fabril (en soles) ............................................................. 163

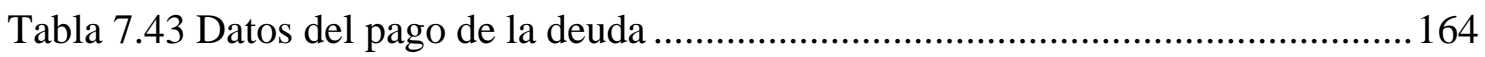

Tabla 7.44 Cuadro del servicio de la deuda (en soles) ............................................. 164

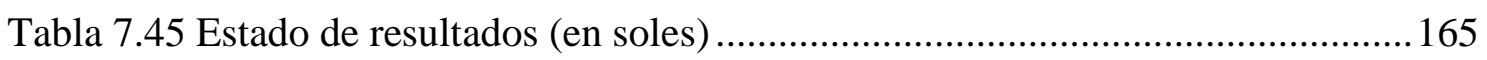

Tabla 7.46 Estado de situación financiera antes de inicio de operaciones (en soles) ... 166

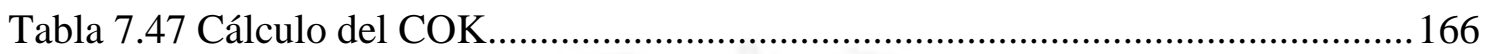

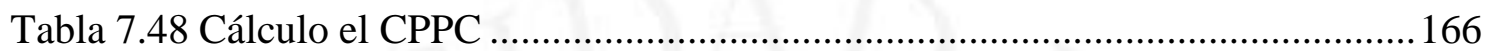

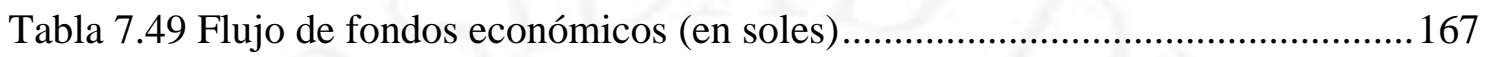

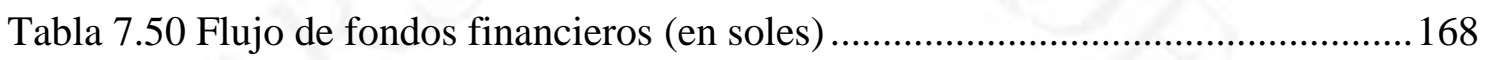

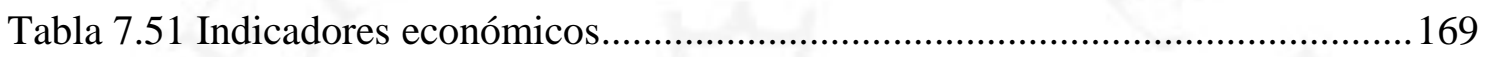

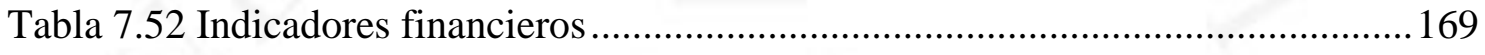

Tabla 7.53 Análisis variación de costos de combustibles +-10\% ….............................. 170

Tabla 7.54 Análisis variación de ventas de combustibles +-10\% ................................. 171

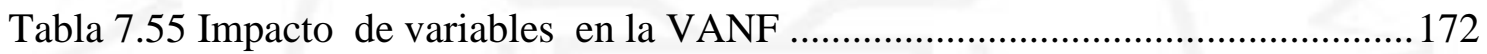

Tabla 8.1 Cálculo del valor agregado del proyecto (en soles) ..................................... 174

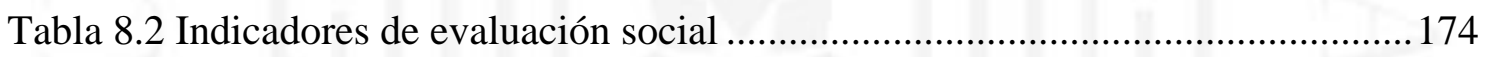




\section{ÍNDICE DE FIGURAS}

Figura 1.1 Venta de vehículos nuevos (unidades y variación anual) .............................6

Figura 1.2 Ventas Petroperú en el mercado interno.................................................... 12

Figura 2.1 Consumo per cápita de petróleo como MP por habitante en barriles - Año

2017-2016

Figura 2.2 Evolución del Parque Peruano Vehicular Estimado: 2007-2016 (Unidades vehiculares) .25

Figura 2.3 Evolución de Licencias de Conducir en el Perú, por clase de emisión: 2007-

2016 (Unidades). .25

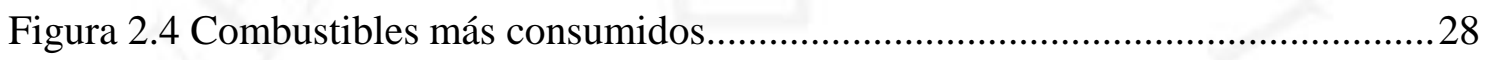

Figura 2.5 Preferencia de servicios no relacionados ................................................28

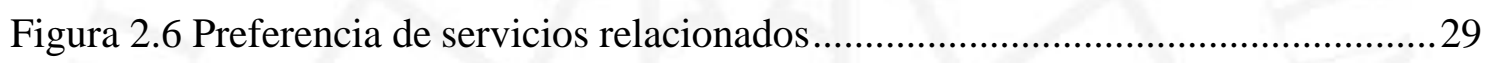

Figura 2.7 Características valoradas para una estación de servicios .............................29

Figura 2.8 Tipo de promociones más valoradas en una estación de servicios.................30

Figura 2.9 Evolución del precio del petróleo .............................................................. 47

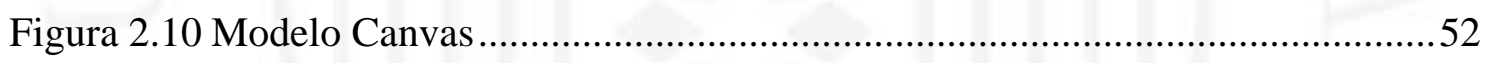

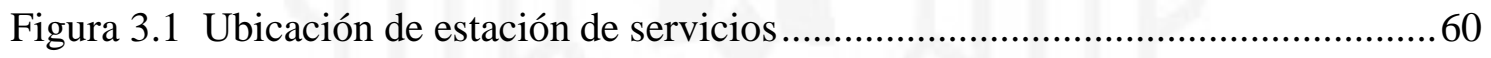

Figura 4.1 Distribución de pistolas en estación de servicio del proyecto ........................66

Figura 5.1 Flujograma para la atención al cliente en la estación de servicios al contado o

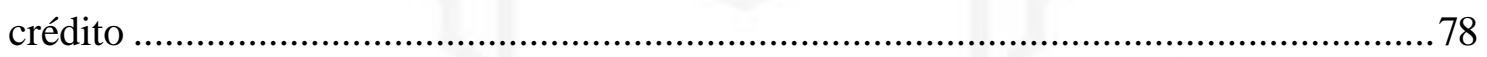

Figura 5.2 Flujograma para realizar un convenio marco de abastecimiento a crédito....79

Figura 5.3 Tanque Diésel B5 - Capacidad 5.200 galones .......................................... 89

Figura 5.4 Tanque Gasohol 97 - Capacidad 4.400 galones......................................... 90

Figura 5.5 Tanque Gasohol 95 - Capacidad 1.300 galones...........................................90

Figura 5.6 Tanque Gasohol 90 - Capacidad 7.700 galones.......................................... 90

Figura 5.7 Tanque de GLP - Capacidad 4.600 galones............................................. 90

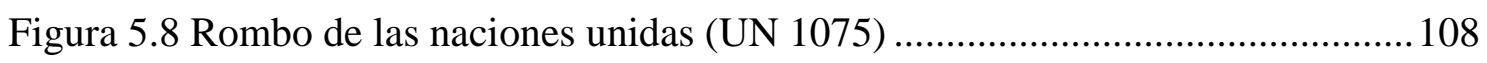

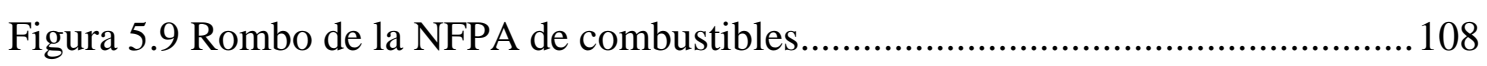

Figura 5.10 Significado del rombo NFPA de combustibles ...................................... 108

Figura 5.11 Plano primer piso estación de servicios.................................................. 129

Figura 5.12 Plano segundo piso estación de servicios .............................................. 130 
Figura 5.13 Plano de ambiente de servicio con cotas.....

Figura 5.14 Cronograma de implementación ............................................................. 133

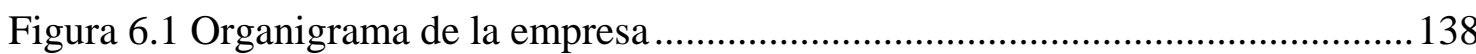




\section{ÍNDICE DE ANEXOS}

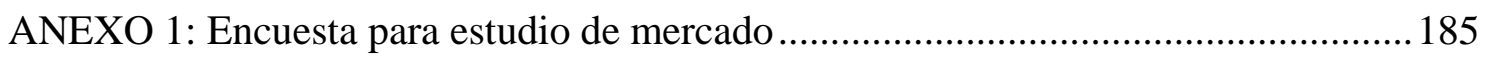

ANEXO 2: Modelo de contrato de exclusividad de abastecimiento con Petroperú ......188 


\section{RESUMEN EJECUTIVO}

El objetivo principal de este proyecto es verificar la factibilidad de implementar una estación de servicios en la ciudad de Huancayo que brinde servicios extras de oferta retail, verificando la viabilidad de mercado, técnica, económica y social.

Mediante una encuesta realizada al público objetivo del proyecto, se encontró que el producto de mayor demanda es el Gasohol 90 y que los servicios no relacionados de mayor preferencia son mini market, comida rápida, farmacia y cajeros automáticos. Así mismo, se observó que los clientes definen como las características más importantes para una estación de servicios la calidad de combustible y calidad de atención. Además, se halló la demanda del proyecto, la cual sería de aproximadamente 22 millones de soles (2,2 millones de galones de combustible) para el año 2019 y con un crecimiento anual aproximado de $3 \%$.

En cuanto a la localización, tras evaluar a tres lugares mediante diferentes factores, se encontró que sería más factible localizar el grifo en el cruce de la calle Real y el Pasaje Salesiano, principalmente por la buena distribución perimétrica, alto flujo vehicular y cercanía a lugares estratégicos.

Por otra parte, se determinó que la capacidad del proyecto estaría limitada por la tecnología, la cual podría abastecer hasta 5,7 millones de galones en total anualmente y siendo la principal variable el número de surtidores.

En cuanto a la evaluación de los aspectos económicos y financieros, se determinó que la inversión total requerida para el proyecto es de S/. 5.995.961 siendo lo más rentable solicitar un financiamiento bancario por el $40 \%$ de la inversión total, pues la TIR es más elevada y alcanza el 32\% respecto a la inversión, además genera un VAN de S/. 2.565.843 en 5 años. Así mismo, el periodo de recupero de la inversión sería de 4 años 8 meses aproximadamente y se obtendría S/. 1,71 por cada S/. 1 invertido.

Finalmente, el valor agregado generado por el proyecto sería de S/. 15.910.342 durante los 5 años de funcionamiento, lo que comprueba que el proyecto impacta positivamente en la sociedad. 


\section{EXECUTIVE SUMMARY}

The main objective of this project is to verify the feasibility of implementing a service station in the city of Huancayo that provides extra services of retail, verifying the market, technical, economic and social viability.

According to the project's survey, the product with the highest demand is Gasohol 90 and the most favorite non-related services are mini-market, fast food, pharmacy and ATMs. In adittion, it was found that customers think that the quality of fuel and service are the most important characteristics for a service station. Furthermore, the demand of the project which would be approximately 22 million soles (2,2 million gallons of fuel) by 2019 and with an approximate annual growth of 3 percent.

In terms of location, after evaluating three places by different factors, it was found that it would be more feasible to locate the service station at the street crossing of "Real" and "Pasaje Salesiano", because of the good perimetric distribution, high traffic flow and proximity to strategic places.

On the other hand, it was determined that the capacity of the project would be limited by technology, which could supply up to 5,7 million gallons in total annually and the main variable being the number of suppliers.

Concerning about the evaluation of the economic and financial aspects, it was determined that the total investment required for the project is S/. 5.995 .961 being the most profitable request a bank financing for $40 \%$ of the total investment, as the IRR is higher and reaches $32 \%$ with respect to investment, also generates a NPV of S /. $2,565,843$ in 5 years. In adittion, the recovery period of the investment would be approximately 4 year 8 months and S /. 1,71 for each S /. 1 inverted.

Finally, the added value generated by the project would be S /. 15.910.342 during the 5 years of operation, which proves that the project has a positive impact on society. 


\section{CAPÍTULO I: ASPECTOS GENERALES}

\subsection{Problemática}

El tema a trabajar es el estudio preliminar para la instalación de una estación de servicios en la ciudad de Huancayo (lo que excluye que se localice en la carretera o los alrededores), departamento de Junín.

A nivel nacional, el parque automotor se ha incrementado en aproximadamente 25\% entre 2012 y 2017 pasando de 2,1 millones a casi 2,7 millones de unidades. (Gestión, 2018). Así mismo, en el año 2017 se vendieron 180.281 vehículos nuevos y se estima que este número de inscripciones de vehículos nuevos sea similar en el año 2018. (Asociación Automotriz del Perú, 2018). Cabe recalcar que el departamento de Junín tiene el sexto parque automotor más grande del país y que aproximadamente el $92 \%$ de sus vehículos están en Huancayo, llegando al año 2018 con alrededor de 65.000 vehículos. (Cámara Lima, 2018)

Por otro lado, desde el 2015 hasta fines del 2016 se realizó la refacción de la carretera central desde la salida de Huancayo hasta Pachachaca, aumentando de esta forma la circulación vehicular y la accesibilidad a esta ciudad.

Por todo ello, el proyecto en desarrollo se torna relevante para la ingeniería industrial, ya que por medio de las herramientas que brinda se podrá satisfacer la necesidad de consumo de combustible vehicular que va cada vez más en aumento. Además, ante el gran aumento del sector A y B en Huancayo, se pone en evidencia la ausencia de una estación servicios que brinde servicios extras de oferta retail (locatarios destinados a la expedición de comida rápida, agente bancario, farmacia, entre otros). En este sentido, las herramientas de ingeniería industrial resultarán sumamente importantes para la gestión de la seguridad y contaminación ambiental, que son dos factores muy relevantes en las estaciones de servicio. 


\subsection{Objetivos de la investigación}

\subsubsection{Objetivo general}

- Verificar la factibilidad de implementar una estación de servicios en la ciudad de Huancayo que brinde servicios extras de oferta retail, verificando su viabilidad técnica, económica y de mercado.

\subsubsection{Objetivos específicos}

- Determinar el nivel de aceptación de los clientes potenciales con respecto al servicio, a través del desarrollo de un estudio de mercado.

- Elegir de forma adecuada y estratégica la localización de la estación de servicios.

- Evaluar el soporte técnico necesario para después contrastarlo con el disponible.

- Evaluar la rentabilidad económica y financiera del proyecto.

\subsection{Alcance de la investigación}

- Unidad de Análisis: Una estación de servicios

- Población: Parque automotor

- Espacio: Huancayo

- Tiempo: 40 semanas

- Limitaciones de la investigación: Muestreo no probabilístico

\subsection{Justificación del tema}

\subsubsection{Técnica}

Las principales tecnologías que se utilizan en una estación de servicios están dirigidas principalmente a los dispensadores, tanques de almacenamiento y bombas para GLP y combustibles líquidos en la parte operativa. Actualmente se cuenta con varias empresas que ofertan dispensadores de combustibles líquidos y GLP en el mercado, con una gran variedad de marcas como las líneas de surtidores Prime y Encore de alta gama y las líneas Legacy y Performer de baja gama, entre otras más. Con respecto a los tanques de almacenamiento, se ha localizado que en Concepción, provincia de Huancayo, existen 
tres empresas que fabrican tanques personalizados según la capacidad que demande el cliente y estas son Cimesa S.A.C, Rodriguez S.A.C. y San Antonio E.I.R.L.

Por otro lado, la tecnología también se aplica en los sistemas de telemedición que miden en tiempo real las entradas, salidas y condiciones internas del combustible en los tanques, y en los softwares de integración que tienen por finalidad hacer más fácil y eficiente la labor de los administrativos de mantener a la empresa ordenada e interconectada a lo largo de toda su cadena de valor.

Las diversas tecnologías mencionadas, se encuentran disponibles en Perú y existen un gran número de proveedores potenciales, por lo que técnicamente el proyecto es justificable.

\subsubsection{Económica}

En la parte económica a nivel nacional se puede apreciar que la demanda de combustible ha ido en aumento. Esto se debe al gran desarrollo del parque automotor que entre 1994 y 2014 ha incrementado en 63\% (Gestión, 2016). Además, como se aprecia en la Figura 1.1, la venta de vehículos ha vuelto a experimentar un alza importante después de un periodo de crecimiento desacelerado. En lo que concierne a Huancayo, al 2015, su parque automotor ascendía a la suma de aproximadamente 60.000 unidades y posee una tasa de crecimiento de 150 vehículos por mes, con lo que se puede apreciar un mercado en crecimiento.

En Huancayo existen en total 71 ofertantes de combustible aproximadamente, no obstante, se puede considerar como competidores directos a 12 de estos por su localización en el centro de la ciudad como se propondrá más adelante para esta estación de servicios. (OSINERGMIN, 2018). Por lo que se puede registrar un gran aumento de la demanda ante una oferta constante. Además, la estación de servicios que se propone, contará con servicios extras relacionados y no relacionados por medio del alquiler de locales. Lo que se traducirá en ingresos pasivos constantes y un aumento de la circulación de clientes. 


\section{Figura 1.1 1}

\section{Venta de vehículos nuevos (unidades y variación anual)}

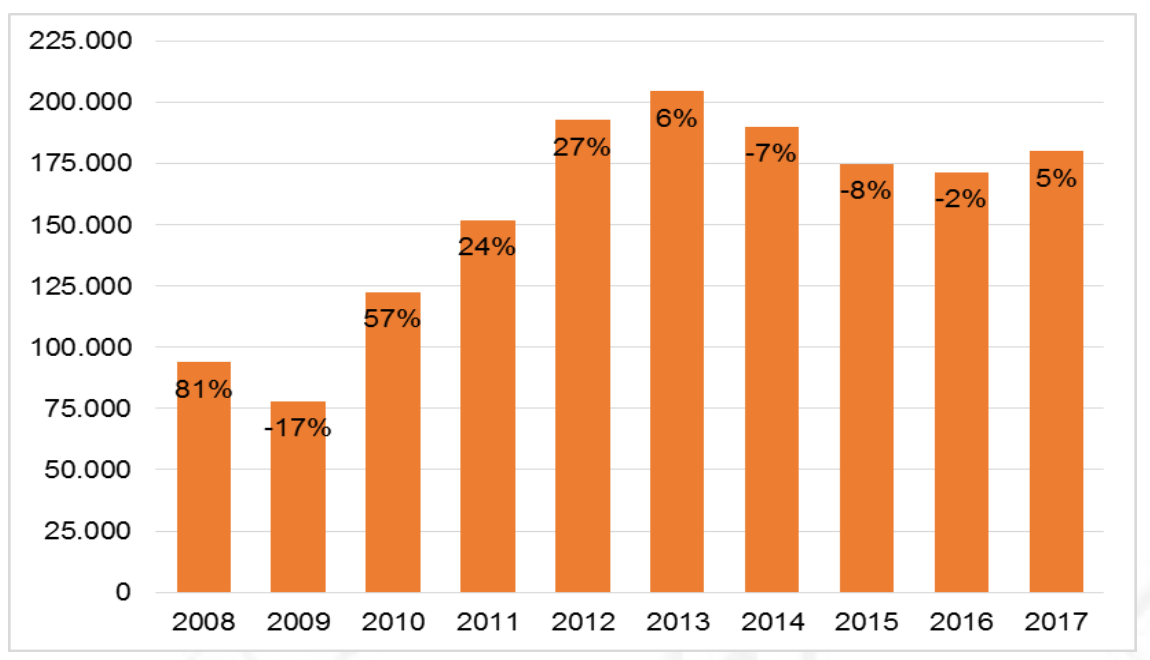

Fuente: Araper, AAP (2018)

\subsubsection{Social}

Con respecto al ámbito social, la implementación de la estación de servicios generará varios puestos de trabajo; no solo para laborar en la empresa de forma directa, sino también de forma indirecta para laborar en los negocios de oferta retail (como locatarios de comida rápida, agente bancario, farmacia, entre otros.) que formarán parte de la estación de servicios.

Además, se contará con todas las medidas de seguridad exigidas por ley y con una constante capacitación del personal en temas de peligros y riesgos en la estación de servicios lo cual es de suma importancia, ya que se manejan sustancias altamente inflamables como los combustibles líquidos.

Así mismo, la empresa manejará un compromiso con el medio ambiente bien marcado al realizar monitorios constantes de impacto ambiental y teniendo por política expedir combustibles con los últimos avances tecnológicos en su composición, de modo que esta no sea de origen fósil al 100\%.

\subsection{Hipótesis del trabajo}

Es viable desde el punto de vista técnico, económico y de mercado implementar una estación de servicios en la ciudad de Huancayo que brinde servicios extras de oferta retail. 


\subsection{Marco referencial}

Para el desarrollo de la presente sección; a continuación, se muestra la comparación del presente trabajo tomando como referencias dos investigaciones ya realizadas a cerca del tema en estudio; plasmando las similitudes y diferencias.

Tabla 1.1

Cuadro comparativo con Plan de negocios de la empresa El Sol S.A.

\begin{tabular}{|c|c|c|}
\hline Tesis & Similitudes & Diferencias \\
\hline $\begin{array}{l}\text { Nombre: Plan de negocios } \\
\text { de la empresa El Sol S.A. } \\
\text { como distribuidor } \\
\text { mayorista de combustibles } \\
\text { líquidos en Lima y Callao } \\
\text { (Palacios Palacios, 2017) }\end{array}$ & $\begin{array}{l}\text { - En ambos se utiliza por } \\
\text { técnica para el análisis del } \\
\text { sector las } 5 \text { fuerzas de Porter. } \\
\text { - Ambos poseen por opciones } \\
\text { de proveedores únicos a } \\
\text { Petroperú o Repsol. } \\
\text { - Poseen la misma población } \\
\text { que es el parque automotor } \\
\text { que cada uno definió para su } \\
\text { respectivo espacio. }\end{array}$ & $\begin{array}{l}\text { - El objetivo general es distinto, } \\
\text { ya que el estudio en } \\
\text { comparación tiene por objetivo } \\
\text { diseñar un plan de negocios } \\
\text { para la conversión de la } \\
\text { empresa distribuidora de } \\
\text { combustible el Sol S.R.L. de } \\
\text { minorista a mayorista. } \\
\text { - Posee un espacio de estudio } \\
\text { distinto, ya que en este caso es } \\
\text { Lima y Callao. } \\
\text { - La evaluación de viabilidad lo } \\
\text { realiza considerando que el } \\
\text { negocio está en marcha ya que } \\
\text { desea aumentar su rentabilidad } \\
\text { de inversión en un } 20 \% \text { en un } \\
\text { plazo de tres años. } \\
\text { Los productos que se ofertan no } \\
\text { coinciden en su totalidad, } \\
\text { porque para este caso solo se } \\
\text { centra en la venta de } \\
\text { combustibles líquidos. }\end{array}$ \\
\hline
\end{tabular}

Elaboración propia 
Tabla 1.2

Cuadro comparativo con estudio preliminar para la instalación de una estación de servicios

\begin{tabular}{|c|c|c|}
\hline Tesis & Similitudes & Diferencias \\
\hline $\begin{array}{l}\text { Nombre: Estudio } \\
\text { preliminar para la } \\
\text { instalación de una estación } \\
\text { de servicio de } \\
\text { combustibles } \\
\text { (Scamarone Ampuero, 2017) }\end{array}$ & $\begin{array}{l}\text { - Ambos realizan la evaluación } \\
\text { de viabilidad considerando } \\
\text { que la empresa no opera, por } \\
\text { lo que se tiene que crear. } \\
\text { - Poseen la misma unidad de } \\
\text { análisis que es la estación de } \\
\text { servicios. } \\
\text { - Poseen la misma población } \\
\text { que es el parque automotor } \\
\text { que cada uno definió para su } \\
\text { respectivo espacio. }\end{array}$ & $\begin{array}{l}\text { - Posee un espacio de estudio } \\
\text { distinto, ya que en este caso es } \\
\text { Lima. } \\
\text { El modelo de servicio que } \\
\text { plantea difiere, ya que en este } \\
\text { caso plantean solo la venta de } \\
\text { combustible y no ofrecen } \\
\text { servicios de venta retail. } \\
\text { - Los productos que se ofertan no } \\
\text { coinciden en su totalidad, } \\
\text { porque para este caso solo se } \\
\text { centra en la venta de } \\
\text { combustibles líquidos. }\end{array}$ \\
\hline
\end{tabular}

Elaboración propia

\subsection{Marco conceptual}

A continuación, se mostrará la teoría relacionada con el tema de estudio por medio de siguiente glosario de términos:

- Bomba: La bomba de combustible es un elemento importante para expedir combustible, ya que es la encargada de hacer que el surtidor se alimente constantemente del combustible. Por lo general, se trata de bombas eléctricas que suelen estar instaladas encima del tanque de combustible o en los alrededores del mismo.

- Diesel B5 S50 UV: Es un combustible que presenta un contenido máximo de azufre de 50 partes por millón (50 ppm) por lo que casi no contiene azufre. Así mismo, en su composición contiene actualmente $5 \%$ en volumen de Bio diesel (B-100). Además, contiene aditivos de performance de última tecnología que le otorga más beneficios.

- Estación de servicios: También conocida comúnmente como grifo, es una instalación que se encarga de adquirir, almacenar y distribuir combustible a los vehículos y maquinarias. 
- Gasohol: Es la mezcla que contienen gasolina con 7.8\% en volumen de alcohol carburante y un octanaje que puede ser de 97, 95, 90 o incluso 84. Además, están formuladas con aditivos multifuncionales de última generación que elevan la estabilidad del combustible e incrementa la vida útil del motor, permitiendo el máximo rendimiento.

- GLP (gas licuado de petróleo): Es una mezcla balanceada de hidrocarburos volátiles, tipo propano y butano. Posee un octanaje mayor a 100.

- Hidrocarburo: Son sustancias químicas producidas en la naturaleza que están formados por átomos de carbono e hidrógeno dispuestos en una gran variedad de formas dando así origen a varios tipos, siendo los principales el petróleo y el gas natural.

- Islas: Son los puntos de venta físicos en los que se expide el combustible. Está conformado por un surtidor, mostrador y el servicio de un vendedor de isla.

- Octanaje: Es la capacidad antidetonante que poseen las gasolinas para evitar las explosiones en las máquinas de combustión interna, de tal manera que se libere o se produzca la máxima cantidad de energía útil. El número de octanaje ideal para cada motor de combustión dependerá del tipo y en menor medida de lo económico.

- Parque automotor: Son todos los vehículos que circulan por las vías de un lugar predefinido, estos pueden ser de tres tipos: particulares, de transporte público y de transporte de carga. El impacto ambiental que poseen se refleja en la contaminación por cada tipo de combustible que se oferta.

- Petróleo crudo: Es la materia prima principal de la industria de refinación del petróleo, está constituido por una mezcla de diferentes tipos de hidrocarburos

- Refinería: También conocido como destilería, es una plataforma industrial destinada a la refinación del petróleo que como resultado se obtiene diversos combustibles fósiles capaces de ser utilizados en motores de combustión como gasolina y petróleo y también como materia prima como es el caso del asfalto, entre otros. 
- Surtidor de combustible: También conocidos como dispensadores de combustible, son las máquinas encargadas de expedir el combustible líquido o gas al consumidor final.

- Tanque de almacenamiento: Son tanques de acero al carbón en los que se almacena el combustible. Deben poseer las condiciones adecuadas de almacenamiento según cada tipo de combustible, en el caso del GLP, la presión y temperatura se consideran como variables críticas.

- Tiendas de conveniencia: Son establecimientos de área mediana que atienden las 24 horas todos los días de semana y tienen un amplio mix de productos centrado en bebidas, alimentación, bazar, etc.

\subsection{Análisis del entorno}

\subsubsection{Análisis de Macro entorno (PESTEL)}

- Políticos-legales: En el Perú existe una asociación de grifos y estaciones de servicio (AGESP) la cual tiene como objetivo “...reunir a los comerciantes minoristas expendedores de toda clase de combustibles automotores, propietarios de grifos, estaciones de servicio y gasocentros, para velar por sus intereses, progreso y fortalecimiento y para representarlos ante las autoridades de gobierno y otras entidades sociales.” (AGESP, 2017).

Así mismo, en el Perú existen varias normas que regulan el transporte y la comercialización de hidrocarburos dentro del territorio nacional. A continuación, se detallan algunas de las más importantes:

a) Decreto Supremo 026-94 EM: Reglamento de Seguridad para el Transporte de Hidrocarburos.

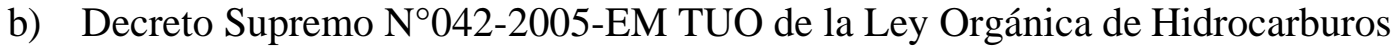

c) Ley N²6221 Ley Orgánica de Hidrocarburos: esta ley “promueve el desarrollo de actividades de hidrocarburos sobre la base de la libre competencia con la finalidad de lograr el bienestar de la persona humana y el desarrollo nacional." (Ley $\left.\mathrm{N}^{\circ} 26221\right)$ 
d) Decreto Supremo 030-98 EM: Reglamento para la Comercialización de Combustibles Líquidos y Otros Productos Derivados de los Hidrocarburos.

e) Decreto Supremo 054-93-EM: Reglamento de Seguridad para establecimientos de Venta al Público de Combustibles Derivados de Hidrocarburos.

f) Decreto Supremo N053-2005-PCM: Ley de control de Insumos Químicos y Productos Fiscalizados.

g) Decreto Supremo No 039-2014-EM: Reglamento para la Protección Ambiental en las Actividades de Hidrocarburos.

Varios de los decretos mencionados se relacionan directamente con aspectos de cuidado y protección del medio ambiente, de tal manera que el impacto en este sea el mínimo.

Por otro lado, en el Perú existe un organismo público encargado de supervisar y regular que las empresas de los sectores eléctricos, hidrocarburos y minería cumplan con las disposiciones legales: este organismo se llama OSINERGMIN (Organismo Supervisor de la Inversión en Energía y Minería). (Cotrina, 2014).

- Económicos: Los precios que establecen las grandes estaciones de servicio no se encuentran regulados por ninguna institución, pero OSINERGMIN semanalmente publica una lista de precios referencial que todas las estaciones de servicio están obligados a poner. Estos pueden variar dependiendo de diferentes factores que consideran las estaciones, así como también la ubicación de la misma.

Otro organismo estatal que influye en el precio de los combustibles es el MEF (Ministerio de Economía y Finanzas) como fue el caso del 9 de mayo del 2018 cuando en una edición extraordinaria del Diario Oficial El Peruano publicó los Decretos Supremos Nº 091-2018-EF, Nº 092-2018-EF, Nº93-2018-EF, Nº942018-EF y $\mathrm{N}^{\circ}$ 095-2018-EF. Los cuales estipulan el incremento de las tasas por cobrar del Impuesto Selectivo al Consumo - ISC, sobre determinados bienes que son comercializados, como es el caso de las bebidas azucaradas, las bebidas no alcohólicas con contenido de azucares, los combustibles con mayor incidencia en el índice de nocividad (aprobado por el Ministerio del Ambiente), algunos tipos de vehículos y los cigarrillos de tabaco negro y rubio. Según el economista Jorge Gonzáles Izquierdo el mayor impacto se vio reflejado en provincia ya que la 
mayoría de vehículos usan petróleo, por el contrario, el Lima el grueso de vehículos usa gas natural. (RPP Noticias, 2018)

Por otro lado, en el año 2018 se tendrá mayor consumo e inversión en el Perú debido principalmente a la mejora de los precios de los metales en el exterior. Se proyecta un crecimiento entre 3,6\% y 3,7\% del PBI, el cual impulsará también al sector servicios. Además, se proyecta para el 2021 alcanzar un crecimiento del $5 \%$ alentado principalmente por el desarrollo de las pequeñas y medianas empresas, la facilitación del comercio exterior y el despliegue de inversión pública. (Ministerio de Economía y Finanzas, 2018)

Con respecto al parque automotor, según la Asociación Automotriz del Perú, este se ha incrementado aproximadamente en $25 \%$ entre el 2012 y 2017 y a pesar que el combustible no es un bien básico, es indispensable para los que deseen transportarse en vehículos que necesitan este tipo de energía.

- Socio-culturales: En el mercado peruano, el tipo de combustible que más se vende es el diésel. Para el caso de Petroperú, este combustible representa aproximadamente el 55\% de las ventas seguido por las gasolinas y gasoholes que representan el 25\%. (Petroperú, 2018)

Figura 1.2

Ventas Petroperú en el mercado interno

VENTAS EN EL MERCADO INTERNO (COMBUSTIBLES, ASFALTOS Y SOLVENTES)

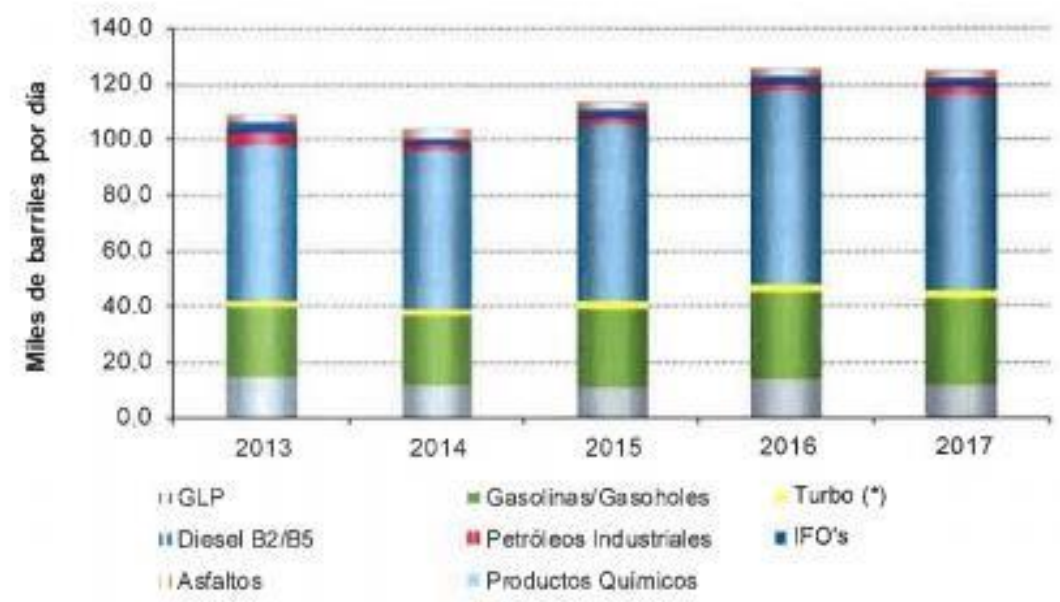

Fuente: Memoria Anual Petroperú (2017)

Otro dato importante a considerar, es que según el diario "El Comercio", la antigüedad promedio del parque automotor peruano es 13 años. Adicional a ello, 
existe una tendencia a la disminución de compra de autos usados ya que hasta el año 2010 se importaban alrededor de 30.000 autos usados, en el año 2011 y 2012 la cifra estuvo cerca de 13.000 autos y a partir del año 2013, la cifra se sitúa debajo de los 2.000 vehículos usados importados al año. (Cámara Lima, 2018)

Con respecto a la preferencia de los usuarios de la ubicación de las estaciones de servicio, estas deben ser ubicadas en medio de una vía pública, casi siempre en esquinas para facilitar el acceso y la salida de los automóviles.

Finalmente, con respecto al monitoreo de los problemas en la industria automotriz, OSINERGMIN supervisa la informalidad, la competencia desleal, la evasión de impuestos, la adulteración, el contrabando, la inseguridad de las estaciones y el impacto ambiental. (Cotrina, 2014)

- Tecnológicos: La distribución de los hidrocarburos se realiza en camiones cisterna que cuentan con las medidas de seguridad necesarias para prevenir cualquier accidente. En el Perú la automatización en las estaciones de servicio es bastante baja durante la dispensación de hidrocarburos en comparación con otros países como Colombia o Estados Unidos en los cuales no se cuenta con personal de atención, sino que el mismo usuario dispensa el hidrocarburo colocando una tarjeta de crédito que activa el surtidor. (Cotrina, 2014).

Sin embargo, sí se utilizan sistemas de información y comunicación para las ventas de tal manera que OSINERGMIN tenga un control más específico y minucioso y le permita combatir la informalidad durante la venta de combustible a través de la validación automática y en tiempo real de transacciones autorizadas entre agentes autorizados. El sistema utilizado se denomina SCOP y utiliza un código de autorización el cual permite validar diferentes datos de los distribuidores, mayoristas y minoristas (no incluye al consumidor final). Los datos que valida son, por ejemplo, si el registro DGH (Dirección General de Hidrocarburos) se encuentra vigente, si está autorizado a adquirir los productos que solicita, el medio de distribución y transporte a utilizar, la cantidad de hidrocarburos solicitados, etc. (Cotrina, 2014).

Así mismo, se han desarrollado tecnologías que permiten la recuperación de vapores para prevenir accidentes así como también sistemas automatizados para el transporte de los mismos.

Por otro lado, con respecto a la tecnología disponible para el cliente final, OSINERGMIN ha desarrollado una aplicación móvil llamada "Facilito" donde 
los usuarios pueden encontrar las estaciones de servicio más cercanas y comparar los precios entre ellas.

- Ecológico: En el Perú existen varias normas y reglamentos que regulan las actividades de Hidrocarburos según el Decreto Supremo Nº15-2006-EM. Es importante tener un adecuado manejo y transporte de los hidrocarburos para evitar cualquier daño al medio ambiente. Es por eso que una de las funciones de OSINERGMIN es medir el impacto ambiental de las actividades de las estaciones de servicio.

\subsubsection{Análisis del sector}

\section{Poder de negociación de los compradores:}

\section{Poder: alto}

En el Perú existen más de 4.732 estaciones de servicio según la Asociación de Grifos y Estaciones de Servicio del Perú (Agesp), de las cuales $42 \%$ pertenecen a cadenas mientras el $58 \%$ son independientes.

La cadena con más presencia es Primax, del Grupo Romero, que al comprar Pecsa en el año 2018, se queda con 1034 estaciones de servicio de las cuales opera 219 y 815 son afiliadas. Sigue en la lista Petroperú con 634 estaciones afiliadas y luego Repsol con 325 estaciones de la cuales 125 son propias y 210 son afiliadas. (Gestión, 2018)

En el centro del país la tendencia es la misma. Aparte de las cadenas antes mencionadas, se encuentran otras como Grupo Soria, Petrón, entre otros. Por todo ello, los clientes tienen una gran variedad de alternativas, pudiendo elegir la de su preferencia basándose en diferentes factores. El factor principal es el precio; sin embargo, las diferentes cadenas de la zona tienen precios bastante similares.

Finalmente se concluye que el poder de negociación de los clientes es alto ya que en el mercado existe gran variedad de estaciones de servicio por lo que pueden cambiar de preferencia en caso no se sientan a gusto o el precio se encuentre bastante elevado en comparación de otros.

\section{Poder de negociación de los Proveedores:}

\section{Poder: alto}

En Perú existen dos productores de combustibles de hidrocarburos. Por un lado, se encuentra Petroperú que posee las refinerías de Talara y Conchán y en el otro lado está 
Repsol con su refinería La Pampilla. Ambos usan como materia prima el petróleo crudo importado de países como Arabia, Ecuador, Brasil, entre otros. Solo Petroperú utiliza como parte de su producción petróleo crudo de Perú, porque este crudo es tan pesado que solo su refinería de Talara tiene la capacidad de procesarlo. Con respecto a los comercializadores mayoristas, en Perú podemos mencionar a Petroperú, Reco S.A.C (empresa comercializadora de Repsol) y Primax (la cual compró a Pecsa).

Al existir dos grandes empresas encargadas de la producción y solo tres encargadas de la comercialización a nivel macro (quienes serían los proveedores de forma directa para este modelo de negocio), el poder de negociación de los mismos es bastante alto ya que las estaciones de servicio deben de coordinar con ellos para poder adquirir los productos que venden. Además, para el caso de esta estación de servicios, se planea usar abanderamiento ${ }^{1}$ con Petroperú, por lo que este último sería el único proveedor acrecentando aún más su poder de negociación.

\section{Riesgo de ingreso de competidores potenciales:}

\section{Poder: moderado}

Las estaciones de servicio son una industria atractiva para los inversionistas ya que como se ha mencionado antes, el parque automotor ha tenido tendencia al crecimiento en los últimos años y el combustible es un producto necesario para el funcionamiento de los automóviles, además, el riesgo que existe ante el aumento del precio de los combustibles, disminuye al tener la posibilidad de trasladar ese incremento al cliente final.

A pesar de eso, la amenaza de nuevos entrantes es moderada ya que para iniciar con una estación de servicio se debe de tramitar varios permisos con OSINERGMIN para la venta y comercialización de hidrocarburos, licencia de funcionamiento con la Municipalidad y contactarse con Petroperú para convertirse en un cliente de ellos. Así mismo, es necesario conseguir un terreno ubicado estratégicamente de tal manera que se obtengan clientes rápidamente y además, se necesita realizar una inversión elevada. A esto se suma el hecho de que el sector de estaciones de servicio se encuentra en la etapa de madurez y que en Huancayo existen varias cadenas de grifos, por lo que el sector en sí, representa una barrera para el ingreso de nuevos competidores.

\footnotetext{
${ }^{1}$ Terminología utilizada para referirse al tipo de contrato de exclusividad que se pacta entre una estación de servicios y el distribuidor mayorista. Consiste en que la estación de servicios solo podrá comprar combustible del mayorista, a cambio esta empresa le otorgara beneficios extras y algunos activos.
} 


\section{Amenaza de productos sustitutos:}

\section{Poder: bajo}

En la actualidad, el combustible es un producto que no tiene sustitutos directos, es decir, si un automóvil consume gasolina a menos que se realicen los cambios necesarios para utilizar otro hidrocarburo seguirá utilizando gasolina para funcionar. Los vehículos poseen diversos tipos de motores que necesitan de algún tipo de combustible en específico para su correcto funcionamiento y mantenibilidad. No obstante, algunas veces las personas deciden migrar de gasolina de cierto octanaje a una con menor octanaje por un tema de precios sin tener en cuenta el aspecto técnico antes mencionado. Sin embargo, ante este escenario totalmente adverso, el cliente sigue consumiendo gasolina por lo que la amenaza de productos sustitutos es baja en la industria.

Por otro lado, no hay que soslayar que la energía eléctrica y los autos híbridos ${ }^{2}$ están empezando a introducirse en el mercado de autos en Perú. En Japón, la mitad de su parque automotor son autos híbridos, mientras que en Perú se registró en el 2015 la venta de 500 autos de este tipo a lo largo del año. Los autos híbridos reducen el consumo de combustible de forma considerable; sin embargo, no la eliminan. Por lo tanto, en la actualidad aún no se considera a la energía eléctrica como un producto sustituto de los combustibles de hidrocarburos en su totalidad; no obstante, nada descarta que a futuro sí se podría considerar como tal según se den los avances tecnológicos.

\section{Rivalidad entre firmas establecidas en el mercado:}

\section{Poder: alto}

Como se mencionó, en el Perú existen 3 grandes cadenas de grifos pero más del $60 \%$ de las estaciones de servicio en el país son independientes.

En el caso de la zona en estudio, también descrito antes, se han venido desarrollando de forma acelerada otras cadenas de grifos a nivel de la zona centro, teniendo una gran presencia en Huancayo por ser la principal zona comercializadora de la región. Actualmente, Huancayo, incluyendo todos sus distritos, cuenta con 71 estaciones de servicio aproximadamente y la zona centro con 12.

\footnotetext{
${ }^{2}$ Son vehículos de tecnología híbrida, que funcionan con motores a gasolina (o diésel) y eléctricos. Cuando se termina de consumir la energía eléctrica, el motor a combustible entra en funcionamiento y a su vez carga las baterías con energía capaz de hacer funcionar de nuevo a los motores eléctricos; lo que se traduce en un mejor rendimiento por galón de combustible.
} 
La rivalidad entre competidores es alta ya que tanto las grandes cadenas a nivel nacional como Primax (la cual compró Pecsa), Repsol, Petroperú y Ava y las demás cadenas locales como Torito y el Grupo Soria buscan expandirse a través de puntos estratégicos para seguir aumentando sus ventas y aumentar su participación de mercado. Cabe recalcar que no todas las estaciones de servicio que son Primax, Repsol o Petroperú pertenecen necesariamente a un mismo dueño sino que algunas son independientes e incluso, buscan distinguirse entre las estaciones de su misma red lo cual aumenta la competitividad.

En estos grifos, las estrategias que se utilizan además de una ubicación estratégica es tener precios competitivos y lanzar promociones frecuentes con acumulación de puntos. No obstante, se encuentran poco desarrollados en brindar servicios extras no relacionados, ofreciendo a lo más una tienda de conveniencia.

Los consumidores valoran el valor agregado que se les ofrece. En este sentido se identificó que se podría lograr una mayor satisfacción del cliente si se ofrecen más servicios no relacionados con el core bussiness del grifo tales como una estación de comida rápida, farmacia, agente bancario, entre otros; como es común en las estaciones de servicio de Lima. 


\section{CAPÍTULO II: ESTUDIO DE MERCADO}

\subsection{Aspectos generales del estudio de mercado}

\subsubsection{Definición del giro de negocios del servicio y tipo de servicio}

El servicio que se ofrece es una estación de servicios que tiene como valor agregado la existencia de varias tiendas relacionadas y no relacionadas de acuerdo a la preferencia de los pobladores de la ciudad de Huancayo. Así mismo, la empresa se mostrará al cliente como un lugar comprometido con el cuidado del medio ambiente al ofrecer biocombustibles, tener una gestión eficiente de la energía y contar con un sistema de aprovechamiento de aguas pluviales. A continuación, se detallarán las características antes mencionadas de acuerdo a los niveles básico, real y aumentado del servicio ofrecido.

\section{Básico}

La empresa ofertará productos derivados de petróleo accesibles a usar según las condiciones y variables ambientales de la región. Estos serán despachados por medio de dispensadores de líquido y gas manipulados por los vendedores de isla.

El cliente se acercará a la estación de servicios para que pueda adquirir el producto que desee según las características de su vehículo.

\section{Real}

La estación de servicios tendrá por nombre comercial "PetroGreen" por el fuerte compromiso que tendrá por el cuidado del medio ambiente y estará ubicada en la ciudad de Huancayo. Los productos a ofrecer serán: Diésel B5, Gasohol 97, Gasohol 95, Gasohol 90, GLP, los cuales serán despachados a través de cuatro islas de surtidores. Además será una estación de servicios que operará bajo la marca de Petroperú mediante la firma de un convenio de abanderamiento lo cual le otorgará presencia de marca y confiabilidad ante el público objetivo. 


\section{Aumentado}

Dentro de esta sección se mencionará las características propias de la empresa que la diferencian de la competencia.

En las estaciones de servicio en general, se suele ofrecer servicios complementarios al de solo abastecer combustibles, no obstante este criterio no está muy desarrollado en Huancayo, ya que a lo mucho poseen un mini market o café. El poseer servicios extras dentro del grifo, permitirá a este último diferenciarse y además obtener una mayor fidelidad del cliente, ya que cada vez son más las personas que tienden a realizar sus compras en centros de negocios integrados que impliquen facilidad, movimiento y rapidez. La ubicación y la impecable imagen y estado de las instalaciones de la estación de servicios impactan de forma positiva en el rendimiento de los servicios complementarios instalados.

Para el caso de este proyecto, las tiendas que ofertarán los servicios complementarios sumarán seis en total y se ubicarán detrás de las islas de abastecimiento.

Servicios relacionados:

- Lavado y engrase

- Venta de lubricantes y cambio de aceite

- Servicio de llantas

Servicios no relacionados:

- Mini market

- Comida rápida

- Farmacia

Cabe resaltar que además de las seis tiendas, se optará por colocar cajeros automáticos que a su vez también podrá cumplir ciertas funciones del agente que tuvo bastante preferencia en la encuesta que se mostrará más adelante; sin embargo, es más práctico que el mismo.

Con respecto al servicio, otro valor agregado se encuentra en la calidad de servicio que brindará el vendedor de isla. La satisfacción del cliente por medio de la atención será sumamente importante dentro de la estrategia de la empresa.

Por otro lado, la estación de servicios operará como una organización sostenible en aras del cuidado del medio ambiente, para lo cual manejará los siguientes términos: 
- Biocombustibles: los productos serán eco friendly, por lo que se tratará de anular la expedición de combustibles cuya composición es de origen fósil al 100\% en la medida que sea posible y según los últimos avances tecnológicos.

- Eficiencia energética: se operará con un $100 \%$ de luces de tecnología led. Lo cual será beneficioso, ya que no requiere de mantenimiento, posee una vida útil de más de 10 años y reduce el consumo energético en aproximadamente $80 \%$.

- Consumo de agua: el grifo contará con un sistema para recoger el agua de la lluvia para usarlo en los servicios sanitarios. Además de un sistema de detección de fugas.

\subsubsection{Principales características del servicio}

\subsubsection{Posición CIIU}

CIIU es la Clasificación Industrial Internacional Uniforme dictada por la oficina de estadística de la ONU (Organización de las Naciones Unidas) con el objetivo de estandarizar todas las diversas actividades económicas y productivas de un país.

Para la presente investigación, se va hacer uso de la CIIU revisión 4 que es la última que se realizó y fue publicada en 2008. 
Tabla 2.14

\section{Relación CIIU del proyecto}

\begin{tabular}{|c|c|c|}
\hline CIIU & Actividad Económica & Descripción \\
\hline 4730 & $\begin{array}{l}\text { Venta al por menor de combustibles } \\
\text { para vehículos automotores en } \\
\text { comercios especializados. }\end{array}$ & $\begin{array}{l}\text { Esta clase comprende la venta al por menor de } \\
\text { combustibles para vehículos automotores y } \\
\text { motocicletas. Se incluyen también la venta al por } \\
\text { menor de productos lubricantes y refrigerantes para } \\
\text { vehículos automotores. }\end{array}$ \\
\hline 4711 & $\begin{array}{l}\text { Venta al por menor en comercios no } \\
\text { especializados con predominio de la } \\
\text { venta de alimentos, bebidas o tabaco }\end{array}$ & $\begin{array}{l}\text { Esta clase comprende la venta al por menor de gran } \\
\text { variedad de productos entre los que predominan, } \\
\text { sin embargo, los productos alimenticios, las } \\
\text { bebidas o el tabaco, como: actividades de venta al } \\
\text { por menor de comercios que venden, además de su } \\
\text { línea principal de productos alimenticios, bebidas o } \\
\text { tabaco, varios otros tipos de productos, como } \\
\text { prendas de vestir, muebles, aparatos, artículos de } \\
\text { ferretería, cosméticos, etcétera. }\end{array}$ \\
\hline
\end{tabular}

Elaboración propia

Fuente: INEI (2010)

\subsubsection{Uso y características del servicio}

Con respecto a las características del servicio que reflejan mejor su propuesta de valor son:

- Ofertar todos los tipos de derivados de petróleo como combustible.

- Vendedores de isla capacitados en servicio al cliente.

- Horario de atención 24/7

- Operar bajo una marca reconocida en la zona centro como lo es Petroperú.

- Brindar servicios extras de oferta retail (el cual le convertiría en el primero de ese tipo en Huancayo) y tiendas de conveniencia.

\subsubsection{Servicios sustitutos y complementarios}

Actualmente, el combustible no tiene sustitutos directos. Esto se debe a que los vehículos necesitan de algún tipo de combustible para que funcionen, ya sea gasolina, petróleo, GLP, etc. 
No obstante, se puede mencionar que la energía eléctrica, a través de los autos híbridos, está surgiendo como una alternativa diferente a los combustibles fósiles. Sin embargo, no logra sustituirlo por completo, ya que estos vehículos aún necesitan de combustibles fósiles para operar aunque en una medida mucho menor.

Por otro lado; se consideran servicios complementarios a los siguientes: lavado y engrase, cambio de aceite, venta de lubricantes, etc.

\subsubsection{Definición del área de influencia del servicio}

Se define como área de influencia a la ciudad de Huancayo departamento de Junín. En lo que concierne a Huancayo, su parque automotor ascendía a la suma de aproximadamente 60.000 unidades al 2015 y actualmente posee una tasa de crecimiento de 150 vehículos por mes. Cabe resaltar que la estación de servicios se perfila de tipo ciudad y no de carretera, por lo que es importante resaltar que su macro localización se centra específicamente en Huancayo ciudad y no en los alrededores o carretera.

\subsubsection{Determinación de la metodología que se empleará en la investigación de mercado}

Con respecto a la metodología que se empleó para llevar a cabo la investigación, en la parte de recopilación de información, se utilizó dos tipos de fuentes:

- Primarias: Recopilación de la información de forma directa, a través, de la observación y análisis del mercado y los clientes gracias a la experiencia laboral propia en el sector en estudio. También se hizo uso de encuestas para recopilación de datos in situ.

- Secundarias: Se recurrió a informes y estudios realizados preliminarmente acerca del tema, haciendo uso de medios como tesis, informes, libros, entre otros. Además, se recopiló información por medio de entrevistas realizadas a expertos del sector de hidrocarburos para desarrollar temas puntuales. Finalmente, se recurrió a estudios y publicaciones de internet, hacienda uso de las fuentes electrónicas de la biblioteca de la Universidad de Lima y publicaciones periódicas de diarios. 
Por otro lado, se van aplicar varias herramientas propias de la investigación de mercado a lo largo del desarrollo del presente capítulo siendo alguna de ellas:

- Modelo de las cinco fuerzas de Porter para el análisis del sector.

- Modelo PESTEL para analizar el macro entorno.

- Encuestas al público objetivo para obtener la data necesaria para el cálculo de la demanda real.

- Matriz EFE para analizar de forma comparativa a la competencia.

- 4 P's del marketing para definir la estrategia de comercialización de la empresa.

\subsection{Análisis de la demanda}

\subsubsection{Cuantificación de los posibles mercados objetivo}

Con respecto al consumo per cápita de combustible en el país, según el Reporte de Monitoreo del sector Hidrocarburos de OSINERGMIN, se consumieron 3 barriles de petróleo en el 2016 (equivalente a 126 galones), un barril más por persona que en el año 2007, poniéndose en evidencia la ligera tendencia al incremento en el consumo de combustibles en el país. Con respecto a la tendencia mundial, esta se ha mantenido estable en los últimos años, caracterizándose por una disminución en el consumo de combustibles en los países de la $\mathrm{OCDE}^{3}$ (Organización para la Cooperación y Desarrollo Económico) y un aumento en los países menos desarrollados como el caso de Perú. Estos datos se evidencian a continuación: (OSINERGMIN , 2018)

Figura 2.1

Consumo per cápita de petróleo como MP por habitante en barriles - Año 2017-2016

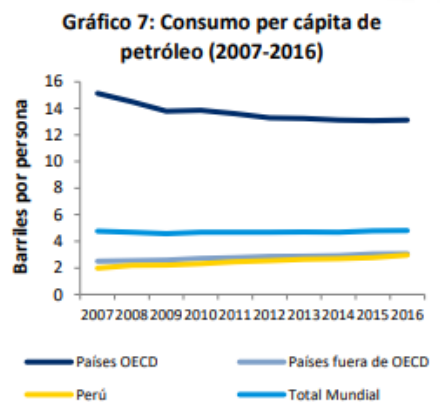

Fuente: Reporte de Monitoreo del sector Hidrocarburos. OSINERGMIN (2018)

\footnotetext{
$\overline{{ }^{3} \text { Fundada en 1961, la Organización para la Cooperación y el Desarrollo Económicos (OCDE) agrupa a } 36}$ países miembros y su misión es promover políticas que mejoren el bienestar económico y social de las personas alrededor del mundo.
} 
Por otro lado, observando el mercado más específico, Junín tiene el sexto parque automotor más grande del Perú, llegando al año 2016 con 67,049 vehículos como se puede observar a continuación:

Tabla 2.2

Número de vehículos según departamentos

\begin{tabular}{l|rrr}
\hline & \multicolumn{1}{|c}{ Pesados } & \multicolumn{1}{c}{ Ligeros } & \multicolumn{1}{c}{ Total } \\
\hline Lima/Callao & 229.838 & 1.523 .081 & 1.752 .919 \\
La Libertad & 46.383 & 143.690 & 190.073 \\
Arequipa & 33.874 & 154.055 & 187.929 \\
Cusco & 11.445 & 62.552 & 73.997 \\
Lambayeque & 11.968 & 56.293 & 68.261 \\
Junín & 13.686 & 53.363 & 67.049 \\
Piura & 7.674 & 47.386 & 55.060 \\
Tacna & 7.953 & 41.429 & 49.382 \\
Puno & 8.103 & 39.593 & 47.696 \\
Áncash & 3.787 & 29.755 & 33.542 \\
Los demás & 24.592 & 111.219 & 135.811 \\
Total & $\mathbf{3 9 9 . 3 0 3}$ & $\mathbf{2 . 2 6 2 . 4 1 6}$ & $\mathbf{2 . 6 6 1 . 7 1 9}$ \\
\hline
\end{tabular}

Fuente: Ministerio de Transportes y Comunicaciones (2017)

Finalmente, es importante recalcar que en el departamento de Junín 33\% de los vehículos son automóviles, $18 \%$ son Station Wagon, $28 \%$ son camionetas, $14 \%$ son ómnibuses y 3\% son camiones y remolques. (Cámara Lima, 2018)

\subsubsection{Demanda potencial}

\subsubsection{Patrones de consumo del servicio}

Con respecto a los patrones de consumo, la oferta en general ha mostrado una tendencia favorable al alza. Por un lado, el parque automotor peruano en su conjunto muestra un crecimiento constante y sólido en los últimos 9 años, como se puede apreciar en la siguiente figura: 
Figura 2.2

Evolución del Parque Peruano Vehicular Estimado: 2007-2016 (Unidades vehiculares)

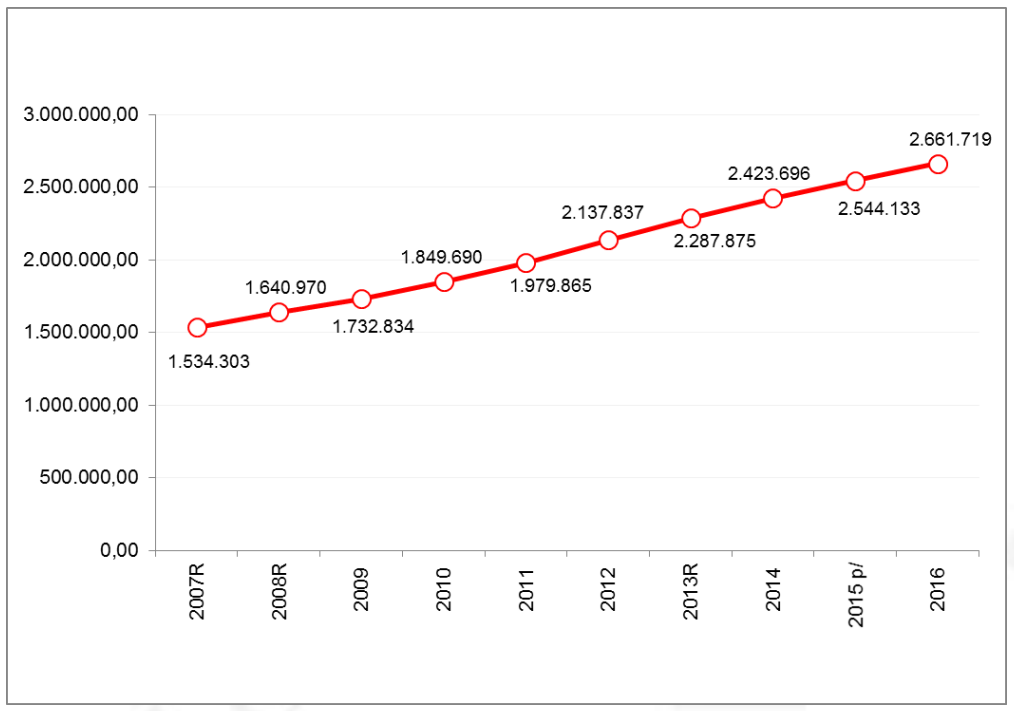

Fuente: MTC - Dirección General de Transporte Terrestre (2017)

Por otro lado, existe una evolución creciente con respecto a la emisión de nuevas licencias de conducir. Otro ítem que muestra un comportamiento interesante es el de revalidación de licencias de conducir que ha alcanzado su mayor pico de los últimos 9 años en el 2016. Lo antes mencionado, tiene sustento en la siguiente figura.

Figura 2.3

Evolución de Licencias de Conducir en el Perú, por clase de emisión: 2007-2016 (Unidades)

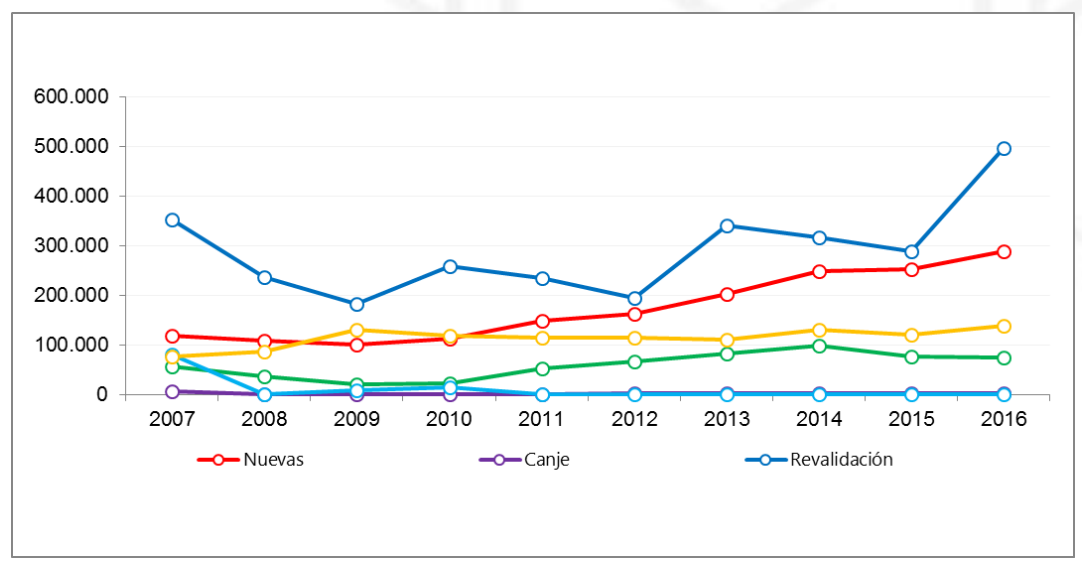

Fuente: MTC - Dirección General de Transporte Terrestre (2017)

Todo esto plasma claramente que no solo existe mayor cantidad de vehículos potenciales para circular por las pistas, sino que esto es correspondido con una gran 
cantidad de personas hábiles técnica y legalmente para conducirlos. Además, ambos poseen comportamientos similares de crecimiento.

\subsubsection{Aplicación de estudios cualitativos y cuantitativos}

Para realizar el estudio de mercado se empleó el método de encuestas. Éstas fueron aplicadas al público objetivo del proyecto que es el parque automotriz de Huancayo.

Para asegurarse que la encuesta esté direccionada netamente hacia el público objetivo, se plantearon 2 preguntas iniciales que actuaron como filtros; estas fueron: ¿conduce usted algún tipo de vehículo? y ¿conduce por las calles de Huancayo al menos $1 \mathrm{vez}$ al mes en promedio? Con esto se pretendió asegurar que las personas que rellenen la encuesta sepan conducir y que estén bastante familiarizados con las calles de Huancayo.

Acto seguido, se plantearon preguntas destinadas a abstraer información necesaria para el cálculo de la demanda potencial. En este sentido se preguntó acerca del tipo de vehículo que maneja (no necesariamente que es dueño), el tipo de combustible que más utiliza, la frecuencia con la que asiste a una estación de servicios, la cadena de grifos de su preferencia y los galones que consume en promedio en cada visita. Por otro lado, para poder calcular la demanda del proyecto se preguntó al final si asistiría a la estación de servicios propuesta y, si en caso sea afirmativo, que indique qué tan seguro se encuentra de esta decisión.

La siguiente sección tuvo por objetivo obtener data relacionada con las características de la estación de servicios y sobre qué es lo que más le gustaría encontrar a los consumidores, dándoles por escoger múltiples opciones. Se plantearon preguntas como: ¿Qué tipo de servicios no relacionado al rubro principal te gustaría encontrar en una estación de servicios?, ¿Qué tipo de servicios relacionado al rubro principal te gustaría encontrar en una estación de servicios? y ¿Qué características consideras como las más importantes para una estación de servicios?

Por último, y teniendo un conocimiento previo de que la ubicación y las promociones que ofrece un grifo son claves para atraer clientes, se formularon 2 preguntas relacionados a estos temas. Por lo que se preguntó de forma abierta el lugar 
donde les gustaría que esté ubicada una estación de servicios y qué tipo de promociones les gustaría que manejen.

Para determinar el tamaño de la muestra y teniendo en consideración que el universo es conocido y no es muy grande, se hizo uso de la siguiente fórmula:

$$
n=\frac{\mathrm{p} \times \mathrm{q} \times \mathrm{N} \times Z^{2}}{e^{2} \times \mathrm{N}+\mathrm{p} \times \mathrm{q} \times Z^{2}}
$$

Donde:

Tabla 2.3

Descripción y valores de la fórmula

\begin{tabular}{c|cc}
\hline Variable & Nombre & Valor utilizado o calculado \\
\hline $\mathbf{n}$ & Tamaño de la muestra & 273 \\
$\mathbf{p}$ & Probabilidad afirmativa & 0,5 \\
$\mathbf{q}$ & Probabilidad negativa & 0,5 \\
$\mathbf{N}$ & Tamaño de la población & 63.359 \\
$\mathbf{Z}$ & Valor en tabla según nivel de confianza & 1,65 \\
$\mathbf{e}$ & Error de la muestra & $5 \%$ \\
\hline
\end{tabular}

Elaboración propia

Por lo tanto, se aplicaron 273 encuestas aceptando un error de 5\% y un $90 \%$ de confianza.

La encuesta realizada se encuentra en los anexos y a continuación se colocarán algunas preguntas de la misma que se consideran importantes para poder conocer al público objetivo:

- ¿Cuál es el combustible que más consume?

El combustible que más se consume es el gasohol 90 y en menor medida el gasohol 95. 
Figura 2.4

Combustibles más consumidos

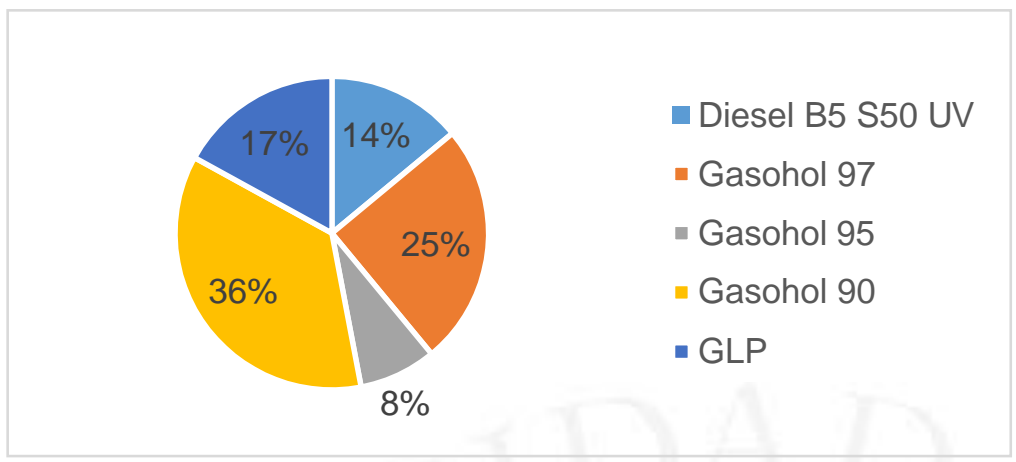

Elaboración propia

- ¿Qué servicios no relacionados le gustaría encontrar en una estación de servicios?

Los servicios no relacionados que más les gustaría encontrar a los clientes son los cajeros automáticos y mini market, ambos con igual de aceptación. Por otro lado, los clientes no valorarían mucho encontrar una lavandería, tienda de detalles, ni café en la estación de servicios.

Figura 2.5

Preferencia de servicios no relacionados

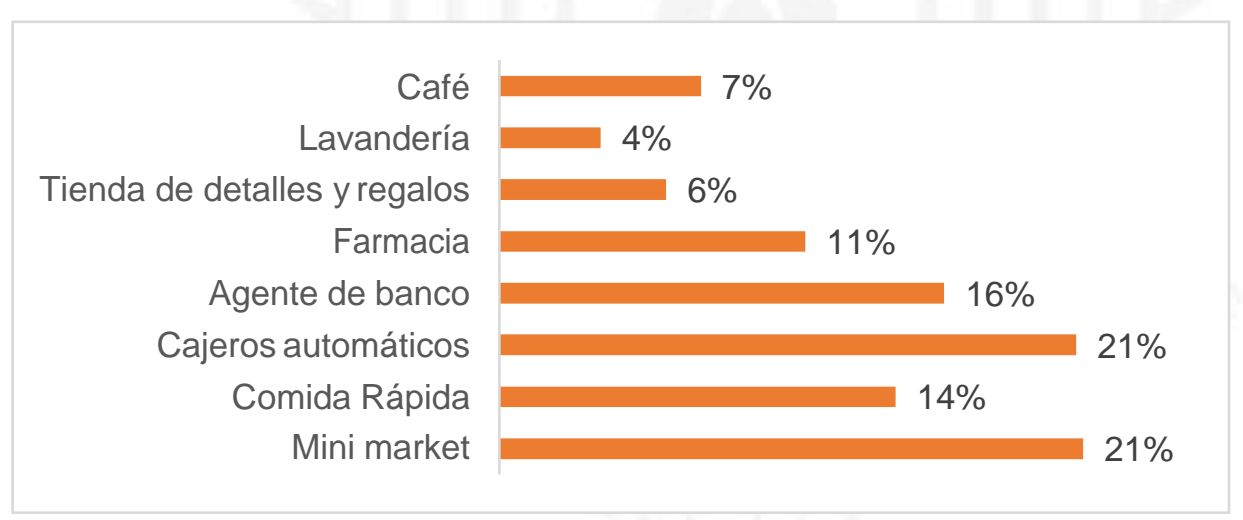

Elaboración propia

- ¿Qué servicios relacionados le gustaría encontrar en una estación de servicios?

El servicio relacionado que más les gustaría encontrar a los clientes es el de lavado y engrase. Por otro lado, los clientes no valorarían mucho encontrar el servicio de alineación y balanceo. 
Figura 2.6

Preferencia de servicios relacionados

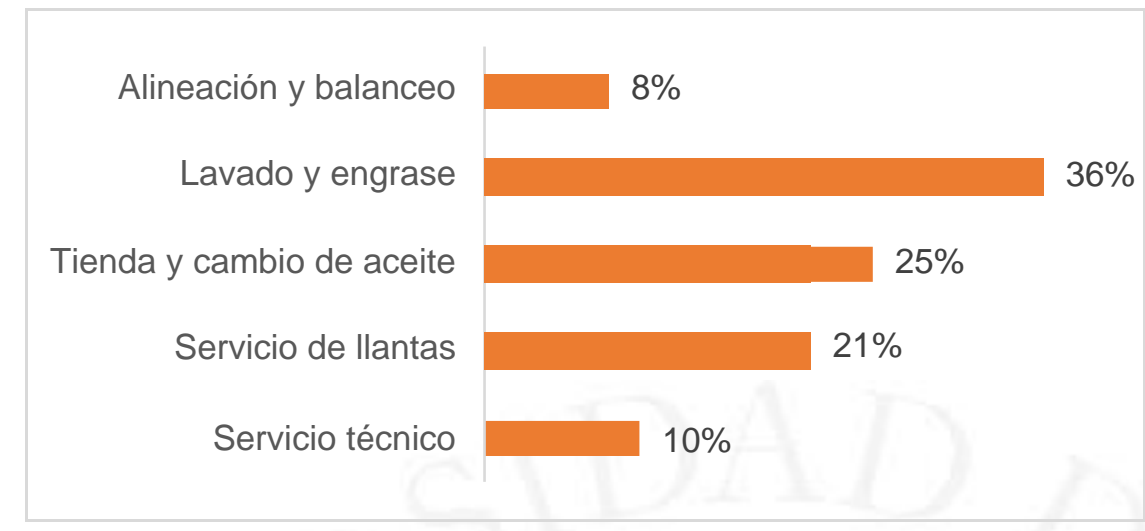

Elaboración propia

- ¿Qué características valora más a la hora de escoger ir a una estación de servicios determinada?

La calidad y cantidad exacta de combustible, así como la calidad de atención por parte de los vendedores son las características más valoradas por los clientes a la hora de escoger una estación de servicios, mientras no es un factor determinante la ubicación idónea.

Figura 2.7

Características valoradas para una estación de servicios

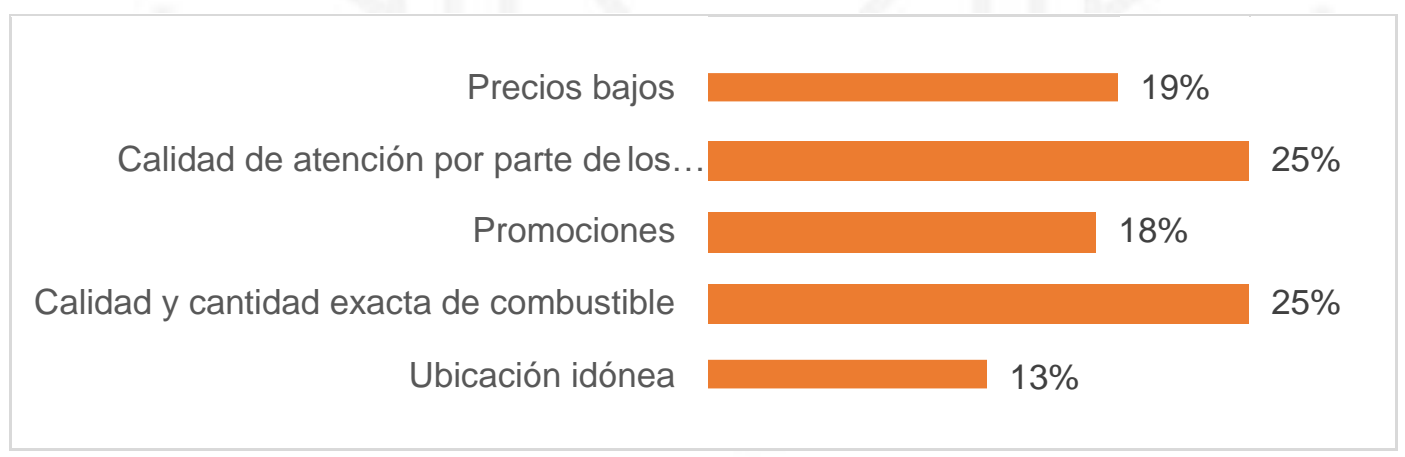

Elaboración propia

- ¿Qué tipos de promociones son las que valora más en una estación de servicios?

La promoción que más valoran los clientes es la de descuentos en combustibles y la menos valorada es la de prendas de vestir. 
Figura 2.8

Tipo de promociones más valoradas en una estación de servicios

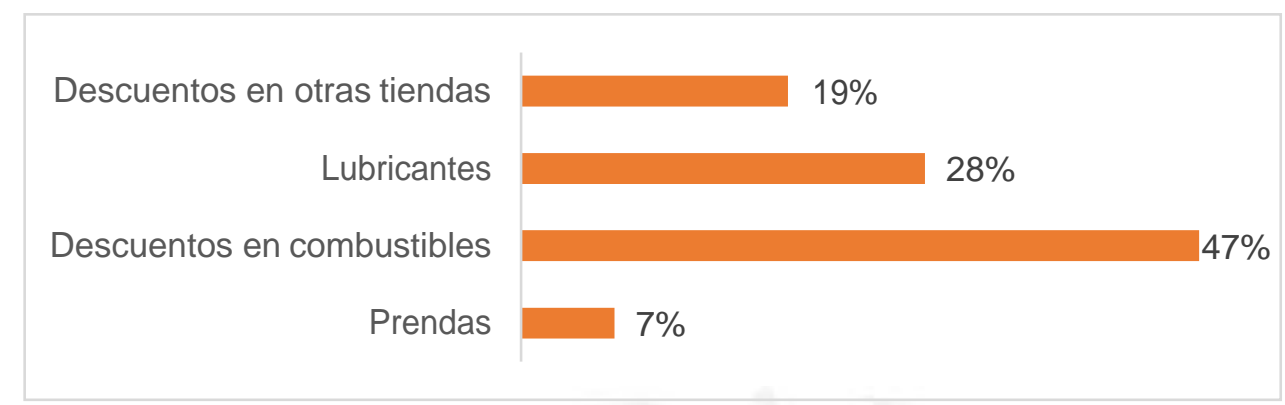

Elaboración propia

\subsubsection{Determinación y proyección de la demanda potencial}

La demanda potencial se obtiene comparando patrones del mercado en el que se piensa insertar con otro similar pero más desarrollado, siendo uno de los patrones más usados los de consumo. En el caso de que se analice un servicio, como es el caso de este proyecto, la demanda potencial se halla teniendo como base la zona de influencia y se apoya bastante en las encuestas.

A continuación, se calculará la demanda potencial del año 2017 para el presente proyecto, para lo cual se hará uso de las siguientes fórmulas:

\section{Demanda potencial $=$ Población $\mathbf{x}$ Ticket promedio unitario}

\section{Ticket promedio unitario $=$ Frecuencia promedio $\mathrm{x}$ Galones promedio $\mathrm{x}$ Precio}

En el caso de una estación de servicios, cada producto posee un comportamiento distinto que se ve condicionado de cierta forma por el tipo de vehículo que manejan. Por lo que se hallará una demanda para cada uno de los productos para al final calcular la demanda potencial final como resultado de la suma total. De igual forma, a cada producto se le asignará el público objetivo en proporción a la participación del producto.

Para calcular el parque automotor de Huancayo en 2017, se tiene como data histórica el parque automotor de Junín en los últimos 9 años. 
Tabla 2.4

Parque vehicular estimado para Junín, años 2007-2016 en unidades vehiculares

\begin{tabular}{c|c}
\hline Año & Unidades vehiculares \\
\hline $\mathbf{2 0 0 7}$ & 46.091 \\
$\mathbf{2 0 0 8}$ & 47.769 \\
$\mathbf{2 0 0 9}$ & 49.404 \\
$\mathbf{2 0 1 0}$ & 51.094 \\
$\mathbf{2 0 1 1}$ & 53.118 \\
$\mathbf{2 0 1 2}$ & 56.237 \\
$\mathbf{2 0 1 3}$ & 59.019 \\
$\mathbf{2 0 1 4}$ & 61.933 \\
$\mathbf{2 0 1 5}$ & 64.576 \\
$\mathbf{2 0 1 6}$ & 67.049 \\
\hline Fuente: Ministerio de Transportes y Comunicaciones (2017)
\end{tabular}

Teniendo en cuenta que el diario Correo afirma que en agosto del 2013 Huancayo contaba con un parque automotor de 54.334 vehículos y que en ese año Junín contaba con 59.019 vehículos, se puede deducir que el parque automotriz del centro de Huancayo representa el 92\% del total de Junín aproximadamente, con lo que se tendría lo siguiente:

Tabla 2.5

Parque vehicular estimado para Huancayo, años 2007-2016 en unidades vehiculares

\begin{tabular}{|c|c|c|}
\hline \multirow{2}{*}{ Año } & \multicolumn{2}{|c|}{ Unidades vehiculares } \\
\hline & Junín & Centro de Huancayo \\
\hline 2007 & 46.091 & 42.432 \\
\hline 2008 & 47.769 & 43.977 \\
\hline 2009 & 49.404 & 45.482 \\
\hline 2010 & 51.094 & 47.038 \\
\hline 2011 & 53.118 & 48.901 \\
\hline 2012 & 56.237 & 51.773 \\
\hline 2013 & 59.019 & 54.334 \\
\hline 2014 & 61.933 & 57.017 \\
\hline 2015 & 64.576 & 59.450 \\
\hline 2016 & 67.049 & 61.727 \\
\hline
\end{tabular}

Elaboración propia

A continuación, se obtuvo el coeficiente de correlación de distintos tipos de regresión para encontrar el método más adecuado para proyectar el número de unidades vehiculares en Junín: 
Tabla 2.6

Coeficiente de correlación de diferentes métodos de proyección

\begin{tabular}{l|c}
\hline \multicolumn{1}{c|}{ Tipo } & R \\
\hline Exponencial & 0,9974 \\
Lineal & 0,9940 \\
Polinómica & 0,9988 \\
Logarítmica & 0,9156 \\
Potencial & 0,9323 \\
\hline
\end{tabular}

Elaboración propia

Del cuadro se concluye que la regresión polinómica posee en coeficiente de correlación mayor $(\mathrm{R})$ por lo que sería la técnica a usar. No obstante, para no proyectar con un escenario demasiado optimista, se decidió usar la proyección lineal. La ecuación de recta que posee es:

$$
y=2398.8 x+42435
$$

Donde " $y$ " es el parque automotor proyectado $y$ " $\mathrm{x}$ " es el número de orden correlativo empezando con 1 para 2009. Reemplazando en la ecuación, el resultado final es que el parque automotor de Junín a fines del 2017 estará conformado por 68.822 vehículos y el de Huancayo por 63.359 vehículos (el 92\% de vehículos en Junín), los cuales serían la población objetivo de este proyecto.

Para el cálculo del ticket promedio se necesita conocer los precios y serán los siguientes:

Tabla 2.7

Valor de venta de productos

\begin{tabular}{l|c}
\hline \multicolumn{1}{c|}{ Producto } & Valor de venta (soles) \\
\hline Diesel B5 & 11,0 \\
Gasohol 97 & 12,5 \\
Gasohol 95 & 12,2 \\
Gasohol 90 & 11,2 \\
GLP & 5,4 \\
\hline
\end{tabular}

Elaboración propia

El análisis que se desarrolló para tomar la decisión de usar los valores de venta para antes mostrados para el año 2017 se presentará más adelante en la sección 2.5.2. El valor de la frecuencia promedio y los galones promedio de consumo se calcularon por 
medio de la encuesta, a través de las preguntas: ¿Con qué frecuencia asiste a una estación de servicios? y ¿Cuántos galones consume?

Una vez recopilados todos los inputs, se procedió con el cálculo de la demanda potencial. Para esto, se multiplicó la proporción de vehículos que utilizan cada tipo de combustible (dato obtenido de la encuesta) por el total de vehículos en el año 2017 en Huancayo. Luego, se multiplicó por el ticket promedio anual según cada tipo y finalmente, se sumaron los resultados parciales. 
Tabla 2.8

Demanda potencial del 2017

\begin{tabular}{|c|c|c|c|c|c|c|c|}
\hline Producto & $\begin{array}{l}\text { Proporción } \\
\text { del parque } \\
\text { automotor }\end{array}$ & Población & $\begin{array}{l}\text { Frecuencia } \\
\text { anual } \\
\text { promedio }\end{array}$ & $\begin{array}{c}\text { Galones } \\
\text { promedio por } \\
\text { visita }\end{array}$ & $\begin{array}{l}\text { Valor de venta por } \\
\text { galón (soles) }\end{array}$ & $\begin{array}{c}\text { Ticket promedio } \\
\text { anual por vehículo } \\
\text { (soles) }\end{array}$ & $\begin{array}{c}\text { Demanda } \\
\text { potencial } \\
\text { año } 2017 \\
\text { (soles) }\end{array}$ \\
\hline Diesel B5 & $14 \%$ & 8.870 & 254 & 7,21 & 11,00 & $20.132,75$ & $178.582 .739,21$ \\
\hline Gasohol 97 & $25 \%$ & 15.840 & 122 & 6,96 & 12,50 & $10.657,18$ & $168.807 .035,97$ \\
\hline Gasohol 95 & $8 \%$ & 5.069 & 124 & 5,47 & 12,20 & $8.253,49$ & $41.834 .612,90$ \\
\hline Gasohol 90 & $36 \%$ & 22.809 & 123 & 8,64 & 11,20 & $11.872,51$ & $270.803 .019,25$ \\
\hline GLP & $17 \%$ & 10.771 & 175 & 6,83 & 5,40 & $6.448,70$ & 69.459.180,21 \\
\hline Total & $100,00 \%$ & 63.359 & & & & & $729.486 .587,54$ \\
\hline
\end{tabular}


Finalmente se obtiene la demanda potencial que es de S/729.486.587,54.

\subsection{Análisis de la oferta}

\subsubsection{Análisis de la competencia. Competencia directa y sus ubicaciones. Participación de mercado}

Como se mencionó en el análisis de las 5 fuerzas, la rivalidad entre competidores es elevada. Se pueden encontrar cadenas nacionales de grandes marcas (Primax, Repsol, Petroperú, Ava), cadenas locales que ya se encuentran posicionadas (Grupo Soria, Torito), cadenas locales que se están desarrollando (Petroamérica, Petrón, Rio branco, entre otros) y demás grifos particulares. Cabe recalcar que la cadena Torito pertenece a Petrored; sin embargo, logró diferenciarse de las demás estaciones de servicio de esta cadena y esto es percibido por los clientes. Logró esto por medio del uso de los colores rojo y amarillo como en el uniforme de los vendedores de isla y algunos adornos alrededor de las instalaciones. De forma similar, PetroGreen tendrá elementos que lo harán distinguirse de otros dentro de la cadena Petrored de Huancayo.

Para calcular la participación de mercado de los principales competidores en toda la ciudad de Huancayo (71 estaciones de servicio), se partió del número de estaciones con las que cuenta cada marca y se le multiplicó por el \% de Preferencia que se obtuvo a partir de la encuesta realizada. Finalmente se multiplicó este porcentaje por la cantidad de estaciones de servicio de cada marca y se obtuvo un puntaje, el cual se ponderó para el cálculo de la participación de mercado.

Tabla 2.9

Participación de mercado

\begin{tabular}{l|ccccc}
\hline Grifos & $\begin{array}{c}\mathbf{N}^{\circ} \text { de } \\
\text { EESS }\end{array}$ & $\begin{array}{c}\mathbf{N}^{\circ} \text { personas que } \\
\text { prefieren la } \\
\text { EESS }\end{array}$ & \% Aceptación & $\begin{array}{c}\text { Puntaje } \\
\text { ponderado }\end{array}$ & $\begin{array}{c}\text { \% } \\
\text { Participación } \\
\text { de mercado }\end{array}$ \\
\hline Petroperú & 18 & 17 & $24 \%$ & 4,37 & $40 \%$ \\
Primax & 6 & 25 & $36 \%$ & 2,14 & $20 \%$ \\
Ava & 2 & 10 & $14 \%$ & 0,29 & $3 \%$ \\
Repsol & 4 & 12 & $17 \%$ & 0,69 & $6 \%$ \\
Otros & 40 & 6 & $9 \%$ & 3,43 & $31 \%$ \\
Total & 71 & 70 & $100 \%$ & 10,91 & $100 \%$ \\
\hline
\end{tabular}

Elaboración propia 


\subsubsection{Descripción de las características del servicio ofertado por los principales competidores}

Para el análisis de la competencia, se seleccionará a la estación de servicio más representativa y céntrica de cada cadena.

La cadena de grifos Petroperú en general se caracteriza por su estrategia de bajos precios, además que su marca posee un gran posicionamiento en provincia sobre todo por la buena calidad de sus productos. Una de las estaciones más importantes es Torito y está ubicada en Av. Parra Nro. 215. Esta empresa posee por estrategia genérica costos, por lo que se caracteriza en el sector por sus precios bajos incluso a veces opta por estar muy por debajo de los demás competidores. No obstante, se han reportado quejas hacia la empresa por la poca durabilidad del combustible que despacha y por la poca cordialidad con la que atienden sus vendedores de isla. Solo posee un servicio adicional y es el de lavado y engrase y se encuentra ubicado en una esquina con salida a 2 avenidas de mediano tránsito.

Con respecto a la cadena de grifos Primax, esta se caracteriza en general por tener una percepción de alta calidad por parte del consumidor, además de la proyección de una imagen moderna. No obstante, no posee un gran posicionamiento de marca en provincia. El grifo José Olaya es el abanderado más importante de Primax. Se caracteriza por manejar precios bajos y bastante uso de promociones, aunque se sabe que ha perdido algunos clientes por el mal servicio que brindaban sus colaboradores. En cuento a la ubicación se encuentra en una esquina pero que tiene salida a calles no muy transitadas, por otro lado, no posee servicios adicionales que no sea la venta de combustible.

Con respecto a la red Repsol, en Huancayo el mejor posicionado es un grifo ubicado en la esquina de las avenidas Callmen del Solar y San Luis; no obstante, estas avenidas no son muy transitadas. La estación de servicios utiliza normalmente precios elevados que los trata de compensar con el uso intensivo de promociones. El trato por parte de los vendedores de isla se podría calificar como medio, además se sabe que solo posee un servicio adicional que es el de su market Repshop.

El grifo Ava se caracteriza por el uso intensivo de promociones; sin embargo, posee precios elevados. Con respecto a la calidad de sus productos se tiene entendido que no hay registro de inconvenientes, que sí los hay por la atención al cliente. De servicios 
adicionales, solo cuenta con venta de lubricantes. Como no posee una cadena de grifos muy numerosa, casi todos los afiliados poseen este comportamiento, el grifó más representativo en Huancayo es el grifo Amazona que se encuentra localizado en una vía principal que es la única salida a la que tiene acceso.

Por otro lado, está el Grupo Soria, que se caracteriza por sus años de antigüedad en el sector de estaciones de servicio en Huancayo, lo que le lleva a tener una percepción favorable del público con respecto a su calidad y garantía. Se sabe que casi no poseen quejas con respecto al servicio que brindan o la calidad en sí de sus productos; no obstante, los precios que manejan son de los más altos del mercado. Ofrece pocas promociones al año siendo aplicadas más que nada en fechas festivas como fiestas patrias, año nuevo, etc. Por servicios extras cuenta con la venta de lubricantes y un mini market. Su ubicación no es muy estratégica, ya que solo tiene salida a una calle y esta no es muy transitada.

\subsubsection{Planes de ampliación}

La cadena de grifos Primax posee actualmente un plan de ampliación agresivo, es por ello que recientemente compró a la empresa Peruana de Combustibles (PECSA). En este sentido las estaciones de servicios que son afiliadas o propias de PECSA están siendo convertidas en grifos Primax de forma periódica.

Repsol no posee un plan de ampliación en Huancayo puesto que la política de la empresa española es la de colocar un número determinado de grifos por lugar, de modo que las estaciones de servicios propias no sean competencia entre sí mismas. En Huancayo ya posee 4 grifos colocados de forma estratégica que les permite cubrir toda la zona.

Con respecto a la cadena de grifos Petroperú, el plan de ampliación existente para la ciudad de Huancayo en el año 2018 es nula, puesto que esta empresa ha tenido una estrategia agresiva de ingreso al mercado y por ahora se enfoca en la consolidación.

Por otro lado, la cadena de grifos Ava posee como estrategia corporativa la ampliación a nivel tanto local como nacional; confirmando esta tendencia en el año 2017 se inauguró una estación adicional en Huancayo. 
Finalmente, el Grupo Soria no posee una estrategia de expansión puesto que viene operando con la misma cantidad de estaciones por varios años.

\subsubsection{Análisis competitivo y comparativo}

Para realizar el análisis competitivo y comparativo del sector industrial de estación de servicios en Huancayo, se va hacer uso de la matriz de perfil competitivo.

Para ello, primero se tienen que definir los factores críticos de éxito, que son aquellos elementos que definen el éxito de un grifo dentro de este sector. En este sentido, se usarán los resultados de la encuesta donde se menciona que los factores que más valoran los clientes de una estación de servicios son: Calidad de atención, calidad y cantidad exacta del producto, competitividad de precio, promociones, ubicación estratégica y servicios adicionales.

Para la evaluación, se tomará por competidor al grifo más representativo y próximo de cada cadena y se le asignará una calificación para cada factor de éxito según las características expuestas en las secciones 2.3.2 y 2.3.3. En el caso de la empresa que se está estructurando en este trabajo, la calificación se asignará simulando que se encuentra en marcha y que además se está cumpliendo con todos los detalles estipulados en este proyecto. A continuación, se muestra la matriz de perfil competitivo: 
Tabla 2.10

Matriz de perfil competitivo

\begin{tabular}{|c|c|c|c|c|c|c|c|c|c|c|c|c|c|}
\hline \multirow{2}{*}{ Factores de éxito } & \multirow{2}{*}{ Pond. } & \multicolumn{2}{|c|}{ Petroperú-Torito } & \multicolumn{2}{|c|}{ Ava-Amazonas } & \multicolumn{2}{|c|}{ Soria } & \multicolumn{2}{|c|}{$\begin{array}{c}\text { Primax -José } \\
\text { Olaya }\end{array}$} & \multicolumn{2}{|c|}{ Repsol-propio } & \multicolumn{2}{|c|}{ PetroGreen } \\
\hline & & Calif. & Result. & Calif. & Result. & Calif. & Result. & Calif. & Result. & Calif. & Result. & Calif. & Result. \\
\hline Calidad de atención & 0,25 & 2,00 & 0,50 & 2,00 & 0,50 & 4,00 & 1,00 & 1,00 & 0,25 & 2,00 & 0,50 & 4,00 & 1,00 \\
\hline $\begin{array}{l}\text { Calidad y cantidad } \\
\text { exacta de producto }\end{array}$ & 0,25 & 2,00 & 0,50 & 4,00 & 1,00 & 4,00 & 1,00 & 3,00 & 0,75 & 4,00 & 1,00 & 4,00 & 1,00 \\
\hline $\begin{array}{c}\text { Competitividad de } \\
\text { precio }\end{array}$ & 0,18 & 4,00 & 0,72 & 2,00 & 0,36 & 1,00 & 0,18 & 3,00 & 0,54 & 2,00 & 0,36 & 2,00 & 0,36 \\
\hline Promociones & 0,17 & 2,00 & 0,34 & 4,00 & 0,68 & 1,00 & 0,17 & 3,00 & 0,51 & 3,00 & 0,51 & 3,00 & 0,51 \\
\hline $\begin{array}{c}\text { Ubicación } \\
\text { estratégica }\end{array}$ & 0,08 & 3,00 & 0,24 & 3,00 & 0,24 & 2,00 & 0,16 & 2,00 & 0,16 & 2,00 & 0,16 & 3,00 & 0,24 \\
\hline $\begin{array}{c}\text { Servicios } \\
\text { adicionales }\end{array}$ & 0,07 & 1,00 & 0,07 & 1,00 & 0,07 & 2,00 & 0,14 & 0,00 & 0,00 & 1,00 & 0,07 & 4,00 & 0,28 \\
\hline & 1,00 & & 2,37 & & 2,85 & & 2,65 & & 2,21 & & 2,60 & & 3,39 \\
\hline
\end{tabular}

Elaboración propia 
Se puede concluir que el competidor más acérrimo es Amazonas-Ava, ya que posee el mayor puntaje ponderado entre la competencia directa; sin embargo, el Grupo Soria también posee un puntaje elevado pese a no ser el mayor. No obstante, también se deduce que en caso cumplir con todas las especificaciones desarrolladas en este documento, el grifo que se está planteando no tendría mayor inconveniente, puesto que posee un pontaje ponderado muy superior con respecto a los demás.

\subsection{Demanda para el proyecto}

\subsubsection{Segmentación del mercado}

Para el proyecto en desarrollo, el mercado estará conformado por el parque automotor.

Geográficamente, el proyecto está segmentado en la zona centro del país, específicamente en el centro de la ciudad de Huancayo. El método de macro localización utilizado para esta elección fue el factor preferencial, ya que los inversionistas tienen amplios conocimientos del territorio y de los patrones de consumo de los ciudadanos de Huancayo. En base a esta elección, se evaluaron otros factores y se corroboró la hipótesis de que el centro de la ciudad de Huancayo es un lugar óptimo para llevar a cabo el proyecto. Además, el hecho de que la estación de servicios esté en el centro de la ciudad de Huancayo va en concordancia al modelo de negocio que apunta a que los clientes sean personas que vayan al establecimiento a realizar sus actividades rutinarias, lo cual no sucedería si es una estación de servicios que se encuentra por ejemplo en la misma carretera.

Desde el aspecto demográfico, el proyecto no posee segmentación, ya que pueden asistir a la estación de servicios hombres y mujeres de forma indistinta. Con respecto a la edad, sucede de igual forma, no se segmenta, ya que, si bien es cierto los menores de edad, y en general los que no tienen licencia, no pueden conducir pero sí pueden hacer uso de los servicios extra que se ofrecerá.

Psicográficamente, tampoco se va a segmentar, puesto que la estación de servicios es accesible a todo tipo de persona; ya sea que tenga diferentes estilos de vida o nivel socioeconómico. 


\subsubsection{Selección de mercado meta}

El mercado meta es el parque automotor de Huancayo, en especial los vehículos que circulen por la ciudad y no tanto por las afueras de Huancayo.

\subsubsection{Determinación de la demanda para el proyecto}

La demanda real del proyecto se va a calcular a partir de la demanda potencial que se obtuvo en la sección 2.2.3.1. En este sentido, la demanda del proyecto resultará de la aplicación de la siguiente fórmula:

\section{Demanda proyecto $=$ Demanda proyectada $x \%$ aceptación $x \%$ seguridad $x$ factor}

La demanda proyectada se obtendrá sumando las demandas parciales según cada tipo de combustible. Estas se obtendrán multiplicando el número de vehículos proyectados en Huancayo para los años de horizonte del proyecto (2019-2023) por la proporción de dicho tipo de combustible (dato obtenido de la encuesta) y finalmente, por el ticket promedio anual; tal como se hizo para el cálculo de la demanda potencial.

Una vez que se calcule la demanda proyectada, se le multiplicará por el \% de aceptación y \% de seguridad o intensidad, ambos obtenidos de la encuesta. Finalmente, para obtener la demanda del proyecto, se le multiplicará por un factor que simule la participación que podría llegar a tener el proyecto, el cual será la mitad de la división de uno entre la cantidad total de grifos en el centro de Huancayo que son 12. Este factor, que es igual a 0,04, asume que cada grifo en el centro de Huancayo se reparte la misma cantidad de clientes; a excepción de PetroGreen, que inicialmente se proyecta que solo tendrá la mitad de participación que un grifo consolidado. 
Tabla 2.11

Demanda del proyecto

\begin{tabular}{|c|c|c|c|c|c|c|c|c|c|}
\hline & & \multicolumn{2}{|c|}{2019} & 2020 & \multicolumn{3}{|c|}{2021} & 2022 & 2023 \\
\hline \multicolumn{2}{|c|}{ Proyección PA Huancayo } & \multicolumn{2}{|c|}{67.775} & 69.984 & \multicolumn{3}{|c|}{72.192} & 74.401 & 76.609 \\
\hline \multicolumn{2}{|c|}{ Demanda proyectada (soles) } & \multicolumn{2}{|c|}{$795.156 .672,09$} & $\begin{array}{c}836.673 .717 \\
23\end{array}$ & \multicolumn{3}{|c|}{$884.647 .601,16$} & $934.509 .818,65$ & $\begin{array}{c}986.299 .36 \\
7,81\end{array}$ \\
\hline \% Aceptación & & \multicolumn{2}{|c|}{0,93} & 0,93 & \multicolumn{3}{|c|}{0,93} & 0,93 & 0,93 \\
\hline$\%$ Seguridad & & \multicolumn{2}{|c|}{0,75} & 0,75 & \multicolumn{3}{|c|}{0,75} & 0,75 & 0,75 \\
\hline Factor & & \multicolumn{2}{|c|}{0,04} & 0,04 & \multicolumn{3}{|c|}{0,04} & 0,04 & 0,04 \\
\hline \multicolumn{2}{|c|}{ Demanda proyecto (soles) } & \multicolumn{2}{|c|}{ 23.109.240,78 } & $\begin{array}{c}24.315 .829,9 \\
1 \\
\end{array}$ & & 25.710.070,91 & & 27.159.191,60 & $\begin{array}{c}\text { 28.664.325, } \\
38\end{array}$ \\
\hline & 2017 & 2018 & 2019 & 2020 & 2021 & 2022 & 2023 & & \\
\hline $\begin{array}{l}\text { Proyección PA } \\
\text { Huancayo }\end{array}$ & 63,359 & 65,567 & 67,775 & 69,984 & 72,192 & 74,401 & 76,609 & & \\
\hline $\begin{array}{l}\text { Demanda } \\
\text { proyectada (soles) }\end{array}$ & $\begin{array}{c}\text { S/.729,486,5 } \\
87.54\end{array}$ & $\begin{array}{c}\text { S/.754,908,491 } \\
.07\end{array}$ & $\begin{array}{l}\text { S/.795,156, } \\
\quad 672.09\end{array}$ & $\begin{array}{c}S / .836,673,7 \\
17.23\end{array}$ & $\begin{array}{c}\text { S/.884,647,601.1 } \\
6\end{array}$ & $\begin{array}{c}\text { S/.934,509,818.6 } \\
5\end{array}$ & $\begin{array}{c}\text { S/.986,299, } \\
367.81\end{array}$ & & \\
\hline \% Aceptación & 0.92 & 0.92 & 0.92 & 0.92 & 0.92 & 0.92 & 0.92 & & \\
\hline$\%$ Seguridad & 0.77 & 0.77 & 0.77 & 0.77 & 0.77 & 0.77 & 0.77 & & \\
\hline Factor & 0.04 & 0.04 & 0.04 & 0.04 & 0.04 & 0.04 & 0.04 & & \\
\hline $\begin{array}{l}\text { Demanda } \\
\text { proyecto (soles) }\end{array}$ & $\begin{array}{c}S / .21,494,40 \\
0.46 \\
\end{array}$ & $\begin{array}{c}\mathrm{S} / .22,243,459 . \\
57\end{array}$ & $\begin{array}{c}\text { S/.23,429,3 } \\
76.54\end{array}$ & $\begin{array}{c}S / .24,652,68 \\
0.72 \\
\end{array}$ & $\mathrm{~S} / .26,066,236.35$ & $\mathrm{~S} / .27, \mathbf{5 3 5}, \mathbf{4 3 1 . 9 3}$ & $\begin{array}{c}\text { S/.29,061,4 } \\
16.55 \\
\end{array}$ & & \\
\hline
\end{tabular}


Se considera importante conocer la demanda también en número de galones para poder calcular la capacidad de la estación de servicio. Para esto, se multiplicó la demanda por la proporción de ingresos de cada tipo de combustible, y se dividió entre el precio del mismo.

Tabla 2.12

Proporción de ingresos anuales según tipo de combustible

\begin{tabular}{c|c}
\hline Producto & $\begin{array}{c}\text { Proporción de } \\
\text { ingresos }\end{array}$ \\
\hline Diesel B5 & $24,48 \%$ \\
Gasohol 97 & $23,14 \%$ \\
Gasohol 95 & $5,73 \%$ \\
Gasohol 90 & $37,12 \%$ \\
GLP & $9,52 \%$ \\
\hline
\end{tabular}

Elaboración propia 
Tabla 2.13

Demanda del proyecto en galones

\begin{tabular}{|c|c|c|c|c|c|}
\hline & 2019 & 2020 & 2021 & 2022 & 2023 \\
\hline Diesel B5(Galones) & 504.709 & 521.159 & 537.602 & 554.052 & 570.494 \\
\hline Gasohol 97(Galones) & 419.831 & 433.515 & 447.192 & 460.876 & 474.553 \\
\hline Gasohol 95(Galones) & 106.603 & 110.078 & 113.551 & 117.025 & 120.498 \\
\hline Gasohol 90(Galones) & 751.674 & 776.174 & 800.662 & 825.161 & 849.650 \\
\hline GLP(Galones) & 399.880 & 412.914 & 425.941 & 438.975 & 452.002 \\
\hline Total galones & 2.184.717 & 2.255 .859 & 2.326 .969 & 2.398.111 & 2.469 .220 \\
\hline
\end{tabular}

Elaboración propia 


\subsection{Venta del servicio}

\subsubsection{Políticas de la plaza}

La empresa cuenta con un servicio de distribución de 0 etapas, donde se despacha la cantidad al cliente en la misma estación de servicio.

El grifo es un detallista, por lo que también formará parte del canal de distribución de Petroperú. Siendo el grifo el penúltimo eslabón de la cadena y se puede clasificar según su tipo de venta en un detallista de comercio tradicional.

- Normas para su comercialización:

Para la comercialización, la principal norma es el Decreto Supremo 030-98 EM: Reglamento para la Comercialización de Combustibles Líquidos y Otros Productos Derivados de los Hidrocarburos.

No obstante, para lograr tal fin también se sujeta a más normas, algunas de ellas son:

- Ley N²6221 Ley Orgánica de Hidrocarburos: esta ley "promueve el desarrollo de actividades de hidrocarburos sobre la base de la libre competencia con la finalidad de lograr el bienestar de la persona humana y el desarrollo nacional." (Ley N²6221)

- Decreto Supremo 054-93-EM: Reglamento de Seguridad para establecimientos de Venta al Público de Combustibles Derivados de Hidrocarburos.

- Decreto Supremo $\mathrm{N}^{\circ}$ 053-2005-PCM: Ley de control de Insumos Químicos y Productos Fiscalizados.

El cumplimiento de todas estas normas y demás conlleva a la obtención del permiso de OSINERGMIN. No obstante, también se requiere de la licencia de funcionamiento de la municipalidad y, en este caso en particular, del convenio de abanderamiento con Petroperú.

Cabe recalcar que para obtener el convenio de abanderamiento primero se debe poner en contacto con el representante de ventas retail de la zona centro oriente de Petroperú y este procederá con la evaluación física y de proyecciones de venta de la estación de servicios. En caso obtener resultados favorables de las 
evaluaciones, se definirán las condiciones comerciales del "convenio de exclusividad" para la firma de ambas partes. No hay que soslayar que este convenio no se trata de una franquicia sino de un contrato de ventas donde se estipulan los siguientes principales términos comerciales:

Por parte de Petroperú:

- Descuentos exclusivos.

- Aumento en el límite de carga y prioridad A1 para el despacho de los combustibles.

- Abastecer de forma exclusiva a algunas entidades públicas que utilicen combustibles para operar como la Policía Nacional del Perú (PNP).

- Brindar asesoramiento y capacitaciones para que puedan operar de forma más eficiente y segura la estación de servicios.

- Costeo de algunos servicios necesarios para la implementación del proyecto que se detallaran en la sección 7.1.1. Estimación de las inversiones de largo plazo.

- Entrega de merchandising y volantes publicitarios.

- Entrega de uniforme Petroperú para los vendedores de isla.

Por parte del cliente:

- Compra de forma exclusiva a Petroperú de los combustibles a ofertar.

Cabe recalcar que se escogió el abanderamiento de Petroperú porque solo esta empresa realiza un contrato por 3 años (las otras empresas como Primax o Repsol firman contratos por tiempo de vigencia no menor a 5 años), lo que permite a PetroGreen tener mayor flexibilidad ya que en el corto plazo puede decidir si renueva o cambia de abanderado según los resultados obtenidos de este primer contrato. Otra razón es que Petroperú, al ser una empresa del estado y no poseer ninguna estación de servicios propia, no pone dentro de sus términos de contrato el aval con la estación de servicios, lo que sí es requisito no negociable en el contrato de las empresas privadas pudiendo llegar incluso en caso extremo de deuda a la expropiación del local. Se considera este ítem muy importante puesto que PetroGreen será una empresa nueva que tendrá que ganar mercado desde un inicio por lo que existe un riesgo significativo para cumplir una demanda similar a la de la competencia; por eso, se mencionó que se considerará solo el $50 \%$ de la participación de mercado promedio de las otras empresas. Finalmente, el último motivo es el posicionamiento de la marca Petroperú, ya que sobre todo en provincia esta marca 
se encuentra bien posicionada y es reconocida como sinónimo de alta calidad, garantía y confiabilidad.

\subsubsection{Análisis de precios}

Los precios en este sector se fijan en base a un análisis de mercado nacional e internacional y análisis de costos de la empresa de forma interna. Si bien es cierto que OSINERGMIN no interviene en el mercado fijando precios o estableciendo límites máximos o mínimos (conforme con la Ley General de Hidrocarburos), esta entidad obliga a todas las estaciones de servicio publicar su lista de precios actualizado en una plataforma virtual denominada "Facilito" a la cual los consumidores tienen libre acceso.

\subsubsection{Tendencia histórica de los precios}

Con respecto a la tendencia histórica de los precios, estos siempre han presentado un comportamiento bastante fluctuante, ya que el precio de la materia prima también lo es. Además, es importante tomar en cuenta que la frecuencia con la que cambia el precio también se ve afectado por la competitividad del mercado donde se encuentre.

A continuación, se analizará la variación del precio que ha tenido la materia prima de estos productos en los últimos años:

Figura 2.9

Evolución del precio del petróleo

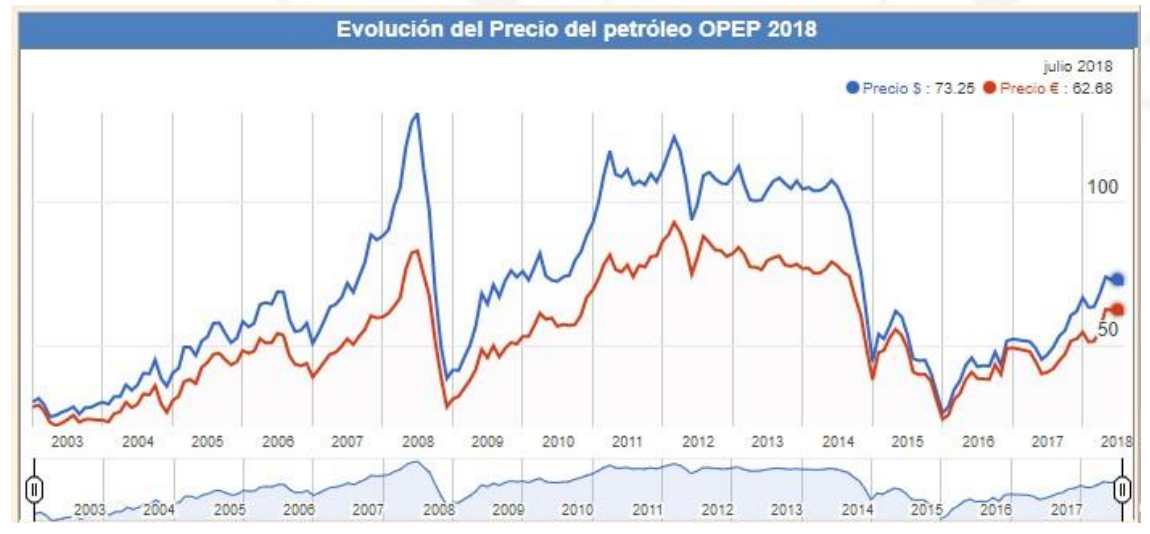

Fuente: Datosmacro (2018)

En el gráfico, se puede apreciar claramente que el precio del petróleo no posee una tendencia fija, por el contrario, pareciera que no sigue ningún tipo de patrón. Se observa que el precio del petróleo alcanzó picos en los años 2008 y 2012 y en el periodo 
de 2014 a 2016, la tendencia fue a la baja, alcanzando sus precios más bajos a fines del 2015. Finalmente, en los últimos dos años (2016-2018) se observa una tendencia al alza.

\subsubsection{Precios actuales y estrategia de precio inicial}

Para fijar el valor de venta, primero se realizará un benchmarking local y en base a ello se obtendrá un valor de venta promedio teniendo en cuenta que la estrategia de esta estación de servicios no es de enfoque en el precio. Posterior a ello, se observará las proyecciones de la variación del precio de la materia prima, el petróleo, en los siguientes años para poder realizar un ajuste al valor de venta promedio hallado inicialmente.

A continuación, se colocan los datos del benchmarking local:

Tabla 2.14

Relación de valores de venta de Diesel B5

\begin{tabular}{l|lcc}
\hline \multicolumn{1}{c|}{ Ciudad } & \multicolumn{1}{c}{ Establecimiento } & $\begin{array}{c}\text { Valor de venta por galón } \\
\text { (soles) }\end{array}$ & Fecha actualización \\
\hline Huancayo & Grifo Huancas E.I.R.L & 10,5 & $23 / 08 / 2018$ \\
Huancayo & Consorcio Súper grifo La Ribera S.R.L & 10,6 & $23 / 08 / 2018$ \\
Huancayo & Victor Raúl López Cifuentes & 10,6 & $23 / 08 / 2018$ \\
Huancayo & Petrogas & 10,7 & $23 / 08 / 2018$ \\
Huancayo & Estación de Servicio Precisión S.R.L & 10,8 & $23 / 08 / 2018$ \\
Huancayo & Grifo San Carlos E.I.R.L & 10,8 & $23 / 08 / 2018$ \\
Huancayo & Inversiones Arwaturo S.R.L & 10,8 & $23 / 08 / 2018$ \\
Huancayo & Servicentro Palián S.A.C & 10,9 & $23 / 08 / 2018$ \\
Huancayo & San Sebastián S.A.C & 11,2 & $23 / 08 / 2018$ \\
Huancayo & Grifo José Olaya E.I.R.L & 11,6 & $23 / 08 / 2018$ \\
Huancayo & Supergrifos Aurelia S.A.C & 11,7 & $23 / 08 / 2018$ \\
Huancayo & Combustibles Calimax E.I.R.L & 11,7 & $23 / 08 / 2018$ \\
\hline
\end{tabular}

Fuente: Facilito-OSINERGMIN (2018)

Con respecto al Gasohol 97:

Tabla 2.15

Relación de valores de venta del petróleo Gasohol 97

\begin{tabular}{c|lcc}
\hline Ciudad & \multicolumn{1}{|c}{ Establecimiento } & $\begin{array}{c}\text { Valor de venta por } \\
\text { galón (soles) }\end{array}$ & Fecha actualización \\
\hline Huancayo & Petrox San Sebastián S.A.C & 12,1 & $23 / 08 / 2018$ \\
Huancayo & Servicentro Palián S.A.C & 12,4 & $23 / 08 / 2018$ \\
Huancayo & Grifo Huancas E.I.R.L & 12,5 & $23 / 08 / 2018$ \\
Huancayo & Petrogas & 12,6 & $23 / 08 / 2018$ \\
Huancayo & Inversiones Arwaturo S.R.L & 12,6 & $23 / 08 / 2018$ \\
Huancayo & Estación de servicios Precisión S.R.L & 12,6 & $23 / 08 / 2018$ \\
\hline
\end{tabular}

Fuente: Facilito-OSINERGMIN (2018) 
Con respecto al Gasohol 95:

Tabla 2.16

Relación de valores de venta del petróleo Gasohol 95

\begin{tabular}{c|lcc}
\hline Ciudad & \multicolumn{1}{|c}{ Establecimiento } & $\begin{array}{c}\text { Valor de venta por galón } \\
\text { (soles) }\end{array}$ & Fecha actualización \\
\hline Huancayo & Victor Raúl López Cifuentes & 11,8 & $23 / 08 / 2018$ \\
Huancayo & Petrogas & 11,8 & $23 / 08 / 2018$ \\
Huancayo & Servicentro Palián S.A.C & 11,9 & $23 / 08 / 2018$ \\
Huancayo & Grifo San Carlos E.I.R.L & 11,9 & $23 / 08 / 2018$ \\
Huancayo & Grifo José Olaya E.I.R.L & 12,5 & $23 / 08 / 2018$ \\
Huancayo & Combustibles Calimax E.I.R.L & 13,4 & $23 / 08 / 2018$ \\
\hline
\end{tabular}

Fuente: Facilito-OSINERGMIN (2018)

Con respecto al Gasohol 90:

Tabla 2.17

Relación de valores de venta del petróleo Gasohol 90

\begin{tabular}{c|lcc}
\hline Ciudad & \multicolumn{1}{|c}{ Establecimiento } & $\begin{array}{c}\text { Valor de venta por galón } \\
\text { (soles) }\end{array}$ & Fecha actualización \\
\hline Huancayo & Victor Raúl López Cifuentes & 10,8 & $23 / 08 / 2018$ \\
Huancayo & Grifo Huancas E.I.R.L & 10,9 & $23 / 08 / 2018$ \\
Huancayo & Consorcio Super grifo la ribera S.R.L & 11,0 & $23 / 08 / 2018$ \\
Huancayo & Servicentro Palián S.A.C & 11,0 & $23 / 08 / 2018$ \\
Huancayo & Inversiones Arwaturo S.R.L & 11,0 & $23 / 08 / 2018$ \\
Huancayo & Petrogas & 11,1 & $23 / 08 / 2018$ \\
Huancayo & Grifo San Carlos E.I.R.L & 11,1 & $23 / 08 / 2018$ \\
Huancayo & Petrox San Sebastián S.A.C & 11,2 & $23 / 08 / 2018$ \\
Huancayo & Estación de servicio Precisión S.R.L & 11,3 & $23 / 08 / 2018$ \\
Huancayo & Grifo José Olaya E.I.R.L & 11,7 & $23 / 08 / 2018$ \\
Huancayo & Supergrifos Aurelia S.A.C & 11,8 & $23 / 08 / 2018$ \\
Huancayo & Combustibles Calimax E.I.R.L & 11,8 & $23 / 08 / 2018$ \\
\hline
\end{tabular}

Fuente: Facilito-OSINERGMIN (2018)

Y finalmente con respecto al GLP:

Tabla 2.18

Relación de valores de venta del GLP

\begin{tabular}{c|lccc}
\hline Ciudad & \multicolumn{1}{|c}{ Establecimiento } & $\begin{array}{c}\text { Valor de venta por } \\
\text { litro (soles) }\end{array}$ & $\begin{array}{c}\text { Valor de venta por } \\
\text { galón (soles) }\end{array}$ & $\begin{array}{c}\text { Fecha } \\
\text { actualización }\end{array}$ \\
\hline Huancayo & Rocío Jacqueline López & 1,4 & 5,2 & $23 / 08 / 2018$ \\
Huancayo & Cira Zenaida Benites de Carrión & 1,4 & 5,3 & $23 / 08 / 2018$ \\
Huancayo & Comercializadora de gas S.R.L & 1,4 & 5,3 & $23 / 08 / 2018$ \\
Huancayo & Combustibles Calimax E.I.R.L & 1,4 & 5,4 & $23 / 08 / 2018$ \\
Huancayo & Supergrifos Aurelia S.A.C & 1,4 & 5,4 & $23 / 08 / 2018$ \\
Huancayo & Petrogas & 1,4 & 5,4 & $23 / 08 / 2018$ \\
Huancayo & Servicentro Palián S.A.C. & 1,4 & 5,4 & $23 / 08 / 2018$ \\
Huancayo & Petrox San Sebastián S.A.C & 1,4 & 5,4 & $23 / 08 / 2018$ \\
Huancayo & Estación de servicio Precisión S.R.L & 1,4 & 5,4 & $23 / 08 / 2018$ \\
Huancayo & Inversiones Arwaturo S.R.L & 1,4 & 5,5 & $23 / 08 / 2018$ \\
\hline
\end{tabular}

Fuente: Facilito-OSINERGMIN (2018) 
Finalmente, sacando un promedio de valor de venta de cada estación, se definieron los siguientes valores iniciales:

Tabla 2.19

Valor de venta (en soles)

\begin{tabular}{l|c}
\hline \multicolumn{1}{c|}{ Producto } & Valor de venta por galón \\
\hline Diésel B5 & 11 \\
Gasohol 97 & 12,5 \\
Gasohol 95 & 12,2 \\
Gasohol 90 & 11,2 \\
GLP & 5,4 \\
\hline
\end{tabular}

Elaboración propia

A continuación, se expondrán los resultados de la proyección del precio de la materia prima a nivel mundial hasta el año 2023 según un estudio realizado por el Departamento de Hidrocarburos de Chile en el año 2016 y que hasta el año 2018 ha sido bastante asertivo.

Tabla 2.20

Precio proyectado de petróleo

\begin{tabular}{r|rr}
\hline \multicolumn{1}{c|}{ Año } & Precio (USD) & \% Crecimiento \\
\hline 2019 & 77,69 & $1,9 \%$ \\
2020 & 79,13 & $1,9 \%$ \\
2021 & 81,29 & $2,7 \%$ \\
2022 & 83,64 & $2,9 \%$ \\
2023 & 86,09 & $2,9 \%$ \\
\hline \multicolumn{2}{|c|}{ Fuente: Departamento de Hidrocarburos - Chile (2016) }
\end{tabular}

Como se sabe, una variable indispensable para fijar el valor de venta del producto, es el costo del mismo. Por tal motivo, a partir del porcentaje de crecimiento en el precio del petróleo para cada año, se proyectará el incremento anual del costo de los productos a ofrecer en este servicio partiendo por el costo para el mes de agosto 2018 de los galones de los productos según lo consultado a un representante de ventas de Petroperú. 
Tabla 2.21

Costos proyectados de combustibles según variación de precio de materia prima (en soles)

\begin{tabular}{l|ccccc}
\hline \multicolumn{1}{c|}{ Producto } & $\mathbf{2 0 1 9}$ & $\mathbf{2 0 2 0}$ & $\mathbf{2 0 2 1}$ & $\mathbf{2 0 2 2}$ & $\mathbf{2 0 2 3}$ \\
\hline Diésel B5 & 9,9 & 10,1 & 10,3 & 10,6 & 10,9 \\
Gasohol 97 & 10,2 & 10,4 & 10,7 & 11,0 & 11,3 \\
Gasohol 95 & 9,9 & 10,1 & 10,4 & 10,7 & 11,0 \\
Gasohol 90 & 9,7 & 9,9 & 10,2 & 10,5 & 10,8 \\
GLP & 4,4 & 4,5 & 4,6 & 4,7 & 4,8 \\
\hline
\end{tabular}

Elaboración propia

En base a los costos por galón proyectado, se calcularán los valores de venta en la estación de servicio. Cabe recalcar que en principio se tratarán de mantener los márgenes de ganancia; sin embargo, solo se trasladará al cliente hasta un 2,5\% en el incremento del costo de los productos:

Tabla 2.22

Valor de venta proyecto (en soles)

\begin{tabular}{l|ccccc}
\hline \multicolumn{1}{c|}{ Producto } & $\mathbf{2 0 1 9}$ & $\mathbf{2 0 2 0}$ & $\mathbf{2 0 2 1}$ & $\mathbf{2 0 2 2}$ & $\mathbf{2 0 2 3}$ \\
\hline Diésel B5 & 11,2 & 11,4 & 11,7 & 12,0 & 12,3 \\
Gasohol 97 & 12,7 & 13,0 & 13,3 & 13,7 & 14,0 \\
Gasohol 95 & 12,4 & 12,7 & 13,0 & 13,3 & 13,7 \\
Gasohol 90 & 11,4 & 11,6 & 11,9 & 12,2 & 12,5 \\
GLP & 5,5 & 5,6 & 5,7 & 5,9 & 6,0 \\
\hline
\end{tabular}

Elaboración propia

No hay que soslayar que la variación de precios en este sector se da de forma constante. Por tal motivo, es indispensable estar atento a las variaciones en la planta de abastecimiento, las leyes como el Impuesto Selectivo al Consumo y a la par realizar un constante benchmarking local de precios. No obstante, el riesgo del aumento del costo de la materia prima disminuye al tener la posibilidad de trasladar esta diferencia al cliente final; sin embargo, no siempre se puede trasladar la totalidad del incremento. 


\subsection{Marketing de servicios}

\subsubsection{Características principales del servicio}

Figura 2.10

Modelo Canvas

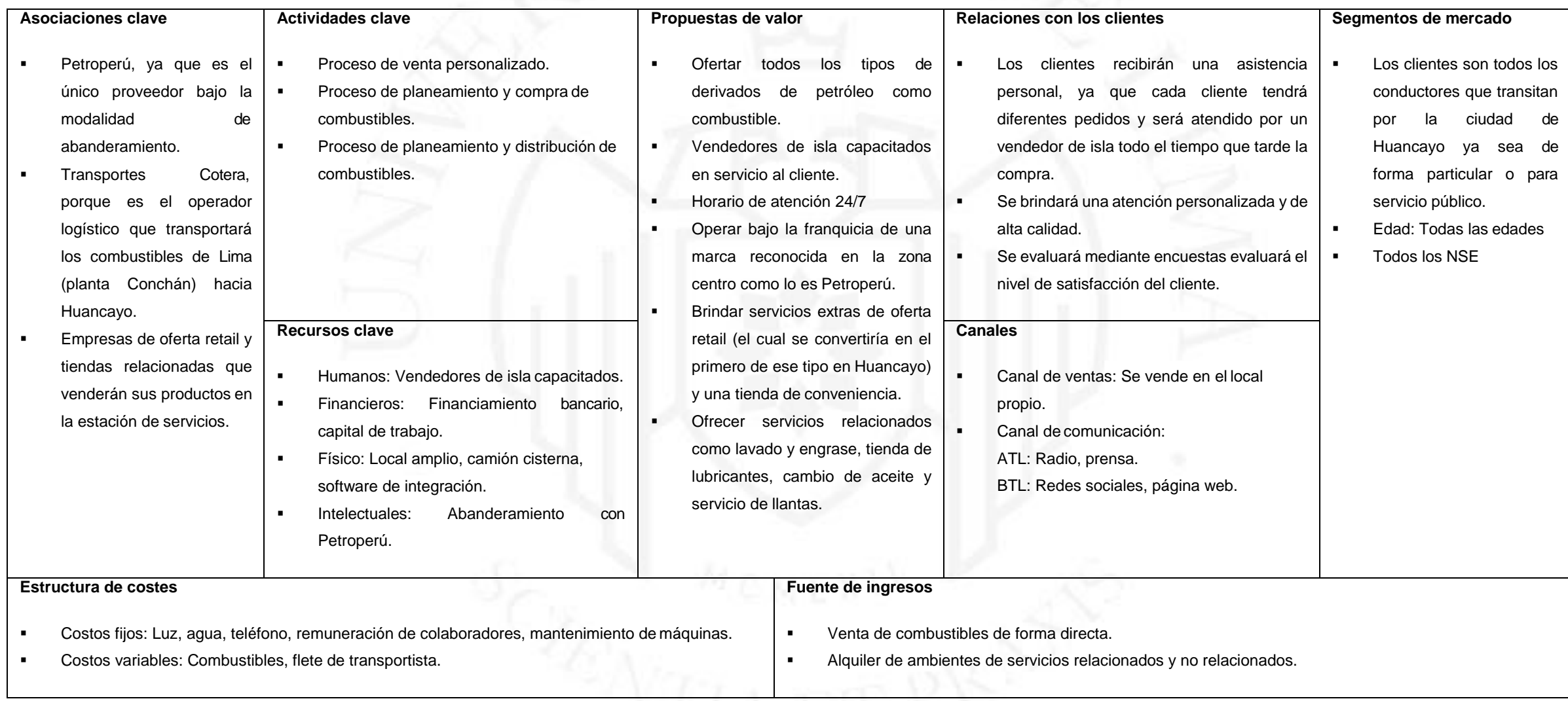

Elaboración propia 


\subsubsection{Publicidad y promoción}

Con respecto a la publicidad, se puede decir que estará orientado principalmente a su marca, puesto que los productos en teoría son los mismos en la mayoría de los grifos. Las campañas publicitarias serán realizadas una parte por Petroperú, que consiste en posicionamiento de su propia marca a través de los diferentes medios (en especial afiches y pancartas) y la otra parte la hará el mismo grifo y consistirá en publicidad específica a su propio establecimiento. Lo harán por los medios tradicionales como radios y prensa en general, pero también por medio de las redes sociales.

Por otro lado, las promociones son la tercera característica más valorada de una estación de servicios. Adicional a ello, según la pregunta de la encuesta referida a preferencia de promociones, se puede apreciar claramente que la gran mayoría (casi el 95\%) quiere obtener descuentos en el combustible, pero también poseen una aceptación considerable la obtención de lubricantes y descuentos en las tiendas dentro del grifo.

En este sentido, se piensa contar con un sistema de acumulación de puntos.

Las características de esta promoción serían las siguientes:

- El cliente acumulará un punto por cada 10 soles de consumo.

- Los clientes que lleguen a 40 puntos podrán canjear un aceite de 1 litro.

- Los clientes que lleguen a 60 puntos podrán obtener un vale de descuento de 20 soles en combustibles.

- Los clientes que lleguen a 20 puntos podrán obtener descuentos en las tiendas de servicio.

Bajo la premisa que el 30\% de la venta utilizará la modalidad de acumulación de puntos para canje de gasolina, se calcula que en el año se gastará aproximadamente la siguiente cantidad de soles en esta promoción: 
Tabla 2.23

Gasto por promoción (en soles)

\begin{tabular}{l|ccccc}
\hline & $\mathbf{2 0 1 9}$ & $\mathbf{2 0 2 0}$ & $\mathbf{2 0 2 1}$ & $\mathbf{2 0 2 2}$ & $\mathbf{2 0 2 3}$ \\
\hline Diesel B5 & $56.572,82$ & $59.526,63$ & $62.939,81$ & $66.487,35$ & $70.172,01$ \\
Gasohol 97 & $53.476,00$ & $56.268,11$ & $59.494,46$ & $62.847,80$ & $66.330,76$ \\
Gasohol 95 & $13.252,69$ & $13.944,65$ & $14.744,22$ & $15.575,26$ & $16.438,42$ \\
Gasohol 90 & $85.787,08$ & $90.266,23$ & $95.441,99$ & $100.821,47$ & $106.408,89$ \\
GLP & $22.003,82$ & $23.152,69$ & $24.480,24$ & $25.860,04$ & $27.293,18$ \\
Total & $\mathbf{2 3 3 . 1 1 1 , 4 1}$ & $\mathbf{2 4 5 . 1 7 8 , 3 0}$ & $\mathbf{2 5 9 . 1 2 1 , 7 1}$ & $\mathbf{2 7 3 . 6 1 3 , 9 2}$ & $\mathbf{2 8 8 . 6 6 6 , 2 5}$ \\
\hline
\end{tabular}

Elaboración propia

Así mismo, bajo la premisa que el $10 \%$ de la venta utilizará la modalidad de acumulación de puntos para canje de lubricantes, se calculó la cantidad de estos que se regalarán:

Tabla 2.24

Cantidad de lubricantes que se regalarán

\begin{tabular}{l|ccccc}
\hline & $\mathbf{2 0 1 9}$ & $\mathbf{2 0 2 0}$ & $\mathbf{2 0 2 1}$ & $\mathbf{2 0 2 2}$ & $\mathbf{2 0 2 3}$ \\
\hline Diesel B5 & 1.415 & 1.489 & 1.574 & 1.663 & 1.755 \\
Gasohol 97 & 1.337 & 1.407 & 1.488 & 1.572 & 1.659 \\
Gasohol 95 & 332 & 349 & 369 & 390 & 411 \\
Gasohol 90 & 2.145 & 2.257 & 2.387 & 2.521 & 2.661 \\
GLP & 551 & 579 & 613 & 647 & 683 \\
\hline
\end{tabular}

Elaboración propia

Cabe recalcar que el costo de los descuentos en las otras tiendas de la estación de servicios no los asumirá el grifo, sino que se tratará de una negociación para que también se puedan promover las ventas de los servicios extra. 


\section{CAPÍTULO III: LOCALIZACIÓN DE SERVICIO}

\subsection{Identificación y análisis detallado de los factores de micro localización}

Los factores de micro localización a tener en cuenta para elegir la mejor opción para la instalación de una estación de servicios con las características que se viene planteando a lo largo del presente trabajo son las siguientes:

\section{- $\quad$ Largo frontis (m)}

El largo del frontis es muy importante ya que mientras más grande sea, permitirá colocar más islas de despacho, facilitará la entrada y salida de vehículos y hará más vistosa la estación de servicios.

Se calificará dicho factor según el siguiente cuadro:

Tabla 3.1

Calificación para Factor "Largo frontis"

\begin{tabular}{|c|c|}
\hline Puntaje & Largo frontis (m) \\
\hline & $<10$ \\
\hline & $>=10 y<20$ \\
\hline & $>=20 y<30$ \\
\hline & $>=30 y<40$ \\
\hline & $>=40$ \\
\hline
\end{tabular}

Elaboración propia

\section{- Flujo vehicular}

Es uno de los factores más importantes conjuntamente con el largo del frontis ya que el que haya bastante tránsito por las calles donde está situada una estación de servicios, atrae una demanda extra por sí misma.

Se calificará dicho factor según el siguiente cuadro: 
Tabla 3.2

Calificación para Factor "Flujo vehicular"

\begin{tabular}{r|l}
\hline \multicolumn{1}{r|}{ Puntaje } & \multicolumn{2}{|c}{ Flujo vehicular } \\
& \\
\hline 2 & Nulo \\
4 & Poco \\
6 & Intermedio \\
8 & Elevado \\
10 & Muy elevado \\
\hline
\end{tabular}

Elaboración propia

\section{- Cercanía a lugares estratégicos}

Con respecto a este factor, que es el segundo más importante, se puede afirmar que es un plus que una estación de servicios se encuentre cerca a puntos estratégicos donde exista confluencia de vehículos, ya que les sería más fácil abastecerse de combustible a los conductores en los lugares más cercanos. Estos lugares podrían ser mercados, universidades, centros empresariales, terminales, entre otros. Cabe resaltar que no se considera como lugares estratégicos a los centros comerciales retail puesto que, si bien es cierto ayudan al mayor flujo de vehículos, son competencia directa de las tiendas de conveniencias propias de la Estación de Servicios; por lo que mantendrán una postura neutral.

Se calificará dicho factor según el siguiente cuadro:

Tabla 3.3

Calificación para Factor "Cantidad de lugares estratégicos cercanos"

\begin{tabular}{r|c}
\hline Puntaje & $\begin{array}{c}\text { Cantidad de } \\
\text { lugares estratégicos } \\
\text { cercanos }\end{array}$ \\
\hline 2 & 0 \\
4 & 1 \\
6 & 2 \\
8 & 3 \\
10 & 4 \\
\hline
\end{tabular}

Elaboración propia

\section{- Área adecuada $\left(\mathbf{m}^{2}\right)$}

El área destinada a la construcción de este servicio es muy importante ya que como se ha mencionado, habrá varias tiendas de conveniencia que deben contar con un espacio adecuado (mientras más área, mayor será el puntaje). Este factor es igual de importante que el factor cercanía a lugares estratégicos. 
Se calificará dicho factor según el siguiente cuadro:

Tabla 3.4

Calificación para Factor "Área adecuada $\left(\mathrm{m}^{2}\right)$ ”

\begin{tabular}{r|l}
\hline \multicolumn{1}{c|}{ Puntaje } & \multicolumn{1}{|c}{ Área adecuada $\left(\mathbf{m}^{\mathbf{2}}\right)$} \\
\hline 2 & $<500$ \\
4 & $>=500 \mathrm{y}<1000$ \\
6 & $>=1000 \mathrm{y}<1500$ \\
8 & $>=1500 \mathrm{y}<2000$ \\
10 & $>=2000$ \\
\hline
\end{tabular}

Elaboración propia

\section{- Costo}

Otro factor a tomar en cuenta es el costo del metro cuadrado del terreno, lo cual permitirá tener una idea de qué tan eficiente es la inversión. Cabe resaltar que el costo de los terrenos en Huancayo se regula según el propio mercado y que varían en función a su cercanía al centro de la ciudad (a más cerca mayor es su valor por $\mathrm{m}^{2}$ ). Es el tercer factor más importante.

Se calificará dicho factor según el siguiente cuadro:

Tabla 3.5

Calificación para Factor "Costo por metro cuadrado"

\begin{tabular}{r|l}
\hline \multicolumn{1}{c|}{ Puntaje } & \multicolumn{1}{c}{$\begin{array}{c}\text { Costo por metro } \\
\text { cuadrado (USD) }\end{array}$} \\
\hline 2 & $>=1200$ \\
4 & $>=900 \mathrm{y}<1200$ \\
6 & $>=600 \mathrm{y}<900$ \\
8 & $>=300 \mathrm{y}<600$ \\
10 & $<300$ \\
\hline Elaboración propia
\end{tabular}

- Cercanía de competidores

Por otro lado, se encuentra la cercanía a otros competidores. Con frecuencia se suele ver a dos o más estaciones de servicio frente a frente o muy cercanas, lo cual no es muy saludable porque hacen que exista canibalismo entre sus demandas relacionadas a sus radios de influencia.

Este factor posee similar grado de importancia que el factor costo. 
Se calificará dicho factor según el siguiente cuadro:

Tabla 3.6

Calificación para Factor "Cantidad de cuadras de la estación más cercana”

\begin{tabular}{r|l}
\hline Puntaje & $\begin{array}{l}\text { Cantidad de cuadras de } \\
\text { la estación más cercana }\end{array}$ \\
\hline 2 & $<2$ \\
4 & $>=2 \mathrm{y}<4$ \\
6 & $>=4 \mathrm{y}<6$ \\
8 & $>=6 \mathrm{y}<8$ \\
10 & $>=8$ \\
\hline Elaboración propia
\end{tabular}

\subsection{Identificación y descripción de las alternativas de micro localización}

Para realizar la elección preliminar de las opciones se realizó una búsqueda a nivel local de los terrenos disponibles que cuenten con un tamaño de frontis y área suficiente, ya que los demás quedarían descartados al imposibilitar la realización del proyecto. A continuación, se describen estas opciones:

\section{- Opción 1:}

Es un terreno ubicado en el Tambo, específicamente en prolongación Trujillo 1173. Posee un área total de $1581.5 \mathrm{~m}^{2} \mathrm{y}$ un costo de 531.475 dólares, en otras palabras, su valor por $\mathrm{m}^{2}$ es de 336 dólares. También se sabe que se encuentra cerca de puntos de referencia como tiendas Makro (sí se considera como lugar estratégico ya que no es competencia directa de las tiendas de conveniencias puesto que es una tienda de venta mayorista) y la Universidad Continental. Posee un frontis de $19.29 \mathrm{~m}$. y solo tiene salida a una calle, la cual posee un flujo vehicular intermedio. La estación de servicio más cercana se encuentra a 7 cuadras.

\section{- Opción 2:}

Es un terreno ubicado en el distrito del Tambo ubicado en el cruce de la calle Real y el Pasaje Salesiano. Posee un área de $2.242 \mathrm{~m}^{2}$ y el costo de 1.350 .000 dólares, es decir el $\mathrm{m}^{2}$ cuesta 601 dólares. Por otro lado, se encuentra cerca de la Galería Huancayo Real y cerca al Instituto Continental. Posee un frontis de $59 \mathrm{~m}$. y tiene salida a una calle principal y a un pasaje; por ende, el flujo vehicular es intermedio. No se encuentran grifos en un perímetro cercano de 8 cuadras. 


\section{- Opción 3:}

Es un terreno ubicado en el centro de Huancayo en el Jr. Cuzco 176. Tiene un área de $574.8 \mathrm{~m}^{2}$ y el costo es de 689.760 dólares; es decir, su precio por $\mathrm{m}^{2}$ es de 1200 dólares. Posee un frontis de 17,5 m. y salida para 1 calle. El flujo vehicular es elevado. La estación de servicio más cercana se encuentra a 5 cuadras.

\subsection{Evaluación y selección de localización}

Los factores a emplear para el método de ranking de factores son:
A. Largo frontis. B. Flujo vehicular. C. Cercanía a lugares estratégicos.
D. Área. E. Costo. F. Cercanía de competidores

Primero, en la matriz de enfrentamiento se calcula el peso que tendrá cada uno de los factores para finalmente elegir la opción óptima en el ranking de factores:

Luego, se realizará la calificación a cada opción con puntaje del 1 a 5 por cada factor.

Tabla 3.7

Matriz de enfrentamiento

\begin{tabular}{c|cccccccc}
\hline & A & B & C & D & E & F & Conteo & Ponderación \\
\hline A & - & 1 & 1 & 1 & 1 & 1 & 5 & $28 \%$ \\
B & 1 & - & 1 & 1 & 1 & 1 & 5 & $28 \%$ \\
C & 0 & 0 & - & 1 & 1 & 1 & 3 & $17 \%$ \\
D & 0 & 0 & 1 & - & 1 & 1 & 3 & $17 \%$ \\
E & 0 & 0 & 0 & 0 & - & 1 & 1 & $6 \%$ \\
F & 0 & 0 & 0 & 0 & 1 & - & 1 & $6 \%$ \\
& & & & & & & $\mathbf{1 8}$ & $\mathbf{1 0 0 \%}$ \\
\hline
\end{tabular}

Elaboración propia 
Tabla 3.8

Matriz de ranking de factores

\begin{tabular}{|c|c|c|c|c|c|c|}
\hline & \multicolumn{2}{|c|}{ Opción 1} & \multicolumn{2}{|c|}{ Opción 2} & \multicolumn{2}{|c|}{ Opción 3} \\
\hline & Calificación & Puntaje & Calificación & Puntaje & Calificación & Puntaje \\
\hline A. Largo frontis (m) & 4 & 1,12 & 10 & 2,80 & 4 & 1,12 \\
\hline B. Flujo vehicular & 6 & 1,68 & 6 & 1,68 & 8 & 2,24 \\
\hline $\begin{array}{l}\text { C. Cantidad de lugares } \\
\text { estratégicos cercanos }\end{array}$ & 6 & 1,02 & 6 & 1,02 & 2 & 0,34 \\
\hline D. Área adecuada $\left(\mathrm{m}^{2}\right)$ & 8 & 1,36 & 10 & 1,70 & 4 & 0,68 \\
\hline $\begin{array}{l}\text { E. Costo por metro } \\
\text { cuadrado }\end{array}$ & 8 & 0,48 & 6 & 0,36 & 2 & 0,12 \\
\hline $\begin{array}{l}\text { F. Cantidad de } \\
\text { cuadras de la estación } \\
\text { más cercana }\end{array}$ & 8 & 0,48 & 10 & 0,60 & 6 & 0,36 \\
\hline Puntaje total & & 6,14 & & 8,16 & & 4,86 \\
\hline
\end{tabular}

Elaboración propia

Finalmente se elige la opción 2 (terreno ubicado en el distritodel Tambo ubicado en el cruce de la calle Real y el Pasaje Salesiano), ya que posee la mayor puntuación.

A continuación, se muestra un mapa donde estará ubicada la estación de servicios:

Figura 3.1

Ubicación de estación de servicios

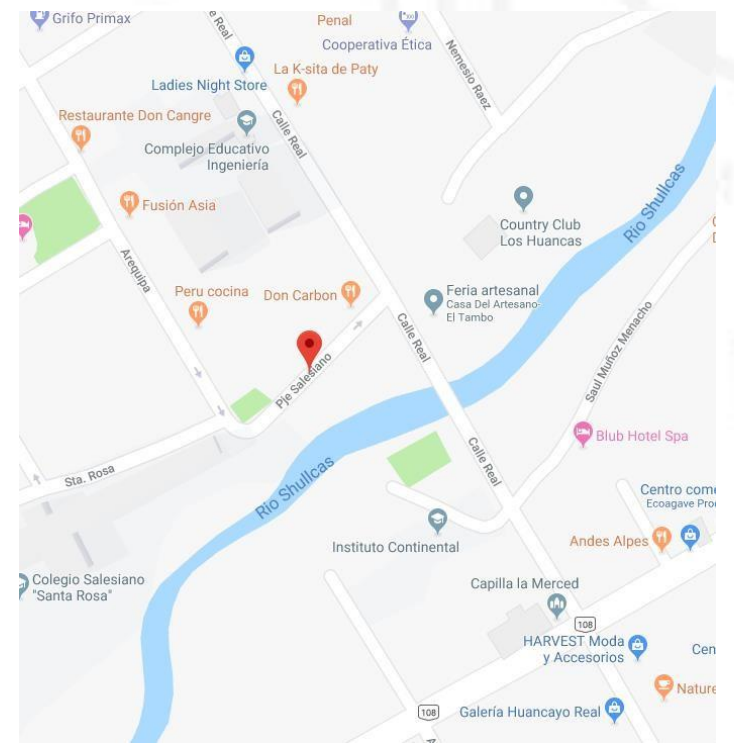

Elaboración propia 


\section{CAPÍTULO IV: DIMENSIONAMIENTO DEL SERVICIO}

\subsection{Relación tamaño-mercado}

La relación tamaño-mercado se obtiene con la demanda del proyecto obtenida en el Capítulo 2.

Tabla 4.1

Relación tamaño-mercado

\begin{tabular}{l|ccccc}
\hline & $\mathbf{2 0 1 9}$ & $\mathbf{2 0 2 0}$ & $\mathbf{2 0 2 1}$ & $\mathbf{2 0 2 2}$ & $\mathbf{2 0 2 3}$ \\
\hline $\begin{array}{l}\text { Diesel B5(Galones) } \\
\text { Gasohol }\end{array}$ & 504.709 & 521.159 & 537.602 & 554.052 & 570.494 \\
$\begin{array}{l}\text { 97(Galones) } \\
\text { Gasohol }\end{array}$ & 419.831 & 433.515 & 447.192 & 460.876 & 474.553 \\
95(Galones) & 106.603 & 110.078 & 113.551 & 117.025 & 120.498 \\
$\begin{array}{l}\text { Gasohol } \\
\text { 90(Galones) }\end{array}$ & 751.674 & 776.174 & 800.662 & 825.161 & 849.650 \\
GLP(Galones) & 399.880 & 412.914 & 425.941 & 438.975 & 452.002 \\
Total galones & $\mathbf{2 . 1 8 4 . 7 1 7}$ & $\mathbf{2 . 2 5 5 . 8 5 9}$ & $\mathbf{2 . 3 2 6 . 9 6 9}$ & $\mathbf{2 . 3 9 8 . 1 1 1}$ & $\mathbf{2 . 4 6 9 . 2 2 0}$ \\
\hline Elaboración propia & & & & &
\end{tabular}

Se observa que el año de mayor demanda es el 2023, por lo que el tamañomercado sería de 2.469.220 galones de combustible.

\subsection{Relación tamaño-recursos}

Se consideran tres los recursos críticos para el funcionamiento del servicio, los cuales se mencionan a continuación:

- Combustibles: Como se señaló en capítulos anteriores, este grifo le comprará el combustible a Petroperú y se abastecerá desde la refinería de Conchán.

Las ventas promedio diarias en el 2017 de GLP fueron de 13.000 barriles lo que serían 546.000 galones, mientras de gasolinas/gasoholes, fueron de 30.000 barriles, equivalente a 1.260.000 galones diarios y finalmente, las ventas de diésel fueron de aproximadamente 80.000 barriles, lo que equivale a 3.360 .000 galones diarios. (Petroperú, 2018)

A continuación, se muestra el porcentaje de esas ventas que representaría el abastecimiento de la estación de servicio del presente proyecto. 
Tabla 4.2

Porcentaje de ventas de Petroperú que representa el abastecimiento del grifo del proyecto

\begin{tabular}{l|ccc}
\hline & GLP & Gasolinas/Gasoholes & Diésel \\
\hline Venta diaria Petroperú 2016 (galones) & 546 & 1.260 .000 & 3.360 .000 \\
Venta anual 2016 Petroperú (galones) & 199.290 .000 & 459.900 .000 & 1.226 .400 .000 \\
Compra estimada año 2023 del proyecto (galones) & 456.522 & 1.459 .148 & 576.199 \\
\% De ventas del proyecto con relación a total & $\mathbf{0 , 2 3 \%}$ & $\mathbf{0 , 3 2 \%}$ & $\mathbf{0 , 0 5 \%}$ \\
Petroperú & &
\end{tabular}

Elaboración propia

Como se observa, el porcentaje de ventas que representaría la estación de servicios del presente proyecto (considerando $0,1 \%$ de mermas para combustibles líquidos) es mínima, además es importante mencionar que, a pesar de atender el $51 \%$ de compra de combustibles a nivel nacional, Petroperú asegura no haber tenido problemas en cubrir demanda del mercado interno. Finalmente, Petro Perú planea ampliar la capacidad de las plantas.

- Transportista:

La empresa que se encargará de transportar los combustibles desde la refinería de Conchán hasta la estación de servicios es la empresa Cotera S.A., la cual tiene 5 camiones cisternas que transportan combustibles en esta ruta, 4 de ellos transportan combustible líquido y tienen entre 5 y 6 compartimentos para cualquier tipo de combustible líquido; y el otro es de exclusivamente GLP. Según la empresa, puede abastecer a las estaciones de servicio en Huancayo cada día y medio.

Los datos de sus vehículos se detallan a continuación: 
Tabla 4.3

Capacidad de cisternas transportista

\begin{tabular}{|c|c|c|c|c|c|c|c|c|}
\hline \multirow[b]{2}{*}{$\begin{array}{c}\text { Placa } \\
\text { vehículo }\end{array}$} & \multirow[b]{2}{*}{$\begin{array}{c}\text { Compartimento } \\
1\end{array}$} & \multirow[b]{2}{*}{$\begin{array}{c}\text { Compartimento } \\
2\end{array}$} & \multirow[b]{2}{*}{$\begin{array}{c}\text { Compartimento } \\
3\end{array}$} & \multicolumn{2}{|c|}{ Capacidad en galones } & \multirow[b]{2}{*}{$\begin{array}{c}\text { Compartimento } \\
6\end{array}$} & \multirow[b]{2}{*}{$\begin{array}{c}\text { Total capacidad cada } \\
\text { día y medio }\end{array}$} & \multirow[b]{2}{*}{$\begin{array}{c}\text { Tipo } \\
\text { combustible }\end{array}$} \\
\hline & & & & $\begin{array}{c}\text { Compartimento } \\
4\end{array}$ & $\begin{array}{c}\text { Compartimento } \\
5\end{array}$ & & & \\
\hline A9T991 & 1.500 & 500 & 3.000 & 1.000 & 1.000 & 2.000 & 9.000 & \\
\hline A5N998 & 2.000 & 1.500 & 750 & 750 & 1.000 & 3.000 & 9.000 & \\
\hline F1W976 & 2.000 & 2.000 & 1.050 & 1.050 & 2.000 & - & 8.100 & Liquido \\
\hline F8X974 & 2.000 & 1.000 & 1.000 & 1.000 & 3.000 & 2.000 & 10.000 & \\
\hline $\begin{array}{c}\text { TD5Q987 } \\
\text { Total general }\end{array}$ & 12.000 & & - & - & - & - & $\begin{array}{l}12.000 \\
48.100\end{array}$ & GLP \\
\hline
\end{tabular}

Fuente: Empresa Cotera S.A. (2018)

Elaboración propia

Tabla 4.4

Comparación entre capacidad transportista y demanda anual

\begin{tabular}{l|cc}
\hline \multicolumn{1}{c|}{ Tipo } & $\begin{array}{c}\text { \# Galones } \\
\text { Total capacidad anual }\end{array}$ & $\begin{array}{c}\text { Demanda } \\
\text { anual }\end{array}$ \\
\hline Líquidos & 8.784 .333 & 2.015 .195 \\
GLP & 9.514 .333 & 452.002 \\
\hline
\end{tabular}

Elaboración propia 
Tomando en cuenta que la capacidad anual del transportista, tanto en combustibles líquidos como en GLP, es bastante mayor a la demanda anual del proyecto para cada uno de estos, se concluye que este factor no limita al proyecto. Además, en caso el proveedor Cotera S.A. tuviera problemas de capacidad, existen otros transportistas que ofrecen el mismo servicio.

- Personal de atención:

Otros de los recursos críticos para el funcionamiento de una estación de servicios es el capital humano, en especial el personal de atención al cliente que serían los vendedores de isla.

En el 2015, del total de la Población Económicamente Activa (PEA) del departamento de Junín, el 97,0\% se encontró en condición de ocupados (698 mil personas), de los cuales el $55,0 \%$ corresponde a PEA ocupada masculina y el 45,0\% a la PEA ocupada femenina. Además, según el último documento estadístico "Evolución del Empleo e Ingresos 2004-2015”, en el departamento de Junín, el 50,6\% de la Población Económicamente Activa (PEA), participa en el mercado laboral de manera subempleada, es decir; son personas que pese a tener trabajo, el tiempo de duración es menor a su nivel y están en condiciones de laborar más o mejor. (Diario Correo, 2016)

A pesar de que el 97\% de la PEA se encuentra en condiciones de ocupado, existe un gran porcentaje de las personas que se encuentra de manera subempleada y desea trabajar más horas o cambiarse a un mejor trabajo. El presente proyecto se ajusta idealmente a estos requerimientos debido a que se trabajarán 3 turnos al día lo que permitirá que los trabajadores puedan tener otras ocupaciones.

Por otro lado, el recurso humano tampoco es un limitante debido a que no se necesita de un personal cualificado, ni de un género específico y se buscaría idealmente a personas entre 18 a 50 años de edad, que constituyen alrededor del $50 \%$ de la PEA en el departamento de Junín. 


\subsection{Relación tamaño-tecnología (cuello de botella de los factores críticos-capacidad instalada)}

Se consideran tres las tecnologías que podrían limitar la capacidad de la estación de servicios:

- Capacidad de tanques de combustible:

Con respecto a esta tecnología, en primer lugar se va a definir el número de tanques que poseerá la estación de servicio y de cuánta capacidad volumétrica será cada una de ellas.

Tabla 4.

Tamaño de tanques

\begin{tabular}{l|c}
\hline \multicolumn{1}{c|}{ Producto } & $\begin{array}{c}\text { Tamaño de } \\
\text { tanque } \\
\text { (galones) }\end{array}$ \\
\hline Diésel B5 & 5.200 \\
Gasohol 97 & 4.400 \\
Gasohol 95 & 1.300 \\
Gasohol 90 & 7.700 \\
GLP & 4.600 \\
\hline
\end{tabular}

Elaboración: propia

El detalle de los cálculos que se realizaron para definir el tamaño de los tanques se explica de forma amplia en el capítulo 5.4.4 del presente proyecto.

El tamaño de los tanques se definió de modo que pueda almacenar el inventario suficiente como para tener una cobertura de 3 días en base a la demanda y además, tomando en cuenta otros factores como el stock de seguridad, el porcentaje de utilización, etc. Teniendo en cuenta que el proveedor principal de transporte de carga posee 5 camiones cisternas, este factor no representa ninguna limitante para la estación de servicios ya que como la descarga del combustible incluso se podría realizar cada día y medio según la capacidad del proveedor.

- Capacidad de abastecimiento de surtidores:

La propuesta de número de surtidores y mangueras se indica en la siguiente figura: 
Figura 4.1

Distribución de pistolas en estación de servicio del proyecto
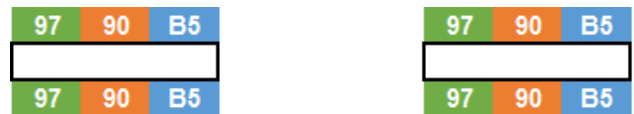

\begin{tabular}{|l|ll|}
\hline 95 & 90 & $B 5$ \\
\hline & & \\
\hline 95 & 90 & $B 5$
\end{tabular}

Elaboración propia

Para calcular la capacidad máxima de abastecimiento de los surtidores, se necesita saber cuánto tiempo al día como máximo el surtidor está abasteciendo según cada tipo de combustible; a este valor se le multiplica por el caudal de cada surtidor (que es un dato conocido) y se obtendría la capacidad máxima.

Para hallar el tiempo máximo; en primer lugar, se calcularon las horas disponibles (tabla 4.7). Se parte bajo el concepto de que si los surtidores estuvieran ocupados todo el día por ambos lados (escenario máximo), las pistolas asignadas a GLP pueden funcionar hasta un máximo de 48 horas en un día (atendiendo en simultáneo por ambos lados del surtidor todo el día). No obstante, hay que tener en cuenta que los grifos presentan diferentes niveles de saturación dependiendo de la hora de día, por tal motivo, para el presente proyecto se elaboró la tabla 4.7 en base a la opinión de expertos. Esto involucra que no serán 24 horas de atención máxima por lado de surtidor, sino solo 16,65.

Con este número de horas de atención por día (16,65 horas), se define que las pistolas de GLP pueden tener por límite máximo de funcionamiento 33,3 horas (ya que son 2 lados del surtidor que puede hacer uso simultáneamente).

De forma similar sucede con los 3 surtidores asignados a líquido, donde se concluye que todas las mangueras derivadas para combustibles líquidos pueden atender un máximo de 99,9 horas por día entre ellas (operando en simultáneo y por ambos lados). Este cálculo salió de la multiplicación 33,3 horas por días por la cantidad de surtidores líquidos que serían 3.

Para distribuir este tiempo de 99,9 horas entre los productos que le corresponde se hizo en base a su participación por $\mathrm{N}^{\circ}$ de mangueras. (Tabla 4.8) obteniendo así las horas disponibles. Se les llama disponible, porque este tiempo no solo incluye el abastecimiento, sino también el de atención y cobranza; por lo que no es un tiempo real que plasme solo el funcionamiento del surtidor. Para hallar las horas reales, se halló la proporción del tiempo total que le corresponde a este 
concepto según tipo de combustible (tabla 4.6) y se le multiplicó a las horas disponibles (tabla 4.8). Finalmente se halló la capacidad multiplicando las horas reales con el caudal.

Tabla 4.6

Proporción de tiempo de abastecimiento

\begin{tabular}{l|cccccccccc}
\hline Producto & \multicolumn{2}{|c}{ B5 } & \multicolumn{1}{c}{ G97 } & G95 & \multicolumn{2}{c}{ G90 } & \multicolumn{2}{c}{ GLP } \\
\hline Galones promedio por visita & 7,21 & & 6,96 & & 5,47 & & 8,64 & & 6,83 & \\
Caudal(gl/min) & 5,00 & & 5,00 & & 5,00 & & 5,00 & & 4,00 & \\
Tiempo abast. & 1,44 & 0,40 & 1,39 & 0,39 & 1,09 & 0,34 & 1,73 & 0,44 & 1,71 & 0,44 \\
Tiempo de atención & 0,67 & 0,18 & 0,67 & 0,19 & 0,67 & 0,20 & 0,67 & 0,17 & 0,67 & 0,17 \\
Tiempo de cobranza & 1,50 & 0,42 & 1,50 & 0,42 & 1,50 & 0,46 & 1,50 & 0,39 & 1,50 & 0,39 \\
Tiempo total & 3,61 & 1,00 & 3,56 & 1,00 & 3,26 & 1,00 & 3,90 & 1,00 & 3,87 & 1,00 \\
\hline
\end{tabular}

Elaboración propia

Tabla 4.7

Porcentaje de ocupación de estación de servicios en un día

\begin{tabular}{|c|c|c|c|}
\hline Turnos & Horario & $\begin{array}{c}\text { Porcentaje } \\
\text { ocupación }\end{array}$ & Minutos \\
\hline \multirow{8}{*}{ Turno 1} & 06:00 AM - 07:00 AM & $100 \%$ & 60 \\
\hline & 07:00 AM - 08:00 AM & $100 \%$ & 60 \\
\hline & 08:00 AM - 09:00 AM & $100 \%$ & 60 \\
\hline & 09:00 AM - 10:00 AM & $80 \%$ & 48 \\
\hline & 10:00 AM - 11:00 AM & $70 \%$ & 42 \\
\hline & 11:00 AM - 12:00 PM & $65 \%$ & 39 \\
\hline & 12:00 PM - 01:00 PM & $65 \%$ & 39 \\
\hline & 01:00 PM - 02:00 PM & $80 \%$ & 48 \\
\hline \multirow{8}{*}{ Turno 2} & 02:00 PM - 03:00 PM & $80 \%$ & 48 \\
\hline & 03:00 PM - 04:00 PM & $85 \%$ & 51 \\
\hline & 04:00 PM - 05:00 PM & $90 \%$ & 54 \\
\hline & 05:00 PM - 06:00 PM & $100 \%$ & 60 \\
\hline & 06:00 PM - 07:00 PM & $100 \%$ & 60 \\
\hline & 07:00 PM - 08:00 PM & $100 \%$ & 60 \\
\hline & 08:00 PM - 09:00 PM & $100 \%$ & 60 \\
\hline & 09:00 PM - 10:00 PM & $90 \%$ & 54 \\
\hline \multirow{8}{*}{ Turno 3} & 10:00 PM - 11:00 PM & $50 \%$ & 30 \\
\hline & 11:00 PM - 12:00 AM & $50 \%$ & 30 \\
\hline & 12:00 AM - 01:00 AM & $40 \%$ & 24 \\
\hline & 01:00 AM - 02:00 AM & $30 \%$ & 18 \\
\hline & 02:00 AM - 03:00 AM & $10 \%$ & 6 \\
\hline & 03:00 AM - 04:00 AM & $10 \%$ & 6 \\
\hline & 04:00 AM - 05:00 AM & $20 \%$ & 12 \\
\hline & 05:00 AM - 06:00 AM & $50 \%$ & 30 \\
\hline $\begin{array}{c}\text { Minutos } \\
\text { totales }\end{array}$ & & & 999 \\
\hline Horas totales & & & 16,65 \\
\hline
\end{tabular}


Tabla 4.8

Capacidad máxima de despacho de surtidores

\begin{tabular}{l|ccccccc}
\hline Combustibles & $\begin{array}{c}\text { Demanda } \\
\text { en } \\
\text { galones } \\
\text { diarios }\end{array}$ & Mangueras & $\begin{array}{c}\text { Participación } \\
\text { en } \\
\text { mangueras }\end{array}$ & $\begin{array}{c}\text { Horas } \\
\text { disponibles } \\
\text { diarias }\end{array}$ & $\begin{array}{c}\text { Horas } \\
\text { efectivas } \\
\text { de } \\
\text { despacho }\end{array}$ & Caudal(gl./h) & $\begin{array}{c}\text { Capacidad } \\
\text { (gl.) }\end{array}$ \\
\hline Diésel B5 & $1.563,00$ & 6 & $33,33 \%$ & 33,30 & 13,30 & 300 & $3.990,28$ \\
Gasohol 97 & $1.300,15$ & 4 & $22,22 \%$ & 22,20 & 8,68 & 300 & $2.605,22$ \\
Gasohol 95 & 330,13 & 2 & $11,11 \%$ & 11,10 & 3,72 & 300 & $1.117,13$ \\
Gasohol 90 & $2.327,81$ & 6 & $33,33 \%$ & 33,30 & 14,78 & 300 & $4.433,67$ \\
GLP & $1.238,36$ & 2 & - & 33,30 & 14,67 & 240 & $3.520,95$ \\
\hline
\end{tabular}

Elaboración propia

\subsection{Relación tamaño-punto de equilibrio}

Para hallar el punto de equilibrio del presente proyecto, se utilizará la fórmula para multiproducto que se detalla a continuación:

- $\mathbf{Q T}=\mathbf{C F T}$

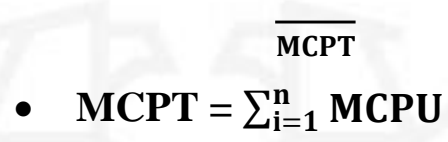

QT $=$ Punto de equilibrio total en galones

$\mathrm{CFT}=$ Costo fijo total

MCPT $=$ Margen de contribución ponderado total

MCPU= Margen de contribución ponderado unitario

Para poder obtener los valores de las fórmulas mencionadas, primero se debe hallar el margen de contribución de cada producto, que será el promedio de los márgenes unitarios para cada año por producto, y los costos fijos totales del negocio.

El margen unitario se calcula restando el valor de venta de cada combustible con los costos variables como el costo del combustible, del transportista y el costo por promociones de combustibles y lubricantes. 
Tabla 4.9

Márgenes de contribución unitarios por galón (en soles)

\begin{tabular}{l|ccccc}
\hline $\begin{array}{c}\text { Tipo } \\
\text { combustible }\end{array}$ & $\begin{array}{c}\text { Márgenes de } \\
\text { contribución } \\
\text { unitarios 2019 }\end{array}$ & $\begin{array}{c}\text { Márgenes de } \\
\text { contribución } \\
\text { unitarios 2020 }\end{array}$ & $\begin{array}{c}\text { Márgenes de } \\
\text { contribución } \\
\text { unitarios 2021 }\end{array}$ & $\begin{array}{c}\text { Márgenes de } \\
\text { contribución } \\
\text { unitarios 2022 }\end{array}$ & $\begin{array}{c}\text { Márgenes de } \\
\text { contribución } \\
\text { unitarios 2023 }\end{array}$ \\
\hline Diésel B5 & 0,8 & 1,16 & 1,11 & 0,98 & 0,96 \\
Gasohol 97 & 1,94 & 2,32 & 2,29 & 2,18 & 2,19 \\
Gasohol 95 & 1,93 & 2,32 & 2,28 & 2,18 & 2,19 \\
Gasohol 90 & 1,13 & 1,46 & 1,45 & 1,33 & 1,32 \\
GLP & 0,61 & 1,05 & 1,04 & 0,99 & 1,00 \\
\hline
\end{tabular}

Elaboración propia

Tabla 4.10

Costos fijos anuales y mensuales del proyecto (en soles)

\begin{tabular}{l|cc}
\hline \multicolumn{1}{c|}{ Concepto } & Monto mensual & Monto anual \\
\hline Remuneraciones vendedores de isla & $17.426,67$ & $209.120,00$ \\
Remuneraciones administrativas & $18.152,78$ & $217.833,33$ \\
Servicio de vigilancia & $5.084,75$ & $61.016,95$ \\
Servicio de limpieza & 932,20 & $11.186,44$ \\
Servicio de contador & $1.271,19$ & $15.254,24$ \\
Total servicio energía eléctrica & $1.124,31$ & $13.491,72$ \\
Servicio de agua & 76,27 & 915,25 \\
Servicio telefónico & 136,75 & $1.641,03$ \\
Alquiler POS & 51,28 & 615,38 \\
Seguro de grifo & $1.271,19$ & $15.254,24$ \\
Materiales de limpieza & 825,55 & $9.906,57$ \\
Materiales de oficina & 289,97 & $3.479,66$ \\
Materiales de atención directa & 116,00 & $1.391,95$ \\
Depreciación fabril y no fabril & $4.718,74$ & $56.624,86$ \\
Amortización & 542,66 & $6.511,90$ \\
Publicidad (Radio y prensa) & 84,75 & $1.016,95$ \\
Servicio de mantenimiento & $1.216,08$ & $14.593,00$ \\
Servicio de perito ambiental & 296,61 & $3.559,32$ \\
Materiales de mantenimiento & 137,15 & $1.645,85$ \\
Total costos fijos & $\mathbf{5 3 . 7 5 4 , 8 9}$ & $\mathbf{6 4 5 . 0 5 8 , 6 4}$ \\
\hline
\end{tabular}

Elaboración propia

Una vez hallados los márgenes de contribución por cada producto y los costos

fijos totales, se procederá a hallar el Margen de contribución ponderado unitario (MCPU), el cual será igual a:

- $\mathbf{M C P U}_{\mathrm{A}}=\mathbf{M C U}_{\mathrm{A}} \times \%$ Participación

- $\%$ Participación $={ }^{\text {Ventas producto } \mathrm{A} \text { en soles }}$

Donde:

Total de ventas en soles

MCPU = Margen de contribución ponderado unitario del producto A

$\mathrm{MCU}=$ Margen de contribución promedio unitario del producto A 
A continuación, se muestra el MCU, el MCUP y el MCPT hallados:

Tabla 4.11

Cálculo de margen de contribución ponderado total

\begin{tabular}{c|ccccc}
\hline & Diesel B5 & Gasohol 97 & Gasohol 95 & Gasohol 90 & GLP \\
\hline $\begin{array}{c}\text { \% Participación } \\
\text { ingresos }\end{array}$ & $24,48 \%$ & $23,14 \%$ & $5,73 \%$ & $37,12 \%$ & $9,52 \%$ \\
MCU & 1,00 & 2,18 & 2,18 & 1,34 & 0,93 \\
MCPU & 0,25 & 0,51 & 0,12 & 0,50 & 0,09 \\
MCPT & & $\mathbf{1 , 4 6}$ & & \\
\hline
\end{tabular}

Elaboración propia

Luego, se calcula el punto de equilibrio total, según la fórmula inicial:

Tabla 4.12

Total galones punto de equilibrio

\begin{tabular}{c|c}
\hline Periodo & QT en galones \\
\hline Mensual & 36.721 \\
Anual & 440.655 \\
\hline
\end{tabular}

Elaboración propia

Finalmente, es importante conocer la participación en galones de cada producto en el punto de equilibrio, el cual se calcula con el porcentaje de participación:

Tabla 4.13

Determinación del punto de equilibrio

\begin{tabular}{c|ccccc}
\hline & Diesel B5 & Gasohol 97 & Gasohol 95 & Gasohol 90 & GLP \\
\hline $\begin{array}{c}\text { \% Participación } \\
\text { ingresos }\end{array}$ & $24,48 \%$ & $23,14 \%$ & $5,73 \%$ & $37,12 \%$ & $9,52 \%$ \\
Q mensual en galones & 8.990 & 8.497 & 2.106 & 13.632 & 3.496 \\
Q anual en galones & 107.875 & 101.970 & 25.271 & 163.582 & 41.958 \\
\hline
\end{tabular}

Elaboración propia 


\subsection{Relación tamaño-inversión}

A continuación, se muestra un cuadro resumen del tamaño de inversión para el presente proyecto:

Tabla 4.14

Cuadro resumen de inversión

\begin{tabular}{l|r}
\hline \multicolumn{1}{c|}{ Concepto } & \multicolumn{2}{c}{ Monto (soles) } \\
\hline Activo fijo tangible & 5.236 .219 \\
Activo fijo intangible & 67.916 \\
Gastos pre operativos & 282.923 \\
Capital de trabajo & 408.903 \\
Inversión total & $\mathbf{5 . 9 9 5 . 9 6 1}$ \\
\hline
\end{tabular}

Nota: Montos no incluyen IGV.

Elaboración propia

Además, se determinó que el financiamiento sería por el 40\% de la inversión total, por lo que este factor tampoco sería una limitante.

\section{Tabla 4.15}

Monto total de financiamiento

\begin{tabular}{l|cc}
\hline & Porcentaje & Monto (soles) \\
\hline Capital propio & $60 \%$ & $3.597 .576,66$ \\
Préstamo bancario & $40 \%$ & $2.398 .384,44$ \\
\hline Elaboración propia
\end{tabular}

\subsection{Selección de la dimensión del servicio}

A continuación, se muestra un cuadro resumen de los diferentes tamaños calculados a lo largo del capítulo:

Tabla 4.16

Determinación de capacidad de proyecto

\begin{tabular}{l|c}
\hline & \# Galones anuales \\
\hline Tamaño-mercado & $2.469 .220,37$ \\
Tamaño-recursos & No es limitante \\
Tamaño-tecnología & $5.718 .546,25$ \\
Tamaño-inversión & No es limitante \\
Tamaño-punto equilibrio & 440.655 \\
\hline
\end{tabular}

Elaboración propia 
Se concluye que la dimensión del servicio estará delimitada por el tamaño de mercado, pues es lo máximo que se podrá atender a pesar de que el tamaño-tecnología sea mayor. Por otro lado, se desprende del presente capítulo que el punto de equilibro es bastante menor a la demanda, por lo que llegar a este no traería mayores complicaciones. Finalmente, es importante mencionar que se está considerando una capacidad tecnológica mayor, ya que, a largo plazo, el proyecto busca aumentar su participación en el mercado; además, se evitará tener cola de clientes en las horas punta. 


\section{CAPÍTULO V: INGENIERÍA DEL PROYECTO}

\subsection{Definición del servicio basada en sus características de operación}

\subsubsection{Especificaciones técnicas del servicio}

Las especificaciones técnicas del servicio se desarrollan a lo largo del Capítulo IV.

\subsection{Tecnología existente y proceso de realización del servicio}

\subsubsection{Descripción y selección del tipo de tecnología a usarse en el servicio}

Las principales tecnologías que se utilizan en una estación de servicios están dirigidas principalmente a los dispensadores, tanques de almacenamiento y bombas para GLP y combustibles líquidos. Actualmente se cuenta con varias empresas que ofertan dispensadores de combustibles líquidos y GLP en el mercado, con una gran variedad de marcas como las líneas de surtidores Prime y Encore de alta gama y las líneas Legacy y Performer de baja gama, entre otras más. Para el presente proyecto se usará surtidores marca Gilbarco modelo Prime de alta de 6 mangueras y caudal de $5 \mathrm{gl} / \mathrm{min}$ (se denomina "Prime" a estos surtidores por ser de la línea Premium y de "alta" porque poseen mayor caudal que los demás tipos de surtidores) y para GLP un surtidor marca Tokheim modelo Quantium 510 GLP de 2 mangueras y de alta con caudal de $4 \mathrm{gl} / \mathrm{min}$. Cabe resaltar que se plantea utilizar surtidores con alto caudal para poder brindar un servicio rápido de despacho y de esta manera satisfacer al cliente y poder atender a una mayor cantidad de los mismos. A continuación, se muestra algunas especificaciones técnicas del surtidor Prime:

- Computador de alta tecnología, con CPU e interfaz integrada. CPU capaz de manejar hasta 6 canales de comunicación. Cuenta con una interfaz de circuito de corriente estándar para automatización y RS-485.

- Unidad de bombeo ST-UBE: Posee funciones de eliminación de aire. A través de dos filtros con malla de acero inoxidable y dos cámaras para la separación 
de aire y gases, proporcionan estabilidad al bombeo y dosificación del combustible. Estructura y paneles de aluminio anodizado, altamente resistentes.

- Libre de puntos de soldadura, minimizando corrosión, con esquinas redondeadas que extiende la vida útil de la manguera.

- Certificación UL-Brasil.

Por otro lado, las especificaciones técnicas del surtidor Tokheim Quantium 510 son:

- Posee un separador de gases con un filtro mayor para garantizar la limpieza del producto sin afectar a su caudal.

- Está diseñado en una ergonómica forma de "L" ocupando muy poco espacio y con un sencillo y eficaz sistema de mangueras retráctil.

- Calibración electrónica

- Poseen las válvulas de alivio y Break-away de seguridad.

- Pantalla de 17 pulgadas multimedia.

- Kit para bajas temperaturas

- Compensación automática de la temperatura

Con respecto a los tanques de almacenamiento (tanques soterrados), se sabe que en Concepción, provincia de Huancayo, existen tres empresas que fabrican tanques personalizados según la capacidad que demande el cliente y estas son Cimesa S.A.C, Rodriguez S.A.C. y San Antonio E.I.R.L. Por otro lado, se sabe que existen 3 tipos de tanque. En este caso, se planea trabajar con la empresa Cimesa S.A.C. debido a que posee mayor experiencia y especialización en la fabricación de tanques para combustible. El tanque soterrado deberá estar diseñado y construido adecuadamente y protegido en su totalidad de la corrosión, para ello el tanque puede ser:

- Tanque construido de plástico reforzado con fibra de vidrio.

- Tanque construido de acero y protegido catódicamente (debe estar revestido con un material dieléctrico adecuado).

- Tanque construido de acero y revestido o recubierto con un material no corrosivo.

- Tanque construido de metal sin medidas adicionales de protección corrosiva si está instalado en un lugar donde un experto en corrosión haya determinado que el terreno no es lo suficientemente corrosivo como para ocasionar deterioro y escape de combustible. 
Para el presente proyecto se utilizará la opción de tanque construido de acero y revestido con un material no corrosivo debido a que es una opción no tan cara y se ajusta a las condiciones del terreno accidentado de la zona.

Por otro lado, la tecnología también se aplica en los sistemas de tele medición que miden en tiempo real las entradas, salidas y condiciones internas del combustible en los tanques, y en los softwares de integración que tienen por finalidad hacer más fácil y eficiente la labor de los administrativos de mantener a la empresa ordenada e interconectada a lo largo de toda su cadena de valor. En esta ocasión, se usará el sistema Sagitarios Plus que posee una gran garantía que le respalda y se diferencia por el alcance de su soporte técnico $24 / 7$.

Las diversas tecnologías mencionadas, se encuentran disponible en Perú y existen un gran número de proveedores potenciales, de los cuales se mencionó los que serían más idóneos según las características del proyecto.

\subsubsection{Proceso de realización del servicio}

\subsubsection{Descripción del proceso del servicio}

\section{Procedimiento para atención al cliente-pago al contado}

El proceso del servicio comprende desde la llegada del cliente a la estación de servicios hasta su salida.

Como se ha definido que la atención al cliente será un factor clave, el proceso inicia cuando el vendedor de isla se da cuenta de la llegada del cliente y le indica la isla más próxima y disponible para que se cuadre. Una vez que el cliente se encuentra estacionado, el personal procede con saludarlo cordialmente y preguntarle sobre el tipo de producto que desea y la cantidad. Después de que el cliente le brinda la información, el vendedor solicita la llave del tapón del tanque. Acto continuo, verifica que el contómetro del surtidor marque 0 (haciéndole notar de este detalle al cliente) y procede con despachar el combustible respectivo. Finalizado el proceso de abastecimiento, el vendedor le pregunta al cliente el medio de pago que utilizará. De ser en efectivo se procede con la validación de la moneda y/o billete, caso contrario (de ser pago con tarjeta de debido o crédito) se procede con hacer uso de POS para realizar el cobro del servicio. Terminado el procedo de cobro, se pregunta al cliente sobre el comprobante de pago que desea, teniendo como alternativas boleta o factura. El cliente decide el tipo de 
comprobante que desea y brinda los datos necesarios como para que se pueda emitir lo solicitado. Después de entregar el comprobante, el vendedor asegura el tanque del vehículo y despide cordialmente al cliente invitándolo a disfrutar de los demás servicios que ofrece la estación de servicios.

\section{Procedimiento para atención al cliente-pago al crédito.}

El proceso inicia cuando el vendedor de isla se da cuenta de la llegada del cliente y le indica la isla más próxima y disponible para que se cuadre. Una vez que el cliente se encuentra estacionado, le dice al vendedor de isla que será una operación a crédito. El personal procede con saludarle cordialmente y primero verifica si la empresa se encuentra en la lista interna de venta a crédito para después visualizar el saldo de crédito que aún posee. Después de validar, el vendedor pide la orden de compra emitida por la empresa del cliente donde se especifica el monto que se abastecerá, el tipo de producto, entre otros. Verifica que la orden de compra sea válida (debe contener la firma de mínimo 2 autoridades de la empresa del cliente) y si el monto es menor que el saldo, procede con el abastecimiento de combustible; caso contrario no abastecerá. Finalizado el proceso de abastecimiento, el vendedor de isla se queda con la orden de compra y despide cordialmente al cliente.

\section{Procedimiento para realizar un convenio de abastecimiento a crédito}

El procedimiento inicia cuando el cliente interesado solicita al administrador de la estación de servicios una proforma del precio de los productos que consumirá en ciertos volúmenes establecidos. Acto continuo, el administrador elabora la propuesta y evalúa su viabilidad. Después de haber elaborado una propuesta adecuada, esta es revisada por el Gerente General, quien, de estar conforme la valida; caso contrario, le comunica al administrador sus observaciones y los términos de discrepancia para que este último elabore una nueva propuesta mejorada. Una vez validada la proforma por el Gerente General, el administrador se la entrega al cliente, quien evalúa la viabilidad de la oferta y si se ajusta a sus necesidades y expectativas. De ser la respuesta negativa, le otorga feedback al administrador para que este negocie y mejore la proforma de modo que satisfaga las necesidades de ambas partes. Cabe resaltar que la cotización define los términos claves del convenio a crédito como los precios de los productos, tiempo de pago, tiempo de facturación, entre otros. 
Después de llegar a un acuerdo con el tema de la cotización, el administrador le pide al cliente que tramite una carta fianza (elemento indispensable para concretizar el contrato de abastecimiento a crédito). El cliente gestiona la carta fianza con su respectiva entidad financiera y esta última, se la entrega a la estación de servicios. Finalmente, el administrador genera un nuevo archivo del convenio que se está originando que contiene la proforma y la carta fianza. 


\subsubsection{Diagrama de flujo del servicio}

Figura 5.1

Flujograma para la atención al cliente en la estación de servicios al contado o crédito

Título: Procedimiento para la atención al cliente en la estación de servicios

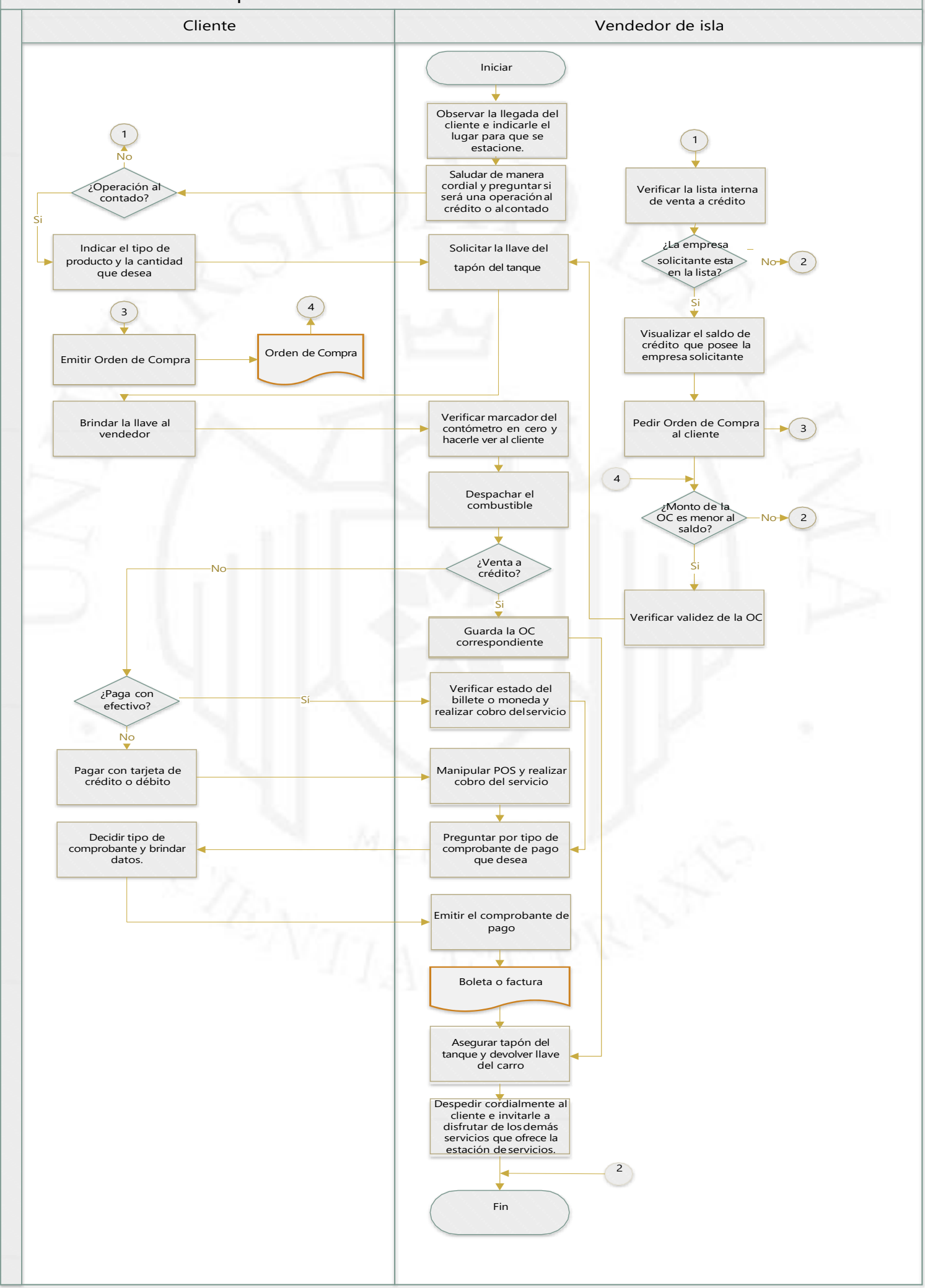

Elaboración propia 
Figura 5.2

Flujograma para realizar un convenio marco de abastecimiento a crédito

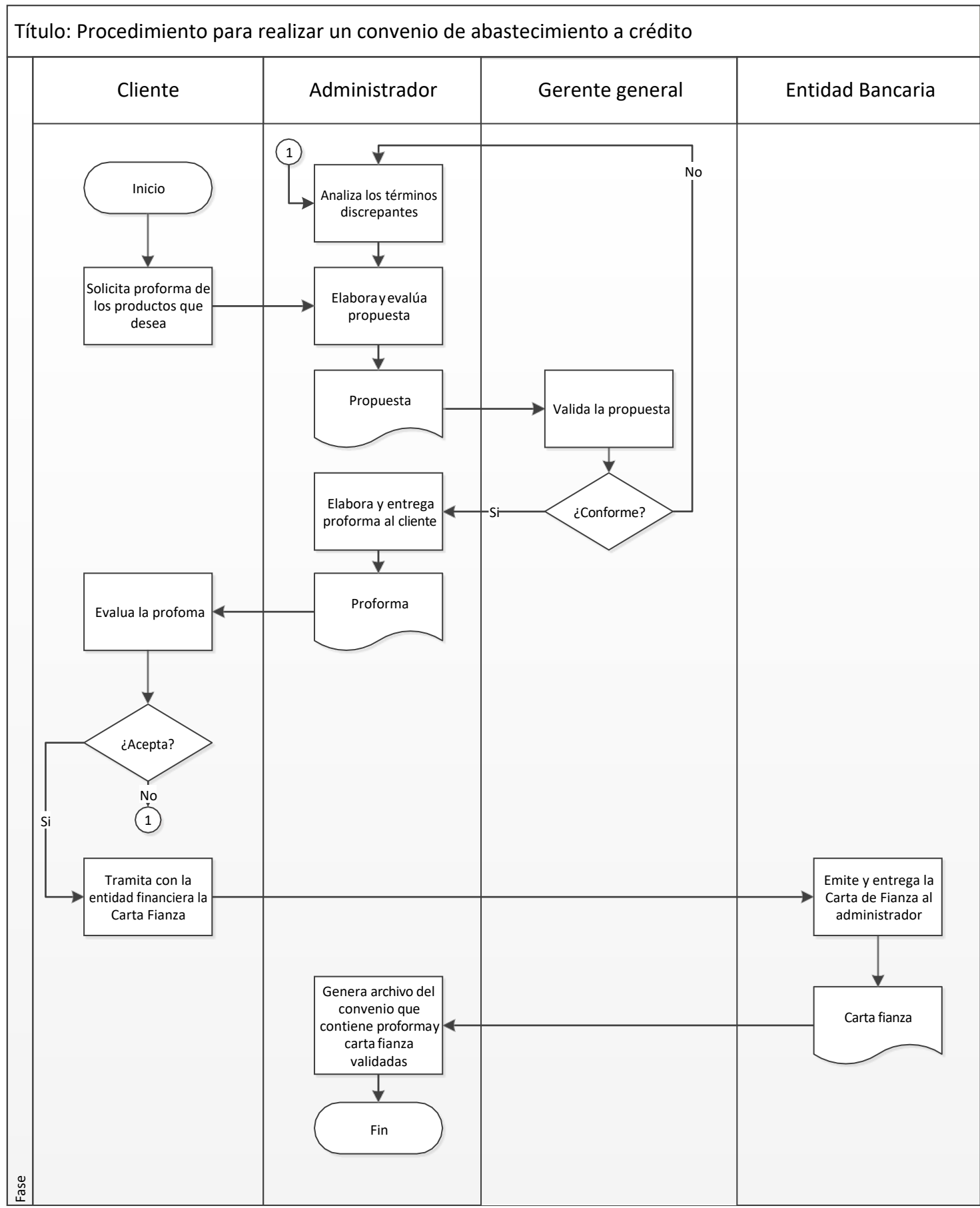

Elaboración propia 


\subsection{Características de las instalaciones y equipo}

De forma general el grifo constará de 2 partes. Una de ellas es la zona de tránsito y estadía regular de personas que está conformada básicamente por la construcción civil principal, ésta contará en el primer piso con las tiendas destinadas a ofrecer servicios extras y en el segundo piso con las oficinas de la parte administrativa del grifo. La otra zona es la de circulación regular de los vehículos que comprenderá las islas de abastecimiento, el patio de maniobras, los estacionamientos, entre otros.

La edificación también contará con elementos enterrados como los tanques de combustible, los tanques de agua, el pozo a tierra y un sistema de drenaje de agua que permitirá reciclar agua de las lluvias y emplearla en actividades secundarias. Las estructuras subterráneas donde se encontrarán estos componentes se harán antes de que se inicie con la pavimentación e inmediatamente después de la nivelación del terreno. Otros equipos importantes serán los surtidores, cuyas características fueron antes mencionadas.

Por otro lado, con respecto a la iluminación, la principal fuente de consumo se encuentra en los letreros luminosos y el alumbrado en la zona de los surtidores. Para ello se contará con 8 luminarias LED de $80 \mathrm{~W}$ distribuidas proporcionalmente en el techo que tendrán una luminancia horizontal aproximada de 100 lux. Se hará uso de tecnología LED porque posee un bajo consumo de energía, menor tamaño, larga vida útil, reduce la emisión de calor, tiempo de encendido corto y es eco friendly al no hacer uso de contaminantes potenciales como el mercurio.

\subsection{Capacidad instalada}

La capacidad instalada de la estación de servicios se ve definida como el potencial máximo de volumen de abastecimiento que puede lograr por tipo de producto en un tiempo definido; para el presente caso se tomará como tiempo base 1 año. Además, se tiene en cuenta la disponibilidad de los equipos, instalaciones y recursos como factores que podrían limitar la capacidad instalada. En este sentido, se ha demostrado que el factor limitante es el número de surtidores, por lo que la capacidad instalada teniendo en cuenta este factor es la siguiente (el cálculo se mostró en el apéndice 4.3): 
Tabla 5.1

Tabla de capacidad instalada

\begin{tabular}{l|cc}
\hline Combustibles & $\begin{array}{c}\text { Capacidad } \\
\text { instalada para } \\
\text { 1 día }\end{array}$ & $\begin{array}{c}\text { Capacidad } \\
\text { instalada } \\
\text { para 1 año }\end{array}$ \\
\hline Diésel B5 & $3.990,28$ & $1.456 .452,20$ \\
Gasohol 97 & $2.605,22$ & $950.905,30$ \\
Gasohol 95 & $1.117,13$ & $407.752,45$ \\
Gasohol 90 & $4.433,67$ & $1.618 .289,55$ \\
GLP & $3.520,95$ & $1.285 .146,75$ \\
\hline \multicolumn{2}{|l}{ Elaboración propia }
\end{tabular}

\subsubsection{Identificación y descripción de los factores que intervienen en brindar el servicio (M-O. Equipo, instalaciones, tecnologías y otros)}

Los principales factores necesarios para brindar el servicio de forma adecuada y con una alta calidad son los siguientes:

- Vendedores de isla (M.O.): Los vendedores de isla serán personas con un rango de edad entre 18 y 44 años (idealmente), no se necesita que posean experiencia previa ni conocimientos técnicos especializados. En cuanto al género puede ser de forma indistinta tanto femenino como masculino. Debe poseer un perfil proactivo de cara a un buen trato al cliente, aunque esta característica también se irá trabajando por medio de capacitaciones sobre servicio al cliente.

- Operador logístico: El operador logístico es un factor importante en la medida que se decidió para el presente trabajo tercerizar el servicio de traslado de combustible desde la planta hasta el local de la estación de servicios. Como ya se mencionó en secciones anteriores, se cuenta con la disponibilidad de la empresa Transportes Cotera S.A. No obstante, se tiene conocimiento de que existe una alta oferta de empresas que pueden realizar estos servicios por lo que no representa una restricción para la capacidad instalada del grifo.

- Tanques subterráneos: Los tanques de almacenamiento de combustible representan un factor importante en el sentido de que deben ser de un tamaño adecuado. Puesto que, si es muy grande cabe el riesgo de que se tenga complicaciones para colocarlo en el terreno, además los tanques de combustible líquido (los combustibles que se encuentran en ese estado tales como diésel y todos los gasoholes) poseen un porcentaje mínimo de combustible (aproximadamente 5\%) que no se puede utilizar debido a que la bomba es incapaz 
de elevarla por la forma cilíndrica del tanque; por lo tanto, a más grande el tanque mayor será la cantidad de combustible inutilizado. Por otro lado, si el tanque es muy pequeño, cabe el riesgo de que la cobertura del inventario que almacena sea menor al lead time del operador logístico (tiempo que se demora en el traslado del combustible) que para el presente proyecto sería de tres días aproximadamente. Para el presente proyecto, los tanques no representan mayor inconveniente, puesto que se cuenta con el área suficiente de terreno como para ubicar los 5 tanques necesarios para la estación de servicios. Además, el tamaño de cada tanque se planifica de modo que pueda tener una cobertura de 1,5 días.

- Surtidores: Los surtidores son un factor clave para brindar un servicio de calidad al cliente, ya que influyen en 2 factores que poseen una alta percepción de calidad para el cliente y estos son la rapidez de atención y la cantidad exacta de combustible que se despacha. En este sentido, los surtidores a emplear deben poseer un alto caudal de despacho de modo que el tiempo de abastecimiento sea el menor posible, además que permitirá atender a una mayor cantidad de vehículos en un menor tiempo. Por otro lado, los surtidores deben ser de alta calidad y garantía, de modo que se evite la des calibración constante y que el despacho resulte de una cantidad menor de combustible (impacto en el cliente) o una cantidad mayor (impacto en la estructura de costos de la empresa). Así mismo, la garantía se torna importante en el contexto de que en la etapa de inicial de funcionamiento existe una alta mortalidad infantil, lo que hace que se reduzca considerablemente su disponibilidad, lo cual podría traducirse en un mal servicio al cliente. Por los motivos expuestos, se puede considerar a los surtidores como el factor más crítico para poder brindar un servicio de calidad de cara al cliente.

\subsubsection{Determinación del factor limitante de la capacidad}

Como se mencionó en los capitulo anteriores, lo que limita la capacidad de atención de la estación de servicio es el número de surtidores.

\subsubsection{Determinación del número de recursos del factor limitante}

Como se mencionó en el acápite anterior, el recurso limitante de la capacidad es el número de surtidores. La cantidad a utilizarse de estos, se definió tomando en cuenta el área del terreno, ya que para una mayor facilidad de maniobra de los vehículos que 
ingresen a la estación de servicios, las islas de surtidores estarán dispuestas en una sola fila y se buscará, en lo posible, que haya la mayor cantidad de espacio entre ellas. Se definió que en el terreno podrían entrar 4 surtidores cómodamente.

Se determinó que un surtidor sería suficiente para abastecer la demanda de GLP y que en 3 se despacharía combustible líquido. El número de mangueras de cada tipo de combustible líquido se obtuvo con una aproximación de acuerdo a la proporción de la demanda. Los resultados se muestran a continuación:

Tabla 5.2

Número de mangueras por tipo de combustible

\begin{tabular}{l|l}
\hline Combustibles & \# Mangueras \\
\hline Diésel B5 & 6 \\
Gasohol 97 & 4 \\
Gasohol 95 & 2 \\
Gasohol 90 & 6 \\
GLP & 2 \\
Total & 20 \\
\hline
\end{tabular}

Elaboración propia

Finalmente, al calcular la capacidad de abastecimiento de estos surtidores, con las mangueras calculadas por tipo de combustible, se notó que se lograba abastecer la demanda de todos los productos, por lo que contar con un mayor número de este recurso generaría costos innecesarios.

\subsubsection{Determinación del número de recursos de los demás factores}

Los otros recursos que se deben usar en la estación de servicios para poder atender la demanda del mercado, la cual se comprobó que será la que limitará las ventas, se detallan a continuación:

- Tanques:

Con respecto a este recurso, en primer lugar, se debe tomar en cuenta que se debe contar con un tanque por tipo de combustible; es decir, se contará con 5 tanques de combustibles, 4 de ellos de combustible líquido y 1 de GLP. Además, hay que tener en cuenta que en caso se calcule que el tamaño de tanque de un combustible es mucho menor a los otros, este podrá ir junto con otro combustible en un tanque de dos compartimentos. 
A continuación, se procederá a definir el volumen de los tanques tomando en cuenta distintas variables que se detallan a continuación:

Tabla 5.3

Tamaño de tanques de combustibles

\begin{tabular}{l|ccccccccc}
\hline Comb & $\begin{array}{c}\text { Dem } \\
\text { diaria } \\
\mathbf{2 0 2 3}\end{array}$ & Rotación & $\begin{array}{c}\text { Inventario } \\
\text { promedio }\end{array}$ & $\begin{array}{c}\text { Stock de } \\
\text { seguridad }\end{array}$ & $\begin{array}{c}\text { Inventario } \\
\text { total }\end{array}$ & $\begin{array}{c}\text { Utilización } \\
\text { max. de } \\
\text { tanque }\end{array}$ & $\begin{array}{c}\text { Tamaño } \\
\text { Cama }\end{array}$ & $\begin{array}{c}\text { Tamaño } \\
\text { de } \\
\text { tanque } \\
\text { ideal }\end{array}$ & $\begin{array}{c}\text { de } \\
\text { tanque } \\
\text { real }\end{array}$ \\
\hline Diesel & 1.563 & 3 & 4.688 & 224 & 4.913 & $100 \%$ & 260 & 5.173 & 5.200 \\
G97 & 1.300 & 3 & 3.900 & 242 & 4.142 & $100 \%$ & 220 & 4.362 & 4.400 \\
G95 & 330 & 3 & 990 & 150 & 1.140 & $100 \%$ & 65 & 1.205 & 1.300 \\
G90 & 2.327 & 3 & 6.983 & 328, & 7.312 & $100 \%$ & 385 & 7.697 & 7.700 \\
GLP & 1.238 & 3 & 3.715 & 370 & 4.085 & $95 \%$ & 230 & 4.542 & 4.600 \\
\hline
\end{tabular}

Elaboración propia

Teniendo en cuenta la demanda diaria de los diferentes combustibles para el año 2023 y una rotación de inventario definida de 3 días (esto quiere decir que se renovará el stock cada dicho periodo), se calculó el inventario promedio por combustible que manejará la empresa. Cabe recalcar que los tanques tendrán capacidad para abastecer a la demanda proyectada diaria por un lapso de 72 horas. No hay que soslayar que para realizar el pedido de los combustibles y la programación de la carga, la cobertura del inventario de 3 días es referencial porque la demanda presenta fluctuaciones por variables como: contratos de abastecimiento temporal a empresas públicas o privadas, lanzamiento de promociones, incremento de circulación de vehículos por la celebración de fiestas tradicionales locales, entre otros. En este sentido, será necesario hacer un control de inventario permanente e in situ al final de cada turno y programar la compra de combustible en base a la información obtenida.

\section{Inventario promedio $=$ Demanda diaria $\mathbf{x}$ Rotación $($ días $)$}

A este resultado, se le sumó el stock de seguridad. Para determinar cuántos galones se debe tener de stock de seguridad para cada uno de los productos, se realizó una simulación con 5 escenarios, variando para cada uno de ellos el nivel de servicio. Primero, se calculó la desviación total, es decir la desviación tanto de la demanda como la del lead time del proveedor (1,5 días) para cada uno de los productos; luego se multiplicó esta desviación por el valor de $\mathrm{Z}$ según el nivel de servicio propuesto.

Por otro lado, se calculó el costo de almacenamiento para los SSC obtenidos y finalmente, se calculó también cuál sería el monto en soles de pérdida de venta si 
se tuviera cada uno de esos SSC y si la desviación total la multiplicamos por 3 (ya que cada pedido debe cubrir 3 días de abastecimiento). 
A continuación, se muestran dichos escenarios:

Tabla 5.4

Cálculo de SSC - NS 95\%

\begin{tabular}{|c|c|c|c|c|c|c|c|c|c|c|}
\hline SSC & $\begin{array}{l}\text { Desviación } \\
\text { total }\end{array}$ & Valor Z & SSC & $\begin{array}{c}\text { Costo de } \\
\text { almacenamiento } \\
\text { en } 3 \text { días }\end{array}$ & $\begin{array}{l}\text { Nivel de } \\
\text { stock }\end{array}$ & $\begin{array}{c}\text { Nivel de } \\
\text { stock } \\
\text { valorizado }\end{array}$ & $\begin{array}{l}\text { Desviación } \\
\text { total } \\
\text { multiplicada } \\
\text { por } 3\end{array}$ & $\begin{array}{c}\text { Pérdida de } \\
\text { venta en } \\
\text { galones en } 3 \\
\text { días }\end{array}$ & $\begin{array}{l}\text { Pérdida de } \\
\text { venta en } 3 \\
\text { días (soles) }\end{array}$ & $\begin{array}{c}\text { Pérdida de } \\
\text { venta + Costo } \\
\text { mensual } \\
\text { abastecimiento } \\
\text { (soles) }\end{array}$ \\
\hline Diesel B5 & 90,5 & 1,96 & 177,4 & 29,6 & 5126,4 & 56032,2 & 271,6 & 94,1 & $1.035,51$ & $1.065,08$ \\
\hline Gasohol 97 & 73,8 & 1,96 & 144,6 & 24,1 & 4265,0 & 48312,1 & 221,3 & 76,7 & 958,82 & 982,92 \\
\hline Gasohol 95 & 18,7 & 1,96 & 36,7 & 6,1 & 1092,1 & 12017,0 & 56,2 & 19,5 & 237,62 & 243,74 \\
\hline Gasohol 90 & 132,1 & 1,96 & 258,8 & 43,1 & 7627,2 & 82281,6 & 396,2 & 137,3 & $1.538,16$ & $1.581,30$ \\
\hline GLP & 70,3 & 1,96 & 137,7 & 22,9 & 4082,8 & 19777,1 & 210,8 & 73,1 & 394,53 & 417,48 \\
\hline Total & & & & 125,9 & 22193,5 & $218.420,0$ & & & $4.164,64$ & $4.290,51$ \\
\hline
\end{tabular}

Tabla 5.5

Cálculo de SSC - NS 96\%

\begin{tabular}{|c|c|c|c|c|c|c|c|c|c|c|}
\hline SSC & $\begin{array}{c}\text { Desviación } \\
\text { total }\end{array}$ & Valor $\mathbf{Z}$ & SSC & $\begin{array}{c}\text { Costo de } \\
\text { almacenamiento } \\
\text { en } 3 \text { días }\end{array}$ & $\begin{array}{l}\text { Nivel de } \\
\text { stock }\end{array}$ & $\begin{array}{c}\text { Nivel de } \\
\text { stock } \\
\text { valorizado }\end{array}$ & $\begin{array}{c}\text { Desviación } \\
\text { total } \\
\text { multiplicada } \\
\text { por } 3\end{array}$ & $\begin{array}{c}\text { Pérdida de } \\
\text { venta en } \\
\text { galones en } 3 \\
\text { días }\end{array}$ & $\begin{array}{l}\text { Pérdida de } \\
\text { venta en } 3 \\
\text { días (soles) }\end{array}$ & $\begin{array}{c}\text { Pérdida de } \\
\text { venta }+ \text { Costo } \\
\text { mensual } \\
\text { abastecimiento } \\
\text { (soles) }\end{array}$ \\
\hline Diesel B5 & 90,5 & 2,05 & 185,6 & 30,9 & 5134,6 & 56121,3 & 271,6 & 86,0 & 945,90 & 976,83 \\
\hline Gasohol 97 & 73,8 & 2,05 & 151,2 & 25,2 & 4271,6 & 48387,3 & 221,3 & 70,1 & 875,85 & 901,05 \\
\hline Gasohol 95 & 18,7 & 2,05 & 38,4 & 6,4 & 1093,8 & 12035,5 & 56,2 & 17,8 & 217,06 & 223,46 \\
\hline Gasohol 90 & 132,1 & 2,05 & 270,7 & 45,1 & 7639,1 & 82409,8 & 396,2 & 125,5 & $1.405,05$ & $1.450,17$ \\
\hline GLP & 70,3 & 2,05 & 144,0 & 24,0 & 4089,1 & 19807,7 & 210,8 & 66,7 & 360,39 & 384,39 \\
\hline Total & & & & 131,6 & 22228,2 & $218.761,6$ & & & $3.804,24$ & $3.935,89$ \\
\hline
\end{tabular}


Tabla 5.6

Cálculo de SSC - NS 97\%

\begin{tabular}{|c|c|c|c|c|c|c|c|c|c|c|}
\hline SSC & $\begin{array}{c}\text { Desviación } \\
\text { total }\end{array}$ & Valor Z & SSC & $\begin{array}{c}\text { Costo de } \\
\text { almacenamiento } \\
\text { en } 3 \text { días }\end{array}$ & $\begin{array}{l}\text { Nivel de } \\
\text { stock }\end{array}$ & $\begin{array}{c}\text { Nivel de } \\
\text { stock } \\
\text { valorizado }\end{array}$ & $\begin{array}{l}\text { Desviación } \\
\text { total } \\
\text { multiplicada } \\
\text { por } 3\end{array}$ & $\begin{array}{l}\text { Pérdida de } \\
\text { venta en } \\
\text { galones en } 3 \\
\text { días }\end{array}$ & $\begin{array}{l}\text { Pérdida de } \\
\text { venta en } 3 \\
\text { días (soles) }\end{array}$ & $\begin{array}{c}\text { Pérdida de } \\
\text { venta }+ \text { Costo } \\
\text { mensual } \\
\text { abastecimiento } \\
\text { (soles) }\end{array}$ \\
\hline Diesel B5 & 90,5 & 2,17 & 196,4 & 32,7 & 5145,4 & 56240,0 & 271,6 & 75,1 & 826,42 & 859,15 \\
\hline Gasohol 97 & 73,8 & 2,17 & 160,0 & 26,7 & 4280,5 & 48487,6 & 221,3 & 61,2 & 765,22 & 791,89 \\
\hline Gasohol 95 & 18,7 & 2,17 & 40,6 & 6,8 & 1096,0 & 12060,2 & 56,2 & 15,5 & 189,64 & 196,41 \\
\hline Gasohol 90 & 132,1 & 2,17 & 286,6 & 47,8 & 7655,0 & 82580,7 & 396,2 & 109,6 & $1.227,57$ & $1.275,33$ \\
\hline GLP & 70,3 & 2,17 & 152,4 & 25,4 & 4097,5 & 19848,6 & 210,8 & 58,3 & 314,86 & 340,27 \\
\hline Total & & & & 139,4 & 22274,4 & $219.217,1$ & & & $3.323,71$ & $3.463,06$ \\
\hline
\end{tabular}

Elaboración propia

Tabla 5.7

Cálculo de SSC - NS 98\%

\begin{tabular}{|c|c|c|c|c|c|c|c|c|c|c|}
\hline SSC & $\begin{array}{c}\text { Desviación } \\
\text { total }\end{array}$ & Valor Z & SSC & $\begin{array}{c}\text { Costo de } \\
\text { almacenamiento } \\
\text { en } 3 \text { días }\end{array}$ & $\begin{array}{c}\text { Nivel de } \\
\text { stock }\end{array}$ & $\begin{array}{c}\text { Nivel de } \\
\text { stock } \\
\text { valorizado }\end{array}$ & $\begin{array}{c}\text { Desviación } \\
\text { total } \\
\text { multiplicad } \\
\text { a por } 3\end{array}$ & $\begin{array}{c}\text { Pérdida de } \\
\text { venta en } \\
\text { galones en } 3 \\
\text { días }\end{array}$ & $\begin{array}{l}\text { Pérdida de } \\
\text { venta en } 3 \\
\text { días (soles) }\end{array}$ & $\begin{array}{c}\text { Pérdida de } \\
\text { venta }+ \text { Costo } \\
\text { mensual } \\
\text { abastecimiento } \\
\text { (soles) }\end{array}$ \\
\hline Diesel B5 & 100,3 & 2,33 & 233,7 & 38,9 & 5182,7 & 56647,4 & 300,9 & 67,2 & 739,21 & 778,16 \\
\hline Gasohol 97 & 73,8 & 2,33 & 171,9 & 28,6 & 4292,3 & 48621,2 & 221,3 & 49,4 & 617,70 & 646,35 \\
\hline Gasohol 95 & 18,7 & 2,33 & 43,6 & 7,3 & 1099,0 & 12093,2 & 56,2 & 12,5 & 153,08 & 160,36 \\
\hline Gasohol 90 & 132,1 & 2,33 & 307,7 & 51,3 & 7676,1 & 82808,7 & 396,2 & 88,5 & 990,93 & $1.042,21$ \\
\hline GLP & 70,3 & 2,33 & 163,7 & 27,3 & 4108,8 & 19903,0 & 210,8 & 47,1 & 254,17 & 281,45 \\
\hline Total & & & & 153,4 & 22358,9 & $220.073,6$ & & & $2.755,09$ & $2.908,52$ \\
\hline
\end{tabular}

Elaboración propia 
Tabla 5.8

Cálculo de SSC - NS 99\%

\begin{tabular}{|c|c|c|c|c|c|c|c|c|c|c|}
\hline SSC & $\begin{array}{l}\text { Desviación } \\
\text { total }\end{array}$ & Valor Z & SSC & $\begin{array}{c}\text { Costo de } \\
\text { almacenamiento } \\
\text { en } 3 \text { días }\end{array}$ & $\begin{array}{l}\text { Nivel de } \\
\text { stock }\end{array}$ & $\begin{array}{c}\text { Nivel de } \\
\text { stock } \\
\text { valorizado }\end{array}$ & $\begin{array}{c}\text { Desviación } \\
\text { total } \\
\text { multiplicada } \\
\text { por } 3\end{array}$ & $\begin{array}{l}\text { Pérdida de } \\
\text { venta en } \\
\text { galones en } 3 \\
\text { días }\end{array}$ & $\begin{array}{l}\text { Pérdida de } \\
\text { venta en } 3 \\
\text { días (soles) }\end{array}$ & $\begin{array}{c}\text { Pérdida de } \\
\text { venta }+ \text { Costo } \\
\text { mensual } \\
\text { abastecimiento } \\
\text { (soles) }\end{array}$ \\
\hline Diesel B5 & 87,0 & 2,58 & 224,5 & 37,4 & 5173,5 & 56546,5 & 261,0 & 36,5 & 401,94 & 439,35 \\
\hline Gasohol 97 & 94,0 & 2,58 & 242,5 & 40,4 & 4363,0 & 49421,7 & 282,0 & 39,5 & 493,50 & 533,92 \\
\hline Gasohol 95 & 58,3 & 2,58 & 150,4 & 25,1 & 1205,8 & 13268,1 & 174,9 & 24,5 & 298,73 & 323,80 \\
\hline Gasohol 90 & 127,4 & 2,58 & 328,7 & 54,8 & 7697,1 & 83035,3 & 382,2 & 53,5 & 599,29 & 654,07 \\
\hline GLP & 143,5 & 2,58 & 370,2 & 61,7 & 4315,3 & 20903,5 & 430,5 & 60,3 & 325,46 & 387,16 \\
\hline Total & & & & 219,4 & 22754,7 & 223.175,2 & & & $2.118,92$ & $2.338,30$ \\
\hline
\end{tabular}


$\mathrm{Al}$ analizar los datos de los 5 escenarios, se observa que con un $99 \%$ de nivel de servicio la suma de la pérdida de venta + el costo de almacenamiento sería menor; por lo que se decide usar los SSC para dicho nivel de servicio; además, se observa que el costo mensual de almacenamiento y el nivel de stock valorizado no aumenta significativamente al aumentar el nivel de servicio.

Luego de sumar el stock de seguridad para cada tipo de combustible, se dividió el resultado entre el porcentaje de utilización máxima del tanque, siendo 95\% para el caso del GLP debido a que por medidas de seguridad no se debe nunca tener el tanque totalmente lleno, y finalmente se sumó la cama para obtener el tamaño del tanque ideal, el cual se redondeó a un tamaño comercial que se observa en la columna "Tamaño de tanque real".

La cama es un espacio de la parte inferior del tanque que está llena de combustible que no puede ser fácilmente absorbido por la bomba debido a la forma del tanque, es decir, realizar este sobre esfuerzo podría malograrla. Debido a esto, este espacio que está lleno de combustible se considera muerto, además, es importante considerar que la cama es un porcentaje del tamaño del tanque, por lo que la desventaja de tener un tanque muy grande es que el espacio muerto aumentará. Para el presente proyecto se definió una cama igual al 5\% del tamaño del tanque real, el cual es un redondeo del tamaño del tanque ideal a la centena más cercana.

Figura 5.3

Tanque Diésel B5 - Capacidad 5.200 galones

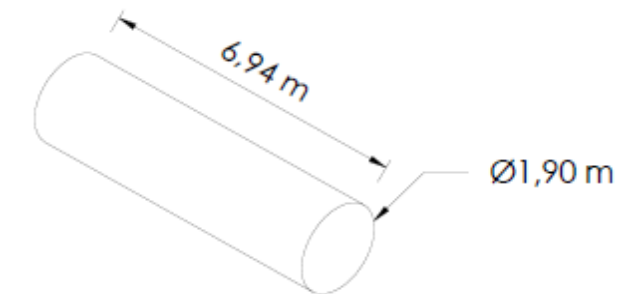

Elaboración propia 
Figura 5.4

Tanque Gasohol 97 - Capacidad 4.400 galones

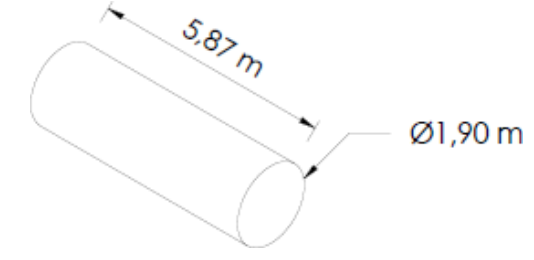

Elaboración propia

Figura 5.5

Tanque Gasohol 95 - Capacidad 1.300 galones

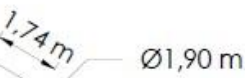

Elaboración propia

Figura 5.6

Tanque Gasohol 90 - Capacidad 7.700 galones

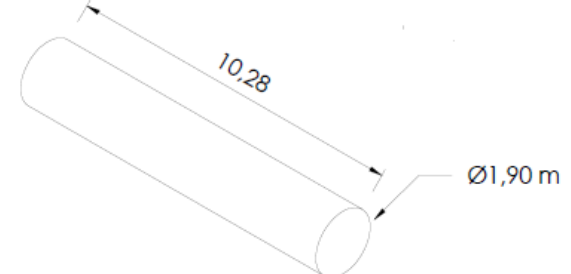

Elaboración propia

Figura 5.7

Tanque de GLP - Capacidad 4.600 galones

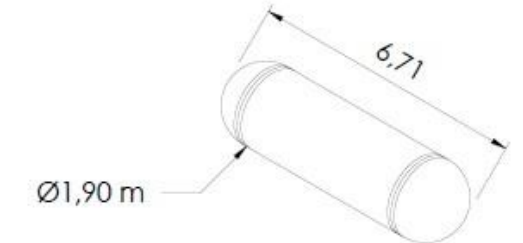

Elaboración propia 
Cabe recalcar que se consideró el mismo radio en todos los tanques para que la profundidad de la excavación sea igual en todos los casos y a partir de las figuras, se notó que es conveniente manejar un solo tanque con dos compartimentos para los gasoholes de 97 y 95, ya que este último sería un tanque bastante pequeño.

Finalmente, es importante considerar que en caso la demanda aumente, lo que se haría como primera medida sería disminuir los días de reposición y como segunda medida, construir nuevos tanques, ya que hay espacio suficiente lo cual se podrá evidenciar en los planos del proyecto.

Para tener una idea de cuánto tendría que disminuir el tiempo de reposición, se proyectó la demanda hacia el año 2028: 
Tabla 5.9

Demanda 2028 vs tamaño tanques

\begin{tabular}{|c|c|c|c|c|c|c|c|c|c|}
\hline Combustibles & $\begin{array}{c}\text { Demanda } \\
\text { diaria } 2028\end{array}$ & Rotación & $\begin{array}{c}\text { Inventario } \\
\text { promedio }\end{array}$ & $\begin{array}{r}\text { Stock de } \\
\text { seguridad }\end{array}$ & $\begin{array}{c}\text { Inventario } \\
\text { total }\end{array}$ & $\begin{array}{c}\text { Utilización } \\
\text { max. de } \\
\text { tanque }\end{array}$ & Cama & $\begin{array}{c}\text { Tamaño } \\
\text { de tanque } \\
\text { ideal }\end{array}$ & $\begin{array}{c}\text { Tamaño } \\
\text { de tanque } \\
\text { real }\end{array}$ \\
\hline Diesel B5 & $1.788,28$ & 2,5 & $4.470,70$ & 224,46 & $4.695,16$ & $100 \%$ & 260,00 & $4.955,16$ & 5200 \\
\hline Gasohol 97 & $1.487,54$ & 2,5 & $3.718,85$ & 242,52 & $3.961,37$ & $100 \%$ & 220,00 & $4.181,37$ & 4400 \\
\hline Gasohol 95 & 377,72 & 2,5 & 944,29 & 150,41 & $1.094,70$ & $100 \%$ & 65,00 & $1.159,70$ & 1300 \\
\hline Gasohol 90 & $2.663,32$ & 2,5 & $6.658,31$ & 328,69 & $6.987,00$ & $100 \%$ & 385,00 & $7.372,00$ & 7700 \\
\hline GLP & $1.416,85$ & 2,5 & $3.542,13$ & 370,23 & $3.912,36$ & $95 \%$ & 230,00 & $4.360,38$ & 4600 \\
\hline
\end{tabular}


Como se observa en el cuadro anterior, tomando en cuenta la demanda diaria del 2028 y disminuyendo la reposición a 2 días y medio; el tamaño del tanque ideal aún sigue siendo menor que los tanques definidos para el proyecto.

- Vendedores de isla:

Como es de conocimiento, una estación de servicios debe operar las 24 horas del día, por lo que para el presente proyecto, se definió que se deberán atender 3 turnos de 8 horas cada uno. Para determinar la cantidad de personas que se necesitan en el abastecimiento de combustibles se tomarán como referencias los porcentajes aproximados de ocupación del grifo que se calcularon para la capacidad de abastecimiento de los surtidores. Se debe tomar en cuenta que la cantidad de vendedores de islas requeridos se da por la hora de ocupación máxima en cada turno. Para el turno 1 y 2 la ocupación máxima es de $100 \%$ por lo que se deberá contar con un vendedor de isla por cada surtidor (como se mencionó en el acápite 4.3, un vendedor puede abastecer simultáneamente dos caras), mientras para el turno 3, la ocupación máxima es de $50 \%$, por lo que solo se necesitarán solo dos vendedores de isla. 
Tabla 5.10

Turnos en estación de servicios según \% de ocupación

\begin{tabular}{|c|c|c|c|}
\hline Turnos & Horario & $\begin{array}{l}\text { Porcentaje } \\
\text { ocupación }\end{array}$ & $\begin{array}{l}\text { \# Vendedores de } \\
\text { isla }\end{array}$ \\
\hline \multirow{8}{*}{ Turno 1} & 06:00 AM - 07:00 AM & $100 \%$ & \multirow{8}{*}{4} \\
\hline & 07:00 AM - 08:00 AM & $100 \%$ & \\
\hline & 08:00 AM - 09:00 AM & $100 \%$ & \\
\hline & 09:00 AM - 10:00 AM & $80 \%$ & \\
\hline & 10:00 AM - 11:00 AM & $70 \%$ & \\
\hline & 11:00 AM - 12:00 PM & $65 \%$ & \\
\hline & 12:00 PM - 01:00 PM & $65 \%$ & \\
\hline & 01:00 PM - 02:00 PM & $80 \%$ & \\
\hline \multirow{8}{*}{ Turno 2} & 02:00 PM - 03:00 PM & $80 \%$ & \multirow{8}{*}{4} \\
\hline & 03:00 PM - 04:00 PM & $85 \%$ & \\
\hline & 04:00 PM - 05:00 PM & $90 \%$ & \\
\hline & 05:00 PM - 06:00 PM & $100 \%$ & \\
\hline & 06:00 PM - 07:00 PM & $100 \%$ & \\
\hline & 07:00 PM - 08:00 PM & $100 \%$ & \\
\hline & 08:00 PM - 09:00 PM & $100 \%$ & \\
\hline & 09:00 PM - 10:00 PM & $90 \%$ & \\
\hline \multirow{8}{*}{ Turno 3} & 10:00 PM - 11:00 PM & $50 \%$ & \multirow{8}{*}{2} \\
\hline & 11:00 PM - 12:00 AM & $50 \%$ & \\
\hline & 12:00 AM - 01:00 AM & $40 \%$ & \\
\hline & 01:00 AM - 02:00 AM & $30 \%$ & \\
\hline & 02:00 AM - 03:00 AM & $10 \%$ & \\
\hline & 03:00 AM - 04:00 AM & $10 \%$ & \\
\hline & 04:00 AM - 05:00 AM & $20 \%$ & \\
\hline & 05:00 AM - 06:00 AM & $50 \%$ & \\
\hline
\end{tabular}

Elaboración propia

- Capacidad de abastecimiento de transportistas:

Como se mencionó en el cálculo de la capacidad de los tanques, se planea re abastecer todos los tipos de combustible cada 3 días. El tamaño de pedido por combustible será igual a la demanda del mismo en 3 días más el porcentaje de mermas que se producen a la hora de realizar la descarga en la estación de servicios, el cual es de 0,1\% para el caso de los combustibles líquidos. Para el abastecimiento de GLP, no existen mermas. 
A continuación, se muestra el tamaño de pedido por combustible:

Tabla 5.11

Tamaño de pedidos de combustibles año 2023

\begin{tabular}{l|rcc}
\hline Producto & $\begin{array}{c}\text { Demanda 3 } \\
\text { días } \\
\text { (galones) }\end{array}$ & $\begin{array}{c}\text { Mermas } \\
\text { transporte } \\
\mathbf{( 0 , 1 \% )}\end{array}$ & $\begin{array}{c}\text { Pedido real } \\
\text { (galones) }\end{array}$ \\
\hline Diésel B5 & $4.688,99$ & 4,7 & $4.693,68$ \\
Gasohol 97 & $3.450,67$ & 3,5 & $3.454,12$ \\
Gasohol 95 & 876,19 & 0,9 & 877,07 \\
Gasohol 90 & $6.178,14$ & 6,2 & $6.184,32$ \\
GLP & $3.286,69$ & - & $3.286,69$ \\
\hline
\end{tabular}

Elaboración propia

Además, se realizó una simulación de los posibles camiones que podría destinar el transportista para abastecer a esta estación de servicios y los compartimentos que debería usar según cada tipo de producto. Esta simulación arrojó como resultado que se usarían 3 camiones cisternas para el abastecimiento:

Tabla 5.1212

Distribución de abastecimiento por compartimentos de camiones del proveedor

\begin{tabular}{l}
\hline \multicolumn{1}{c}{ Producto } \\
\hline Diésel B5 \\
Gasohol 97 \\
Gasohol 95 \\
Gasohol 90 \\
GLP \\
\hline
\end{tabular}

\begin{tabular}{c|c|cccccc}
\hline $\begin{array}{c}\text { Placa } \\
\text { vehículo }\end{array}$ & $\begin{array}{c}\text { Tipo } \\
\text { combustible }\end{array}$ & $\mathbf{C 1}$ & $\mathbf{C 2}$ & $\mathbf{C 3}$ & $\mathbf{C 4}$ & $\mathbf{C 5}$ & C6 \\
\hline A9T991 & \multirow{2}{*}{ Líquido } & 1.500 & 500 & 3.000 & 1.000 & 1.000 & 2.000 \\
A5N998 & 2.000 & 1.500 & 750 & 750 & 1.000 & 3.000 \\
TD5Q987 & GLP & 12.000 & & - & - & - & - \\
\hline
\end{tabular}

Elaboración propia 


\subsubsection{Cálculo de la capacidad de atención}

Como se mencionó en el capítulo 5.3.2., el factor limitante es el número de los surtidores y la capacidad máxima de atención en galones, por tipo de combustible, se definió en el capítulo anterior en el acápite 4.3. A continuación se mostrará este resultado en número de vehículos máximos que se podrán atender en un día por tipo de combustible.

Se debe tomar en cuenta que el tiempo disponible diario asume que se abastecen por las dos caras de los surtidores simultáneamente, además considera el porcentaje de ocupación del grifo en cada hora del día y que solo se puede abastecer un tipo de combustible por cara para el caso de los líquidos. Finalmente, es importante mencionar que el tiempo total promedio de abastecimiento por vehículo varía ya que se calculó en base a los galones promedio que se abastecen de cada tipo de combustible.

Tabla 5.1313

\section{Capacidad de atención diaria}

\begin{tabular}{l|ccccc}
\hline & B5 & G97 & G95 & G90 & GLP \\
\hline $\begin{array}{l}\text { Tiempo disponible diario } \\
\text { (horas) }\end{array}$ & 33,3 & 22,2 & 11,1 & 14,71 & 33,3 \\
$\begin{array}{l}\text { Tiempo disponible (minutos) } \\
\begin{array}{l}\text { Tiempo total promedio de } \\
\text { abastecimiento por vehículo } \\
\text { (minutos) }\end{array}\end{array}$ & 1.998 & 1.332 & 666 & 882 & 1.998 \\
$\begin{array}{l}\text { \# De vehículos atendidos al } \\
\text { día }\end{array}$ & 548 & 3,54 & 3,1 & 3,88 & 3,6 \\
\hline
\end{tabular}

Elaboración propia

\subsection{Resguardo de la calidad}

\subsubsection{Calidad del proceso y del servicio}

La calidad del servicio estará relacionada con lo siguiente:

- Combustibles de buena calidad.

- Seguridad en el local.

- Disponibilidad de combustibles.

- Rapidez en la atención.

- Profesionalidad y trato de los vendedores de isla. 
- Capacidad de satisfacer las necesidades de los clientes en cuanto a servicios extra ya sean relacionados como no relacionados.

- Orden y limpieza de las diferentes áreas del local y máquinas.

- Prestigio de la estación de servicios.

- Reducción del impacto ambiental.

Además, es importante recalcar que se realizará un control de calidad del servicio que se expondrá más adelante. Es importante recalcar que el papel que tendrán los vendedores de isla es trascendental, pues sus acciones influirán directamente en la percepción que obtenga cada cliente acerca de la calidad del servicio prestado. Los vendedores, además de brindar un trato cortés y amable, deben dar a conocer a los clientes las novedades del negocio, como por ejemplo, los descuentos y promociones, e incentivarlos a comprar en los servicios extras dándoles a conocer lo que brinda cada uno de ellos.

\subsubsection{Niveles de satisfacción del cliente}

Para medir la satisfacción del cliente se realizarán encuestas una vez al mes. Las encuestas incluirán preguntas claves, breves y directas. Los vendedores de isla, serán los encargados de solicitar al cliente el llenado de las encuestas luego de atenderlos. Se le solicitará a cada uno de los 10 vendedores de isla que recopilen 5 encuestas.

\section{$\underline{\text { Preguntas de la encuesta }}$}

1. ¿Del 1 al 10, qué tan satisfecho te encuentras con el servicio brindado por este grifo? Meta: El promedio mensual aceptable es de 8 puntos.

2. ¿Del 1 al 10, qué tan amable y cortés fue el trato de la persona que lo atendió?

Meta: El promedio mensual aceptable es de 8 puntos.

3. ¿En qué podríamos mejorar para brindarle un mejor servicio?

La información de las encuestas será registrada y analizada por los directivos del grifo para poder activar planes de acción. Después de poner en práctica estos planes, se medirán los resultados a través de nuevas encuestas siendo este sistema parte del proceso de mejora continua. 
Finalmente, se contará con una página web donde los clientes podrán colocar las quejas y recomendaciones para de esta manera, monitorear los distintos inconvenientes $\mathrm{u}$ oportunidades de mejora que son identificadas por ellos.

\subsubsection{Medidas de resguardo de la calidad}

Para resguardar la calidad tanto de los productos ofrecidos como la de la atención al cliente, el grifo será sometido a procesos de control externos, los cuales son una forma de auditoría de Petroperú y OSINERGMIN, e internos, que son propuestos por la misma empresa para poder controlar y satisfacer eficazmente las necesidades de los clientes.

a) Procesos externos:

- Inspecciones de Petroperú: Esta empresa realiza inspecciones aleatorias a sus grifos abanderados, en ellas, los auditores se hacen pasar por clientes y abastecen combustible para posteriormente realizarles una muestra y observar si los mismos han sufrido alguna alteración. Esto se debe a que algunas estaciones de servicio tienen malas prácticas como mezclar el combustible con agua o no realizarle a sus tanques una limpieza oportuna lo que genera que el combustible que se vende esté sucio.

- Inspecciones por parte de OSINERGMIN: Los inspectores de esta entidad, además de realizar muestras de calidad a los combustibles, verifican que la cantidad abastecida sea la pactada para lo cual hacen uso de "serafines" o medidores. Además, comprueban la seguridad del local, verificando por ejemplo que los extintores hayan tenido el mantenimiento adecuado y que las señales de seguridad estén legibles. Por otro lado, revisan que la estación de servicios emita comprobantes de pago y que los precios ofrecidos coincidan con los estipulados en la aplicación "Facilito".

Si el grifo no cumple con alguna de estas disposiciones, se le colocará una multa y en ciertos casos, hasta se podría clausurar el local.

b) Procesos internos:

Para un controlar la calidad del servicio ofrecido se implementarán los siguientes planes:

- Elaborar plan de mantenimiento adecuado de tanques y surtidores para mantener la calidad del producto. 
- Cumplir con el monitoreo ambiental exigido por la ley.

- Realizar los mantenimientos adecuados a los dispositivos de seguridad.

- Elaborar plan de revisión interno del mantenimiento del local para ver si es necesario renovar ciertos elementos como stickers de distintas señales o si es necesario realizar algún retoque en la pintura.

- Realizar auditorías a los locales alquilados de comida rápida, farmacia, mini market, tienda de lubricantes, cambio de aceite, servicio de llantas y lavado y engrase, tanto en materia de producto o servicio final como en calidad de atención al cliente.

- Capacitar a los vendedores de isla en servicio de atención al cliente.

- Evaluar a los vendedores de isla mediante encuestas.

- Monitorear indicadores de calidad y generar de planes de acción a partir de encuestas.

- Elaborar un horario de limpieza, donde se revise varias veces al día las buenas condiciones de los distintos espacios, especialmente los servicios higiénicos.

\subsection{Impacto ambiental}

Primero se deben identificar los posibles impactos ambientales que traerá el presente proyecto:

- En la fase construcción: Los impactos ambientales al realizar las obras serán principalmente la generación de polvo y ruido debido sobre todo al uso de maquinaria pesada.

- En la fase de operación: Se generará emisión de productos gaseosos, óxidos de nitrógeno, que al incorporarse a la atmósfera serán inflamables ya que se juntarán con el oxígeno del aire. Estos gases se emitirán principalmente en tres procesos: Descarga de combustible en tanque, almacenamiento del combustible en tanques y al momento de abastecer a los automóviles.

Por otro lado, se generarán efluentes líquidos de tipo doméstico, generados por desechos de consumo humano, así como efluentes del mismo servicio que serán generados principalmente por la operación de lavado y engrase.

Además, el presente proyecto utilizará bastante energía eléctrica sobre todo para el funcionamiento de las bombas que llevará el combustible hacia los surtidores. 
En cuanto a los desechos sólidos, se descartará tanto basura orgánica como inorgánica proveniente de las oficinas y de los demás servicios con los que contará el grifo; es decir, los desechos de los servicios alquilados. Así mismo, otro impacto será el ruido generado por la concentración de varios vehículos del parque automotor en un solo punto, por el compresor de aire y al activar el grupo electrógeno.

Finalmente, es importante mencionar que existe una probabilidad muy grande de que se generen derrames de combustible en el momento de la descarga a los tanques.

- En la fase de cierre: Los impactos ambientales en esta etapa serán como en la construcción, principalmente la generación de polvo y ruido debido al uso de maquinaria pesada. Además, existe una gran probabilidad de derrame de combustible.

Para evaluar dichos impactos, se utilizará la matriz Leopold, para lo cual se definieron las siguientes valoraciones:

Tabla 5.1414

Valoración de la magnitud del impacto para matriz Leopold

\begin{tabular}{|c|c|}
\hline \multicolumn{2}{|c|}{$\begin{array}{c}\text { Valoración de la magnitud del } \\
\text { impacto }\end{array}$} \\
\hline Impactos negativos & - \\
\hline Impactos positivos & + \\
\hline Alteración alta & $10,9,8$ \\
\hline Alteración media & $7,6,5,4$ \\
\hline Alteración baja & $3,2,1$ \\
\hline
\end{tabular}

Tabla 5.15

Valoración de la importancia del impacto para matriz Leopold

\begin{tabular}{|c|c|}
\hline \multicolumn{2}{|c|}{$\begin{array}{c}\text { Valoración de la importancia del } \\
\text { impacto }\end{array}$} \\
\hline Intensidad alta & $10,9,8$ \\
\hline Intensidad media & $7,6,5,4$ \\
\hline Intensidad baja & $\underline{3,2,1}$ \\
\hline
\end{tabular}

Luego se procedió a elaborar la matriz Leopold: 
Tabla 5.16

\section{Matriz Leopold}

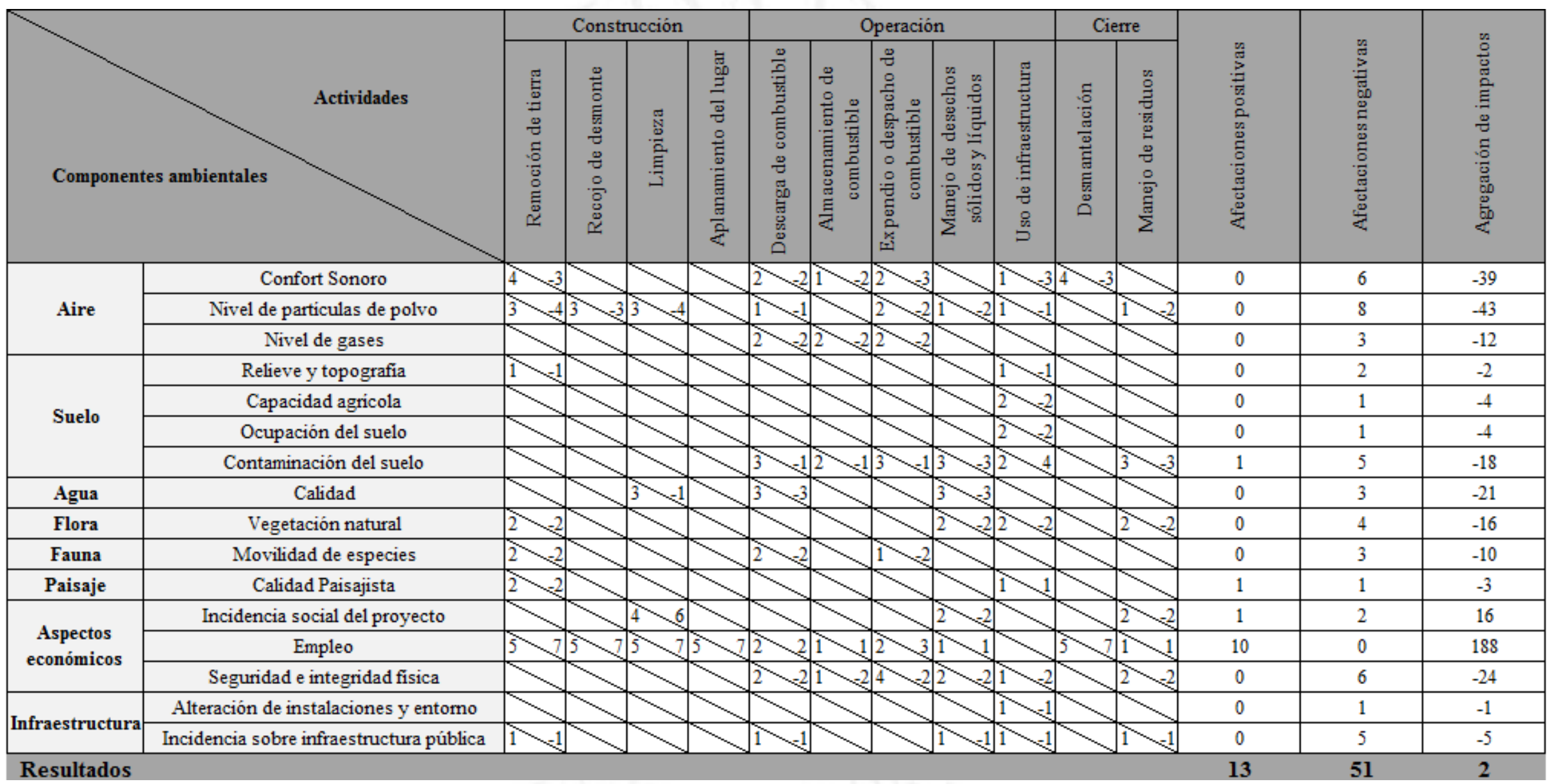

Elaboración propia 
Al colocar los valores en la matriz Leopold se concluye que, a pesar de que el proyecto puede tener varios impactos negativos ambientalmente, estos no son relevantes siempre y cuando se cumplan con un plan ambiental que asegure que las intensidades de estos no aumenten; a continuación, se propone dicho plan:

- Polvo: Se utilizará agua para atenuar el impacto del polvo en la etapa de construcción y cierre.

- Gases: Cumplir estrictamente el plan de mantenimiento de los tanques, surtidores y válvulas para evitar un exceso de emisión de gases. Además, se implementará un sistema de detección de fugas en los tanques y en las tuberías.

- Efluentes líquidos: Se realizarán inspecciones de las uniones y válvulas de entrada y salidas para evitar derrames por fugas. Además, se realizarán capacitaciones adecuadas al personal de venta para evitar derrames en los puntos de atención a los clientes. Se implementará un sistema de detección de fugas en los tanques y en las tuberías.

- Desechos sólidos: Se colocarán cilindros de acuerdo a cada tipo de material para poder clasificar la basura y de esta manera, poder reciclar.

- Ruidos: Se colocará al grupo electrógeno y al compresor en cuartos alejados para evitar este tipo de contaminación. Además, se optará por comprar un grupo electrógeno encapsulado e insonorizado.

- Suelos: La zona donde se colocarán los tanques estará cimentada, compactada e impermeabilizada. Se realizará un control de limpieza de suelos con derrames de hidrocarburos.

- Utilización de agua y energía: Se hará uso de la tecnología led y se instalará un sistema de recolección de agua de lluvias que a través de tuberías llenará un tanque donde se podrá utilizar el agua captada para los servicios higiénicos. Así mismo, se instalará una trampa de grasa, la cual es un sistema que se usa para evitar la contaminación indiscriminada de los sistemas de evacuación normales. Estas consisten en la construcción de 2 cabinas herméticas, una de ellas recepciona los desechos y mediante un proceso de rebose controlado pasa a una segunda cabina y por la densidad del agua esta evacúa hacia el sistema convencional y el restante en grasas y aceites se traslada hacia una cabina más pequeña de donde son expulsados a lugares predeterminados. 
Por otro lado, se vigilarán los equipos y se realizará un correcto mantenimiento de los mismos y se cumplirá con los monitoreos exigidos por ley.

Finalmente, es importante mencionar que el presente proyecto debe cumplir con todo lo estipulado en el DECRETO SUPREMO No 039-2014-EM Reglamento para la Protección Ambiental en las Actividades de Hidrocarburos, el cual menciona ciertos puntos principales a tomar en cuenta:

- Artículo 13.- De los Estudios Ambientales Los Estudios Ambientales aplicables a las Actividades de Hidrocarburos.

Este artículo menciona que antes de empezar las actividades de la estación de servicios, se debe estar autorizado por el Ministerio de Energía y Minas, para lo cual se deberá elaborar una Declaración de Impacto Ambiental (DIA), Estudio de Impacto Ambiental Semidetallado (EIA-sd), Estudio de Impacto Ambiental Detallado (EIA-d) o una Evaluación Ambiental Estratéfica (EAE), según se requiera dependiendo del potencial de impacto negativo.

- Artículo 52.- Manejo y almacenamiento de productos químicos

Menciona que se debe realizar en áreas seguras e impermeabilizadas.

- Artículo 58.- Monitoreo en puntos de control de efluentes y emisiones

Señala que se debe efectuar el monitoreo de los respectivos puntos de control de los efluentes y emisiones de sus operaciones, así como los análisis físicos y químicos correspondientes, con una frecuencia que se aprobará al inicio de las operaciones y se deberá presentar ante el Ministerio de Energía y Minas. Estos informes deben ser firmados por ingenieros autorizados.

- Artículo 59.- Límites Máximos Permisibles y Estándares de Calidad Ambiental

Menciona que se deberán cumplir con los Límites Máximos Permisibles vigentes y que se diseñarán, seleccionarán, operarán y mantendrán los equipos a manera de reducir o eliminar las emisiones fugitivas.

- Artículo 60.- Estándares de Calidad Ambiental de Ruido

Señala que la emisión de ruidos deberá ser controlada a fin de no sobrepasar los valores establecidos en el Reglamento Nacional de Estándares de Calidad Ambiental de Ruido. 


\section{- Artículo 64.- Capacitación del personal}

Menciona que todo el personal deberá contar con capacitación actualizada sobre los aspectos ambientales asociados a sus actividades y responsabilidades. (MINEM, 2014)

\subsection{Seguridad y salud ocupacional}

En primera instancia se va hacer uso de la matriz IPERC para poder identificar los peligros, riesgos y el nivel de significancia de estos que se generan en las diferentes actividades que se realiza en la estación de servicios. Para el presente trabajo, se ha realizado matriz IPERC de 2 procedimientos que consideramos los de mayor incidencia a nivel de seguridad y salud ocupacional y que se realizan con mayor frecuencia; estos son el descargue de combustible y la atención al cliente (abastecimiento de combustible).

De la primera matriz IPERC se puede apreciar que más del $80 \%$ de las actividades poseen un nivel de riesgo moderado. Esto debido a que el grifo poseerá procedimientos claros y detallados para que el personal lleve a cabo sus funciones, además se programará capacitaciones constantes en materias de seguridad y salud ocupacional en las diferentes actividades que desempeñan. No obstante, las actividades de inspección inicial y final de la carga en la parte superior de la cisterna poseen un nivel de riesgo importante. Esto se explica porque el operario tiene que subir encima del cisterna para verificar que la carga llegue precintada (inspección inicial) y para asegurarse de que el combustible se haya descargado en su totalidad (inspección final); esto genera que exista una probabilidad de que se caiga por alguna mala maniobra o problemas con la superficie lo cual podría generar hasta una lesión irreversible al tratarse de una caída de más de 3 metros. Ante ello, se plantea, aparte de capacitar y definir políticas claras de seguridad, el uso de equipos de protección personal como un arnés de seguridad, casco de protección, botas para superficies resbalosas y guantes. Otra actividad que posee un riesgo importante es el drenado del combustible al tanque, ya que de ocurrir algún derrame de combustible existe probabilidad de que ocurra hasta un incendio. Para ello, se contará con los siguientes equipos de seguridad contra incendios: 
Tabla 5.17

Equipos contra incendio

\begin{tabular}{c|lcc}
\hline $\mathbf{N}^{\circ}$ & \multicolumn{1}{|c}{ DESCRIPCIÓN } & CANTIDAD & UBICACIÓN \\
\hline 1 & Extintores de P.Q.S.(polvo químico seco) de 12 Kg de & 2 & En isla y en tanque \\
2 & contenido de 20 unid. de capacidad & GLP \\
3 & Extintores de dioxido de carbono de 7 Kg. de capacidad & 2 & Ambientes interiores \\
4 & Baldes reglamentarios con arena seca & 4 & En islas \\
5 & Cilindros de 200 litros de agua & 2 & En islas \\
6 & Cilindro con trapo húmedo & 4 & En isla y almacén \\
& Extintores de P.Q.S.-BC de 50 Kg de contenido de 140 & 1 & En patio de maniobras \\
\hline
\end{tabular}

Elaboración propia

La segunda matriz IPERC del proceso de atención al cliente, posee solo una actividad que posee un nivel de riesgo importante, que es en el abastecimiento de combustible ya que este se puede derramar y generar un incendio. Ante ello, también entra en acción los elementos antes listados.

Por otro lado, la estación de servicios contará con varios carteles que son de carácter obligatorio para todas las personas dentro del local, con el fin de reforzar las políticas planteadas y hacerlas recordar; estas son:

Tabla 5.18

Tabla de señalización

\begin{tabular}{c|l}
\hline N $^{\circ}$ DE CARTEL & \multicolumn{1}{c}{ CONTENIDO } \\
\hline 1 & Atención las 24 horas \\
2 & Prohibido el comercio ambulatorio \\
3 & Prohibido cualquier fuego abierto a menos de 50 \\
4 & metros \\
5 & Ap fumar \\
6 & Prohibido el ingreso de personas no autorizadas \\
7 & Zona de tanques y punto de transferencia de GLP \\
8 & Parada de emergencia \\
9 & Peligro de gas inflamable \\
10 & Gas combustible, no fumar \\
11 & Tanque llenar al 80\% GLP \\
12 & Rombo de las naciones unidas (UN 1075) \\
13 & Rombo de la NFPA \\
14 & SS/HH-Damas \\
15 & SS/HH-Varones \\
16 & Vestidores \\
17 & Tableros eléctricos \\
18 & Prohibido la atención a vehículos con pasajeros \\
19 & Cuarto de máquinas \\
20 & Apague su celular \\
21 & Aire \\
22 & Agua \\
23 & Zona exclusiva de vehículos de GLP \\
\hline
\end{tabular}

Elaboración propia 
Tabla 5.19

Matriz IPERC del proceso de descargue de combustible

\begin{tabular}{|c|c|c|c|c|c|c|c|c|c|c|c|c|}
\hline \multirow[b]{2}{*}{$\mathrm{N}^{\circ}$} & \multirow[b]{2}{*}{ ACTIVIDAD } & \multirow[b]{2}{*}{ PELIGRO } & \multirow[b]{2}{*}{ RIESGO } & \multicolumn{4}{|c|}{$\begin{array}{l}\text { SUB ÍNDICES DE } \\
\text { PROBABILIDAD }\end{array}$} & \multirow[b]{2}{*}{ 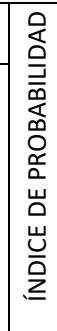 } & \multirow[b]{2}{*}{ 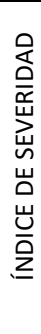 } & \multirow[b]{2}{*}{ 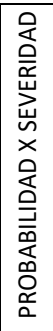 } & \multirow[b]{2}{*}{ 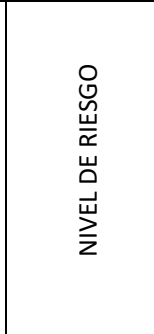 } & \multirow{2}{*}{ 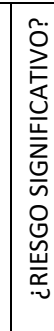 } \\
\hline & & & & 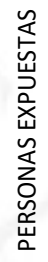 & 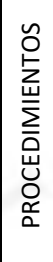 & 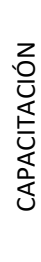 & 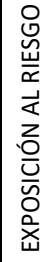 & & & & & \\
\hline 1 & $\begin{array}{l}\text { Ingreso de camión cisterna a la } \\
\text { estación de servicios }\end{array}$ & Camión cisterna & $\begin{array}{l}\text { Atropello a personal, impacto con otros } \\
\text { vehículos o surtidores }\end{array}$ & 1 & 1 & 1 & 3 & 6 & 2 & 12 & MODERADO & NO \\
\hline 2 & $\begin{array}{l}\text { Inspección inicial de carga en la parte } \\
\text { superior de cisterna }\end{array}$ & Camión cisterna & Caida a distinto nivel & 1 & 1 & 1 & 3 & 6 & 3 & 18 & IMPORTANTE & $=S 1$ \\
\hline \multirow{3}{*}{3} & \multirow{3}{*}{ Varillaje inicial de tanques } & $\begin{array}{l}\text { Método de trabajo-posición } \\
\text { inadecuada }\end{array}$ & Problemas muscuesqueléticos & 1 & 1 & 1 & 3 & 6 & 2 & 12 & MODERADO & NO \\
\hline & & Combustible & $\begin{array}{c}\text { Contacto directo y frecuente del combustible } \\
\text { con la piel }\end{array}$ & 1 & 1 & 1 & 3 & 6 & 2 & 12 & MODERADO & NO \\
\hline & & Combustible & Inhalación de sustancias químicas & 1 & 1 & 1 & 3 & 6 & 2 & 12 & MODERADO & NO \\
\hline 4 & Traslado del equipo de descarga & $\begin{array}{c}\text { Equipos de descarga(manguera, } \\
\text { abrazaderas, etc) }\end{array}$ & Impacto o contusiones & 1 & 1 & 1 & 3 & 6 & 2 & 12 & MODERADO & NO \\
\hline 5 & Instalación del equipo de descarga & Herramientas auxiliares & Impacto o contusiones & 1 & 1 & 1 & 3 & 6 & 2 & 12 & MODERADO & NO \\
\hline \multirow[t]{2}{*}{6} & \multirow[t]{2}{*}{ Drenado del combustible al tanque } & Combustible derramado & $\begin{array}{c}\text { Contacto directo y frecuente del combustible } \\
\text { con la piel }\end{array}$ & 1 & 1 & 1 & 3 & 6 & 2 & 12 & MODERADO & NO \\
\hline & & Combustible derramado evaporado & Iniciación de incendio & 1 & 1 & 1 & 3 & 6 & 3 & 18 & IMPORTANTE & $\equiv \mathrm{SI}$ \\
\hline 7 & Desinstalación del equipo de descarga & Herramientas auxiliares & Impacto o contusiones & 1 & 1 & 1 & 3 & 6 & 2 & 12 & MODERADO & NO \\
\hline 8 & Traslado del equipo de descarga & $\begin{array}{l}\text { Equipos de descarga(manguera, } \\
\text { abrazaderas, etc) }\end{array}$ & Impacto o contusiones & 1 & 1 & 1 & 3 & 6 & 2 & 12 & MODERADO & NO \\
\hline 9 & Desconche del combustible & Camión cisterna & $\begin{array}{c}\text { Atropello a personal, impacto con otros } \\
\text { vehículos o surtidores }\end{array}$ & 1 & 1 & 1 & 3 & 6 & 2 & 12 & MODERADO & NO \\
\hline 10 & $\begin{array}{l}\text { Inspección final de carga en la parte } \\
\text { superior de cisterna }\end{array}$ & Camión cisterna & Caida a distinto nivel & 1 & 1 & 1 & 3 & 6 & 3 & 18 & IMPORTANTE & $=S 1$ \\
\hline 11 & $\begin{array}{c}\text { Salida de camión cisterna a la estación } \\
\text { de servicios }\end{array}$ & Camión cisterna & $\begin{array}{l}\text { Atropello a personal, impacto con otros } \\
\text { vehículos o surtidores }\end{array}$ & 1 & 1 & 1 & 3 & 6 & 2 & 12 & MODERADO & NO \\
\hline
\end{tabular}

๑ Elaboración propia 
Tabla 5.20

Matriz IPERC del proceso de atención al cliente

\begin{tabular}{|c|c|c|c|c|c|c|c|c|c|c|c|c|}
\hline \multirow[b]{2}{*}{$\mathrm{N}^{\circ}$} & \multirow[b]{2}{*}{ ACTIVIDAD } & \multirow[b]{2}{*}{ PELIGRO } & \multirow[b]{2}{*}{ RIESGO } & \multicolumn{4}{|c|}{$\begin{array}{l}\text { SUB ÍNDICES DE } \\
\text { PROBABILIDAD }\end{array}$} & \multirow{2}{*}{ 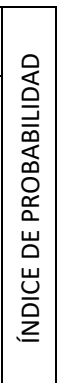 } & \multirow{2}{*}{ 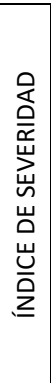 } & \multirow{2}{*}{ 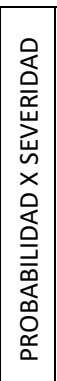 } & \multirow{2}{*}{ 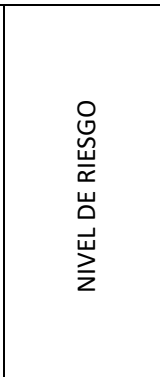 } & \multirow{2}{*}{ 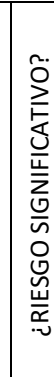 } \\
\hline & & & & 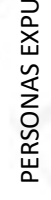 & 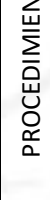 & 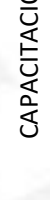 & 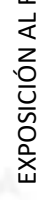 & & & & & \\
\hline 1 & $\begin{array}{l}\text { Desplazamiento inicial del } \\
\text { vendedro hacia la isla }\end{array}$ & $\begin{array}{l}\text { Piso irregular o con alguna } \\
\text { anomalía }\end{array}$ & Caida al mismo nivel, golpe, entre otros & 1 & 1 & 1 & 3 & 6 & 1 & 6 & TOLERABLE & NO \\
\hline 2 & $\begin{array}{c}\text { Ingreso de vehículo a la estación } \\
\text { de servicio }\end{array}$ & Vehículo & $\begin{array}{c}\text { Atropello a personal, impacto con otros } \\
\text { vehículos o surtidores }\end{array}$ & 1 & 1 & 1 & 3 & 6 & 2 & 12 & MODERADO & NO \\
\hline 3 & $\begin{array}{c}\text { Detención de vehículo en } \\
\text { movimiento }\end{array}$ & Vehículo & Impacto o contusiones & 1 & 1 & 1 & 3 & 6 & 2 & 12 & MODERADO & NO \\
\hline 4 & \multirow{5}{*}{ Abastecimiento de combustible } & Combustible líquido derramado & Iniciación de incendio & 1 & 1 & 1 & 3 & 6 & 3 & 18 & IMPORTANTE & SI \\
\hline 5 & & Combustible gas en fuga & $\begin{array}{l}\text { Iniciación de incendio, contacto directo de } \\
\text { presión y bajas temperaturas }\end{array}$ & 1 & 1 & 1 & 3 & 6 & 3 & 18 & IMPORTANTE & SI \\
\hline 6 & & Combustible & $\begin{array}{c}\text { Contacto directo y frecuente del combustible } \\
\text { con la piel }\end{array}$ & 1 & 1 & 1 & 3 & 6 & 2 & 12 & MODERADO & NO \\
\hline 7 & & Combustible & Inhalación de sustancias químicas & 1 & 1 & 1 & 3 & 6 & 2 & 12 & MODERADO & NO \\
\hline 8 & & Combustible & Contacto e irritación de la vista & 1 & 1 & 1 & 3 & 6 & 2 & 12 & MODERADO & NO \\
\hline 9 & Abandono del vehiculo de la isla & Vehículo & $\begin{array}{c}\text { Atropello a personal, impacto con otros } \\
\text { vehículos o surtidores }\end{array}$ & 1 & 1 & 1 & 3 & 6 & 2 & 12 & MODERADO & NO \\
\hline 10 & Abandono del vehiculo del grifo & Vehículo & $\begin{array}{c}\text { Atropello a personal o personas en general, } \\
\text { impacto con otros vehículos }\end{array}$ & 1 & 1 & 1 & 3 & 6 & 2 & 12 & MODERADO & NO \\
\hline 11 & \multirow{2}{*}{ Limpieza del área de trabajo } & $\begin{array}{c}\text { Piso de isla de trabajo irregular o } \\
\text { con alguna anomalía }\end{array}$ & Caida al mismo nivel, golpe, entre otros & 1 & 1 & 1 & 3 & 6 & 2 & 12 & MODERADO & NO \\
\hline 12 & & Vehículo & Atropello o impacto con el personal & 1 & 1 & 1 & 3 & 6 & 2 & 12 & MODERADO & NO \\
\hline
\end{tabular}

laboración propia 
Figura 5.8

Rombo de las naciones unidas (UN 1075)

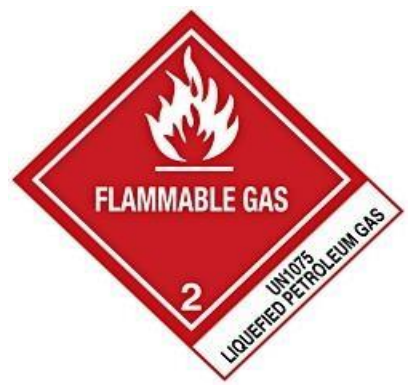

Fuente: OSINERGMIN (2017)

Figura 5.9

Rombo de la NFPA de combustibles

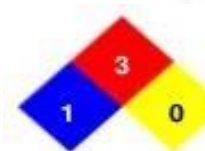

GASOLINA

(Gasolina natural) UN - 1203

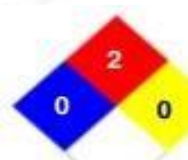

DIESEL

$U N-1202$

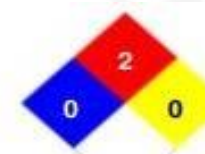

KEROSENE

$U N$ - 1223

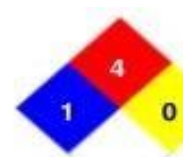

G.L.P. UN -1075

Fuente: OSINERGMIN (2017)

Figura 5.10

Significado del rombo NFPA de combustibles

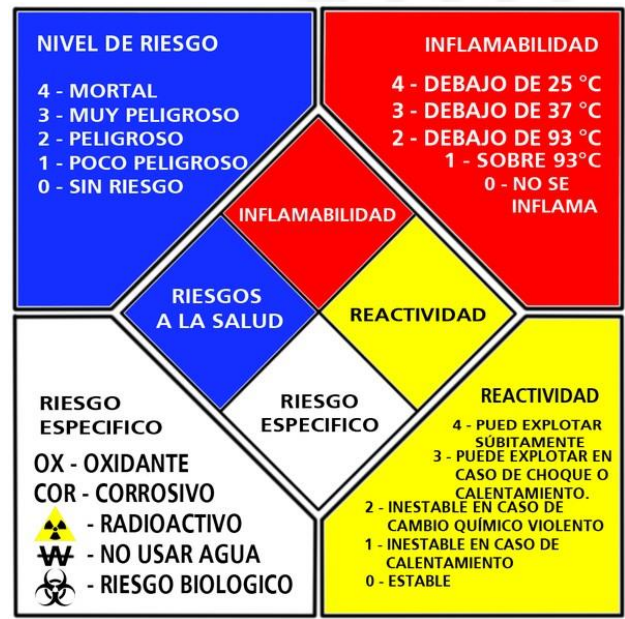

Fuente: Seguridad industrial (2018) 


\subsection{Sistema de mantenimiento}

El sistema de mantenimiento es una pieza clave para la estación de servicios, puesto que posee máquinas como los surtidores que necesitan tener una disponibilidad de 24 horas. Para esta parte se está considerando que se hará uso del mantenimiento preventivo y reducir al mínimo del mantenimiento reactivo. En general el mantenimiento se está manejando en 2 niveles. Un primer nivel que cosiste básicamente en la limpieza externa de las máquinas que será ejecutado por el personal de limpieza, el cual será de una empresa tercera. Se eligió tercerizar este servicio porque se necesita personal especializado por tratarse de máquinas complejas; en este sentido, contratar técnicos para esta actividad resultaría costoso y generaría tiempos muertos al personal teniendo en cuenta que la labor no es diaria; es decir, sería ineficiente y no económica. Cabe resaltar que se firmarán contratos para la homologación de estos proveedores y de esta manera, asegurar la calidad y disponibilidad del servicio.

Por otro lado, está el segundo nivel que involucra la parte técnica de las máquinas como revisión general o cambio planificado de componentes, este nivel será ejecutado por técnicos especialistas en cada máquina pero que no formarán parte de la empresa ya que estos servicios también serán tercerizados. A continuación, se muestra la tabla de mantenimiento que plasma el detalle del mantenimiento, su frecuencia y los instrumentos y materiales que se necesita.

En el caso del grupo electrógeno y la compresora, la frecuencia está definida por las horas que la máquina opera, porque estas máquinas son usadas de forma eventual cuando existe una descarga del aire en el tanque (compresora) o cuando no haya fluido eléctrico público (grupo electrógeno). Por otro lado, solo para el grupo electrógeno se está considerando como parte del mantenimiento el arranque de la máquina de forma semanal, porque esta máquina se usa después de periodos largos por lo que existe una gran posibilidad de que internamente se malogre por inacción. 
Tabla 5.21

Programa de mantenimiento preventivo

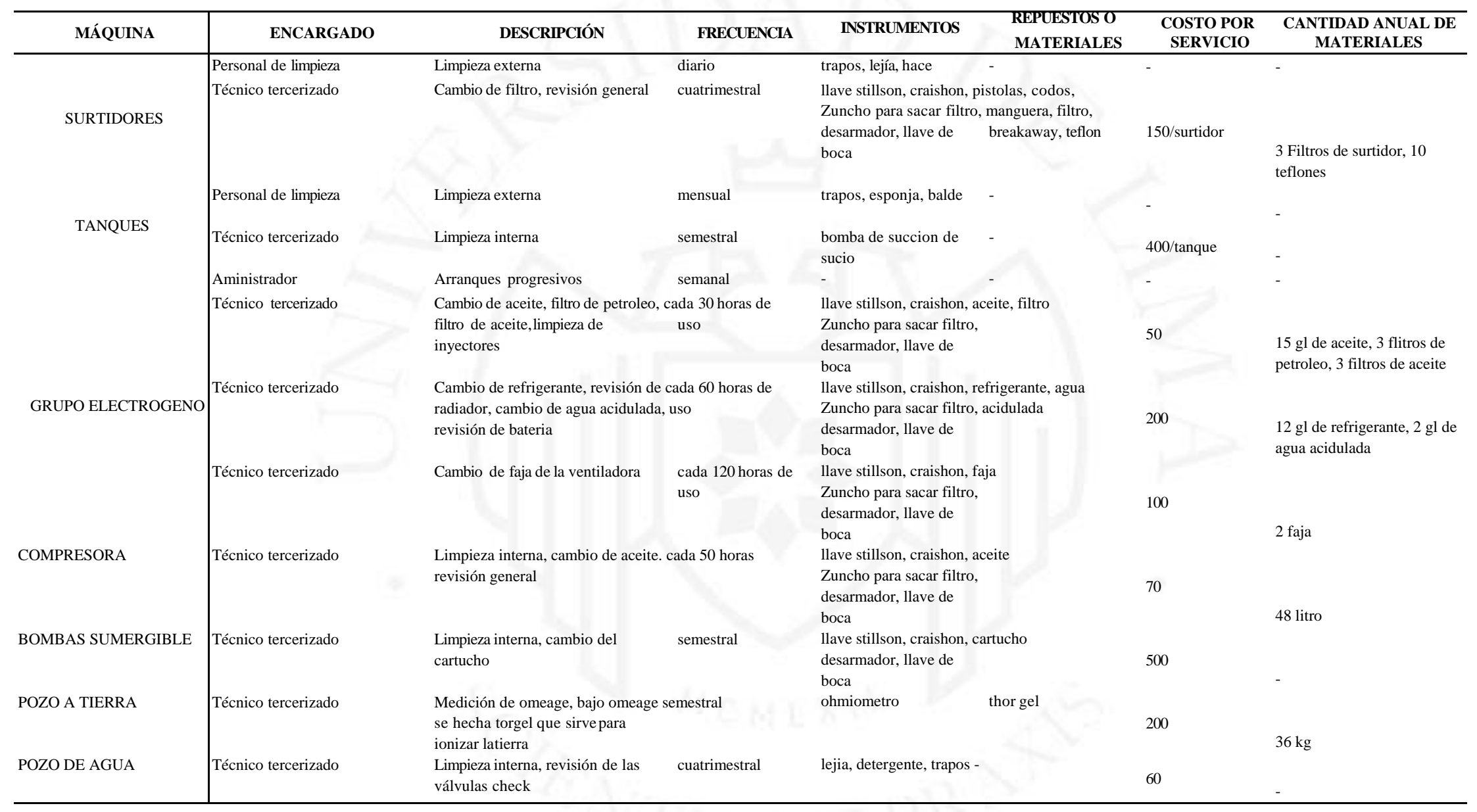

Elaboración propia 
Por otro lado, en el cuadro se muestra los instrumentos necesarios para llevar a cabo el mantenimiento; no obstante, es bueno resaltar que será responsabilidad del técnico contar con sus instrumentos. También están los repuestos y materiales, estos sí serán propiedad de la empresa y serán almacenados ya que se trata de elementos de uso común y planificado.

No hay que soslayar que el mantenimiento descrito aplica durante la vida útil de las máquinas mencionadas. No involucra la etapa de mortalidad infantil, ya que las fallas se darán de forma frecuente y será responsabilidad de la empresa que instale o venda la máquina. Sin embargo, se considerará un cuadro de mantenimiento reactivo de acuerdo a las fallas más comunes en una estación de servicios durante su operación.

Tabla 5.22

Cuadro de mantenimiento reactivo

\begin{tabular}{l|lrr}
\hline \multicolumn{1}{c|}{ Máquina } & \multicolumn{1}{c}{ Falla } & $\begin{array}{c}\text { Frecuencia } \\
\text { anual apróx }\end{array}$ & $\begin{array}{r}\text { Costo por servicio } \\
\text { (soles) }\end{array}$ \\
\hline GRUPO & Ruptura de faja & 1 & 400 \\
ELECTRÓGENO & Avería de motor & 0,5 & 6.000 \\
COMPRESORA & Ruptura de faja & 1 & 400 \\
BOMBA SUMERGIBLE & Sobrecalentamiento de motor & 2 & 500 \\
& Averío de cartucho & 0,5 & 2.664 \\
\hline
\end{tabular}

Elaboración propia

Con respecto a la limpieza de la estación de servicios, el detalle de los horarios de este personal se muestra a continuación:

Tabla 5.23

Programa de limpieza semanal

\begin{tabular}{|c|c|c|c|c|c|c|c|}
\hline . & $\mathbf{L}$ & M & M & $\mathbf{J}$ & V & $\mathbf{S}$ & D \\
\hline 09:00 AM - 10:00 AM & \multicolumn{7}{|c|}{ Limpieza de servicios higiénicos } \\
\hline 10:00 AM - 11:00 AM & \multicolumn{7}{|c|}{ Limpieza administrativos } \\
\hline 11:00 AM - 12:00 PM & \multicolumn{7}{|c|}{ Limpieza administrativos } \\
\hline 12:00 PM - 01:00 PM & \multicolumn{7}{|c|}{ Limpieza de islas } \\
\hline 01:00 PM - 02:00 PM & \multicolumn{7}{|c|}{ Almuerzo } \\
\hline 02:00 PM - 03:00 PM & \multicolumn{7}{|c|}{ Limpieza de servicios higiénicos } \\
\hline 03:00 PM - 04:00 PM & \multicolumn{7}{|c|}{ Limpieza de islas } \\
\hline 04:00 PM - 05:00 PM & \multicolumn{7}{|c|}{ Limpieza de surtidores } \\
\hline 05:00 PM - 06:00 PM & \multicolumn{7}{|c|}{ Limpieza de servicios higiénicos } \\
\hline
\end{tabular}

Elaboración propia 


\subsection{Programa de operaciones del servicio}

\subsubsection{Consideraciones sobre la vida útil del proyecto}

La vida útil del proyecto dependerá de diversos factores como el crecimiento del parque automotor en Huancayo, la capacidad que tenga la estación de servicios de satisfacer la demanda, la rentabilidad que obtenga el presente proyecto y la presencia de competidores. Para efectos de la investigación, el proyecto se evaluará en un horizonte de 5 años, debido a las siguientes razones:

- Permitirá estimar la capacidad aproximada requerida para poder cubrir la demanda de esos años.

- Se prevé que dentro de este horizonte del proyecto, se encuentre el periodo de recupero de la inversión. Esto se comprobará en el capítulo VII.

- Se espera que estos años sean de consolidación del proyecto; donde se podrá aprender más sobre las maneras más eficientes de llevar a cabo el negocio para luego pensar en poder replicar el modelo en otros grifos y así, poder establecer una cadena de grifos.

Cabe recalcar que la idea es que esta estación de servicios pueda tener mucho más tiempo de atención; sin embargo, luego de 5 años será necesario realizar una evaluación sobre la capacidad para ver si se podrá abastecer la demanda de los siguientes años, también se debe considerar comprar más surtidores y realizar ciertos mantenimientos renovativos.

\subsubsection{Programa de operaciones del servicio durante la vida útil del proyecto}

La operación principal será el abastecimiento de combustibles; sin embargo, hay operaciones que servirán de soporte a este proceso:

- Descuentos y promociones: La ejecución de los mismos se realizará en las islas de atención y se llevará a cabo por los vendedores de isla.

- Elaboración de pedidos a transportista: Se realizarán pedidos de reabastecimiento de combustibles cada día y medio.

- Descarga de combustibles: Se realizará cuando el camión del transportista llegue a la estación de servicios. 
- Limpieza: El plan de limpieza se detalló en el acápite 5.7.

- Mantenimiento: El plan de mantenimiento se detalló en el acápite 5.7.

- Inspecciones ambientales: Se realizarán de acuerdo a la frecuencia indicada por el Ministerio de Energía y Minas.

- Proceso de contabilidad y pago de impuestos: La contabilidad es una tarea diaria y el pago de impuestos debe llevarse a cabo mensualmente.

- Servicio de seguridad: Se contratará personal de seguridad para los tres turnos, a través de una empresa tercera.

- Administración página web y redes sociales: La empresa realizará actualizaciones de contenido para tener una página web interactiva, además se debe monitorear diariamente los mensajes de las redes sociales y recoger las posibles quejas y sugerencias.

- Plan de calidad de servicio: Mensualmente se realizarán encuestas de satisfacción al cliente, se premiarán a los vendedores con mejor desempeño y se determinarán los planes de acción a ejecutar para mejorar los puntos débiles del servicio. Además, también se realizarán las auditorías en calidad a los otros servicios que se encuentran en el grifo.

\subsection{Requerimiento de materiales, personal y servicios}

\subsubsection{Materiales para el servicio}

Los materiales que se necesitarán tanto para el servicio directo como para las áreas de soporte se detallan a continuación:

Tabla 5.24

Requerimiento de insumos para atención directa

\begin{tabular}{l|lcc}
\hline $\begin{array}{l}\text { Insumos para atención } \\
\text { directa }\end{array}$ & Unidad & Requerimiento & $\begin{array}{c}\text { Cantidad } \\
\text { requerida anual }\end{array}$ \\
\hline Combustible & galones & $4.495 .654 * 1,001$ & 4.500 .149 \\
\hline
\end{tabular}

Nota: Se calculó un promedio anual, ya que la demanda no es constante y se consideró las mermas que hay en el proceso para combustibles líquidos.

Elaboración propia 
Tabla 5.25

Requerimiento de materiales de atención directa

\begin{tabular}{l|ccc}
\hline $\begin{array}{l}\text { Materiales de atención } \\
\text { directa }\end{array}$ & Unidad & Requerimiento & $\begin{array}{c}\text { Cantidad } \\
\text { requerida anual }\end{array}$ \\
\hline Papel de boletas y facturas & rollos & $\frac{2 \text { rollos }}{\text { día }} \times 365$ días & 730 \\
Papel contómetro para POS & rollos & $\frac{1 \text { rollo }}{\text { día }} \times 365$ días & 365 \\
\hline
\end{tabular}

Elaboración propia

Tabla 5.26

Requerimiento de materiales de oficina

\begin{tabular}{|c|c|c|c|}
\hline Materiales de oficina & Unidad & Requerimiento & $\begin{array}{c}\text { Cantidad } \\
\text { requerida anual }\end{array}$ \\
\hline Papel de oficina & millares & $\frac{1 \text { millar }}{\text { mes }} \times 12$ meses & 12 \\
\hline Lapiceros & unidades & $\frac{15 \text { unidades }}{\text { mes }} \times 12$ meses & 180 \\
\hline Correctores & unidades & $\frac{15 \text { unidades }}{\text { mes }} \times 12$ meses & 180 \\
\hline Post its & cientos & $\frac{2 \text { cientos }}{\text { semana }} \times 52$ semanas & 104 \\
\hline Cuadernos & unidades & $\frac{6 \text { unidades }}{\text { cuatrimestre }} \times 3$ cuatrimestres & 18 \\
\hline Tintas de impresora & juegos de tintas & $\frac{1 \text { juego }}{\text { trimestre }} \times 4$ trimestres & 4 \\
\hline
\end{tabular}

Elaboración propia

Tabla 5.27

Requerimiento de materiales de limpieza

\begin{tabular}{l|ccc}
\hline Materiales de limpieza & Unidad & Requerimiento & $\begin{array}{c}\text { Cantidad } \\
\text { requerida } \\
\text { anual }\end{array}$ \\
\hline Aromatizante & unidades & $\frac{1 \text { aromatizante }}{\text { semana }-\mathrm{SSHH}} \times 52$ semanas $\times 5 \mathrm{SSHH}$ & 260 \\
Papel higiénico & rollos grandes & $\frac{2 \text { rollos }}{\text { día }-\mathrm{SSHH}} \times 365$ días $\times 5 \mathrm{SSHH}$ & 3650 \\
Jabón líquido para manos & $\begin{array}{c}\text { envases de } 400 \\
\mathrm{ml}\end{array}$ & $\frac{2 \text { envases }}{\text { semana }-\mathrm{SSHH}} \times 52$ semanas $\times 5 \mathrm{SSHH}$ & 520 \\
\hline
\end{tabular}

Elaboración propia 
Tabla 5.28

Requerimiento de materiales para mantenimiento de máquinas

\begin{tabular}{l|ccc}
\hline $\begin{array}{c}\text { Materiales para } \\
\text { mantenimiento de } \\
\text { máquinas }\end{array}$ & Unidad & Requerimiento & $\begin{array}{c}\text { Cantidad } \\
\text { requerida } \\
\text { anual }\end{array}$ \\
\hline Filtros de surtidores & unidades & 3 & 3 \\
Teflones & unidades & 10 & 10 \\
Aceite para grupo & galones & 15 & 15 \\
electrógeno & unidades & 3 & 3 \\
Filtros de petróleo & unidades & 3 & 3 \\
Filtros de aceite & galones & 12 & 12 \\
Refrigerante & galones & 2 & 2 \\
Agua acidulada & unidades & 2 & 2 \\
Fajas & litros & 48 & 48 \\
Aceite para compresora & kilogramos & 36 & 36 \\
Gel & & &
\end{tabular}

Elaboración propia

\subsubsection{Determinación del requerimiento de personal de atención al cliente}

El cálculo número de vendedores de isla se realizó en el apéndice 5.4.4. Determinación del número de recursos de los demás factores. Se muestran los resultados a continuación:

Tabla 5.29

Número de vendedores por turno

\begin{tabular}{c|cc}
\hline & Horario & \# Vendedores \\
\hline Turno 1 & 06:00 AM - 02:00 PM & 4 \\
Turno 2 & 02:00 PM - 10:00 PM & 4 \\
Turno 3 & 10:00 PM - 06:00 AM & 2 \\
\hline
\end{tabular}

Elaboración propia

\subsubsection{Servicios de terceros}

Existen algunos servicios que no serán gestionados directamente por la empresa del presente proyecto, sino que se contratará a personas o empresas especializadas. Esto se realizará con el objetivo de poder enfocarse en el core del negocio.

Los servicios de terceros serán:

- Transportista: Se encargará de realizar la carga de combustibles en la refinería de Petroperú en Conchán, trasladará dicho combustible y lo llevará a la estación de servicios en Huancayo para poder realizar la descarga. La empresa transportista 
será Cotera S.A. que es la más conocida y además, la de mayor confiabilidad de la zona.

- Contador: Se contratará a una persona especialista que pueda llevar las cuentas financieras del negocio, entre sus funciones tendrá elaborar los estados de resultados y balance de cuentas mensuales e informar sobre los diferentes cobros de impuestos.

- Perito de monitoreo ambiental: Se contratará a una persona que pueda llevar a cabo el informe de monitoreo ambiental.

- Personal de mantenimiento: Se contratará a la mano de obra encargada de realizar el mantenimiento; sin embargo, los materiales serán suministrados por la empresa.

- Vigilancia y limpieza: El primer proceso se tercerizará a la empresa Liderman, que tiene sucursal en Huancayo, y cuyos años de experiencia y buenos antecedentes, la han hecho una de las empresas líder en este rubro. Por otro lado, el proceso de limpieza estará a cargo de la empresa OLICH Clean, una empresa también reconocida en la ciudad de Huancayo.

Es importante mencionar que la empresa tampoco gestionará los servicios de lavado y engrase, tienda y cambio de aceite, servicio de llantas, mini market, farmacia y comida rápida; sin embargo, no pagará por el servicio de un tercero, sino que se alquilará el espacio para que los empresarios puedan colocar sus negocios. En el caso de lavado y engrase, el espacio que se alquilará debe contar con las rendijas para el drenaje del agua, para los otros casos, solo se alquilará el local debidamente pintado y con puertas de vidrio; es decir, no se alquilará el espacio amoblado. Cabe recalcar que los residuos de estas operaciones sí serán tratados por la empresa y las acciones están detalladas en el acápite 5.6 Impacto ambiental. Por otro lado, estos espacios contarán con sus propios medidores de agua y luz para que las personas a las que se les alquile el espacio, puedan gestionar ellos mismos el pago sus servicios. 


\subsubsection{Otros requerimientos}

a) Energía eléctrica:

En el caso del presente proyecto, la energía eléctrica será proporcionada por la empresa concesionaria perteneciente a la región centro (ELECTROCENTRO SA) mediante un suministro trifásico en 220 v y 60 hz. El sistema eléctrico raíz consistirá en:

- Un tablero de transferencia con acceso de energía desde la red pública y un generador eléctrico.

- Un tablero general de 3 llaves de 3 fases y 2 llaves de 2 fases más 1 llave de 2 fases de reserva.

- Desde el tablero general se conecta a los tableros de surtidores, tablero de alumbrado y tablero de la edificación.

- Se prevé la colocación de la botonera de emergencia conectada desde el tablero general y el tablero de surtidores.

- Se prevé la instalación de 1 pozo a tierra que actuará en conjunto con el pararrayo en caso existan descargas eléctricas fuertes y no afecten a las máquinas del grifo.

En líneas generales el costo por concepto de energía eléctrica es fijo y variable a la vez. La parte fija se da en el caso de las instalaciones eléctricas de las oficinas o de las tiendas. Por otro lado, es variable porque va depender de la venta que se realice durante el día, es decir, variará en función a los galones despachados.

Las principales luminarias que posee la estación de servicios son los letreros luminosos y el alumbrado bajo la zona de surtidores, puesto que van a permitir que el grifo siga desarrollando su actividad principal de forma adecuada, que es la de despachar combustible, las 24 horas. En el caso de los letreros luminosos (que serán la lista de precios, las flechas de entrada y salida, el tótem, entre otros), se usará a un 20\% pasada la media noche siempre y en cuando el brillo máximo no supere las $50 \mathrm{~cd} / \mathrm{m}^{2}$ según las recomendaciones del Instituto de Astrofísica de Canarias. Con respecto a las luminarias del techo, el número de ellas será calculado con la siguiente fórmula: 


$$
N 1=\frac{I x A}{N 2 \times L \times P}
$$

Donde:

N1: Número de fuentes luminosas utilizadas

I: Iluminación requerida en lux $\left(\mathrm{lum} / \mathrm{m}^{2}\right)$

A: Área iluminada

P: Potencia del fluorescente en Watts

N2: Número de lámparas por fuente luminosa

\section{L: Lúmenes por lámpara}

Según las recomendaciones del Instituto de Astrofísica de Canarias, lo recomendable es requerir de una iluminación de 100 lux aproximadamente. El área objetivo que se desea iluminar es de aproximadamente $640 \mathrm{~m}^{2}$ y se hará uso de luminarias LED MVLUZVERDE que posee una potencia de $80 \mathrm{~W}$ de 90 lumen. Con los datos antes expuestos resulta que se debe colocar 9 luminarias LED en el techo. Cabe resaltar que el cálculo se hizo suponiendo condiciones ideales, es decir, no se tomó en cuenta una tasa de depreciación por el uso de los focos ni el desgaste por suciedad, polvo y otros elementos que obstaculizan la luminosidad máxima de los fluorescentes.

b) Agua:

El suministro de agua se da a través de una tubería matriz de 2" que pasa por la Av. Principal desde donde se conecta al medidor. El desagüe de las aguas negras será conectado a la red pública proyectada y el desagüe pluvial excedente (la cantidad de agua pluvial que no se logra almacenar por el sistema de drenaje por haber excedido la capacidad del tanque $-5 \mathrm{~m}^{3}$ ) evacuado a los jardines y veredas que a la vez conectarán a las cunetas.

Con respecto a la red de agua, esta será captada de la red matriz y conducida a varios servicios que requiere el bloque administrativo. Por otro lado, de forma gradual un porcentaje mínimo del agua es derivada por otras tuberías a los tanques cisternas subterráneos. La estación de servicios posee 2 tanques cisternas, uno destinado al lavado y engrase de $15 \mathrm{~m}^{3}$ y el otro también de $15 \mathrm{~m}^{3}$ pero que posee 2 compartimentos uno de 
$10 \mathrm{~m}^{3}$ para almacenar agua para el resto del grifo y otro de $5 \mathrm{~m}^{3}$ destinado a recolectar el agua captada por el sistema de drenaje pluvial.

La red de desagüe consiste en un sistema de evacuación de las aguas negras que se realizará por medio de tuberías PVC. Se emplearán 2 vías. La primera recolecta el desagüe del lavado y engrase y lo envía a la cisterna de recirculación desde donde después del uso respectivo es conectada a la trampa de grasa para ser procesada de forma adecuada y expulsada a la red pública. La otra vía recolecta todo el desaguie de aguas negras del bloque administrativo y lo envía de forma directa a la trampa de grasa para luego expulsarla.

\subsection{Soporte físico del servicio}

\subsubsection{Factor edificio}

Para el factor edificio, se comprará un terreno sobre el cual se edificará y realizará todas las instalaciones necesarias para obtener la estación de servicios. No obstante, su superficie es muy irregular por lo que es necesario realizar trabajos con maquinaria pesada para nivelar todo y poder empezar a edificar. Estos trabajos consisten en desmonte de tierra, aplanamiento de superficie, destrucción de rocas, rellenos, etc.

Algunos materiales principales y de uso común que se empleará en la construcción son los fierros de 5/8, 1/2 y 1/4 y alambre de amarre para elaborar el armazón de las vigas, columnas y zapatas, y las bolsas de cemento, arena gruesa, arena fina, ladrillo, etc; para obtener el concreto de las edificaciones. Por otro lado, el grifo también cuenta con estructuras netamente metálicas como el techo canopy, se construirán vigas, correas y tensores metálicos para cargar estructuras del techo canopy. Los perfiles y láminas indicados serán de calidad $\mathrm{A}^{\prime} 36$, todos los materiales serán galvanizados en caliente según las normas ASTM 1-23 y A-153. Para proteger las soldaduras de campo se utilizará galvanizado en frio en aerosol tipo zinc.

A continuación, se explica con mejor detalle las áreas que comprenderá toda la estación de servicios:

- Zona de descarga: La zona de descarga no ocupa gran espacio, pero debe estar cerca de los tanques soterrados para que el combustible no tenga ningún 
inconveniente en su traslado al tanque. Además, necesita ser un área con gran accesibilidad para que el camión cisterna no tenga ningún inconveniente de estacionarse y descargar. El área será de $4.55 \mathrm{~m}$ de largo y $1 \mathrm{~m}$ de ancho. Estas medidas se obtuvieron teniendo como referencia otras estaciones de servicio ya que no se cuenta con medidas estándares de esta zona.

- Área de tanques: Como se mencionó el acápite 5.4.4, se tendrán 3 tanques líquidos, tomando en cuenta que los combustibles gasohol 95 y 97 se almacenarán en un mismo tanque con dos compartimentos, además, se contará con un cuarto tranque de GLP. Los tanques estarán ubicados bajo tierra y deben estar cerca de los surtidores de abastecimiento. Para el cálculo del área que requiere se tomó como primera referencia las medidas de los tanques ya mencionadas secciones atrás. Además, se cuenta con 2 tanques de agua, el tanque 1 destinado específicamente para el lavado y engrase de vehículos ya que el agua representa para este negocio un insumo fundamental y el tanque 2 para abastecer de agua a las demás instalaciones cuando sea necesario. Ambos tanques poseen una capacidad volumétrica total de $15 \mathrm{~m}^{3}$ con la diferencia de que el segundo tanque posee 2 compartimentos, uno de $10 \mathrm{~m}^{3}$ que almacenará el agua para consumo de las demás instalaciones y otro de $5 \mathrm{~m}^{3}$ que almacenará el agua recolectada por el sistema de recolección de agua pluvial. Las medidas de los 6 tanques mencionados se detallan a continuación:

Tabla $\quad 5.30$

Medidas tanques

\begin{tabular}{l|ccc}
\hline \multicolumn{1}{c|}{ Tipo } & Largo & Ancho & Profundidad \\
\hline Tanque B5 & 8,50 & 2,90 & 2,90 \\
Tanque G90 & 11,50 & 2,90 & 2,90 \\
Tanque G95 y G97 & 9,00 & 2,90 & 2,90 \\
Tanque GLP & 8,50 & 2,90 & 2,90 \\
Tanque agua 1 & 3,00 & 2,20 & 3,50 \\
Tanque agua 2 & 3,00 & 2,20 & 3,50 \\
\hline
\end{tabular}

Elaboración propia

- Cuarto grupo electrógeno: El grupo electrógeno debe encontrarse principalmente cerca de los surtidores y del tablero de mando de las instalaciones eléctricas. Las dimensiones del cuarto donde estará ubicado el grupo electrógeno es 4,7 m de largo con 2,85 m de ancho. Estas medidas se optaron tomando como referencia 
instalaciones existentes de otras estaciones de servicio, ya que no se cuenta con estándares de este ítem.

- Almacén de repuestos y tablero de mando de instalación eléctrica (repuestos de surtidores, serafín, compresora, uniforme de vendedores de isla): En el almacén de repuestos, también se encontrará la compresora de aire y el tablero de mando de las instalaciones eléctricas. De igual forma que no se cuenta con un estándar de medida de almacén para grifo, por lo que se definió en base a la cantidad de elementos que entraría. Las dimensiones son: 7,7 $\mathrm{m}$ de largo y 4,7 $\mathrm{m}$ de ancho.

- Pozo a tierra: El pozo a tierra debe estar ubicado en una zona despejada y alejada del tablero de mando de instalaciones eléctricas, sus dimensiones son de $3 \mathrm{~m}$ de profundidad y un diámetro de $0.5 \mathrm{~m}$.

- Estacionamientos: Los estacionamientos regulares deben ser como mínimo de 2,5 metros de ancho y 5 metros de largo; mientras los estacionamientos para personas con discapacidad deben ser como mínimo de 3,8 metros de ancho y 5 metros de largo. (Neufert, 2013)

Además, según la norma peruana A. 120 “Accesibilidad para personas con discapacidad y de las personas adultas mayores", cuando un establecimiento tiene de 6 a 20 estacionamientos, debe tener, como mínimo, un estacionamiento para discapacitados. Para el presente proyecto se están considerando 2 estacionamientos para personas con discapacidad y 9 estacionamientos regulares. (MIMP, 2018)

Además, cabe resaltar que esta área debe estar cerca del local de los demás servicios para facilitar su acceso al cliente a estas tiendas.

- Zona de aire y agua: Según Neufert, el espacio para esta área debe ser de 3,7 metros de ancho y 5 metros de largo para autos. Como no se desea excluir de este servicio a los buses, que serán un cliente estratégico, las dimensiones que se manejarán en este espacio serán de 5 metros de ancho y 11,85 metros de largo. Se tiene que tener en cuenta que esta zona necesita estar cerca de compresora y del tanque de agua subterráneo.

- Sistema recolección de agua pluvial: Al no ser esta un área donde se realizarán actividades, el tamaño es bastante variable; sin embargo, se debe tomar en cuenta que el sistema será más efectivo mientras el área sea mayor; por esta razón, se designó un área de 24,2 metros de ancho y 2,55 metros de largo para este sistema. 
Este se ubicó al norte del local de manera que pueda recolectar el agua de la lluvia con mayor facilidad.

- Servicios higiénicos: En el presente proyecto se contará con 5 servicios higiénicos. Dos de ellos se encontrarán en el primer piso, uno será de hombres y el otro de mujeres, ambos contarán con un ambiente para personas discapacitadas. En el segundo piso, se construirá un baño completo para el gerente general y cerca de los vestidores de los vendedores de islas, se colocarán otros servicios higiénicos, uno de hombres y uno de mujeres, estos se encuentran exactamente arriba de los servicios del primer piso para ahorrar costos en instalaciones de tuberías y para aprovechar la fuerza de la caída de agua. El tamaño de los servicios varía en función del número de inodoros y lavamanos.

- Área de mini market: Se definió un área de $9 \times 6 \mathrm{~m}^{2}$. Si bien es cierto no existe un área estándar para el mini market, se consideró el espacio suficiente para que entren al menos dos góndolas y un espacio para la caja. Aparte de esta área, se construirá un cuarto que servirá como almacén del mini market, el cual será de $2,35 \times 3,25 \mathrm{~m}^{2}$.

- Área de farmacias: Se definió un área de 5,9 x 6,5 $\mathrm{m}^{2}$, el cual sería un espacio suficiente para que se coloquen dos estantes pequeños y un espacio de atención.

- Área de comida rápida: Este será el segundo espacio alquilado más grande y tendrá un área de 6,5 x 11,2 m². Se definió que la mitad del espacio sería suficiente para una cocina y mesa de preparación y en la otra mitad, podrían entrar cómodamente cuatro mesas para atención. No hay que soslayar que por razones de seguridad, se debe encontrar un poco distante de los tanques de combustible, especialmente del tanque de GLP.

- Área de cajeros: Esta área será de 2,35 x 2,55 m². Acá entrarán dos cajeros con sus respectivos espacios para los usuarios. Lo recomendable es que se encuentre cerca de la parte comercial.

- Área de lavado y engrase: Este espacio se definió tomando en cuenta las dimensiones de un ómnibus, pues estos también podrían formar parte de la clientela. El área será de $14 \times 12 \mathrm{~m}^{2}$. Se debe tomar en cuenta que en este espacio también se venderán lubricantes y se realizarán cambios de aceite; así mismo, en este lugar estará ubicado el servicio de llantas. Todos estos servicios deberán ser gestionados por un mismo inquilino. 
- Cuarto vigilancia: Tendrá por dimensiones 2,8 x 2,7 $\mathrm{m}^{2}$. Este cuarto podrá ser amueblado con un escritorio para colocar la computadora que monitoreará las cámaras de seguridad.

- Vestidores: Se contará con 2 vestidores; ya que, según el libro de Neufert, deben existir vestidores tanto para hombres como para mujeres. En este libro también se menciona que una persona necesita $0,5 \mathrm{~m}^{2}$ para cambiarse. Los cuartos para cambiarse en este proyecto serán de $1,2 \times 1,4 \mathrm{~m}^{2}$ para una mayor comodidad y el área total de los vestidores será de 4,4 x 2,8 m².

- Área de oficinas: Se construirá una oficina independiente para el gerente general de la empresa donde podrá recibir cómodamente a dos personas, este espacio será de 3,2 x 2,75 $\mathrm{m}^{2}$. Cerca de ese lugar, se deben encontrar las oficinas de los demás empleados administrativos para los cuales se ha designado un área de 5,8 x 4,4 $\mathrm{m}^{2}$, la cual permitirá además la colocación de un estante para almacenar documentos.

- Sala de reuniones: Se colocará una sala de reuniones de 3,15 x 4,4 m², en la cual, según se observará en el plano, podrá entrar una mesa de reuniones con 8 sillas y un espacio para poder proyectar.

\subsubsection{El ambiente del servicio}

El ambiente donde se llevará a cabo el servicio final es el área de surtidores, la cual está delimitada por el techo (canopy) que debe cubrir las cuatro islas (se construirá una isla por surtidor para mayor facilidad de tránsito).

Este ambiente debe ser construido según todas las especificaciones que se mencionan en el Decreto Supremo N ${ }^{\circ}$ 054-93-EM:

- Cada isla debe contar con un depósito de arena, depósito de trapos húmedos y un extintor.

- En zonas urbanas, el ancho de entrada será entre 6 y 8 metros y la salida entre 3,6 y 6 metros.

- Los ángulos en la entrada y la salida deben ser entre $30^{\circ}$ y $45^{\circ}$ medido desde el alineamiento del borde interior de la calzada. 
- El establecimiento deberá contar únicamente con una entrada y/o salida sobre la misma calle.

- Las estaciones eléctricas se encontrarán a una distancia mínima de 7,6 metros de los puntos de emanación de gases (surtidores y zona de descarga).

- Las cajas de interruptores deben tener una distancia mínima de 3 metros de los surtidores y de la zona de descarga.

- Debe existir un retiro mínimo de 3 metros entre la isla de despacho y el borde interior de la vereda. Esta distancia se medirá del borde más cercano de la isla del surtidor y/o dispensador hasta el borde interior de la vereda.

- Los surtidores y/o dispensadores deberán estar instalados en forma fija.

- Las máquinas que despachan combustibles deben estar debidamente identificadas según el combustible que expenden, indicándose si el combustible lleva aditivos, acorde a la normativa vigente.

- La altura mínima del techo de la isla de surtidores es 3,90 metros respecto al piso del patio de maniobras; sin embargo, para el presente proyecto se considerará un alto de 5 metros por motivos estéticos.

- Los radios de giro de las estaciones donde se abastecerán también vehículos de carga pesada, deben ser como mínimo de 14 metros.

A continuación, se detallan otras dimensiones:

- Tamaño de surtidores e islas: Los surtidores de combustible líquido cotizados por el proveedor tienen un ancho de 1,65 metros, altura de 2,20 metros y profundidad de 44 centímetros; mientras el surtidor de GLP posee las siguientes dimensiones: ancho de 60 centímetros, altura de 2 metros y profundidad de 44 centímetros. Las dimensiones de una isla que contiene solo un surtidor son: 3,62 metros de ancho y 1,2 metros de profundidad. (Neufert, 2013)

- Espacio entre islas continuas: La medición de esta variable se considera entre el límite final de una isla con el límite inicial de la otra. Según el libro Neufert: "El arte de proyectar en arquitectura", el valor de la variable debe ser de 4 metros. 


\subsection{Disposición de la instalación del servicio}

\subsubsection{Disposición general}

En base a la descripción detallada de las áreas de la sección 5.10.1 se procederá a realizar el análisis relacional de la estación de servicios para así definir la localización de las áreas con respecto a los demás.

Tabla 5.31

Lista de códigos según valor de proximidad

\begin{tabular}{c|c}
\hline Código & Valor de proximidad \\
\hline $\mathrm{A}$ & Absolutamente necesario \\
$\mathrm{E}$ & Especialmente necesario \\
$\mathrm{I}$ & Importante \\
$\mathrm{O}$ & Normal u ordinario \\
$\mathrm{U}$ & Sin importancia \\
$\mathrm{X}$ & No recomendable \\
$\mathrm{XX}$ & Altamente no recomendable \\
\hline
\end{tabular}

Elaboración propia

Tabla 5.32

Lista de razones o motivos

\begin{tabular}{c|c}
\hline $\mathbf{N}^{\circ}$ & Motivo \\
\hline 1 & Secuencia del proceso \\
2 & Reducción de costos en materiales de \\
instalación \\
3 & Control y mantenimiento de maquinaria \\
4 & Polvo, residuos, ruido \\
5 & Conveniencia \\
6 & Control de calidad \\
7 & Comodidad \\
\hline
\end{tabular}

Elaboración propia 
Tabla 5.33

Tabla relacional de actividades

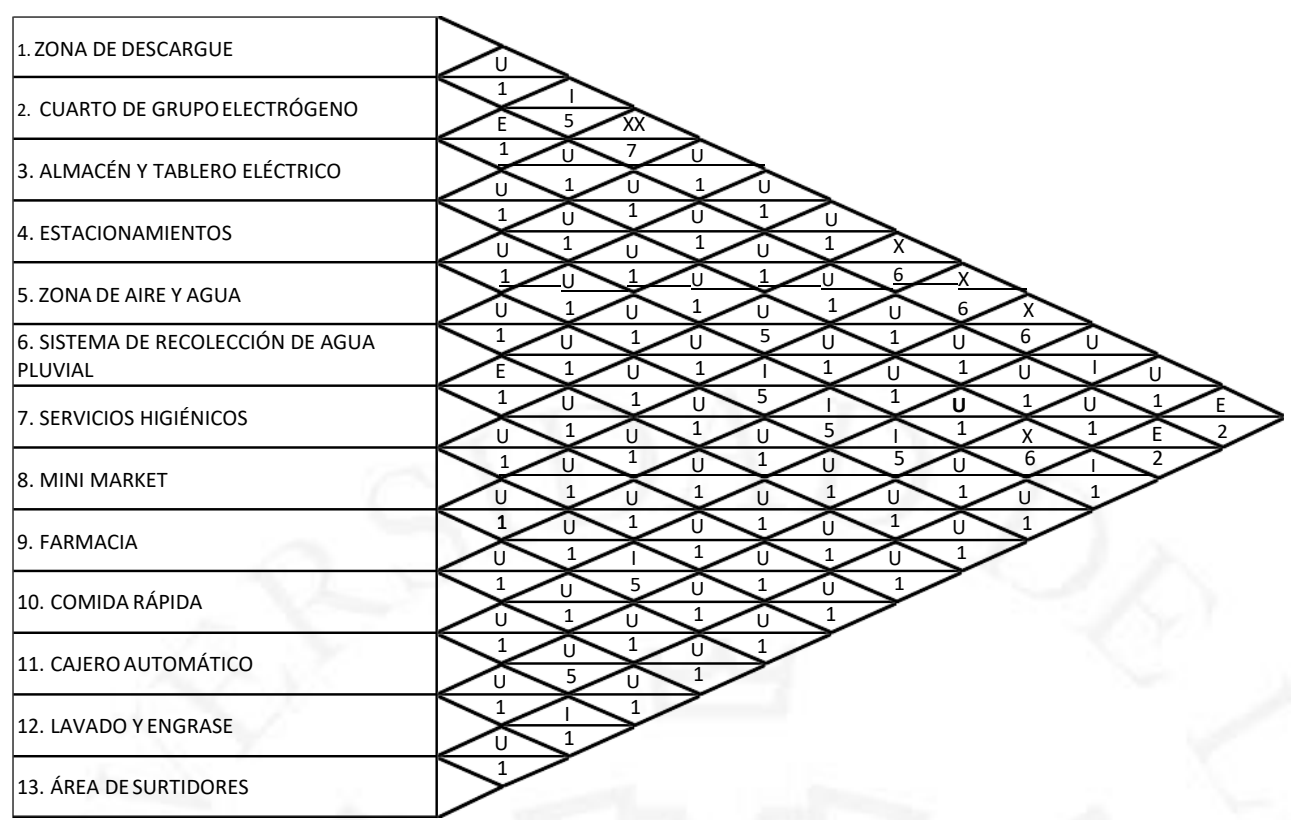

Elaboración propia 
Tabla 5.34

Tabla de símbolo de actividades

\begin{tabular}{|l|c|}
\hline \multicolumn{1}{|c|}{ Actividad } & Símbolo \\
\hline 1. Zona de descarga & 1 \\
\hline 2. Cuarto de grupo electrógeno & \\
\hline 3. Almacén y tablero electrónico & \\
\hline 4. Estacionamiento & \\
\hline 5. Zona de aire y agua & \\
\hline 6. Sistema de recolección de agua pluvial & \\
\hline 13. Área de surtidores & \\
\hline 10. Comida rápida & \\
\hline 11. Cajeros & \\
\hline 8. Mini market & \\
\hline
\end{tabular}

Elaboración propia 
Tabla 5.35

Agrupación de las actividades de acuerdo a sus valores de proximidad

\begin{tabular}{|c|c|c|c|}
\hline $\mathbf{E}$ & $\mathbf{I}$ & $\mathbf{X}$ & $\mathbf{X X}$ \\
\hline $2-3$ & $1-3$ & $1-8$ & $1-4$ \\
\hline $6-7$ & $11-13$ & $1-9$ & \\
\hline $2-13$ & $8-11$ & $1-10$ & \\
\hline $1-13$ & $4-10$ & $3-12$ & \\
\hline & $4-9$ & & \\
\hline & $4-11$ & & \\
\hline & $3-13$ & & \\
\hline
\end{tabular}

Elaboración propia

Tabla 5.36

Diagrama relacional de actividades

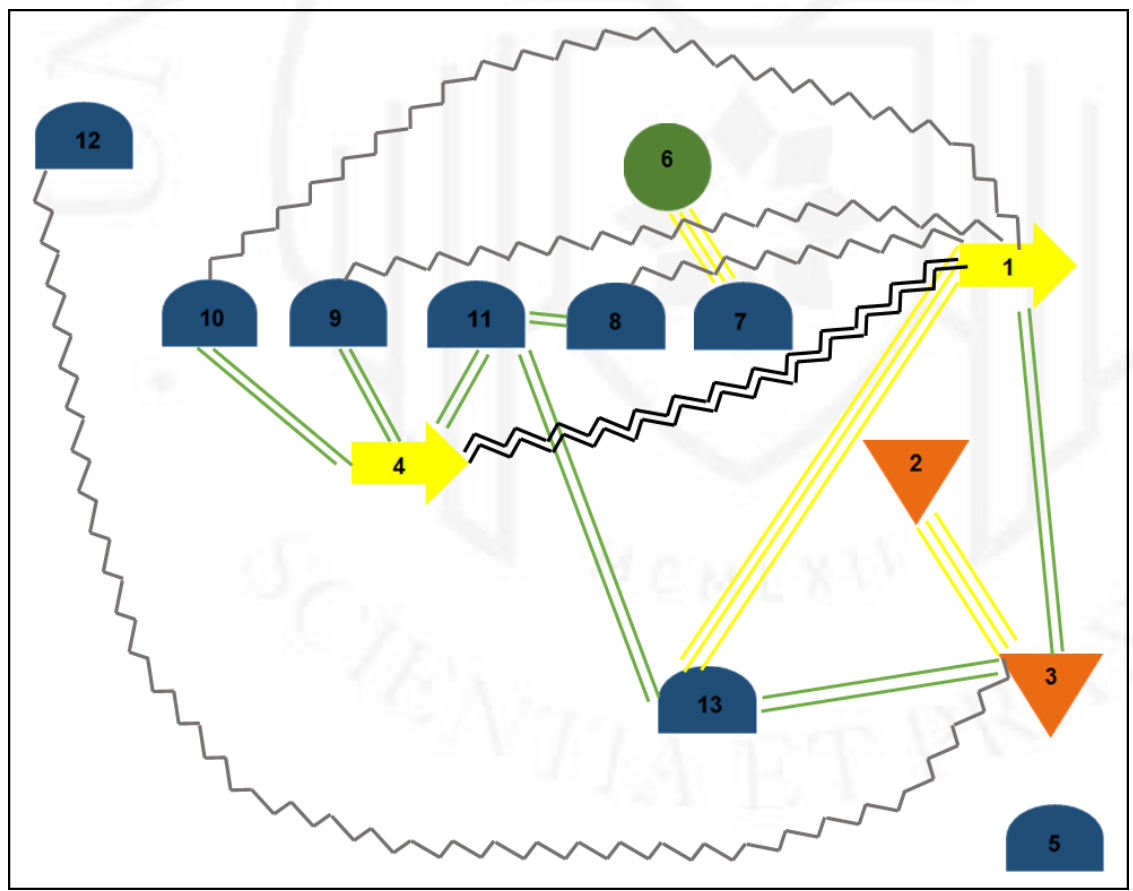

Elaboración propia

A continuación, se detalla la distribución óptima, según el análisis previo, para colocar las áreas antes descritas: 


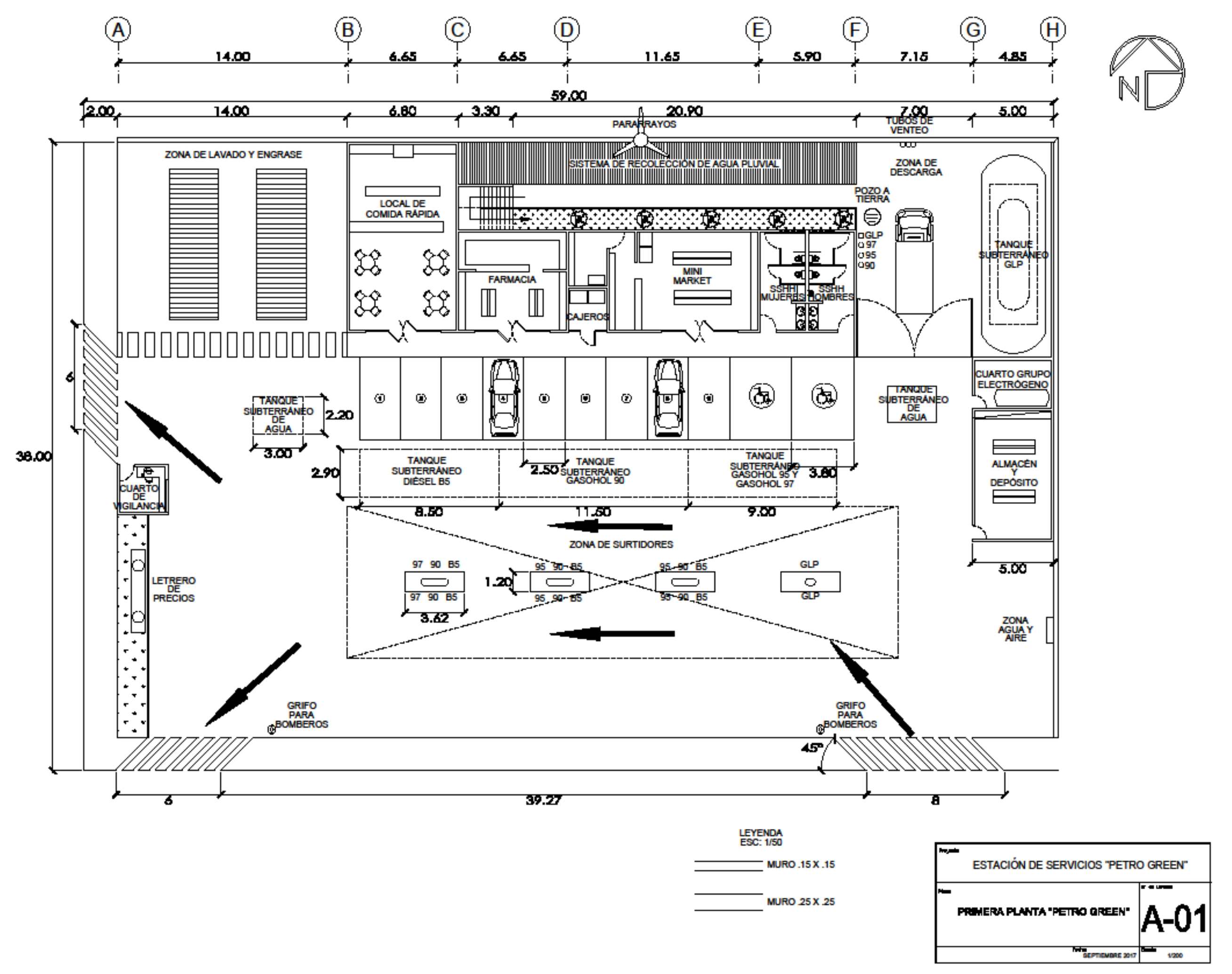




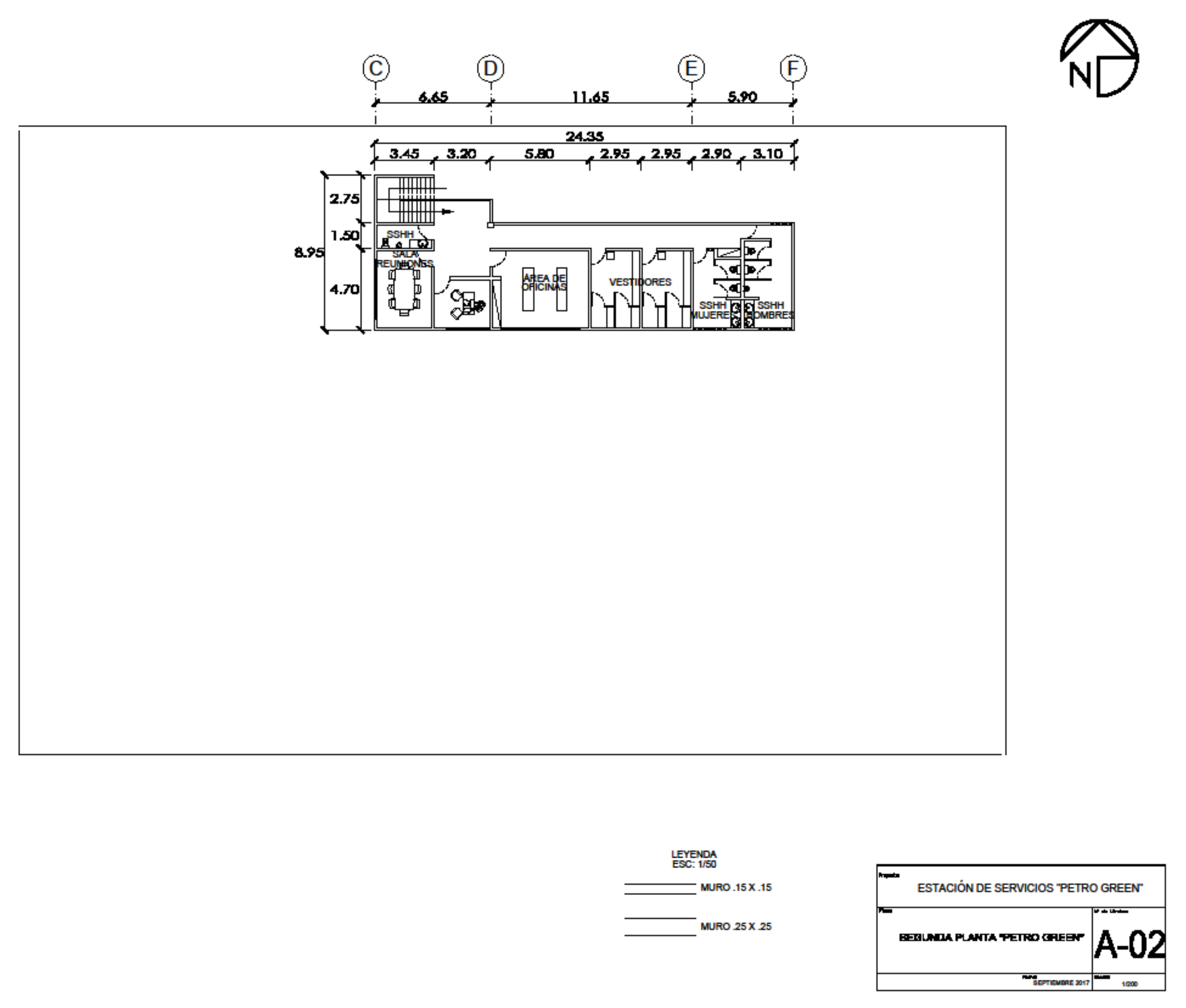


5.12.2. Disposición de detalle

En la disposición de detalle se mostrarán ciertas medidas del ambiente de surtidores para demostrar que el proyecto cumple con las distancias exigidas por el reglamento peruano:

- El ancho de entrada será de 8 metros y la salida de 6 metros.

- Los ángulos en la entrada y la salida son de $45^{\circ}$.

- Las estaciones eléctricas se encontrarán a una distancia mínima de 7,6 metros de los puntos de emanación de gases. En el presente proyecto la distancia de la zona de surtidores al tablero eléctrico es de 12,33 metros.

- Las cajas de interruptores deben tener una distancia mínima de 3 metros de la zona de descarga. En el presente proyecto esta medida es de 10,03 metros.

- Debe existir un retiro mínimo de 3 metros entre la isla de despacho y el borde interior de la vereda. En el proyecto esta distancia es de 8,8 metros.

- Los radios de giro de las estaciones donde se abastecerán también vehículos de carga pesada, deben ser como mínimo de 14 metros. En el plano que se muestra a continuación se encuentran trazados los radios de giro y se demuestra que la distribución cumple con este requerimiento.

Espacio entre islas continuas: La medición de esta variable se considera entre el límite final de una isla con el límite inicial de la otra. Según el libro Neufert: "El arte de proyectar en arquitectura", el valor de la variable debe ser de 4 metros. 


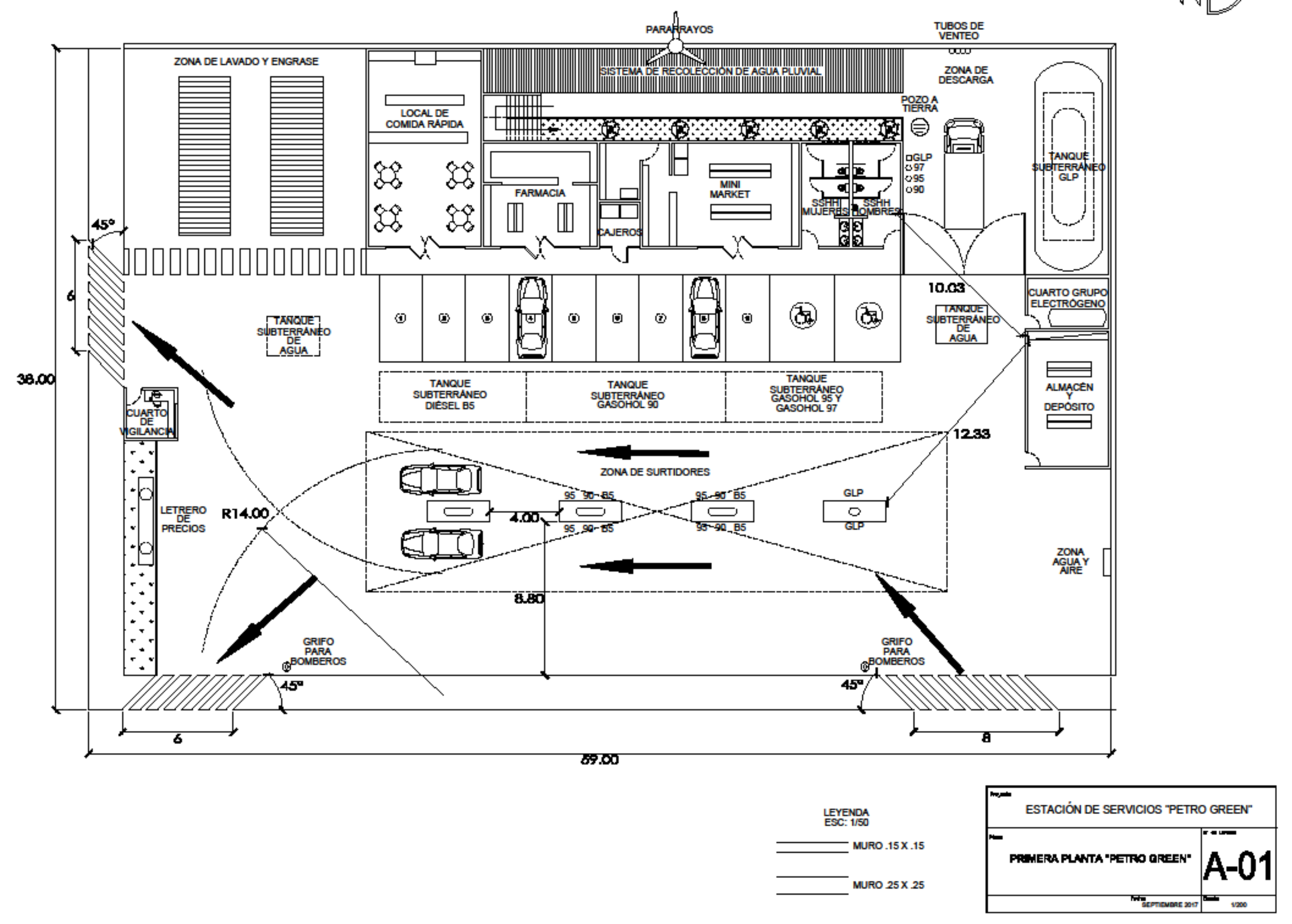




\subsection{Cronograma de implementación del proyecto}

Figura 5.14

Cronograma de implementación

\begin{tabular}{|c|c|c|c|c|c|c|c|c|c|c|c|c|}
\hline \multirow{2}{*}{$\begin{array}{l}\text { Cronograma de avance } \\
\text { Actividad }\end{array}$} & \multicolumn{4}{|c|}{ Cuatrimestre 1} & \multicolumn{4}{|c|}{ Cuatrimestre 2} & \multicolumn{4}{|c|}{ Cuatrimestre 3} \\
\hline & Enero & Febrero & Marzo & Abril & Mayo & Junio & Julio & Agosto & Septiembre & Octubre & Noviembre & Diciembre \\
\hline \multicolumn{13}{|l|}{ Busqueda del terreno } \\
\hline \multirow{2}{*}{\multicolumn{13}{|c|}{$\begin{array}{l}\text { Compra y documentación del terreno } \\
\text { Consolidación y ajuste del proyecto }\end{array}$}} \\
\hline & & & & & & & & & & & & \\
\hline \multicolumn{13}{|c|}{ Presentació y aprobación del proyecto } \\
\hline \multicolumn{13}{|c|}{ Acondicionamiento del terreno } \\
\hline \multicolumn{13}{|c|}{ Edificación de ambientes y pavimentación } \\
\hline \multicolumn{13}{|c|}{ Compra de maquinaria } \\
\hline \multicolumn{13}{|c|}{ Construcción de parte metälica } \\
\hline \multicolumn{13}{|c|}{ Instalación de los sistemas de luz y agua } \\
\hline \multicolumn{13}{|c|}{$\begin{array}{l}\text { Instalación de maquinaria } \\
\text { Trámite de convenio de abanderamiento }\end{array}$} \\
\hline \multicolumn{13}{|c|}{ Tramite del convenio de abanderamiento } \\
\hline \multicolumn{13}{|c|}{ Pintado General } \\
\hline \multicolumn{13}{|c|}{ Trámite de licencia de funcionamiento } \\
\hline \multicolumn{13}{|l|}{ Retoque de detalles } \\
\hline Puesta en marcha dellocal & & & & & & & & & & & & \\
\hline
\end{tabular}

Elaboración propia 


\section{CAPÍTULO VI: ORGANIZACIÓN ADMINISTRATIVA}

\subsection{Formación de la organización empresarial}

Uno de los puntos más importantes a definir para la formación de la organización empresarial es el tipo de empresa que se constituirá. Para el inicio del negocio se creará una persona jurídica del tipo S.A.C. (Sociedad Anónima Cerrada), esta modalidad se considera la más conveniente en este caso ya que permite independizar los bienes de la empresa de los bienes propios, permite tener más de un accionista y no precisa cumplir con tantos requerimientos legales como se exige a la persona jurídica S.A que generalmente es conveniente para empresas grandes. Esta última característica permitirá a la empresa ser más dinámica, pues no será obligada; por ejemplo, a conformar un Directorio.

Características:

- Es la alternativa ideal para empresas familiares.

- El número de accionistas no puede ser menor de dos y como máximo tendrá 20 accionistas.

- Se impone el derecho de adquisición preferente por los socios, salvo que el estatuto disponga lo contrario.

- Se constituye por los fundadores al momento de otorgarse la escritura pública que contiene el pacto social y el estatuto, en cuyo caso suscriben íntegramente las acciones.

- El Capital Social está representado por acciones nominativas y se conforma con los aportes (en bienes y/o en efectivo) de los socios, quienes no responden personalmente por las deudas sociales.

- Es una persona jurídica de Responsabilidad Limitada.

- No puede inscribir sus acciones en el Registro Público del Mercado de Valores.

- Predomina el elemento personal, dentro de un esquema de sociedad de capitales.

- Surge como reemplazo de la Sociedad Comercial de Responsabilidad Limitada S.R.L. que aún se mantiene.

- Obliga a la empresa a tener reservas legales. (Wapa Perú, 2017) 
Otro punto importante a considerar para la organización empresarial es la determinación de la visión y la misión de la empresa, pues esta será fundamental para establecer las directrices de las operaciones:

- Visión: Ser la empresa líder en abastecimiento de combustibles en la ciudad de Huancayo por la calidad de nuestros productos y la excelencia en el servicio al cliente.

- Misión: Proveer combustibles de calidad y una amplia opción de servicios en un solo lugar para facilitar la vida de nuestros clientes.

\subsection{Requerimientos de personal directivo, administrativo y de servicios; y funciones generales de los principales puestos}

El representante de la empresa ante las autoridades competentes será el gerente general, quien además se encargará de direccionar la estrategia de la empresa y tomar las decisiones principales; el gerente será apoyado por un asistente que se enfocará más en la parte comercial. Por otra parte, la estación de servicio contará con un administrador y con referencia a la parte operativa contará con 10 vendedores de isla.

Tabla 6.1

Puestos de trabajo

\begin{tabular}{l|c}
\hline \multicolumn{1}{c|}{ Puestos de trabajo } & Cantidad \\
\hline Gerente general & 1 \\
Asistente & 1 \\
Administrador & 1 \\
Vendedores de isla & 10 \\
\hline
\end{tabular}

Elaboración propia

Los requerimientos y funciones de cada puesto se detallan a continuación:

\section{Gerente general:}

Requerimientos:

- Titulado en Ingeniería Industrial o Administración.

- Cinco años de experiencia mínima en jefaturas de empresas del rubro.

- Estudios de post grado en gestión. 
Funciones:

- Representar legalmente a la empresa ante las autoridades locales.

- Supervisar y controlar todas las etapas del proyecto.

- Realizar benchmarking local para el crecimiento de la empresa.

- Garantizar el correcto funcionamiento del local.

- Negociar con proveedores y empresas clientes potenciales.

- Elaborar el presupuesto anual de toda la empresa.

- Realizar el plan estratégico de la empresa, definiendo los objetivos anuales.

- Revisar y aprobar proformas de venta a crédito.

- Evaluar a los postulantes para ocupar el puesto de asistente y administrador.

- Revisar procesos de mejora continua.

- Definir salarios de trabajadores y realizar pagos a trabajadores y servicios de outsourcing.

- Monitorear la labor del contador y recibir retroalimentación de los estados financieros para la toma de decisiones.

- Realizar el cobro de las ventas a crédito.

- Realizar el pago de impuestos.

- Realizar los pagos de salario a trabajadores.

\section{Asistente:}

Requerimientos:

- Titulado o bachiller en Ingeniería Industrial, Administración o Marketing.

- Dos años de experiencia mínima trabajando en áreas comerciales.

Funciones:

- Apoyar al gerente general a definir y actualizar la estrategia comercial de la empresa.

- Elaborar los planes de publicidad.

- Manejar la página web de la empresa y las redes sociales.

- Realizar capacitaciones a vendedores de isla en servicio al cliente.

- Revisar resultados de encuestas de servicio al cliente y accionar planes de acción para los puntos débiles. 
- Elaborar mecanismos de recompensa a trabajadores operativos que brinden un servicio de calidad.

- Realizar auditorías de atención al cliente en los servicios alquilados.

- Actualizar la lista de precios en la aplicación "Facilito".

- Revisar el mantenimiento de la infraestructura del lugar; por ejemplo, cerciorarse que los stickers con señalizaciones se encuentren en buen estado y si no fuera así, gestionar el cambio.

\section{Administrador:}

Requerimientos:

- Titulado en Ingeniería Industrial o Administración.

- Tres años de experiencia mínima en el área de logística o en el área de gestión en empresas del rubro.

Funciones:

- Supervisar las labores de los servicios de outsourcing de transportista, mantenimiento, perito de inspección ambiental, vigilancia y limpieza.

- Supervisar la labor del personal operativo.

- Realizar los pedidos de combustible.

- Supervisar la descarga de combustible en el grifo.

- Evaluar a los postulantes para ocupar los puestos operativos.

- Capacitar al personal en salud y seguridad ocupacional y en aspectos del cuidado del medio ambiente.

- Realizar control de limpieza de suelos.

- Elaborar proformas para venta a crédito.

- Recoger las quejas, reclamos y sugerencias de los clientes de la estación de servicio y compensarlos ante cualquier eventualidad.

- Monitoreo del sistema SCOP.

\section{Vendedor de isla:}

Requerimientos:

- Mayores de 18 años e idealmente menores de 44 años.

- Secundaria completa. 
Funciones:

- Abastecer combustible.

- Realizar cobro por combustible a clientes.

- Verificar líneas de crédito de empresas autorizadas.

- Solicitar a personas llenar encuestas de evaluación del servicio.

- Pasar tarjeta de acumulación de puntos para promociones de los clientes y realizar el canje según sea el caso.

\subsection{Esquema de la estructura organizacional}

La estructura organizacional será en un principio bastante simple y se irá modificando de acuerdo a los requerimientos de las diferentes áreas y del crecimiento de la estación de servicio; sobre todo en caso se decidiera abrir otro grifo "PetroGreen" y convertirlo en cadena. La estructura inicial se muestra a continuación:

\section{Figura 6.1}

Organigrama de la empresa

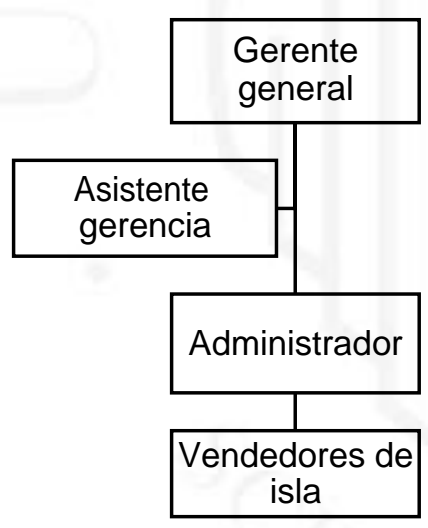

Elaboración propia 


\section{CAPÍTULO VII. PRESUPUESTOS Y EVALUACIÓN DEL PROYECTO}

Considerar que todos los montos incluidos en este capítulo, no incluyen IGV.

\subsection{Inversiones}

A continuación, se muestra el cuadro de resumen de la inversión:

Tabla 7.1

Cuadro de resumen de inversión

\begin{tabular}{l|l}
\hline \multicolumn{1}{c|}{ Concepto } & \multicolumn{1}{c}{ Monto (soles) } \\
\hline Activo fijo tangible & 5.236 .219 \\
Activo fijo intangible & 67.916 \\
Gastos pre operativos & 282.923 \\
Capital de trabajo & 408.903 \\
Inversión total & $\mathbf{5 . 9 9 5 . 9 6 1}$ \\
\hline
\end{tabular}

Elaboración propia

\subsubsection{Estimación de las inversiones de largo plazo}

Primero se muestran todos los cálculos relacionados al activo tangible, comenzando por un cuadro resumen:

Tabla 7.2

Cuadro resumen de inversión en activo tangible

\begin{tabular}{l|l}
\hline Concepto & Monto (soles) \\
\hline Equipo, maquinarias e implementos & 303.547 \\
Equipos de oficina & 4.686 \\
Terreno & 4.387 .500 \\
Construcción e instalaciones generales & 540.486 \\
Inversión total a. fijo tan. & $\mathbf{5 . 2 3 6 . 2 1 9}$ \\
\hline
\end{tabular}

Elaboración propia

Con respecto al costo del terreno, los detalles fueron mencionados en el Capítulo 3 de localización de servicio. 


\section{Tabla 7.3}

Detalle de equipo, maquinarias e implementos

\begin{tabular}{|c|c|c|}
\hline Concepto & Monto (soles) & Cantidad \\
\hline Extintores y equipos contra incendios & 6.593 & Según Tabla 5.11 \\
\hline Hidrantes e instalación & 3.644 & 2 unidades \\
\hline $\begin{array}{l}\text { Surtidores e instalación (incluye instalación todo } \\
\text { sistema) }\end{array}$ & 81.983 & 3 líquidos y 1 de GLP \\
\hline Tanques combustible líquido & 40.720 & 3 unidades \\
\hline Tanque GLP & 57.500 & 1 unidad \\
\hline Bombas para tanque de agua & 1.653 & 3 unidades \\
\hline Bombas combustible líquido & 12.712 & 3 unidades \\
\hline Bomba GLP & 14.407 & 1 unidad \\
\hline Válvulas de seguridad GLP & 358 & 4 unidades \\
\hline Compresora & 11.017 & 1 unidad \\
\hline Sistema de detección de fugas e instalación & 11.706 & 6 sensores y 1 alarma \\
\hline Grupo electrógeno & 33.051 & 1 unidad \\
\hline Tablero de transferencia & 5.508 & 1 unidad \\
\hline Medidor de luz e instalación & 3.000 & 5 unidades \\
\hline Medidor de agua e instalación & 2.000 & 5 unidades \\
\hline Tubos de venteo e instalación & 475 & 2 unidades \\
\hline Trampa de grasa e instalación & 1.271 & 1 unidad \\
\hline Pararrayo e instalación & 11.017 & 1 unidad \\
\hline Serafin & 1.695 & 1 unidad \\
\hline Tótem & 0 & (Convenio Petro Perú) \\
\hline Computadora vigilante & 864 & 1 unidad \\
\hline Kit de 8 cámaras de seguridad DVR 500 GB & 2.373 & 1 unidad \\
\hline Total equipo, maquinarias e implementos & 303.547 & \\
\hline
\end{tabular}

Nota: Costos de instalación de equipos, incluyen transportes a la estación de servicios.

Elaboración propia

Tabla 7.4

Detalle de equipos de oficina

\begin{tabular}{l|ll}
\hline Concepto & \multicolumn{1}{|c}{ Monto (soles) } & Cantidad \\
\hline Muebles y sillas & 932 & 3 juegos \\
Estantes y otros & 1.161 & 4 juegos \\
Computadores e impresoras & 2.593 & 4 juegos \\
Total equipos de oficina & $\mathbf{4 . 6 8 6}$ & \\
\hline
\end{tabular}

Elaboración propia 


\section{Tabla 7.5}

Detalle de construcción e instalaciones generales

\begin{tabular}{|c|c|c|}
\hline Concepto & Monto (soles) & Detalle \\
\hline Acondicionamiento de terreno & 42.373 & \\
\hline Pavimentación & 60.805 & \\
\hline Construcción de locales & 297.900 & Área construida $735 \mathrm{~m}^{2}$ \\
\hline $\begin{array}{l}\text { Construcción sistema de recolección agua } \\
\text { pluvial }\end{array}$ & 8.305 & \\
\hline Construcción pozo a tierra & 847 & \\
\hline Construcción cerco de seguridad GLP & 3.390 & \\
\hline Construcción del techo metálico & 89.695 & \\
\hline Construcción de tanques de agua & 10.169 & 2 tanques de agua \\
\hline Pintado general & 0 & (Convenio Petro Perú) \\
\hline Señalización local & 0 & (Convenio Petro Perú) \\
\hline Instalación sistema eléctrico & 16.627 & \\
\hline Instalación sistema de agua y desagüe & 8.475 & \\
\hline Instalación sistema de mangueras aire y agua & 1.695 & \\
\hline Plantado áreas verdes & 205 & Área $24,2 \mathrm{~m}^{2}$ \\
\hline Total construcción e instalaciones generales & 540.486 & \\
\hline
\end{tabular}

Elaboración propia

A continuación, se muestra el cálculo del activo intangible:

Tabla 7.6

Activo intangible

\begin{tabular}{l|r}
\hline \multicolumn{1}{c|}{ Concepto } & Monto (soles) \\
\hline Proyecto de grifo & $22.033,90$ \\
Convenio abanderamiento Petro Perú & 0 \\
Licencia municipalidad & $1.271,19$ \\
Permiso OSINERGMIN & 0 \\
Inscripción como empresa & $1.271,19$ \\
ERP e instalación & $28.254,58$ \\
Sistema telemedición e instalación & $14.830,51$ \\
Instalaciones POS, teléfono e internet & 254,24 \\
Total activo intangible & $\mathbf{6 7 . 9 1 5 , 5 9}$ \\
\hline
\end{tabular}

Elaboración propia

El monto de proyecto grifo consiste en el pago al ingeniero a cargo del proyecto por la elaboración, autorización y firma del detalle técnico de todas las instalaciones del sistema eléctrico, de agua y desagüe, de mangueras y aire y de la obra en general.

Por otro lado, el costo de registrarse como parte de la cadena Petrored es de 0 soles, puesto que no involucra ningún pago inicial ni mensual por parte del afiliado (tal cual se estipula en el modelo de convenio antes mostrado en el capítulo 2.1.2.1.). Por el 
contrario, Petroperú cubre algunos gastos de la estación de servicios para representarlo como estación Petrored. El monto de ahorro es de 79.513,8 soles y el detalle se plasma en las siguientes tablas: 
Tabla 7.7

Costos de transporte

\begin{tabular}{|c|c|c|c|c|c|c|}
\hline ITEM & DESCRIPCIÓN & UND. & CANT. & P.U.S/. & PARCIA LS/. & SUB TOTALS/. \\
\hline 1,00 & TRANSPORTE & & & & & $1.500,00$ \\
\hline 1,01 & Transporte de materiales, herramientas, equipos y bienes publicitarios, durante ejecución del & UND & 1,00 & $1.500,00$ & $1.500,00$ & \\
\hline
\end{tabular}

Fuente: Petroperú (2018).

\section{Tabla 7.8}

Costos de pintura y gráficas - Parte 1

\begin{tabular}{|c|c|c|c|c|c|c|}
\hline ITEM & DESCRIPCIÓN & \multicolumn{2}{|c|}{ UND. CANT. } & P.U.S/. & PARCIALS/. & SUB TOTALS/. \\
\hline 1,00 & $\begin{array}{l}\text { PINTURA Y GRAFICAS EN EDIFICACION PRINCIPAL CERCOS PERIMETRICOS Y PATIO D } \\
\text { REVOQUE Y PINTURA EN MUROS Y CIELOS RASOS }\end{array}$ & E MAN & OBRAS & & & $5.664,54$ \\
\hline 1,01 & Imprimante en muros, parapetos, columnas y otros con imprimante para muros (E.P.S. & M2 & 78,00 & 7,80 & 608,40 & \\
\hline 1,02 & Pintura en muros, parapetos, columnas y otros con esmalte sintético (E.P.S. $=3.00$ mils) & M2 & 378,00 & 8,00 & $3.024,00$ & \\
\hline 1,03 & Pintura en zócalos de muros, parapetos, columnas y otros con esmalte sintético (E.P.S. = 3.00 mils) & M2 & 45,80 & 5,00 & 229,00 & \\
\hline 1,04 & Pintura en frisos de muros, parapetos, columnas y otros con esmalte sintético (E.P.S. & M2 & 22,60 & 8,00 & 180,80 & \\
\hline 1,05 & $\begin{array}{l}\text { Suministro de pack de pinturas para retoques } \\
\text { ROTULADOS }\end{array}$ & UND & 1,00 & 250,00 & 250,00 & \\
\hline 1,06 & $\begin{array}{l}\text { Rotulados }-\mathrm{L}=\text { de } 4.10 \text { hasta } 8.00 \mathrm{~m} \text { y } \mathrm{h}=\text { variable } \\
\text { ELEMENTOS VARIOS }\end{array}$ & UND & 1,00 & 310,00 & 310,00 & \\
\hline 1,07 & Pintura en elementos de concreto y/o similares con esmalte sintético (E.P.S. $=3.00$ mils) & M2 & 1,00 & 8,00 & 8,00 & \\
\hline 1,08 & Pintura en elementos de concreto y/o similares con pintura para tráfico (E.P.S. $=6.00$ mils) & M2 & 48,40 & 8,50 & 411,40 & \\
\hline 1,09 & Pintura en elementos metálicos y/o similares con esmalte sintético y anticorrosivo standard & M2 & 23,75 & 11,25 & 267,19 & \\
\hline 1,10 & Pintura en tapas metálicas de zona de descarga con esmalte epóxico y anticorrosivo epóxico & M2 & 20,46 & 12,50 & 255,75 & \\
\hline 1,11 & Rotulado de $0.20 \mathrm{~m}$ x $0.20 \mathrm{~m}$ en tapas metálicas de zona de descarga con esmalte sintético & UND & 12,00 & 10,00 & 120,00 & \\
\hline 2,00 & PINTURA Y GRÁFICAS EN CANOPYS & & & & & $\mathbf{2 . 4 7 7 , 5 5}$ \\
\hline 2,01 & $\begin{array}{l}\text { Aplicación de anticorrosivo standard a columnas metálicas de canopy (E.P.S. = } \\
1.00 \text { mil) }\end{array}$ & M2 & 33,60 & 10,00 & 336,00 & \\
\hline 2,02 & Pintura en friso de canopy con esmalte sintético (E.P.S. = 3.0 mils) & M2 & 84,00 & 10,50 & 882,00 & \\
\hline 2,03 & Logotipo e Isotipo principal y otros rotulados de vinil opaco $-\mathrm{L}=$ hasta $5.50 \mathrm{~m}$ y $\mathrm{h}=$ hasta $0.90 \mathrm{~m}$ & UND & 3,00 & 300,00 & 900,00 & \\
\hline 2,04 & Pintura en columnas de canopy con esmalte sintético (E.P.S. = 3.0 mils) & M2 & 33,60 & 9,50 & 319,20 & \\
\hline 2,05 & Pintura en zócalos de columnas de canopy con esmalte sintético (E.P.S. $=3.0$ mils) & M2 & 4,48 & 9,00 & 40,35 & \\
\hline
\end{tabular}

Fuente: Petroperú (2018) 


\section{Tabla 7.9}

Costos de pintura y gráficas - Parte 2

\begin{tabular}{|c|c|c|c|c|c|c|}
\hline ITEM & DESCRIPCIÓN & UND. & CANT. & P.U.S/. & PARCIALS/. & SUB TOTALS/. \\
\hline 3,00 & $\begin{array}{l}\text { PINTURA Y GRÁFICAS EN SURTIDORES Y DISPENSADORES } \\
\text { PINTURA }\end{array}$ & & & & & $2.957,43$ \\
\hline 3,01 & Pintura en friso de surtidor con esmalte sintético y anticorrosivo standard (E.P.S. & M2 & 3,00 & 9,00 & 27,00 & \\
\hline 3,02 & Limpieza y desengrasado de caras galvanizadas de surtidor con limpiador multipropósito & M2 & 9,60 & 3,50 & 33,60 & \\
\hline 3,03 & Pintura en tableros de pistolas de descarga de surtidor con esmalte sintético (E.P.S. $=3.00$ mils) & M2 & 3,84 & 7,50 & 28,80 & \\
\hline 3,04 & Pintura en superficies varias de surtidor con esmalte sintético (E.P.S. $=3.00$ mils) - & M2 & 0,00 & 0,00 & 0,00 & \\
\hline 3,05 & Pintura en superficies varias de dispensador de GLP con acrilico y laca acrilica & M2 & 0,00 & 0,00 & 0,00 & \\
\hline 3,06 & $\begin{array}{l}\text { Pintura en bases metálicas de surtidores con esmalte sintético y anticorrosivo standard } \\
\text { GRAFICAS }\end{array}$ & M2 & 0,90 & 8,25 & 7,43 & \\
\hline 3,07 & Logotipo e Isotipo principal de vinil opaco $-\mathrm{L}=$ hasta $1.20 \mathrm{~m}$ y h= hasta $0.10 \mathrm{~m}$ & UND & 10,00 & 50,00 & 500,00 & \\
\hline 3,08 & Gráficas para cubiertas de surtidores o dispensadores - Área de $1.10 \mathrm{~m} 2$ aprox. & UND & 10,00 & 160,60 & $1.606,00$ & \\
\hline 3,09 & Grafica circular de cubierta de dispensadore GLP $\square=0.40 \mathrm{~m}$ & UND & 10,00 & 32,10 & 321,00 & \\
\hline 3,10 & Grafica rectangular de productos para surtidores o dispensadores $-\mathrm{L}=36.00 \mathrm{~cm}$ y $\mathrm{h}=6.00 \mathrm{~cm}$ & UND & 16,00 & 11,35 & 181,60 & \\
\hline 3,11 & Grafica circular de productos para columnas de canopy $-\square=0.30 \mathrm{~m}$ & UND & 16,00 & 15,75 & 252,00 & \\
\hline 4,00 & PINTURA EN ZONA DE ALMACENAMIENTO DE GLP & & & & & 518,91 \\
\hline 4,01 & Pintura en cerca metálica de zona de almacenamiento de GLP con esmalte sintético y & M2 & 43,43 & 8,50 & 369,16 & \\
\hline 4,02 & Pintura en tuberías internas de zona de almacenamiento de GLP con esmalte sintético y & M2 & 2,00 & 8,25 & 16,50 & \\
\hline 4,03 & Pintura en sardinel base de cerco metálico de zona de almacenamiento de GLP con & M2 & 9,05 & 9,00 & 81,45 & \\
\hline 4,04 & Pintura en defensas metálicas de zona de almacenamiento de GLPcon esmalte sintético y base & M2 & 5,60 & 9,25 & 51,80 & \\
\hline 5,00 & PINTURA PARA SEÑALIZACIÓN EN ISLAS DE SURTIDORES Y PATIO DE MANIOBRAS & & & & & $1.850,05$ \\
\hline 5,01 & Pintado de flechas direccionales, de entrada y de salida en patio de maniobras con & UND & 12,00 & 20,00 & 240,00 & \\
\hline 5,02 & Pintado de pasos de cebra inclinados en patio de maniobras con pintura para tráfico (E.P.S. $=6.00$ & M2 & 54,90 & 9,50 & 521,55 & \\
\hline 5,03 & Pintado de áreas de estacionamiento en islas de surtidores con pintura para tráfico (E.P.S. $=6.00$ & UND & 8,00 & 16,50 & 132,00 & \\
\hline 5,04 & Pintado de rotulos lineas circulos flechas indicando el recorrido de la tuberia de GLP Y otros con & M2 & 5,00 & 9,50 & 47,50 & \\
\hline 5,05 & Pintura en sardineles ingreso y salida $45 \mathrm{ml}$ x 0.30 y veredas en market y edificacion $22 \mathrm{x}$ & M2 & 101,00 & 9,00 & 909,00 & \\
\hline
\end{tabular}

Fuente: Petroperú (2018) 
Tabla 7.10

Costos instalaciones eléctricas

\begin{tabular}{|c|c|c|c|c|c|}
\hline ITEM & DESCRIPCIÓN & CANT & P.U.S/. & PARCIALS/. & SUB TOTALS/. \\
\hline 1,00 & SUB TABLERO ELECTRICO & & & & $1.104,24$ \\
\hline 1,01 & Sub Tablero Eléctrico & UND 1,00 & 550,00 & 550,00 & \\
\hline 1,02 & Interruptor Termomagnético C 63A, 2P, 10kA & UND 1,00 & 56,88 & 56,88 & \\
\hline 1,03 & Interruptor Termomagnético C 40A, 2P, 10kA e Interruptor Diferencial de 40A, 2P, 30mA & UND 1,00 & 156,38 & 156,38 & \\
\hline 1,04 & Interruptor Termomagnético C 20A, 2P, 10kA e Interruptor Diferencial de $25 \mathrm{~A}, 2 \mathrm{P}, 30 \mathrm{~mA}$ & UND 2,00 & 143,34 & 286,68 & \\
\hline 1,05 & Conexión entre tablero eléctrico principal existente y sub tablero eléctrico & UND 1,00 & 54,30 & 54,30 & \\
\hline 2,00 & ALIMENTACIÓN ELÉCTRICA PARA BIENES PUBLICITARIOS INSTALACIONES & SUPERFICIE & & & $3.006,00$ \\
\hline 2,01 & Conducto metálico rígido (RMC) de $\square=1$ " & ML 46,50 & 33,50 & 1557,75 & \\
\hline 2,02 & Conducto metálico rígido (RMC) de $\square=3 / 4$ " & ML 25,50 & 21,50 & 548,25 & \\
\hline 2,03 & Conducto metálico flexible con forro de PVC de $\square=1$ " & ML 3,00 & 33,50 & 100,50 & \\
\hline 2,04 & Conducto metálico flexible con forro de PVC de $\square=3 / 4$ ", & ML 4,00 & 21,50 & 86,00 & \\
\hline 2,05 & Cable TTRF-70 2x6mm2 + Cable CPT 2.5mm2 & ML 46,50 & 11,50 & 534,75 & \\
\hline 2,07 & Cable TTRF-70 2x2.5mm2 + Cable CPT 2.5mm2 & ML 27,50 & 6,50 & 178,75 & \\
\hline 3,00 & PUESTA A TIERRA & & & & $1.230,00$ \\
\hline 3,01 & Pozo de Puesta a Tierra Vertical & UND 1,00 & 1200,00 & 1200,00 & \\
\hline 3,02 & Conexión de estructura de bienes publicitarios y/o sub tablero a tierra & UND 1,00 & 30,00 & 30,00 & \\
\hline 4,00 & PRUEBAS ELÉCTRICAS & & & & 250,00 \\
\hline 4,01 & Pruebas Eléctricas & UND 1,00 & 250.00 & 250,00 & \\
\hline
\end{tabular}

Fuente: Petroperú (2018) 
Tabla 7.11

Costos de fabricación e instalación de bienes publicitarios

\begin{tabular}{|c|c|c|c|c|c|c|}
\hline ITEM & DESCRIPCIÓN & UND & CANT. & P.U.S/. & PARCI ALS/. & SUB TOTALS/. \\
\hline 1,00 & TOTEM & & 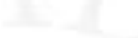 & & & $19,650.00$ \\
\hline 1,02 & Tótem $2.60 \mathrm{~m} \mathrm{x} \mathrm{7.00m} \mathrm{(ver} \mathrm{planos} \mathrm{y} \mathrm{Anexo} \mathrm{I)}$ & UND & 1,00 & $19.650,00$ & $19,650.00$ & \\
\hline 2,00 & LOGOTIPO E ISOTIPO LUMINOSO EN ALTO RELIEVE & & & & & $6.900,00$ \\
\hline 2,01 & Logotipo Luminoso LED $4.50 \mathrm{~m}$ x $0.34 \mathrm{~m} \times 0.10 \mathrm{~m}$ (ver planos y Anexo VII) & UND & 2,00 & $3.450,00$ & $6.900,00$ & \\
\hline 3,00 & BANDEROLA LUMINOSA & & & & & $4.800,00$ \\
\hline 3,01 & Banderola Luminosa $1.55 \mathrm{~m}$ x $0.50 \mathrm{~m}$ x $0.20 \mathrm{~m}$ (ver planos y Anexo IV) & UND & 4,00 & $1.200,00$ & $4.800,00$ & \\
\hline 4,00 & LETRERO LUMINOSO MARKET & & & & & $1.000,00$ \\
\hline 4,01 & Letrero Luminoso $1.50 \mathrm{~m} \times 0.34 \mathrm{~m} \times 0.10 \mathrm{~m}$ & UND & 1,00 & $1.000,00$ & $1.000,00$ & \\
\hline 5,00 & FLECHA REFLECTIVA & & & & & $2.460,00$ \\
\hline 5,01 & Flecha Reflectiva $0.70 \mathrm{~m} \times 1.10 \mathrm{~m}$ x $0.18 \mathrm{~m}$ (ver planos y Anexo VI) & UND & 3,00 & 820,00 & $2.460,00$ & \\
\hline 6,00 & DEPÓSITO & & & & & $1.440,00$ \\
\hline 6,01 & Depósito para Papeles (ver planos) & UND & 4,00 & 200,00 & 800,00 & \\
\hline 6,02 & Depósito para Arena y Trapos Húmedos (ver planos) & UND & 4,00 & 160,00 & 640,00 & \\
\hline 7,00 & SEÑALETICA & & & & & $3.810,00$ \\
\hline 7,01 & Letrero de $0.30 \mathrm{~m} \times 0.30 \mathrm{~m}$ & UND & 12,00 & 45,00 & 540,00 & \\
\hline 7,02 & Letrero de $0.35 \mathrm{~m} \times 0.12 \mathrm{~m}$ & UND & 1,00 & 10,00 & 10,00 & \\
\hline 7,03 & Letrero de $0.20 \mathrm{~m} \times 0.30 \mathrm{~m}$ & UND & 2,00 & 15,00 & 30,00 & \\
\hline 7,04 & Letrero de $0.28 \mathrm{~m} \times 0.70 \mathrm{~m}$ para islas de surtidores de combustibles líquidos & UND & 8,00 & 60,00 & 480,00 & \\
\hline 7,05 & Letrero de $1.20 \mathrm{~m} \times 0.75 \mathrm{~m}$ & UND & 11,00 & 250,00 & $2.750,00$ & \\
\hline
\end{tabular}

Fuente: Petroperú (2018)

Tabla 7.12

Costos seguridad y salud

\begin{tabular}{|c|c|c|c|c|c|c|}
\hline ITEM & DESCRIPCIÓN & UND & CANT. & $\begin{array}{l}\text { P.U.S/. } \\
\end{array}$ & PARCIA LS/. & SUB TOTALS/. \\
\hline 1,00 & SEGURIDAD Y SALUD & & & & & 640,00 \\
\hline 1,01 & Equipos de Protección Individual & UND & 4,00 & 80,00 & 320,00 & \\
\hline 1,02 & Equipos de Protección Colectiva & GLB & 1,00 & 170.00 & 170,00 & \\
\hline 1,03 & Señalización Temporal de Seguridad & GLB & 1,00 & 150.00 & 150,00 & \\
\hline
\end{tabular}

Fuente: Petroperú (2018) 
Finalmente se muestra el cálculo de los gastos pre operativos, los cuales forman parte también de la inversión:

Tabla 7.13

Gastos pre operativos

\begin{tabular}{l|r}
\hline \multicolumn{1}{c|}{ Concepto } & \multicolumn{1}{c}{ Monto (soles) } \\
\hline Intereses pre operativos & $277.160,64$ \\
Gasto de mantenimiento (mortalidad infantil) & $1.525,42$ \\
Gastos contingencias & $4.237,29$ \\
Total gastos pre operativos & $\mathbf{2 8 2 . 9 2 3 , 3 5}$ \\
\hline
\end{tabular}

Elaboración propia

El detalle del cálculo de los intereses pre operativos se podrá revisar en el acápite 7.4.1 Presupuesto del servicio a la deuda.

\subsubsection{Estimación de las inversiones de corto plazo}

El total de gastos iniciales comprende los gastos en compra de combustible (incluido el flete) y los que se detalla en el cuadro de "Otros costos iniciales de operación"; sin embargo, el monto del capital de trabajo del presente proyecto solo representa el gasto en compra de combustible y flete para la primera semana, el cual asciende a la suma de S/. $408.902,89$.

El motivo es que como resultado de la venta de la primera semana se obtendrá un ingreso en efectivo de S/443.190,92, ya que en la estación de servicios en los primeros meses solo se manejará venta al contado que es el formato tradicional. Este ingreso será suficiente para realizar la compra de combustible de la siguiente semana e incluso se obtendrá una utilidad bruta semanal en efectivo de S/34.288,03 que en un mes ascenderá a S/137.152,11, con lo cual se podrán pagar a fin de mes los "Otros costos iniciales de operación".

Cabe resaltar que si bien es cierto no se contará con venta al crédito los primeros meses, sí se contará con la modalidad de pago vía tarjeta de crédito o débito y el monto de capital de trabajo propuesto soportaría una venta de hasta $\mathrm{S} / 95.000,00$ soles mensuales con estas modalidades de pago (este monto está por encima del promedio de venta en Huancayo vía tarjeta de crédito o débito en un negocio de este tipo). 
Tabla 7.14

Cálculo de capital de trabajo

\begin{tabular}{l|ll}
\hline \multicolumn{1}{c|}{ Concepto } & \multicolumn{1}{c}{ Monto (soles) } & \multicolumn{1}{c}{ Tiempo } \\
\hline Gastos en combustible primera semana & $393.172,87$ & 1 semana \\
Flete combustible líquido & $15.730,02$ & 1 semana \\
Total & $\mathbf{4 0 8 . 9 0 2 , 8 9}$ & \\
\hline
\end{tabular}

Elaboración propia

Tabla 7.15

Otros costos iniciales de operación

\begin{tabular}{l|rl}
\hline \multicolumn{1}{c|}{ Concepto } & Monto (soles) & Tiempo \\
\hline Remuneración vendedores de isla & $17.426,67$ & $1 \mathrm{mes}$ \\
Remuneración administrativo & $18.152,78$ & $1 \mathrm{mes}$ \\
Servicio de vigilancia y limpieza & $6.016,95$ & $1 \mathrm{mes}$ \\
Servicio de luz & $1.124,31$ & $1 \mathrm{mes}$ \\
Servicio de agua & 76,27 & $1 \mathrm{mes}$ \\
Servicio telefónico & 136,75 & $1 \mathrm{mes}$ \\
Servicio de internet & 85,47 & $1 \mathrm{mes}$ \\
Alquiler POS (3 VISA y 1 Mastercard) & 51,28 & $1 \mathrm{mes}$ \\
Materiales atención, oficina y limpieza & $1.231,51$ & 1 mes \\
Seguro & $1.271,19$ & 1 mes \\
Uniforme vendedores de isla & 0 & (Convenio Petro \\
& \multicolumn{2}{|c}{ Perú) } \\
Gasto de promoción & 0 & Perú) \\
Total capital de trabajo & $\mathbf{4 5 . 5 7 3 , 1 8}$ & \\
\hline
\end{tabular}

Elaboración propia 


\subsection{Costos de las operaciones del servicio}

\subsubsection{Costos de materiales del servicio}

Primero, se mostrarán los cálculos del costo del insumo principal del proyecto, los combustibles:

Tabla 7.16

Costo de combustibles (en soles)

\begin{tabular}{|c|c|c|c|c|c|}
\hline Combustible & 2019 & 2020 & 2021 & 2022 & 2023 \\
\hline Diesel B5 & $4.983 .187,05$ & $5.238 .343,07$ & $5.549 .510,71$ & $5.885 .180,23$ & $6.235 .570,06$ \\
\hline Gasohol 97 & $4.296 .497,98$ & $4.515 .853,46$ & $4.784 .103,82$ & $5.073 .476,70$ & $5.375 .539,60$ \\
\hline Gasohol 95 & $1.060 .725,06$ & $1.113 .857,29$ & $1.180 .022,56$ & $1.251 .397,79$ & $1.325 .903,08$ \\
\hline Gasohol 90 & $7.324 .892,18$ & $7.700 .031,50$ & $8.157 .428,16$ & $8.650 .841,04$ & $9.165 .891,82$ \\
\hline GLP & $1.750 .704,91$ & $1.839 .352,52$ & $1.948 .613,59$ & $2.066 .478,07$ & $2.189 .511,33$ \\
\hline Total & $/ 19.416 .007,19$ & $20.407 .437,84$ & 21.619.678,84 & 22.927.373,82 & 24.292.415,88 \\
\hline
\end{tabular}

Nota: En primer año incluye stock de seguridad y \% de cama. Además, incluye merma de 0,01\% para combustibles líquidos.

Elaboración propia 
A continuación, se mostrarán los cálculos de los costos de los otros materiales que se necesitan para llevar a cabo el proyecto, comenzando por un cuadro resumen:

Tabla 7.17

Cuadro de resumen de costos de materiales del servicio

\begin{tabular}{l|r}
\hline \multicolumn{1}{c|}{ Concepto } & Monto anual (soles) \\
\hline Materiales de limpieza & $9.906,57$ \\
Materiales de atención directa & $1.391,95$ \\
Materiales de oficina & $3.479,66$ \\
Materiales para mantenimiento de & \\
máquinas & $1.645,85$ \\
Total & $\mathbf{1 6 . 4 2 4 , 0 3}$ \\
\hline
\end{tabular}

Elaboración propia

Tabla 7.18

Detalle de costos de materiales de limpieza

\begin{tabular}{l|lccc}
\hline Materiales de limpieza & Unidad & $\begin{array}{c}\text { Cantidad } \\
\text { requerida } \\
\text { anual }\end{array}$ & $\begin{array}{c}\text { Costo unitario } \\
\text { (soles) }\end{array}$ & $\begin{array}{c}\text { Costo total anual } \\
\text { (soles) }\end{array}$ \\
\hline Aromatizante & unidades & 260 & 15,25 & $3.966,10$ \\
Papel higiénico & rollos grandes & 3650 & 0,67 & $2.459,11$ \\
Jabón líquido para manos & envases de $400 \mathrm{ml}$ & 520 & 6,69 & $3.481,36$ \\
Total & & & & $\mathbf{9 . 9 0 6 , 5 7}$ \\
\hline
\end{tabular}

Elaboración propia

Tabla 7.19

Detalle de costos de materiales de atención directa

\begin{tabular}{c|cccc}
\hline $\begin{array}{c}\text { Materiales de atención } \\
\text { directa }\end{array}$ & Unidad & $\begin{array}{c}\text { Cantidad } \\
\text { requerida } \\
\text { anual }\end{array}$ & $\begin{array}{c}\text { Costo unitario } \\
\text { (soles) }\end{array}$ & $\begin{array}{c}\text { Costo total } \\
\text { anual (soles) }\end{array}$ \\
\hline Papel de boletas y facturas & rollos & 730 & 1,27 & 927,97 \\
$\begin{array}{c}\text { Papel contómetro para POS } \\
\text { Total }\end{array}$ & rollos & 365 & 1,27 & 463,98 \\
\hline
\end{tabular}

Elaboración propia 
Tabla 7.20

Detalle de costos de materiales de oficina

\begin{tabular}{c|cccc}
\hline Materiales de oficina & Unidad & $\begin{array}{c}\text { Cantidad } \\
\text { requerida } \\
\text { anual }\end{array}$ & $\begin{array}{c}\text { Costo unitario } \\
\text { (soles) }\end{array}$ & $\begin{array}{c}\text { Costo total anual } \\
\text { (soles) }\end{array}$ \\
\hline Papel de oficina & millares & 12 & 16,95 & 203,39 \\
Lapiceros & unidades & 180 & 0,85 & 152,54 \\
Correctores & unidades & 180 & 2,12 & 381,36 \\
Post its & cientos & 104 & 21,19 & $2.203,39$ \\
Cuadernos & unidades & 18 & 5,08 & 91,53 \\
Tintas de impresora & juegos de tintas & 4 & 111,86 & 447,46 \\
Total & & & & $\mathbf{3 . 4 7 9 , 6 6}$ \\
\hline
\end{tabular}

Elaboración propia

Tabla 7.21

Detalle de costos de materiales de mantenimiento

\begin{tabular}{l|ccrr}
\hline $\begin{array}{c}\text { Materiales para } \\
\text { mantenimiento de } \\
\text { máquinas }\end{array}$ & Unidad & $\begin{array}{c}\text { Cantidad } \\
\text { requerida } \\
\text { anual }\end{array}$ & $\begin{array}{c}\text { Costo } \\
\text { unitario } \\
\text { (soles) }\end{array}$ & $\begin{array}{c}\text { Costo total } \\
\text { anual (soles) }\end{array}$ \\
\hline Filtros de surtidores & unidades & 3 & 68,86 & 206,57 \\
Teflones & unidades & 10 & 1,69 & 16,95 \\
Aceite para grupo & galones & 15 & 18,01 & 270,13 \\
electrógeno & unidades & 3 & 27,97 & 83,90 \\
Filtros de petróleo & unidades & 3 & 18,64 & 55,93 \\
Filtros de aceite & galones & 12 & 6,99 & 83,90 \\
Refrigerante & galones & 2 & 2,54 & 5,08 \\
Agua acidulada & unidades & 2 & 50,85 & 101,69 \\
Fajas & litros & 48 & 13,56 & 650,85 \\
Aceite para compresora & kilogramos & 36 & 4,75 & 170,85 \\
Gel & & & & $\mathbf{1 . 6 4 5 , 8 5}$ \\
Total & & & & \\
\hline
\end{tabular}

Elaboración propia 
Adicional a ello; a continuación, se presentan ciertos gastos diversos que se darán en algunos años del presente proyecto:

Tabla 7.22

Gastos del proyecto (en soles)

\begin{tabular}{|c|c|c|c|c|c|c|c|}
\hline Concepto & Gasto & Necesidad & 2019 & 2020 & 2021 & 2022 & 2023 \\
\hline Equipos de protección personal & 225 & 2 juegos anuales & 449 & 449 & 449 & 449 & 449 \\
\hline Tuberías combustible líquido & 2.448 & Según distancias plano (para 5 años) & 2.448 & - & - & - & - \\
\hline Tuberías GLP & 4.544 & Según distancias plano (para 5 años) & 4.544 & - & - & - & - \\
\hline Leds & 551 & $\begin{array}{l}9 \text { luminarias } \\
\text { (para los } 5 \text { años) }\end{array}$ & 4.958 & - & - & - & - \\
\hline Manguera aire & 23 & 4 metros anuales & 90 & 90 & 90 & 90 & 90 \\
\hline Manguera agua & 13 & 3 metros anuales & 38 & 38 & 38 & 38 & 38 \\
\hline Botonera de emergencia & 72 & 1 unidad cada 2 años & 72 & - & 72 & - & 72 \\
\hline Tachos de basura para reciclaje & 42 & 2 juegos cada 2 años & 85 & - & 85 & - & 85 \\
\hline Accesorios servicios higiénicos & 55 & 9 juegos anuales & 496 & 496 & 496 & 496 & 496 \\
\hline Accesorios primeros auxilios & 21 & 1 juego anual & 21 & 21 & 21 & 21 & 21 \\
\hline Total & & & 13.201 & 1.095 & 1.251 & 1.095 & 1.251 \\
\hline
\end{tabular}




\subsubsection{Costo de los servicios}

A continuación, se mostrarán los cálculos de los costos de los servicios que se necesitan para llevar a cabo el proyecto, comenzando por un cuadro resumen:

Tabla 7.23

Cuadro resumen de costos de servicios

\begin{tabular}{l|r}
\hline Concepto & $\begin{array}{c}\text { Monto anual } \\
\text { (soles) }\end{array}$ \\
\hline Consumo de agua & 915,25 \\
Consumo de electricidad & $13.491,72$ \\
Servicio telefónico & $1.641,03$ \\
Servicio internet & $1.025,64$ \\
Alquiler POS & 615,38 \\
Transporte de combustible & $824.394,89$ \\
Servicios tercerizados (outsourcing) & $105.609,95$ \\
Total & $\mathbf{9 4 7 . 6 9 3 , 8 7}$ \\
\hline Elaboración propia &
\end{tabular}

A continuación, se detallará el cálculo de los montos calculado en la tabla 7.21:

Tabla 7.24

Detalle de costo por consumo de agua

\begin{tabular}{l|cc}
\hline \multicolumn{1}{c|}{ Concepto } & $\begin{array}{c}\text { Costo mensual } \\
\text { (soles) }\end{array}$ & $\begin{array}{c}\text { Costo total } \\
\text { anual (soles) }\end{array}$ \\
\hline Consumo de agua & 76,27 & 915,25 \\
Total & & $\mathbf{9 1 5 , 2 5}$ \\
\hline
\end{tabular}

Elaboración propia 
Tabla 7.25

Detalle de costo por consumo de electricidad (en soles)

\begin{tabular}{|c|c|c|c|c|c|c|c|}
\hline 、 & $\begin{array}{l}\text { Potencia } \\
\text { Watts }\end{array}$ & $\begin{array}{c}\text { Horas de uso } \\
\text { semanal }\end{array}$ & $\begin{array}{c}\text { Costo por } \\
\text { kwatt-hora }\end{array}$ & Cantidad & Costo semanal & Costo mensual & $\begin{array}{c}\text { Costo total } \\
\text { anual }\end{array}$ \\
\hline Cámaras de seguridad & 250 & 168 & 0,45 & 6 & 113,22 & 452,89 & $5.434,73$ \\
\hline Focos LED & 15 & 105 & 0,45 & 9 & 6,37 & 25,48 & 305,70 \\
\hline Computadora & 300 & 105 & 0,45 & 5 & 70,76 & 283,06 & $3.396,71$ \\
\hline Luminarias LED de techos & 80 & 70 & 0,45 & 9 & 22,64 & 90,58 & $1.086,95$ \\
\hline Bomba GLP/Surtidores & 500 & 116,55 & 0,45 & 1 & 26,18 & 104,73 & $1.256,78$ \\
\hline Bomba liquido/ Surtidores & 200 & 116,55 & 0,45 & 4 & 41,89 & 167,57 & $2.010,85$ \\
\hline Total & & & & & & & $13.491,72$ \\
\hline
\end{tabular}

Elaboración propia

Tabla 7.26

Detalle de costo de transporte (en soles)

\begin{tabular}{l|rrrrrr}
\hline \multicolumn{1}{c|}{ Combustible } & \multicolumn{1}{c}{$\begin{array}{c}\text { Costo por } \\
\text { galón }\end{array}$} & $\mathbf{2 0 1 9}$ & $\mathbf{2 0 2 0}$ & $\mathbf{2 0 2 1}$ & $\mathbf{2 0 2 2}$ & $\mathbf{2 0 2 3}$ \\
\hline Diesel B5 & 0,34 & $171.251,99$ & $176.664,06$ & $182.237,82$ & $187.814,11$ \\
Gasohol 97 & 0,34 & $142.472,45$ & $146.954,18$ & $151.590,59$ & $156.229,10$ & $160.865,52$ \\
Gasohol 95 & 0,34 & $36.209,69$ & $37.314,47$ & $38.491,75$ & $39.669,56$ & $40.846,83$ \\
Gasohol 90 & 0,34 & $255.046,75$ & $263.109,71$ & $271.410,84$ & $279.715,73$ & $288.016,86$ \\
GLP & 0,42 & $169.695,17$ & $174.963,44$ & $180.483,55$ & $186.006,16$ & $191.526,27$ \\
Total & & $\mathbf{7 7 4 . 6 7 6 , 0 5}$ & $\mathbf{7 9 9 . 0 0 5 , 8 6}$ & $\mathbf{8 2 4 . 2 1 4 , 5 5}$ & $\mathbf{8 4 9 . 4 3 4 , 6 6}$ & $\mathbf{8 7 4 . 6 4 3 , 3 4}$ \\
\hline
\end{tabular}

Nota: En primer año se incluye stock de seguridad y \% de cama. Se incluye 0,01\% de merma para los combustibles líquidos.

Elaboración propia 
Tabla 7.27

Detalle de costo por servicios tercerizados

\begin{tabular}{l|ccc}
\hline \multicolumn{1}{c|}{ Concepto } & $\begin{array}{c}\text { Costo } \\
\text { (soles) }\end{array}$ & Veces por año & $\begin{array}{c}\text { Costo anual } \\
\text { (soles) }\end{array}$ \\
\hline $\begin{array}{l}\text { Servicio del contador } \\
\text { Servicio del perito de monitoreo }\end{array}$ & $1.271,19$ & 12 & $15.254,24$ \\
ambiental & 593,22 & 6 & $3.559,32$ \\
Servicio de los técnicos de & Ver detalle & Ver detalle & \\
mantenimiento & 932,20 & 12 & $14.593,00$ \\
Servicio de limpieza & $5.084,75$ & 12 & $11.186,44$ \\
Servicio de seguridad & & & $61.016,95$ \\
Total & & & $\mathbf{1 0 5 . 6 0 9 , 9 5}$ \\
\hline
\end{tabular}

Elaboración propia

El costo de los servicios técnicos de mantenimiento, que es la suma de los

servicios de mantenimiento tanto programado como reactivo, se coloca a continuación:

Tabla 7.28

Costo de servicios de terceros para mantenimiento programado

\begin{tabular}{|c|c|c|c|c|c|}
\hline Máquina & Servicio & $\begin{array}{l}\text { Costo mano } \\
\text { de obra }\end{array}$ & Frecuencia & $\begin{array}{c}\text { Uso } \\
\text { anual } \\
\text { máquina }\end{array}$ & $\begin{array}{l}\text { Costo } \\
\text { total } \\
\text { anual } \\
\text { (soles) }\end{array}$ \\
\hline SURTIDORES & $\begin{array}{l}\text { Cambio de filtro, revisión } \\
\text { general }\end{array}$ & 150/surtidor & cuatrimestral & Constante & 1.800 \\
\hline TANQUES & $\begin{array}{l}\text { Limpieza interna } \\
\text { Cambio de aceite, filtro de }\end{array}$ & 400/tanque & $\begin{array}{l}\text { semestral } \\
\text { cada } 30\end{array}$ & $\begin{array}{l}\text { Constante } \\
60 \text { horas }\end{array}$ & $\begin{array}{c}3.200 \\
100\end{array}$ \\
\hline & $\begin{array}{l}\text { petróleo, filtro de aceite, } \\
\text { limpieza de inyectores }\end{array}$ & 50 & horas & & \\
\hline \multirow{3}{*}{ GRUPO ELECTRÓGENO } & Cambio de refrigerante, & & cada 60 & 60 horas & 200 \\
\hline & $\begin{array}{l}\text { cambio de agua acidulada, } \\
\text { revisión de batería }\end{array}$ & 200 & & & \\
\hline & $\begin{array}{l}\text { cambio de faja de la } \\
\text { ventiladora }\end{array}$ & 100 & $\begin{array}{l}\text { cada } 120 \\
\text { horas }\end{array}$ & 60 horas & 50 \\
\hline COMPRESORA & $\begin{array}{l}\text { Limpieza interna, cambio } \\
\text { de aceite. revisión general }\end{array}$ & 70 & $\begin{array}{l}\text { cada } 50 \\
\text { horas }\end{array}$ & $\begin{array}{l}1095 \\
\text { horas }\end{array}$ & 1.533 \\
\hline BOMBAS SUMERGIBLE & $\begin{array}{l}\text { Limpieza interna, cambio } \\
\text { del cartucho }\end{array}$ & 500 & semestral & Constante & 1.000 \\
\hline \multirow[t]{2}{*}{ POZO A TIERRA } & Medición de omeage. Bajo & & semestral & Constante & 400 \\
\hline & $\begin{array}{l}\text { omeage se hecha torgel que } \\
\text { sirve para ionizar la tierra }\end{array}$ & 200 & & & \\
\hline POZO DE AGUA & $\begin{array}{l}\text { Limpieza interna, revisión } \\
\text { de las válvulas check }\end{array}$ & 60 & cuatrimestral & Constante & 180 \\
\hline TOTAL & & & & & 8.463 \\
\hline
\end{tabular}

Elaboración propia 
Tabla 7.29

Costo de servicios de terceros para mantenimiento reactivo

\begin{tabular}{l|lcrr}
\hline \multicolumn{1}{c|}{ Máquina } & \multicolumn{1}{c}{ Falla } & $\begin{array}{c}\text { Frecuencia } \\
\text { anual apróx }\end{array}$ & $\begin{array}{c}\text { Costo } \\
\text { por } \\
\text { servicio } \\
\text { (soles) }\end{array}$ & $\begin{array}{c}\text { Costo } \\
\text { total } \\
\text { anual } \\
\text { (soles) }\end{array}$ \\
\hline GRUPO ELECTRÓGENO & $\begin{array}{l}\text { Ruptura de faja } \\
\text { Avería de motor } \\
\text { Ruptura de faja }\end{array}$ & 1 & 400 & 400 \\
COMPRESORA & $\begin{array}{l}\text { Sobrecalentamiento de } \\
\text { motor }\end{array}$ & 1 & 4000 & 3.000 \\
BOMBA SUMERGIBLE & Averío de cartucho & 0,5 & 500 & 1.000 \\
TOTAL & & & 2.664 & 1.330 \\
\hline
\end{tabular}

Elaboración propia

\subsubsection{Costo del personal}

Tanto para el personal de atención al cliente, como para el de soporte interno, se calculó un factor de 1,45; el cual, al ser multiplicado por el sueldo sin beneficios, da como resultado un monto que incluye la paga de CTS, gratificaciones, vacaciones, asignaciones familiares y servicio social de salud.

\subsubsection{Personal de atención al cliente}

Tabla 7.30

Cálculo de remuneraciones de vendedores de isla (en soles)

\begin{tabular}{l|cccccc}
\hline \multicolumn{1}{c|}{ Personal } & Cantidad & Salario & $\begin{array}{c}\text { Total } \\
\text { mensual }\end{array}$ & $\begin{array}{c}\text { Total anual } \\
\text { sin beneficios }\end{array}$ & Factor & $\begin{array}{c}\text { Total anual } \\
\text { con beneficios }\end{array}$ \\
\hline $\begin{array}{l}\text { Vendedor de } \\
\text { isla }\end{array}$ & 10 & $1.200,00$ & $12.000,00$ & $144.000,00$ & 1,45 & $209.120,00$ \\
\hline
\end{tabular}

Elaboración propia

\subsubsection{Personal de soporte interno del servicio}

Tabla 7.31

Cálculo de remuneraciones de personal administrativo (en soles)

\begin{tabular}{l|ccrrrr}
\hline \multicolumn{1}{c|}{ Personal } & Cantidad & Salario & Total mensual & $\begin{array}{c}\text { Total anual } \\
\text { sin beneficios }\end{array}$ & Factor & $\begin{array}{c}\text { Total anual } \\
\text { con } \\
\text { beneficios }\end{array}$ \\
\hline Gerente & 1 & $6.500,00$ & $6.500,00$ & $78.000,00$ & 1,45 & $113.273,33$ \\
general & 1 & $3.500,00$ & $3.500,00$ & $42.000,00$ & 1,45 & $60.993,33$ \\
Administrador & 1 & $2.500,00$ & $2.500,00$ & $30.000,00$ & 1,45 & $43.566,67$ \\
$\begin{array}{l}\text { Asistente } \\
\text { Total }\end{array}$ & & & & & & $\mathbf{2 1 7 . 8 3 3 , 3 3}$ \\
\hline
\end{tabular}

Elaboración propia 


\subsection{Presupuesto de ingresos y egresos}

\subsubsection{Presupuesto de ingreso por ventas}

A continuación, se muestran los precios a los que se venderá el combustible en el presente proyecto.

Tabla 7.32

Valor de venta por galón (en soles)

\begin{tabular}{l|ccccc}
\hline \multicolumn{1}{c|}{ Producto } & $\mathbf{2 0 1 9}$ & $\mathbf{2 0 2 0}$ & $\mathbf{2 0 2 1}$ & $\mathbf{2 0 2 2}$ & $\mathbf{2 0 2 3}$ \\
\hline Diésel B5 & 11,2 & 11,4 & 11,7 & 12,0 & 12,3 \\
Gasohol 97 & 12,7 & 13,0 & 13,3 & 13,6 & 14,0 \\
Gasohol 95 & 12,4 & 12,7 & 13,0 & 13,3 & 13,6 \\
Gasohol 90 & 11,4 & 11,6 & 11,9 & 12,2 & 12,5 \\
GLP & 5,5 & 5,6 & 5,7 & 5,9 & 6,0 \\
\hline
\end{tabular}

Elaboración propia

Otros ingresos con los que contará el proyecto, serán los alquileres de las tiendas de conveniencia:

Tabla 7.33

Ingresos por servicios relacionados

\begin{tabular}{l|rr}
\hline \multicolumn{1}{c|}{ Local } & Área $\left(\mathbf{m}^{\mathbf{2}}\right)$ & \multicolumn{2}{c}{$\begin{array}{c}\text { Ingresos mensuales sin IGV } \\
\text { (soles) }\end{array}$} \\
\hline Lavado y engrase & 168 & 4.200 \\
Comida rápida & 72,8 & 1.820 \\
Mini market & 61,6 & 1.541 \\
Farmacia & 38,4 & 959 \\
Espacio cajeros & 6 & 1.000 \\
\hline Elaboración propia & &
\end{tabular}

Cabe recalcar que el precio de alquiler dependerá del tamaño del área de cada local; sin embargo, para el caso de los cajeros, el banco paga aproximadamente S/. 500 por cada cajero instalado. Además, como se mencionó antes, cada local contará con su propio medidor de agua y luz para que puedan hacer sus pagos directamente; así mismo, los gastos para tratar los desechos de estos lugares serán asumidos por el arrendatario y las acciones se detallan en el acápite 5.6 Impacto ambiental. 
Tabla 7.34

Presupuesto de ingresos (en soles)

\begin{tabular}{|c|c|c|c|c|c|}
\hline & 2019 & 2020 & 2021 & 2022 & 2023 \\
\hline \multicolumn{6}{|l|}{ Venta combustibles } \\
\hline Diesel B5 & $5.657 .282,25$ & $5.952 .662,58$ & $6.293 .981,23$ & $6.648 .734,76$ & 7.017.200,63 \\
\hline Gasohol 97 & $5.347 .599,95$ & $5.626 .811,03$ & $5.949 .445,73$ & $6.284 .779,89$ & $6.633 .075,77$ \\
\hline Gasohol 95 & $1.325 .269,25$ & $1.394 .464,75$ & $1.474 .421,71$ & $1.557 .525,92$ & $1.643 .842,36$ \\
\hline Gasohol 90 & $8.578 .707,66$ & $9.026 .622,65$ & $9.544 .198,54$ & $10.082 .147,11$ & $10.640 .889,07$ \\
\hline GLP & $2.200 .381,68$ & $2.315 .268,90$ & $2.448 .023,69$ & $2.586 .003,93$ & $2.729 .317,54$ \\
\hline Total venta combustibles & $23.109 .240,78$ & $24.315 .829,91$ & $25.710 .070,91$ & $27.159 .191,60$ & $28.664 .325,38$ \\
\hline \multicolumn{6}{|l|}{ Alquiler } \\
\hline Lavado y engrase & $50.400,00$ & $50.400,00$ & $50.400,00$ & $50.400,00$ & $50.400,00$ \\
\hline Comida rápida & $21.840,00$ & $21.840,00$ & $21.840,00$ & $21.840,00$ & $21.840,00$ \\
\hline Mini market & $18.491,25$ & $18.491,25$ & $18.491,25$ & $18.491,25$ & $18.491,25$ \\
\hline Farmacia & $11.505,00$ & $11.505,00$ & $11.505,00$ & $11.505,00$ & $11.505,00$ \\
\hline Espacio cajeros & $12.000,00$ & $12.000,00$ & $12.000,00$ & $12.000,00$ & $12.000,00$ \\
\hline Total alquiler & $114.236,25$ & $114.236,25$ & $114.236,25$ & $114.236,25$ & $114.236,25$ \\
\hline Total ingresos & 23.223.477,03 & 24.430.066,16 & 25.824.307,16 & 27.273.427,85 & 28.778.561,63 \\
\hline
\end{tabular}




\subsubsection{Presupuesto operativo de costos}

A continuación, se detalla el presupuesto de los costos del servicio:

Tabla 7.35

Presupuesto de costos del servicio (en soles)

\begin{tabular}{|c|c|c|c|c|c|}
\hline & 2019 & 2020 & 2021 & 2022 & 2023 \\
\hline Combustible & $19.416 .007,19$ & $20.407 .437,84$ & $21.619 .678,84$ & $22.927 .373,82$ & $24.292 .415,88$ \\
\hline Transportista & $774.676,05$ & $799.005,86$ & $824.214,55$ & $849.434,66$ & $874.643,34$ \\
\hline Servicio energía eléctrica parte operaciones & $4.354,58$ & $4.354,58$ & $4.354,58$ & $4.354,58$ & $4.354,58$ \\
\hline Remuneración vendedores de isla & $209.120,00$ & $209.120,00$ & $209.120,00$ & $209.120,00$ & $209.120,00$ \\
\hline Servicio de mantenimiento & $14.593,00$ & $14.593,00$ & $14.593,00$ & $14.593,00$ & $14.593,00$ \\
\hline Servicio de perito ambiental & $3.559,32$ & $3.559,32$ & $3.559,32$ & $3.559,32$ & $3.559,32$ \\
\hline $\begin{array}{l}\text { Comisión POS }(0,42 \% \text { de ventas } \\
\text { combustible })\end{array}$ & $97.382,93$ & $102.467,53$ & $108.342,90$ & $114.449,53$ & $120.792,20$ \\
\hline Materiales de atención directa & $1.391,95$ & $1.391,95$ & $1.391,95$ & $1.391,95$ & $1.391,95$ \\
\hline Materiales de mantenimiento & $1.645,85$ & $1.645,85$ & $1.645,85$ & $1.645,85$ & $1.645,85$ \\
\hline Otros gastos & $13.201,41$ & $1.094,63$ & $1.251,41$ & $1.094,63$ & $1.251,41$ \\
\hline Depreciación fabril & $28.296,06$ & $28.296,06$ & $28.296,06$ & $28.296,06$ & $28.296,06$ \\
\hline Total & 20.564.228,34 & 21.572.966,62 & 22.816.448,45 & 24.155.313,40 & 25.552.063,59 \\
\hline
\end{tabular}

Nota: Monto de mantenimiento ya incluye mantenimiento reactivo.

Elaboración propia 
El cálculo del \% de ventas de combustible que representaría

el gasto por

comisión de POS se detalla a continuación a partir de los siguientes datos:

Tabla 7.36

Tarifa comisión Visanet

\begin{tabular}{l|cc}
\hline \multicolumn{1}{c|}{ Tipo de tarjeta } & Concepto & Tarifa de VISANET sin IGV \\
\hline Tarjetas de crédito & Comisión Visa Crédito (CVC) & $4,15 \%$ \\
Tarjetas de débito & Comisión Visa Débito (CVD) & $3,25 \%$ \\
\hline
\end{tabular}

Fuente: Visanet (2017)

Elaboración propia

Tabla 7.37

Tarifa comisión Mastercard

\begin{tabular}{l|lc}
\hline \multicolumn{1}{c|}{ Tipo de tarjeta } & \multicolumn{1}{c}{ Concepto } & Tarifa de VISANET sin IGV \\
\hline Tarjetas de crédito & $\begin{array}{l}\text { Comisión Mastercard Crédito } \\
\text { (CMC) }\end{array}$ & $\begin{array}{l}\text { Comisión Mastercard Débito } \\
\text { Tarjetas de débito }\end{array}$ \\
\hline
\end{tabular}

Fuente: Mastercard (2017)

Elaboración propia

Tabla 7.38

Porcentajes de ventas con tarjetas

\begin{tabular}{ll|c}
\hline \multicolumn{1}{c|}{ Concepto } & Porcentaje \\
\hline Ventas totales & & $\mathbf{1 0 \%}$ \\
& C = Venta con tarjeta de crédito & $\mathbf{8 \%}$ \\
& Porcentaje Visa crédito (PVC) & $7,2 \%$ \\
& Porcentaje Mastercard crédito (PMC) & $0,8 \%$ \\
& D = Venta con tarjeta de débito & $\mathbf{2 \%}$ \\
& Porcentaje Visa débito (PVD) & $1,8 \%$ \\
Porcentaje Mastercard débito (PMD) & $0,2 \%$ \\
\hline
\end{tabular}

Elaboración propia

Para obtener el factor se usó la siguiente fórmula:

CVC $x$ PVC + CMC x PMC + CVD x PVD + CMD x PMD = $\mathbf{0 , 4 2 \%}$ 


\subsubsection{Presupuesto operativo de gastos administrativos}

A continuación, se detalla el presupuesto de los gastos generales:

Tabla 7.39

Presupuesto de gastos generales (en soles)

\begin{tabular}{|c|c|c|c|c|c|}
\hline & 2019 & 2020 & 2021 & 2022 & 2023 \\
\hline \multicolumn{6}{|l|}{ Gastos administrativos } \\
\hline Remuneración gerente general & $113.273,33$ & $113.273,33$ & $113.273,33$ & $113.273,33$ & $113.273,33$ \\
\hline Remuneración administrador & $60.993,33$ & $60.993,33$ & $60.993,33$ & $60.993,33$ & $60.993,33$ \\
\hline Remuneración asistente & $43.566,67$ & $43.566,67$ & $43.566,67$ & $43.566,67$ & $43.566,67$ \\
\hline Servicio de vigilancia & $61.016,95$ & $61.016,95$ & $61.016,95$ & $61.016,95$ & $61.016,95$ \\
\hline Servicio de limpieza & $11.186,44$ & $11.186,44$ & $11.186,44$ & $11.186,44$ & $11.186,44$ \\
\hline Servicio de contador & $15.254,24$ & $15.254,24$ & $15.254,24$ & $15.254,24$ & $15.254,24$ \\
\hline $\begin{array}{l}\text { Servicio energía eléctrica parte } \\
\text { administrativa }\end{array}$ & $9.137,14$ & $9.137,14$ & $9.137,14$ & $9.137,14$ & $9.137,14$ \\
\hline Servicio de agua & 915,25 & 915,25 & 915,25 & 915,25 & 915,25 \\
\hline Servicio telefónico & $1.641,03$ & $1.641,03$ & $1.641,03$ & $1.641,03$ & $1.641,03$ \\
\hline Alquiler POS & 615,38 & 615,38 & 615,38 & 615,38 & 615,38 \\
\hline Seguro de grifo & $15.254,24$ & $15.254,24$ & $15.254,24$ & $15.254,24$ & $15.254,24$ \\
\hline Materiales de limpieza & $9.906,57$ & $9.906,57$ & $9.906,57$ & $9.906,57$ & $9.906,57$ \\
\hline Materiales de oficina & $3.479,66$ & $3.479,66$ & $3.479,66$ & $3.479,66$ & $3.479,66$ \\
\hline Otros gastos & $13.201,41$ & $1.094,63$ & $1.251,41$ & $1.094,63$ & $1.251,41$ \\
\hline Depreciación no fabril & $27.888,12$ & $27.888,12$ & $27.888,12$ & $27.888,12$ & $27.239,82$ \\
\hline Amortización & $6.511,90$ & $6.511,90$ & $6.511,90$ & $6.511,90$ & $6.511,90$ \\
\hline \multicolumn{6}{|l|}{ Gastos comerciales } \\
\hline Publicidad (Radio y prensa) & $1.016,95$ & $1.016,95$ & $1.016,95$ & $1.016,95$ & $1.016,95$ \\
\hline Promociones lubricantes & $97.966,10$ & $103.067,80$ & $109.000,00$ & $115.135,59$ & $121.508,47$ \\
\hline Gastos por descuentos en combustibles & $233.111,41$ & $245.178,30$ & $259.121,71$ & $273.613,92$ & $288.666,25$ \\
\hline Total gastos administrativo y comercial & $725.936,13$ & 730.997,94 & $751.030,33$ & 771.501,35 & 792.435,04 \\
\hline
\end{tabular}

Total gastos administrativo y comercial 
Tabla 7.40

Depreciación fabril (en soles)

\begin{tabular}{|c|c|c|c|c|c|c|}
\hline Activo fijo tangible & Importe & Valor residual & $\begin{array}{c}\text { Valor } \\
\text { depreciable }\end{array}$ & $\begin{array}{c}\% \\
\text { Depreciación }\end{array}$ & Total depreciación & Valor en 2023 \\
\hline $\begin{array}{l}\text { Extintores y equipos contra } \\
\text { incendios }\end{array}$ & 6.593 & 636 & 5.958 & $10 \%$ & 2.979 & 3.614 \\
\hline Hidrantes e instalación & 3.644 & 0 & 3.644 & $10 \%$ & 1.822 & 1.822 \\
\hline Surtidores e instalación & 81.983 & 13.771 & 68.212 & $10 \%$ & 34.106 & 47.877 \\
\hline Tanques combustible líquido & 40.720 & 0 & 40.720 & $10 \%$ & 20.360 & 20.360 \\
\hline Tanque GLP & 57.500 & 0 & 57.500 & $10 \%$ & 28.750 & 28.750 \\
\hline Bombas combustible líquido & 12.712 & 1.500 & 11.212 & $10 \%$ & 5.606 & 7.106 \\
\hline Bomba GLP & 14.407 & 2.000 & 12.407 & $10 \%$ & 6.203 & 8.203 \\
\hline Compresora & 11.017 & 500 & 10.517 & $10 \%$ & 5.258 & 5.758 \\
\hline Grupo electrógeno & 33.051 & 1.500 & 31.551 & $10 \%$ & 15.775 & 17.275 \\
\hline Pararrayo e instalación & 11.017 & 0 & 11.017 & $10 \%$ & 5.508 & 5.508 \\
\hline $\begin{array}{l}\text { Sistema de detección de fugas e } \\
\text { instalación }\end{array}$ & 11.706 & 0 & 11.706 & $10 \%$ & 5.853 & 5.853 \\
\hline Tablero de transferencia & 5.508 & 0 & 5.508 & $10 \%$ & 2.754 & 2.754 \\
\hline Medidor de luz & 3.000 & 0 & 3.000 & $10 \%$ & 1.500 & 1.500 \\
\hline Trampa de grasa e instalación & 1.271 & 0 & 1.271 & $10 \%$ & 636 & 636 \\
\hline Serafin & 1.695 & 500 & 1.195 & $10 \%$ & 597 & 1.097 \\
\hline Total depreciación fabril & & & & & 137.709 & 158.115 \\
\hline
\end{tabular}

Nota: Se deprecian activos mayores a 1/4 del valor de una UIT.

Elaboración propia 
Tabla 7.41

Depreciación no fabril (en soles)

\begin{tabular}{|c|c|c|c|c|c|c|}
\hline Activo fijo tangible & Importe & Valor residual & $\begin{array}{c}\text { Valor } \\
\text { depreciable }\end{array}$ & $\begin{array}{c}\% \\
\text { Depreciación }\end{array}$ & Total depreciación & Valor en 2023 \\
\hline Terreno & $4.387 .500,00$ & $4.387 .500,00$ & 0,00 & $0 \%$ & 0 & 4.387 .500 \\
\hline Edificaciones & $540.486,22$ & 0,00 & $540.486,22$ & $5 \%$ & 135.122 & 405.365 \\
\hline Bombas de para tanque de agua & $1.652,54$ & 150,00 & $1.502,54$ & $10 \%$ & 751 & 901 \\
\hline Estantes y otros & $1.161,02$ & 508,47 & 652,54 & $10 \%$ & 326 & 835 \\
\hline Computadores e impresoras & $2.593,22$ & 0,00 & $2.593,22$ & $25 \%$ & 2.593 & 0 \\
\hline Total depreciación no fabril & & & & & 136.199 & 4.794.601 \\
\hline
\end{tabular}

Nota: Se deprecian activos mayores a $1 / 4$ del valor de una UIT.

Elaboración propia

Tabla 7.42

Amortización no fabril (en soles)

\begin{tabular}{|c|c|c|c|c|c|c|c|}
\hline Activo fijo intangible & Importe & Valor residual & $\begin{array}{c}\text { Valor } \\
\text { depreciable }\end{array}$ & $\begin{array}{c}\% \\
\text { Amortización } \\
\end{array}$ & $\begin{array}{c}\text { Depreciación } \\
\text { anual }\end{array}$ & $\begin{array}{c}\text { Total } \\
\text { depreciación }\end{array}$ & $\begin{array}{c}\text { Valor en } \\
2023 \\
\end{array}$ \\
\hline Proyecto de grifo & 22.034 & 0 & 22.034 & $10 \%$ & 2.203 & 11.017 & 11.017 \\
\hline ERP e instalación & 28.255 & 0 & 28.255 & $10 \%$ & 2.825 & 14.127 & 14.127 \\
\hline
\end{tabular}

Nota: Se deprecian activos mayores a 1/4 del valor de una UIT.

Elaboración propia

Total valor de salvamento (100\% Activo tangible + $0 \%$ Activo intangible+ $100 \%$ Capital de trabajo $)=\mathrm{S} /$

4.998.289 


\subsection{Presupuestos financieros}

\subsubsection{Presupuesto de servicio de deuda}

Se eligió financiar la deuda con el banco BBVA Continental, pues es el que ofrece una menor tasa de interés (TEA: 11,89\%) para las empresas pequeñas. Cabe recalcar que del total de la inversión, el $60 \%$ será financiado por los mismos empresarios y el $40 \%$ a través de un préstamos bancario.

Los datos del pago de la deuda se muestran a continuación:

Tabla 7.43

Datos del pago de la deuda

\begin{tabular}{l|c}
\hline \multicolumn{2}{c}{ Datos } \\
\hline Deuda (soles) & $2.398 .384,44$ \\
Gracia parcial (años) & 1 \\
Gracia parcial (semestres) & 2 \\
TEA & $11,89 \%$ \\
Tasa semestral & $5,78 \%$ \\
Amortización (años) & 5 \\
Amortización (semestres) & 10 \\
Cuotas & Semestrales \\
\hline Elaboración propia &
\end{tabular}

A continuación, se muestra el cuadro consolidado por año del servicio de la deuda, el cual es la suma de las cuotas semestrales:

Tabla 7.44

Cuadro del servicio de la deuda (en soles)

\begin{tabular}{c|cccccc}
\hline & Año 0: 2018 & $\mathbf{2 0 1 9}$ & $\mathbf{2 0 2 0}$ & $\mathbf{2 0 2 1}$ & $\mathbf{2 0 2 2}$ & $\mathbf{2 0 2 3}$ \\
\hline Amortización & 0,00 & $378.355,15$ & $423.341,58$ & $473.676,90$ & $529.997,08$ & $593.013,73$ \\
Intereses & $277.160,64$ & $266.536,76$ & $221.550,33$ & $171.215,02$ & $114.894,83$ & $51.878,18$ \\
Cuota & $277.160,64$ & $644.891,91$ & $644.891,91$ & $644.891,91$ & $644.891,91$ & $644.891,91$ \\
\hline
\end{tabular}

Elaboración propia 


\subsubsection{Presupuesto de estado de resultados}

Tabla 7.45

Estado de resultados (en soles)

\begin{tabular}{|c|c|c|c|c|c|}
\hline Rubro & 2019 & 2020 & 2021 & 2022 & 20223 \\
\hline Ingreso por ventas & $23.109 .240,78$ & 24.315.829,91 & $25.710 .070,91$ & $27.159 .191,60$ & $28.664 .325,38$ \\
\hline (-) Costo de producción & $20.535 .932,28$ & $21.544 .670,56$ & $22.788 .152,39$ & 24.127.017,34 & $25.523 .767,53$ \\
\hline (-) Depreciación fabril & $27.541,74$ & $27.541,74$ & $27.541,74$ & $27.541,74$ & $27.541,74$ \\
\hline (=) Utilidad Bruta & $2.545 .766,77$ & $2.743 .617,61$ & 2.894.376,78 & $3.004 .632,53$ & $3.113 .016,11$ \\
\hline (-) Gastos generales & $691.536,11$ & $696.597,91$ & $716.630,31$ & $737.101,33$ & $758.683,33$ \\
\hline (-) Depreciación no fabril & $27.888,12$ & $27.888,12$ & $27.888,12$ & $27.888,12$ & $27.239,82$ \\
\hline (-) Amortización & $6.511,90$ & $6.511,90$ & $6.511,90$ & $6.511,90$ & $6.511,90$ \\
\hline (+) Ingresos por alquiler & $114.236,25$ & $114.236,25$ & $114.236,25$ & $114.236,25$ & $114.236,25$ \\
\hline (=) Utilidad Operativa & $1.934 .066,89$ & $2.126 .855,93$ & $2.257 .582,70$ & $2.347 .367,43$ & $2.434 .817,31$ \\
\hline (-) Gastos financieros & $266.536,76$ & $221.550,33$ & $171.215,02$ & $114.894,83$ & $51.878,18$ \\
\hline$(=)$ Utilidad antes de impuestos & $1.667 .530,13$ & $1.905 .305,60$ & $2.086 .367,68$ & $2.232 .472,59$ & $2.382 .939,13$ \\
\hline (-) Impuesto a la renta & $491.921,39$ & $562.065,15$ & $615.478,47$ & $658.579,42$ & $702.967,04$ \\
\hline (=) Utilidad antes de reserva legal & $1.175 .608,74$ & $1.343 .240,44$ & $1.470 .889,22$ & $1.573 .893,18$ & 1.679.972,09 \\
\hline (-) Reserva legal & $117.560,87$ & $134.324,04$ & $147.088,92$ & $157.389,32$ & $163.152,17$ \\
\hline (=) Utilidad disponible & 1.058.047,87 & 1.208.916,40 & $1.323 .800,29$ & $1.416 .503,86$ & 1.516.819,91 \\
\hline
\end{tabular}

Nota: Empresa no obligada a pagar participaciones, ya que tiene menos de 20 trabajadores.

Elaboración propia 


\subsubsection{Presupuesto de estado de situación financiera}

Tabla 7.46

Estado de situación financiera antes de inicio de operaciones (en soles)

\begin{tabular}{|c|c|c|c|}
\hline \multicolumn{2}{|c|}{ Activo } & \multicolumn{2}{|c|}{ Pasivo y patrimonio } \\
\hline Activo corriente & & Pasivo corriente & \\
\hline Caja y bancos & $408.902,89$ & Pasivo no corriente & \\
\hline Gastos pre operativos & $282.923,35$ & Deudas a largo plazo & $2.398 .384,44$ \\
\hline Activo no corriente & & Patrimonio & \\
\hline Activos fijos tangibles & $5.236 .219,27$ & Capital accionista & $3.597 .576,66$ \\
\hline Activos fijos intangibles & $67.915,59$ & & \\
\hline Total activo & $5.995 .961,11$ & Total pasivo y patrimonio & $5.995 .961,11$ \\
\hline
\end{tabular}

Elaboración propia

\subsection{Flujo de fondos netos}

Para este acápite, se calculó el COK y el CPPC del proyecto:

Tabla 7.47

Cálculo del COK

\begin{tabular}{l|lr}
\hline \multicolumn{1}{c|}{ Concepto } & \multicolumn{1}{c}{ Detalle } & \multicolumn{1}{c}{ Tasa } \\
\hline Rf & Tasa libre de riesgo & $5,33 \%$ \\
Beta & Indicador de Riesgo de Mercado & 1 \\
Prima de riesgo & Plus por cambiar activos sin riesgo por activo con riesgos & $6,22 \%$ \\
Riesgo país & Grado de riesgo de un país para inversiones extranjeras & $2 \%$ \\
Cálculo & Rf + Beta * (Prima de riesgo) + Riesgo país & $\mathbf{1 3 , 5 5 \%}$ \\
\hline
\end{tabular}

Fuente: Gestión 2017

Elaboración propia

Tabla 7.48

Cálculo el CPPC

\begin{tabular}{l|rrrr}
\hline \multicolumn{1}{c|}{ Rubro } & Importe (soles) & \% Participación & Costo Dinero & Tasa de descuento \\
\hline $\begin{array}{l}\text { Capital } \\
\text { propio }\end{array}$ & $3.597 .576,66$ & $60 \%$ & $13,55 \%$ & $8,128 \%$ \\
$\begin{array}{l}\text { Préstamo } \\
\text { bancario }\end{array}$ & $2.398 .384,44$ & & & \\
Total & $\mathbf{5 . 9 9 5 . 9 6 1 , 1 1}$ & $40 \%$ & $11,89 \%$ & $3,353 \%$ \\
\hline
\end{tabular}

Nota: IR de $29,5 \%$

Elaboración propia

Finalmente, se decidió elaborar los flujos de fondos, tanto económico como financiero, con el COK por ser un coeficiente más ácido 


\subsubsection{Flujo de fondos económicos}

Tabla 7.49

Flujo de fondos económicos (en soles)

\begin{tabular}{|c|c|c|c|c|c|c|}
\hline Rubro & 2018 & 2019 & 2020 & 2021 & 2022 & 2023 \\
\hline Inversión total & -5.995 .961 & & & & & \\
\hline (=) Utilidad antes de reserva legal & & 1.175.609 & 1.343.240 & 1.470.889 & 1.573.893 & 1.679.972 \\
\hline (+) Amortización de intangible & & 6.512 & 6.512 & 6.512 & 6.512 & 6.512 \\
\hline (+) Depreciación fabril & & 27.542 & 27.542 & 27.542 & 27.542 & 27.542 \\
\hline (+) Depreciación no fabril & & 27.888 & 27.888 & 27.888 & 27.888 & 27.240 \\
\hline (+) Participaciones $(0 \%)$ & & 0 & 0 & 0 & 0 & 0 \\
\hline$(+)$ Intereses $x(1-t)$ & & 187.908 & 156.193 & 120.707 & 81.001 & 36.574 \\
\hline (+) Valor salvamento & & & & & & 4.998.289 \\
\hline Flujo neto de fondos económicos & -5.995 .961 & 1.425 .459 & 1.561.375 & 1.653.538 & 1.716 .836 & 6.776 .129 \\
\hline Factor de actualización & 1,0 & 0,9 & 0,8 & 0,7 & 0,6 & 0,5 \\
\hline VAN & -5.995 .961 & 1.255 .388 & 1.211 .027 & 1.129 .494 & 1.032 .813 & 3.590 .029 \\
\hline Flujo de caja acumulado & & 1.255 .388 & 2.466 .415 & 3.595 .909 & 4.628 .722 & 8.218 .751 \\
\hline Valor actual neto & & -4.740 .573 & -3.529 .546 & -2.400 .052 & -1.367 .239 & 2.222 .790 \\
\hline
\end{tabular}

Elaboración propia 


\subsubsection{Flujo de fondos financieros}

Tabla 7.50

Flujo de fondos financieros (en soles)

\begin{tabular}{|c|c|c|c|c|c|c|}
\hline Rubro & 2018 & 2019 & 2020 & 2021 & 2022 & 2023 \\
\hline Inversión total & -5.995 .961 & & & & & \\
\hline Préstamo & 2.398 .384 & & & & & \\
\hline (=) Utilidad antes de reserva legal & & 1.175.609 & 1.343.240 & 1.470 .889 & 1.573 .893 & 1.679.972 \\
\hline (+) Amortización de intangible & & 6.512 & 6.512 & 6.512 & 6.512 & 6.512 \\
\hline (+) Depreciación fabril & & 27.542 & 27.542 & 27.542 & 27.542 & 27.542 \\
\hline (+) Depreciación no fabril & & 27.888 & 27.888 & 27.888 & 27.888 & 27.240 \\
\hline (+) Participaciones $(0 \%)$ & & 0 & 0 & 0 & 0 & 0 \\
\hline (-) Amortización de deuda & & 378.355 & 423.342 & 473.677 & 529.997 & 593.014 \\
\hline (+) Valor salvamento & & & & & & 4.998 .289 \\
\hline Flujo neto de fondos financiero & -3.597 .577 & 859.195 & 981.841 & $\mathbf{1 . 0 5 9 . 1 5 4}$ & 1.105 .838 & 6.146.541 \\
\hline Factor de actualización & 1,0 & 0,9 & 0,8 & 0,7 & 0,6 & 0,5 \\
\hline VAN & -3.597 .577 & 756.685 & 761.531 & 723.484 & 665.249 & 3.256 .470 \\
\hline Flujo de caja acumulado & & 756.685 & 1.518 .216 & 2.241 .700 & 2.906 .949 & 6.163 .419 \\
\hline Valor actual neto & & -2.840 .892 & -2.079 .361 & -1.355 .877 & -690.627 & 2.565 .843 \\
\hline
\end{tabular}

Elaboración propia 


\subsection{Evaluación económica y financiera}

\subsubsection{Evaluación económica: VAN, TIR, B/C, PR}

Tabla 7.51

Indicadores económicos

\begin{tabular}{l|r}
\hline VAN económico (soles) & 2.222 .790 \\
Relación(B/C) & 1,37 \\
TIR & $24 \%$ \\
Periodo de recupero & 4,9 (4 años,10 meses, 24 días) \\
\hline Elaboración propia
\end{tabular}

\subsubsection{Evaluación financiera: VAN, TIR, B/C, PR}

Tabla 7.52

Indicadores financieros

\begin{tabular}{l|r}
\hline VAN financiero (soles) & 2.565 .843 \\
Relación (B/C) & 1,71 \\
TIR & $32 \%$ \\
Periodo de recupero & 4,7 (4 años, 8 meses, 12 días) \\
\hline Elaboración propia
\end{tabular}

Elaboración propia

\subsubsection{Análisis de los resultados económicos y financieros del proyecto}

Los resultados de los análisis realizados muestran que el proyecto es rentable tanto desde el punto de vista económico como desde el punto de vista financiero. En ambos casos, el VAN es positivo, es decir, es deseable llevar a cabo el proyecto. La TIR en ambos casos es bastante mayor que el COK (14\%), lo que significa que el retorno obtenido supera las expectativas del proyecto por parte de los accionistas.

Por otro lado, el proyecto presenta una relación B/C mayor a 1 en ambos casos, lo cual indica que la utilidad generada es mayor a los recursos empleados. Finalmente, el periodo de recupero indica que la inversión se recuperará dentro del horizonte planificado del proyecto.

Es importante mencionar que los resultados financieros indican que el escudo fiscal generado por los intereses finalmente resulta beneficioso para el inversionista. 


\subsubsection{Análisis de sensibilidad del proyecto}

Uno de los parámetros más inciertos del proyecto es el costo de combustible, que es un commoditie y además es el principal insumo de la estación de servicios. Es importante determinar qué tan sensible es la Tasa Interna de Retorno (TIR) y el Valor actual neto (VAN) con respecto a dicha variable. Cabe resaltar que los cálculos para el análisis de sensibilidad a lo largo del presente capítulo se realizaron haciendo uso del complemento de Excel "Risk Simulator" con porcentaje de error de 5\% y de confiabilidad de 95\% para obtener una mayor precisión del estudio.

En primer lugar, se determinó cómo afecta la variación de los costos de los combustibles en $+-10 \%$ de los años 2020 al 2023. Se decidió no tomar en cuenta la variación del costo del año 2019 puesto que son datos con menor variabilidad por ser el más próximo a los datos obtenidos de fuente primaria de costos 2018.

A continuación, se plasma el cuadro resumen de variación donde se muestran los límites inferior y superior del rango de variación de la VAN y TIR así como el promedio.

Tabla 7.53

Análisis variación de costos de combustibles +-10\%

\begin{tabular}{l|llllll}
\hline Ratio & $\begin{array}{l}\text { Lim. } \\
\text { Inferior }\end{array}$ & $\begin{array}{l}\text { Lim. } \\
\text { Superior }\end{array}$ & Promedio & $\begin{array}{l}\text { Valor } \\
\text { actual }\end{array}$ & Aumento & Disminución \\
\hline $\begin{array}{l}\text { VAN ECON. } \\
\text { (SOLES) }\end{array}$ & $2.016 .515,01$ & $2.429 .064,82$ & $2.222 .789,91$ & $2.222 .789,91$ & $9,28 \%$ & $9,28 \%$ \\
TIR ECON. & $22,55 \%$ & $26,39 \%$ & $24,46 \%$ & $24,46 \%$ & $7,90 \%$ & $7,80 \%$ \\
$\begin{array}{l}\text { VAN FINAN. } \\
\text { (SOLES) }\end{array}$ & $2.337 .482,80$ & $2.794 .202,82$ & $2.565 .842,81$ & $2.565 .842,81$ & $8,90 \%$ & $8,90 \%$ \\
TIR FINAN. & $28,94 \%$ & $34,56 \%$ & $31,74 \%$ & $31,74 \%$ & $8,90 \%$ & $8,80 \%$ \\
\hline Elaboración propia
\end{tabular}

Para el caso del límite inferior se sigue teniendo una TIR, tanto económica como financiera, mayor al COK (14\%), además se evidencia que no existe una gran disminución de esta, ya que varía en aproximadamente 10\%, al cambiar en $10 \%$ el costo del combustible. Así mismo, también se cuenta con un VAN mucho mayor a cero.

Por otro lado, esta sensibilidad resultaría bastante beneficiosa si se usa a favor del proyecto, prueba de ello es una TIRF casi de $35 \%$ en el escenario optimista, lo cual indica 
que el negocio sería rentable; sin embargo, es importante mencionar que cuando baja el costo del insumo, probablemente lo que haría la estación de servicio sería también reducir el precio al cliente final para ser competitivo y de la misma manera, cuando suba el costo, la empresa subiría el precio al cliente final para mantener el margen de ganancia.

Otra variable importante es la cantidad de galones vendidos, la cual cambiaría por ejemplo según el éxito que tenga la publicidad y la estrategia de entrada del proyecto en mención.

Acto seguido, se presenta el cuadro resumen de los resultados de forma similar que en el caso de la variable costos:

Tabla 7.54

Análisis variación de ventas de combustibles +-10\%

\begin{tabular}{|c|c|c|c|c|c|c|}
\hline Ratio & $\begin{array}{l}\text { Lim. } \\
\text { Inferior }\end{array}$ & $\begin{array}{l}\text { Lim. } \\
\text { Superior }\end{array}$ & Promedio & $\begin{array}{l}\text { Valor } \\
\text { actual }\end{array}$ & Aumento & Disminución \\
\hline $\begin{array}{l}\text { VAN ECON. } \\
\text { (SOLES) }\end{array}$ & $2.016 .515,01$ & $2.429 .064,82$ & $2.222 .789,91$ & $2.222 .789,91$ & $9,28 \%$ & $9,28 \%$ \\
\hline TIR ECON. & $22,55 \%$ & $26,39 \%$ & $24,46 \%$ & $24,46 \%$ & $7,90 \%$ & $7,80 \%$ \\
\hline $\begin{array}{l}\text { VAN } \\
\text { FINAN. } \\
\text { (SOLES) }\end{array}$ & $2.337 .482,80$ & $2.794 .202,82$ & $2.565 .842,81$ & $2.565 .842,81$ & $8,90 \%$ & $8,90 \%$ \\
\hline TIR FINAN. & $28,94 \%$ & $34,56 \%$ & $31,74 \%$ & $31,74 \%$ & $8,90 \%$ & $8,80 \%$ \\
\hline
\end{tabular}

Elaboración propia

Se puede concluir que la variable ventas es similar a la variable costos en lo que concierne a sensibilidad, pues los limites inferior y superior de las VAN y TIR económicas y financieras son bastante similares en ambos casos.

Además, también se analizó la variable "cama" por cada tanque a usar, puesto que si bien es cierto existe una metodología previa para calcular su volumen, este valor no es exacto en la realidad. Bajo las mismas premisas planteadas al inicio se obtuvo una $\mathrm{VANF}=<8.969 .778,49 ; 8.969 .313,05>$. Con respecto al valor actual que es de 8.602.783 se puede notar que la variación máxima es de $4.26 \%$ la cual no resulta significativa comparando con la variación producto de las variables costos de combustible y venta de combustible; que en ambos casos fueron de 9.28\% que representa casi el doble del impacto que tuvo la variable "cama". 
En este sentido se concluye que las variables más importantes según el análisis de sensibilidad haciendo uso de la herramienta Risk Simulator son el costo de los combustibles y el volumen de venta de combustible que fueron analizados en la primera parte de la presente sección.

\section{Tabla 7.55}

Impacto de variables en la VANF

\begin{tabular}{l|c}
\hline \multicolumn{1}{c|}{ Variable } & Variación máxima de VANF \\
\hline Cama & $4,26 \%$ \\
Costo de combustibles & $9,28 \%$ \\
Volumen de venta & $9,28 \%$ \\
\hline
\end{tabular}

Elaboración propia 


\section{CAPÍTULO VIII. EVALUACIÓN SOCIAL DEL PROYECTO}

\subsection{Identificación de las zonas y comunidades de influencia del proyecto}

El proyecto influirá en las personas que se encuentran en las zonas y comunidades más cercanas; en este sentido se pueden identificar 2 lugares públicos de alta concurrencia que son el centro comercial Open Plaza y el Instituto Continental y a las personas que frecuenten la calle Real, la cual es una de las calles principales de la ciudad de Huancayo, y el Pasaje Salesiano. La zona de influencia también comprende todos los lugares que pueden ser potencialmente afectados en el corto, mediano o largo plazo como negocios locales, otras estaciones de servicio, etc.

\subsection{Impacto en la zona de influencia}

Este proyecto posee un impacto positivo en sus zonas de influencia y en las personas que la conforman debido a que la estación de servicios mejorará la calidad de vida de la comunidad al brindar facilidad para poder encontrar varios servicios no relacionados e indispensables en un solo lugar.

Por otro lado, la implementación de la estación de servicios generará varios puestos de trabajo; no solo para laborar en la empresa de forma directa, sino también de forma indirecta en los negocios de oferta retail.

Así mismo, la empresa manejará un compromiso con el medio ambiente bien marcado al seguir las políticas expuestas a lo largo del trabajo y velará por la seguridad propia y de la comunidad en general.

Este proyecto va a tener un beneficio directo en la comunidad, ya que demostrará que una estación de servicios de primer nivel y alta calidad no solo es exclusiva de las ciudades centralizadas de Perú (como Lima) e impulsará la modernización de la ciudad. 


\subsection{Impacto social del proyecto}

Además de los beneficios antes mencionados, también se puede decir que el proyecto generará un beneficio extra a la sociedad por medio del pago de impuestos al estado peruano.

La tasa social de descuento general es del $0 \%$ porque la inversión que se realizará es privada y la rentabilidad de la empresa beneficiará de forma exclusiva a los accionistas de la misma.

La inversión total asciende a S/ 5.995.961 y genera 13 puestos de trabajo directos. En resumen, y como se muestra en la tabla adjunta, se necesita una inversión de S/ 461.228 para crear un puesto de trabajo.

Por otro lado, se puede apreciar que el proyecto genera 2,65 soles de valor agregado por cada sol de inversión lo cual indica que lo que genera es mucho mayor a lo que demanda el proyecto.

Tabla 8.1

Cálculo del valor agregado del proyecto (en soles)

\begin{tabular}{l|ccccc}
\hline \multicolumn{1}{c|}{ Año } & $\mathbf{2 0 1 9}$ & $\mathbf{2 0 2 0}$ & $\mathbf{2 0 2 1}$ & $\mathbf{2 0 2 2}$ & $\mathbf{2 0 2 3}$ \\
\hline Utilidad antes de Impuestos & 1.667 .530 & 1.905 .306 & 2.086 .368 & 2.232 .473 & 2.382 .939 \\
Salarios anuales & 426.953 & 426.953 & 426.953 & 426.953 & 426.953 \\
Interes de deuda & 266.537 & 221.550 & 171.215 & 114.895 & 51.878 \\
Amortización de deuda & 378.355 & 423.342 & 473.677 & 529.997 & 593.014 \\
Depreciación & 55.430 & 55.430 & 55.430 & 55.430 & 54.782 \\
Valor agregado & $\mathbf{2 . 7 9 4 . 8 0 5}$ & $\mathbf{3 . 0 3 2 . 5 8 1}$ & $\mathbf{3 . 2 1 3 . 6 4 3}$ & $\mathbf{3 . 3 5 9 . 7 4 8}$ & $\mathbf{3 . 5 0 9 . 5 6 6}$ \\
\hline
\end{tabular}

Elaboración propia

Tabla 8.2

Indicadores de evaluación social

\begin{tabular}{l|r}
\hline Valor agregado acumulado (soles) & $\mathbf{1 5 . 9 1 0 . 3 4 2}$ \\
Valor agregado acumulado/Inversión Total & $\mathbf{2 , 6 5}$ \\
Inversión Total/N $\mathbf{N}^{\circ}$ empleos & $\mathbf{4 6 1 . 2 2 8}$ \\
\hline Elaboración propia &
\end{tabular}




\section{CONCLUSIONES}

- El presente proyecto es justificable desde el punto de vista tecnológico por la gran disponibilidad y variedad de proveedores y tecnología existente en Perú e incluso a nivel local en Huancayo.

- El proyecto propuesto es viable a nivel del macroentorno económico puesto que se ha registrado en los últimos años un gran aumento de la demanda ante una oferta constante.

- El presente modelo de estación de servicio planteado que ofrece servicios extras de oferta retail no relacionados, con un marcado interés en la responsabilidad social y ambiental, posee una gran aceptación en el parque automotor de Huancayo, lo cual da una base sólida al proyecto.

- El poseer servicios extras dentro del grifo, permitirá a este último diferenciarse y además obtener una mayor fidelidad del cliente, ya que cada vez son más las personas que tienden a realizar sus compras en centros de negocios integrados que impliquen facilidad, movimiento y rapidez. La ubicación y la impecable imagen y estado de las instalaciones de la estación de servicios impactarán de forma positiva en el rendimiento de los servicios complementarios instalados.

- Luego de realizar un análisis del macro y micro entorno, se determinó que existe una oportunidad de negocio bastante buena en esta industria ya que, si bien es cierto que el poder de los compradores y proveedores es alto, el producto posee una amenaza casi nula de productos sustitutos además de que el riesgo de ingreso de nuevos competidores es moderado teniendo en cuenta la alta inversión inicial y la experiencia previa que se necesita en el sector. En el ámbito del macro entorno, el gran incremento del poder adquisitivo de los peruanos conjuntamente con la existencia de una asociación que vele por los derechos e intereses de los vendedores de isla como AGESP, hacen aún más atractivo el sector.

- El sector industrial posee una demanda totalmente creciente con proyección a seguir esta misma tendencia a futuro, esto se debe principalmente al gran incremento del parque automotor en Huancayo. 
- Existe una gran rivalidad entre competidores en el mercado actual de estaciones de servicio en Huancayo. Los competidores más importantes son las cadenas de grifos locales; no obstante, también se deduce que, de cumplir con todas las especificaciones desarrolladas en este documento, el grifo que se está planteando no tendría mayor inconveniente, puesto que cumple con todos los factores críticos abstraídos de los gustos y preferencias del cliente.

- La capacidad instalada se ve limitada por el tamaño tecnología, específicamente por el número de surtidores. A pesar de que la estación de servicios no tendría ningún inconveniente en cubrir la demanda proyectada hasta el 2023, se consideró en la distribución del terreno, espacio suficiente como para la instalación de nuevos surtidores para un posible exceso de demanda posterior.

- El total de inversión que se necesita es de S/.5.995.961, de los cuales más del 80\% corresponde a activo fijo tangible (S/.5.236.219); además incluye S/.408.903 de capital de trabajo para iniciar operaciones de la estación de servicios.

- Se obtuvo un VAN económico de S/ 2.222.790; VAN financiero de S/ 2.565.843; TIR económico de $24 \%$ y TIR financiero de $32 \%$; de lo cual se concluye que el proyecto genera rentabilidad con o sin financiamiento, no obstante, con la última opción la rentabilidad es mayor.

- Teniendo en cuenta que el tamaño mercado es de 2.469.220,37 galones anuales y el tamaño punto de equilibrio es de 440.655; se puede apreciar que el punto de equilibrio se encuentra muy por debajo de la demanda, lo cual reduce bastante el riesgo de no generar utilidades.

- Se puede concluir que la variable ventas es similar a la variable costos con respecto a la sensibilidad, pues los límites inferior y superior de las VAN y TIR económicas $\mathrm{y}$ financieras son similares.

- El proyecto posee un impacto social positivo ya que genera 2,65 soles de valor agregado por cada sol invertido; es decir, lo que genera es mucho mayor a lo que demanda. 


\section{RECOMENDACIONES}

A continuación, detallaremos las recomendaciones:

- Evaluar el negocio en estos años del horizonte del proyecto y si resulta exitoso, empezar a replicar el modelo y crear una cadena, ya que además de generar mayores ganancias, la marca también se empezaría a hacer más conocida.

- Estar abiertos siempre a las críticas y oportunidades de mejora; además, tener flexibilidad para el cambio; por ejemplo, cambiar alguna tienda de conveniencia de acuerdo a como varían las necesidades de las personas.

- Mantener un constante monitoreo a la competencia para ofrecer siempre al cliente para captar sus necesidades y ofrecerles un valor diferenciado de forma constante e innovadora.

- Realizar promociones personalizadas para los clientes que dan mayores ganancias a la empresa y de esta manera, fidelizarlos.

- Mantener un buen ambiente de trabajo, tanto entre el personal operativo como administrativo, para que este sea reflejado en la atención al público.

- Crear indicadores en cada área para medir constantemente el buen desempeño del negocio y poder elaborar planes de acción a tiempo.

- Cumplir con las políticas de medio ambiente y seguridad con bastante disciplina, implementando los puntos de control expuestos en el trabajo y aplicando la mejora continua, para que de esta manera se cuide la buena reputación de la empresa y se evite que se involucre en algún evento de negligencia.

- Se recomienda ofrecer un canal de distribución adicional a la vía tradicional que abastezca el combustible en el local de forma directa. Este nuevo canal consistiría en llevar combustible al lugar que solicite el cliente (previa negociación, pedido mayor o igual a 1.000 galones de combustible). Para contar con este segundo canal de distribución, será necesario la compra de un camión cisterna de capacidad de 1.500 galones.

Este servicio de delivery estaría respaldado por la marca Petrogreen y pasaría a formar parte del grupo de ventajas competitivas que posee la estación de servicios. 
Cabe resaltar, que el camión cisterna debe llevar el combustible desde la planta de Petroperú hacia el punto solicitado. 


\section{REFERENCIAS}

AGESP. (25 de Enero de 2017). Acta de Asamblea General. Recuperado de http://agesp.com/

Asociación Automotriz del Perú. (2018). Venta e Inmatriculación de Vehículos Nuevos $2018 . \quad$ Recuperado de https://aap.org.pe/estadisticas/ventas_inmatriculaciones_vehiculos_nuevos/inm2018/

Cámara Lima. (2018). Aumento continuo del Parque Automotor. Recuperado de https://www.camaralima.org.pe/repositorioaps/0/0/par/r816_3/comercio\%20exte rior.pdf

Cotrina, J. M. (2 de Marzo de 2014). Prezi. Recuperado de http://es.slideshare.net/juanmanueljaracotrina/monografia-sistemas-deinformacion-en-las-estaciones-de-servicio

Diario Correo. (2016). Subempleo alcanza a más del 50\% de la PEA en Junín . Recuperado de http://diariocorreo.pe/ciudad/subempleo-alcanza-a-mas-del-50de-la-pea-en-junin-694889/

Gestión. (2016). Parque vehicular en Perú se incrementó en $63 \%$ en los últimos 10 años. Recuperado de https://gestion.pe/economia/parque-vehicular-peru-incremento63-ultimos-10-anos-152332

Gestión. (15 de Diciembre de 2018). Parque vehicular en Perú se incrementó entre 2012 y 2017. Recuperado de https://gestion.pe/economia/incremento-desde2012-de-vehiculos

Gestión. (2018). Existen más de 4,700 estaciones de servicio en todo el país. Recuperado de https://gestion.pe/economia/existen-4-700-estaciones-servicio-pais-226062

MIMP. (2018). Normas para personas con discapacidad. Recuperado de https://www.mimp.gob.pe/adultomayor/archivos/Norma_A_120.pdf

MINEM. (2014). Decreto Supremo $N^{\circ} 039-2014-E M$. Recuperado de http://www.minem.gob.pe/minem/archivos/DS-039-2014-EM(2).pdf 
Neufert, E. (2013). Arte de proyectar en arquitectura. Barcelona: Gustavo Gili.

OSINERGMIN . (2018). Reporte semestral del monitoreo del mercado ehidrocarburos. Recuperado de http://www.osinergmin.gob.pe/seccion/centro_documental/Institucional/Estudio s_Economicos/Reportes_de_Mercado/RSMMH-II-2017.pdf

Palacios Palacios, J. L. (2017). Plan de negocios de la empresa El Sol S.A. como distribuidor mayorista de combustibles líquidos en Lima y Callao. Recuperado de www.ulima.edu.pe

Petroperú. (2018). Memoria anual Petroperú 2017. Recuperado de https://www.petroperu.com.pe/transparencia/archivos/MemoriaPETROPERU20 17.pdf

Scamarone Ampuero, F. A. (2017). Estudio preliminar para la instalación de una estación de servicio de combustibles . Recuperado de www.ulima.edu.pe

Wapa Perú. (2017). Sociedad Anónima Cerrada S.A.C. Recuperado de http://wapaperu.mpdl.org/index.php?option=com_content $\&$ view $=$ article $\& i d=19$ $8 \&$ Itemid $=24$ 


\section{BIBLIOGRAFÍA}

Alvaro Carvajal, J. J. (2012). Análisis de factibilidad para la implementación e instalación de una estación de servicios de combustibles derivados del petroleo en el sector Chongon. Guayaquil: Escuela superior Politecnica del Litoral.

Barletta, F., Pereira, M., Robert, V., \& Yoguel, G. (2013). Argentina: dinámica reciente del sector de software y servicios informáticos. Revista de la CEPAL(110), 137$155 . \quad$ Recuperado de http://www.cepal.org/publicaciones/xml/1/50511/RVE110Yoqueletal.pdf

Boletin empresarial. (20 de Abril de 2017). Boletin empresarial. Recuperado de Boletin empresarial: http://aempresarial.com/web/informativo.php?id=19852

Choy, M., \& Chang, G. (2014). Medidas macroprudenciales aplicadas en el Perú. Lima: Banco Central de Reserva del Perú. Recuperado de http://www.bcrp.gob.pe/docs/Publicaciones/Documentos-deTrabajo/2014/documento-de-trabajo-07-2014.pdf

Chuquihuaccha, B. (2007). Estudio de Impacto Ambiental para viabilidad de una estación de servicios de combustibles líquidos. Recuperado de cybertesis.uni.edu.pe/bitstream/uni/342/1/chuquihuaccha_lb.pdf

Cuesta, J. (26 de Noviembre de 2015). La importancia del ciclo de servicio. Recuperado de https://prezi.com/qqrx_u_vzfvq/la-importancia-del-ciclo-de-servicios/

Funseam. (01 de Setiembre de 2016). Fundación de sostenibilidad energética y ambiental. Recuperado de Fundación de sostenibilidad energética y ambiental: http://www.funseam.com/es/observatorio-best-practices/repsol-sl/estaciones-deservicio-sostenibles

Gestión. (2017). Determinando la tasa de descuento de un proyecto (caso práctico). Recuperado de http://blogs.gestion.pe/deregresoalobasico/2017/02/determinando-la-tasa-dedescue-2.html

Gestión. (11 de Enero de 2017). Se venderían 180,000 vehículos nuevos en el presente año, afirma Scotiabank, pág. 3. Recuperado de https://gestion.pe/economia/venderian-180-000-vehiculos-nuevos-presente-anoafirma-scotiabank-126352 
Gestión. (2018). CCL: Vehículos con mayor antigüedad y de mayor contaminación deberían pagar el impuesto vehicular. Recuperado de https://gestion.pe/economia/ccl-vehiculos-mayor-antigueedad-mayorcontaminacion-deberian-pagar-impuesto-vehicular-228273

Importaciones y Tecnologías. (2013). Importaciones y Tecnologías. Recuperado de http://www.imptec.com.pe/index.php/productos/estaciones-de-servicios

INEI. (14 de Octubre de 2015). Menu Recursivo. Recuperado de INEI: https://www.inei.gob.pe/media/MenuRecursivo/publicaciones_digitales/Est/Lib 0883/Libro.pdf

MINEM. (2015). Decreto Supremo $N^{o}$ 054-93-EM. Recuperado de http://www.osinergmin.gob.pe/seccion/centro_documental/PlantillaMarcoLegal Busqueda/Modificatoria\%20del\%20Reglamento\%20de\%20seguridad\%20para\% 20Establecimientos\%20de\%20Venta\%20al\%20Publico\%20de\%20Combustible s\%20Derivados\%20de\%20Hidroc.pdf

Ministerio de Economía y Finanzas. (2018). MEF : economía peruana crecería más de $3.6 \%$ este año y superaría el 5\% hacia el 2021. Recuperado de https://andina.pe/agencia/noticia-mef-economia-peruana-creceria-mas-36-esteano-y-superaria-5-hacia-2021-711291.aspx

Ministerio de Vivienda, Construcción y Saneamiento. (2017). Norma A.120. Accesibilidad para personas con discapacidad y de las personas adultas mayores. Recuperado https://www.mimp.gob.pe/adultomayor/archivos/Norma_A_120.pdf

MTC. (20 de Junio de 2017). Ministerio de transporte y comunicaciones. Recuperado de Ministerio de transporte y comunicaciones: http://www.mtc.gob.pe/estadisticas/publicaciones.html

Oro Azul. (2017). Estudio de impacto ambiental definitivo de la estación de servicio "Virgen de Fátima". Recuperado de https://maeloja.files.wordpress.com/2015/04/estudio-de-impacto-ambientalgasolinera-catacocha.pdf

OSINERGMIN. (2017). ¿Cómo supervisa Osinergmin que los grifos vendan combustibles de buena calidad? Recuperado de http://www.osinergmin.gob.pe/grifos/supervision/supervisi\%C3\%B3n-grifos 
Osinerming. (2012). Facilito. Recuperado de Facilito: http://www.facilito.gob.pe/facilito/pages/facilito/menuPrecios.jsp

Osinerming. (2015). La industria de los hidrocarburos líquidos en Perú. Lima: GRÁFICA BIBLOS S.A.

Pemex. (15 de Abril de 2002). Pemex. Recuperado de Pemex: http://www.ref.pemex.com/octanaje/o38/16.htm

Petroperú S.A. (2016). Memoria Anual 2016. Recuperado de https://www.petroperu.com.pe/transparencia/archivos/MemoriaPETROPERU20 16.pdf

RPP Noticias. (2018). González Izquierdo negó que alza del ISC ayude a reactivar la economía en el corto plazo. Recuperado de https://rpp.pe/economia/economia/video-gonzalez-izquierdo-niega-que-alza-delisc-ayude-a-reactivar-la-economia-en-el-corto-plazo-noticia-1122285

Secretaria ambiental. (14 de Octubre de 2008). Secretaria ambiental. Recuperado de Secretaria ambiental: http://www.seam.gov.py/sites/default/files/users/control/gas.corona_trinidad_ad elaida.pdf

SUNAT. (10 de Junio de 2016). Aduanet. Recuperado de Aduanet: http://www.aduanet.gob.pe/operatividadAduana/

Wittmann, R. (2006). ¿Hubo una revolución en la lectura a finales del siglo XVIII? En G. Cavallo, \& R. Chartier, Historia de la lectura en el mundo occidental (págs. 435-472). México D.F.: Santillana. 
ANEXOS 


\section{ANEXO 1: Encuesta para estudio de mercado}

1. Conduce Ud. un vehículo

Sí

No (Fin de encuesta)

2. Transita frecuentemente por la ciudad de Huancayo

Sí

No (Fin de encuesta)

3. En qué distrito vive:

4. Qué tipo de vehículo maneja

- Auto

- Camioneta

- Minivan

- Camión

- Tráiler

5. Tipo de combustible que usa para su vehículo

- Diésel B5 S50 UV

- $\quad$ Gasohol 97

- Gasohol 95

- Gasohol 90

- $\quad$ Gasohol 84

- GLP (gas licuado de petróleo)

- Otros:

6. ¿Cuál de las siguientes cadenas de grifos es de su preferencia?

- Petroperú

- Primax

- Ava

- Repsol

- Otros: 
7. Con qué frecuencia asiste a una estación de servicios.

- Diaria

- 2 veces por semana

- 1 ves por semana

- 2 veces por mes

- 1 ves por mes

8. Cuántos galones en promedio consume en cada visita:

9. Elija cuatro de los siguientes servicios que más le interesaría en una estación de servicio

- Mini market

- Comida Rápida

- Cajeros automáticos

- Agente de banco

- Farmacia

- Tienda de detalles y regalos

- Lavandería

- Café

10. Elija 2 de los siguientes servicios que más le interesaría en una estación de servicio

- Servicio técnico

- Servicio de llantas

- Tienda y cambio de aceite

- Lavado y engrase

- Alineación y balanceo

11. Elija 3 de las siguientes características que más le interesaría en una estación de servicio

- Precios bajos

- Calidad de atención por parte de los griferos

- Promociones

- Calidad y cantidad exacta de combustible

- Multiservicio

12. Elija 2 de las siguientes promociones que más le interesaría en una estación de servicio

- Prendas de vestir

- Descuentos en combustibles

- Lubricantes

- Descuentos en otras tiendas

- Otros: 
13. En qué parte de Huancayo le gustaría que se encuentre ubicada la estación de servicios:

14. De instalarse en Huancayo una nueva estación de servicios que ofrezca todos los tipos de combustibles, con alta calidad de servicios y con servicios adicionales como comida rápida, agentes bancarios, farmacias, entre otros, ¿usted asistiría?

- Sí

- No

15. Si respondió sí, de la siguiente escala qué tan seguro esta de su intención de asistir a la estación de servicios, siendo 1 improbable que asista y 10 definitivamente asistiría.

$\begin{array}{llllllllll}1 & 2 & 3 & 4 & 5 & 6 & 7 & 8 & 9 & 10\end{array}$




\section{ANEXO 2: Modelo de contrato de exclusividad de abastecimiento con Petroperú}

A continuación, se detalla la plantilla tentativa de dicho convenio:

MODELO DE CONTRATO DE PROMOCIÓN DE VENTAS N [*]-[*]-20[*]

Conste por el presente documento el Contrato de Promoción de Ventas, que celebran de una parte:

Petróleos del Perú - PETROPERÚ S.A., con Registro Único de Contribuyente (RUC) $\mathrm{N}^{\circ}$ 20100128218, con domicilio en Av. Enrique Canaval Moreyra No 150, San Isidro, Lima, debidamente representada por su Gerente [*], Sr. [*], identificado con DNI $\mathrm{N}^{\circ}\left[{ }^{*}\right]$, debidamente facultado con poderes inscritos en el Asiento $\mathrm{N}^{\circ}\left[{ }^{*}\right]$ de la Partida Electrónica № 11014754 del Registro de Personas Jurídicas de la Zona Registral $N^{\circ}$ IX - Sede Lima de la Superintendencia Nacional de los Registros Públicos (SUNARP), en adelante, PETROPERÚ; y de la otra parte,

[*], con Registro Único de Contribuyente (RUC) $\mathrm{N}^{\circ}{ }^{[*]}$, con domicilio en [*], Distrito de [*], Provincia de [*] y Departamento de [*], debidamente representado por su [*], el(la) $\operatorname{Sr}(a)$. [*] $^{*}$, identificado(a) con DNI $\mathrm{N}^{\mathrm{o}}\left[{ }^{*}\right]$, con Poder inscrito en la

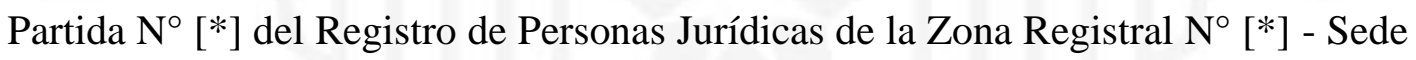
[*] de la Superintendencia Nacional de los Registros Públicos (SUNARP), con código de cliente $\mathrm{N}^{\circ}\left[{ }^{*}\right]$, código destinatario $\mathrm{N}^{\circ}{ }^{[*]}$ y Ficha de Registro

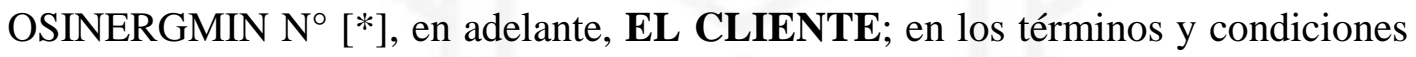
siguientes:

\section{CLÁUSULA PRIMERA: OBJETO DEL CONTRATO}

Por el presente Contrato, EL CLIENTE se obliga a adquirir en forma exclusiva de PETROPERÚ, todos los combustibles y otros productos derivados de los hidrocarburos que requiera, utilizando el nombre de PETROPERÚ y sus signos distintivos, únicamente para la venta de los referidos productos. 


\section{CLÁUSULA SEGUNDA: PLAZO DEL CONTRATO}

Las partes acuerdan que el plazo de vigencia del presente Contrato será de [*] ([*]) años, período que se computará a partir de la fecha de su suscripción.

Al término del plazo de vigencia del presente Contrato, éste se prorrogará automática y consecutivamente por períodos de un (1) año, salvo que, alguna de las partes manifieste a la otra su voluntad de no renovarlo, hecho que deberá ser comunicado por escrito y con una anticipación no menor de treinta (30) días calendario a la fecha de vencimiento.

\section{CLÁUSULA TERCERA: PRECIO Y FORMA DE PAGO}

3.1. PETROPERÚ facturará a EL CLIENTE sus productos al precio de venta en Planta, según lo establecido en la Lista Oficial de Precios que PETROPERÚ tenga vigente a la fecha de la venta, sobre el cual, PETROPERÚ podrá aplicar un descuento que será informado oportunamente a EL CLIENTE. La Lista Oficial de Precios de PETROPERÚ puede ser modificada sin previo aviso.

3.2. Las partes acuerdan que, en caso EL CLIENTE efectúe el pago de sus facturas mediante la utilización de cheques que no puedan hacerse efectivos, PETROPERÚ aplicará, sin requerimiento previo y de manera automática, a partir del día siguiente en que debió realizarse dicho pago, hasta el día en que éste se haga efectivo, el interés moratorio y compensatorio según la Tasa Activa para Moneda Nacional (TAMN), publicada por el Banco Central de Reserva del Perú al día siguiente en que EL CLIENTE debió hacer el pago, así como los costos financieros y gastos administrativos que correspondan.

33. En el caso de ventas al crédito, EL CLIENTE deberá extender a favor de PETROPERÚ, una Carta Fianza Bancaria irrevocable, solidaria, incondicionada, de 
realización automática y sin beneficio de excusión u otra garantía que PETROPERÚ previamente apruebe, por el monto contemplado en la Autorización de Facilidad de Pago otorgada a EL CLIENTE. La Carta Fianza Bancaria u otra garantía previamente aprobada por PETROPERÚ, deberá ser presentada por EL CLIENTE antes de la primera compra a crédito y con una vigencia en función al tiempo que EL CLIENTE estime utilizar este sistema de compra. Excepcionalmente, se podrá otorgar a EL CLIENTE crédito sin garantía, siempre y cuando cumpla con los requisitos previstos en el Manual de Créditos y Cobranzas vigente de PETROPERÚ.

3.4. Las facturas serán emitidas una vez que el Producto sea entregado a EL CLIENTE o a las personas autorizadas por aquél.

35. El plazo para el pago de las facturas por ventas al crédito será contabilizado desde la fecha de emisión de la factura. En caso que EL CLIENTE no cumpla con el pago de las facturas dentro del plazo establecido en la Autorización de Facilidad de Pago o Autorización de Línea de Crédito, según corresponda, PETROPERÚ aplicará, sin requerimiento previo y de manera automática, a partir del día siguiente al vencimiento de la factura y hasta el día efectivo de su pago, el interés moratorio y compensatorio según la Tasa Activa para Moneda Nacional (TAMN), publicada por el Banco Central de Reserva del Perú al día siguiente del vencimiento del pago de la factura, así como los costos financieros y gastos administrativos que correspondan.

3.6. En la eventualidad que la fecha de vencimiento de la factura se produzca en “día no hábil” (que para efectos del presente Contrato, se entenderá el sábado, domingo o feriado a nivel nacional o regional establecido por la autoridad competente), EL CLIENTE deberá cancelarla el día hábil inmediato siguiente al de la fecha de vencimiento. 
3.7. En caso EL CLIENTE no cancele las facturas vencidas, PETROPERÚ podrá suspender el suministro hasta que EL CLIENTE cumpla con su obligación de pago, sin perjuicio de la aplicación de los intereses antes señalados y de la facultad de resolver el Contrato y ejecutar las garantías otorgadas a su favor.

3.8 EL CLIENTE declara que, en caso que garantice el cumplimiento de sus obligaciones derivadas de la adquisición o suministro de combustibles por éste u otros contratos que celebre con PETROPERÚ, mediante alguna fianza, hipoteca u otra garantía real o personal a favor de PETROPERÚ, dichas garantías ampararán además el cumplimiento de cualquier otra obligación derivada del presente Contrato, incluido el pago de intereses, penalidades, reembolsos, indemnizaciones por daños y perjuicios o cualquier otro concepto que EL CLIENTE adeude a PETROPERÚ.

\section{CLÁUSULA CUARTA: FLETE}

El servicio de transporte de la Planta y/o Terminal de Ventas al establecimiento de EL CLIENTE, será responsabilidad exclusiva de EL CLIENTE, salvo pacto en contrario, en cuyo caso se firmará una adenda que formará parte integrante de este Contrato.

\section{CLÁUSULA QUINTA: RESPONSABILIDADES DEL CLIENTE}

Las partes acuerdan expresamente que los siguientes hechos son de responsabilidad única y exclusiva de EL CLIENTE:

5.1. PETROPERÚ no es partícipe de los actos y relaciones jurídicas que celebre EL CLIENTE con terceros, por lo que en ningún caso será responsable por cualquier actuación de EL CLIENTE que resulte ajena a los términos o condiciones del presente Contrato. En particular, será de exclusiva responsabilidad de EL CLIENTE el cumplimiento de las normas y regulaciones de protección al consumidor, debiendo además proteger la imagen y reputación de PETROPERÚ frente al público y los consumidores. 
5.2. PETROPERÚ no tendrá responsabilidad legal (civil, penal ni administrativa) por la calidad de los productos o por el manejo inadecuado de los combustibles por parte de EL CLIENTE o las personas que los transportan, desde el momento en que los combustibles sean despachados de la Planta y/o Terminal de Ventas de PETROPERÚ.

5.3. Cualquier daño al ambiente por derrames u otros eventos, ocurridos después de que el producto es despachado de la Planta y/o Terminal de Ventas de PETROPERÚ, incluido su transporte, así como los ocasionados por EL CLIENTE en el Grifo y/o Estación de Servicios, incluyendo las eventuales necesidades de remediación ambiental y los reclamos o conflictos de índole social o similares que pudieran sucederse como consecuencia de dichos derrames u otros eventos, serán de exclusiva responsabilidad de EL CLIENTE, debiendo proteger y preservar la imagen y reputación de PETROPERÚ.

\section{CLÁUSULA SEXTA: OBLIGACIONES DE PETROPERÚ.}

Por el presente Contrato PETROPERÚ se obliga a:

6.1. Garantizar, como productor de combustibles, el abastecimiento oportuno y periódico de los productos pactados a EL CLIENTE, salvo que existan razones de índole operativo o situaciones que califiquen como caso fortuito o fuerza mayor. Estas situaciones deberán ser comunicadas oportunamente a EL CLIENTE.

6. Otorgar a EL CLIENTE el apoyo promocional y publicitario que PETROPERÚ considere necesario, a fin de incentivar las ventas del Grifo y/o Estación de Servicios.

63. Asistir, capacitar y asesorar técnicamente a EL CLIENTE y su personal, cuando resulte necesario. 
64. Realizar la identificación y el mantenimiento del Grifo y/o Estación de Servicios denominado [*], ubicado en [*], Distrito de [*], Provincia de [*] y Departamento de [*], de acuerdo a las especificaciones, colores, marcas y diseños establecidos por PETROPERÚ.

65. Otorgar uniformes de acuerdo a las especificaciones, colores y diseños establecidos por PETROPERÚ (de acuerdo a las políticas promocionales y publicitarias vigentes).

\section{CLÁUSULA SÉTIMA: OBLIGACIONES DE EL CLIENTE}

Por el presente Contrato EL CLIENTE se obliga a:

7.1. Mantener durante el período de vigencia del presente Contrato la identificación del establecimiento según las especificaciones, colores, diseño y demás características contenidas en el Manual de Identificación de Estaciones de Servicio afiliadas a PETROPERÚ vigente, no pudiendo realizar cambios a los colores, ni a los signos distintivos y/o marcas con que se identifiquen las edificaciones, instalaciones y equipos.

72. Cumplir con todas las obligaciones legales a su cargo y contar con todos los permisos y autorizaciones necesarias para comercializar combustibles.

73. Cumplir de manera oportuna con el pago al que se refiere la Cláusula Tercera del presente Contrato.

7.4. Vender exclusivamente en el establecimiento, los combustibles y otros productos suministrados por PETROPERÚ, los cuales serán adquiridos por EL CLIENTE directamente de PETROPERÚ y comercializados a través de los 
establecimientos indicados en el numeral 6.4 de la Cláusula Sexta del presente Contrato.

75. Dar correcto uso al material de publicidad y promoción de ventas que le suministre PETROPERÚ, colocando los avisos, carteles y otros materiales proporcionados por PETROPERÚ con dicho fin.

7.6. Mantener el Grifo y/o Estación de Servicios bajo niveles óptimos de organización, orden y limpieza. PETROPERÚ podrá efectuar visitas sin previo aviso a fin de comprobar el cumplimiento de esta obligación.

7.7. Realizar oportunamente los trámites que resulten necesarios para la identificación del Grifo y/o Estación de Servicios, así como asumir el pago de los tributos por publicidad ante la Municipalidad correspondiente. Cualquier multa o sanción por la omisión de la presente obligación será asumida por EL CLIENTE.

78. Mantener debidamente uniformado al personal que atiende en el Grifo y /o Estación de Servicios, procurando el adecuado uso de los uniformes con los colores y logos de PETROPERÚ, además de la presentación del personal general y de isla, conforme con la práctica establecida por PETROPERÚ.

79. Facilitar a los representantes autorizados de PETROPERÚ, la realización de visitas al establecimiento, cuantas veces fuera necesario, a fin de verificar el cumplimiento de los términos de este Contrato, así como, permitirle realizar tomas de muestras de combustibles con la finalidad de velar por su calidad y cantidad.

7.10. Asistir a los cursos de capacitación que PETROPERÚ organice, así como brindar las facilidades del caso al personal a su cargo, que también será capacitado. La imposibilidad de asistencia deberá contar con la correspondiente justificación. 
7.11. Comunicar y solicitar previamente la autorización de PETROPERÚ para instalar y/o realizar publicidad de otros productos y/o servicios complementarios, siempre que no compitan con los productos que le suministra PETROPERÚ.

7.12 Reparar los daños que pudiera ocasionar el personal de EL CLIENTE o terceros a las estructuras y/u otras instalaciones de propiedad de EL CLIENTE materia de la identificación, a fin de cuidar la presentación e imagen institucional de la cadena de Grifos y/o Estaciones de Servicio de la cadena PETRORED.

7.13. Defender, proteger y relevar de toda responsabilidad a PETROPERÚ y a sus empleados respecto de cualquier reclamación, pretensión, demanda o acción de cualquier índole incluyendo los costos y gastos, daños o pérdidas de cualquier clase que pudiera formularse o incurrirse por EL CLIENTE, sus empleados, agentes subcontratistas o por terceras personas, por concepto de daños personales, físicos o mentales, muerte, daños a la propiedad, lucro cesante o daño emergente causados o motivados por la actividad o la labor realizada bajo el presente contrato. Asimismo, EL CLIENTE releva a PETROPERÚ de toda responsabilidad respecto de daños que pudiera sufrir EL CLIENTE o cualquiera de sus trabajadores como consecuencia de la verificación de los tanques del Grifo y/o Estación de Servicios u otra actividad relacionada con la manipulación, traslado o despacho de los combustibles; así como en caso de asalto, ya sea en la caseta de cobro, oficina o en cualquier otra área del Grifo y/o Estación de Servicios.

7.14. Mantener precios de venta al público que sean competitivos, atendiendo a los cambios que se produzcan en el mercado y la competencia. 


\section{CLÁUSULA OCTAVA: CUMPLIMIENTO Y GESTIÓN AMBIENTAL Y SOCIAL}

8.1. Las partes se obligan a dar cumplimiento a lo dispuesto en las normas ambientales y sociales que se encuentren vigentes y a cualquier otra que resulte de aplicación para el presente Contrato.

8.2. La gestión ambiental y social de sus operaciones, tanto por acciones como por omisiones, es responsabilidad total y exclusiva de EL CLIENTE en su calidad de Titular de Actividades de Hidrocarburos en el Grifo y/o Estación de Servicios.

8.3. EL CLIENTE, en el marco de los estándares de PETROPERÚ deberá cumplir con lo establecido en los siguientes documentos: i) Política de Gestión Integrada de la Calidad, Ambiente, Seguridad y Salud en el Trabajo; ii) Política de Responsabilidad Social; y, iii) Política sobre Asuntos Comunitarios, los cuales serán entregados a EL CLIENTE a la suscripción del presente Contrato.

\section{CLÁUSULA NOVENA: PRIVACIDAD Y CONFIDENCIALIDAD EMPRESARIAL}

9.1. El CLIENTE deberá cumplir con la Política Corporativa de Seguridad de la Información de PETROPERÚ. Para tal efecto, PETROPERÚ le entregará un ejemplar del mismo a la firma del presente Contrato. Asimismo, EL CLIENTE deberá guardar confidencialidad y reserva de la información a la que acceda en virtud del presente Contrato y reportar de inmediato cualquier irregularidad de seguridad de la información detectada.

9.2. El presente Contrato ha sido negociado y será ejecutado según las reglas de buena fe y común intención de las partes. En tal sentido, EL CLIENTE se obliga a 
mantener en estricta confidencialidad toda la información recibida de PETROPERÚ o generada como consecuencia de la ejecución del presente Contrato. Asimismo, se obliga a utilizar dicha información únicamente para el cumplimiento de las obligaciones a su cargo, salvo que medie autorización expresa dada por escrito por el representante autorizado de PETROPERÚ.

9.3. Dicha obligación tiene vigencia indefinida, independientemente a la vigencia del presente Contrato y su incumplimiento hará responsable a EL CLIENTE de los daños y perjuicios que pudiera ocasionar a PETROPERÚ.

\section{CLÁUSULA DÉCIMA: CUMPLIMIENTO DE NORMAS DEL SISTEMA DE INTEGRIDAD}

EL CLIENTE deberá observar y cumplir lo dispuesto en i) el Código de Integridad de PETROPERÚ; ii) la Política Corporativa Antifraude y Anticorrupción de PETROPERÚ; y, iii) los Lineamientos del Sistema de Integridad, en lo que le sea aplicable a las obligaciones a su cargo. Para tal efecto, PETROPERÚ le entregará un ejemplar de dichos documentos a la firma del presente Contrato.

Asimismo, EL CLIENTE declara haber suscrito con carácter de declaración jurada el formulario "Conozca a su Cliente" y la "Declaración Jurada de Compromiso de lucha contra el Lavado de Activos y Financiamiento del Terrorismo", los mismos que constituyen anexos de este Contrato.

\section{CLÁUSULA DÉCIMO PRIMERA: CAMPAÑAS PROMOCIONALES}

PETROPERÚ comunicará a EL CLIENTE la realización de acciones promocionales o del inicio de campañas publicitarias en las cuales EL CLIENTE deberá participar, obligándose a lo siguiente: 
11.1 Cumplir con la activación de las campañas Publicitarias y Promocionales que realice PETROPERÚ, participando diligente y responsablemente en ellas, permitiendo la colocación de material publicitario (banderolas, afiches, ánforas, entre otros), efectuando la distribución de volantes, tickets, o cualquier otro formato publicitario y/o promocional considerado para la ejecución de las mismas.

11.2 Brindar las facilidades necesarias al personal de impulso para activaciones de campañas promocionales y a los representantes de PETROPERÚ durante el proceso de supervisión inopinada, de la correcta ejecución de las campañas.

11.3 Asumir la responsabilidad del pago de multas o sanciones impuestas por las autoridades competentes, originadas ante la indebida ejecución de las promociones o campañas publicitarias o por cualquier tipo de infracción relacionada con éstas, debiendo mantener a PETROPERÚ libre de responsabilidad ante las autoridades competentes.

11.4 Tener expuesto el material publicitario que anuncia las campañas publicitarias, durante el periodo de vigencia de las mismas y retirarlo cuando éstas hayan concluido.

11.5 Asimismo, de evidenciarse la no activación de las campañas promocionales o publicitarias o de verificarse sanciones impuestas por las autoridades por infracciones a las normas legales que regulan las actividades promocionales, su participación en campañas promocionales y publicitarias será suspendida por un semestre, contado a partir de la ocurrencia del hecho que la originó, luego de lo cual, su participación será sometida a evaluación por parte de PETROPERÚ.

11.6 PETROPERÚ comunicará a EL CLIENTE la realización de Campañas Promocionales Compartidas. En caso EL CLIENTE confirme su participación, éste participará del gasto correspondiente a la activación de dichas campañas mediante la adquisición de merchandising, productos de consumo masivo, entre otros, así como 
del gasto en la producción de banderolas, volantes, afiches, etc. destinados a su publicidad.

11.7 La aceptación por parte de EL CLIENTE de este tipo de promociones, lo obliga al cumplimiento de las obligaciones contenidas en todos los literales de la presente cláusula.

\section{CLÁUSULA DÉCIMO SEGUNDA: RESOLUCIÓN DEL CONTRATO}

12.1. PETROPERÚ podrá resolver el presente Contrato en cualquier momento y sin expresión de causa, para lo cual, comunicará por escrito a EL CLIENTE con treinta (30) días de anticipación a la fecha efectiva de resolución del Contrato, sin que haya lugar a reclamo por daños y perjuicios por parte de EL CLIENTE.

En caso que, a criterio de PETROPERÚ, existan indicios de relaciones directas o indirectas de EL CLIENTE con actividades de Lavado de Activos, Financiamiento del Terrorismo o delitos conexos, $\mathrm{u}$ otros delitos que puedan poner en riesgo la reputación de PETROPERÚ, el Contrato podrá ser resuelto por PETROPERÚ de manera unilateral e inmediata, sin necesidad de cursar la comunicación previa prevista en el párrafo anterior. En este caso, el Contrato quedará resuelto una vez recibida por EL CLIENTE la comunicación de PETROPERÚ manifestando su decisión de resolver el Contrato.

12.2. EL CLIENTE podrá resolver el Contrato, previa comunicación mediante carta notarial con treinta (30) días calendario de anticipación, debiendo abonar a PETROPERÚ la penalidad equivalente al $100 \%$ del gasto publicitario por identificación y/o mantenimiento del Grifo y/o Estación de Servicio señalado en el numeral 6.4 de la Cláusula Sexta del presente Contrato, menos un [*] $(1 /[*])$ del valor gastado en la identificación y menos un doceavo (1/12) del valor gastado en el mantenimiento por cada mes que el Contrato estuvo vigente, incluidas las prórrogas automáticas a las que se refiere la Cláusula Segunda del presente Contrato. 
Para efectos de este cálculo, PETROPERÚ comunicará por escrito los importes gastados por cada concepto y se calculará un doceavo o un [*], según corresponda, después de la comunicación efectuada por EL CLIENTE.

12.3. Asimismo, las partes de común acuerdo podrán resolver el presente Contrato, debiendo para ello suscribir el documento correspondiente. En este caso no existirán penalidades o reclamos por daños y perjuicios.

12.4. En caso de incumplimiento de obligaciones por parte de EL CLIENTE, PETROPERÚ podrá requerirle mediante Carta Notarial que satisfaga su prestación dentro de un plazo no mayor a quince (15) días calendario, bajo apercibimiento de que si la prestación no se cumple dentro del plazo señalado, el Contrato quedará resuelto de pleno derecho; en cuyo caso, EL CLIENTE estará obligado a abonar a PETROPERÚ el 100\% del gasto publicitario en que haya incurrido para la identificación y/o mantenimiento del Grifo y/o Estación de Servicios señalado en el numeral 6.4 de la Cláusula Sexta del presente Contrato, además de la respectiva indemnización por los daños y perjuicios que se deriven de dicho incumplimiento.

\section{1}

12.5. Concluida la vigencia del presente Contrato o en caso se produzca por cualquier causa su resolución, EL CLIENTE se obliga a retirar todo el material de publicidad y promoción de ventas que le haya sido proporcionado por PETROPERÚ en virtud del presente Contrato, debiendo ponerlo inmediatamente a su disposición, asumiendo todos los costos que ello implique. Adicionalmente, en un plazo no mayor de treinta (30) días calendario, EL CLIENTE se obliga a retirar toda pintura u otra característica que identifique a PETROPERÚ con el Grifo y/o Estación de Servicios, debiendo asumir todos los costos que ello implique, caso contrario, PETROPERÚ podrá iniciar las acciones legales correspondientes. 


\subsection{CLÁUSULA DÉCIMO TERCERA: CASO FORTUITO O FUERZA MAYOR}

13.1. PETROPERÚ y EL CLIENTE convienen en que ninguno de ellos resultará responsable por el incumplimiento de una obligación, o por su ejecución parcial, tardía o defectuosa, siempre que ello se deba a Caso Fortuito o de Fuerza Mayor, definido como la causa no imputable, consistente en un evento extraordinario, imprevisible e irresistible, que impide la ejecución de la obligación o determina su cumplimiento parcial, tardío o defectuoso, tal como lo define el artículo $1315^{\circ}$ del Código Civil.

13.2 De perdurar la situación de Caso Fortuito o Fuerza Mayor, por un período mayor de tres (3) días hábiles continuos o diez (10) días hábiles acumulados en el mes calendario, que hiciese aconsejable la resolución del presente Contrato, será de aplicación lo dispuesto en los artículos $1316^{\circ}$ y $1371^{\circ}$ del Código Civil. La resolución operará en forma inmediata, mediante Carta Notarial que curse la parte afectada.

\section{CLÁUSULA DÉCIMO CUARTA: CONFLICTO DE INTERESES}

EL CLIENTE garantiza no conocer de algún conflicto de intereses respecto al presente Contrato y garantiza expresamente que desconoce o que no existe razón para pensar que alguno de los trabajadores de PETROPERÚ tiene interés particular o derechos de alguna clase en los negocios de EL CLIENTE. Si existiera conflicto de intereses, PETROPERÚ podrá dar por resuelto el Contrato, sin multa o pago de ningún tipo de penalidad o indemnización, a partir de la fecha del aviso correspondiente, sin perjuicio de las acciones legales a que diere lugar.

\section{CLÁUSULA DÉCIMO OUINTA: SOLUCIÓN DE CONTROVERSIAS}

Las Partes acuerdan que toda controversia, incluidas las referidas a la celebración, existencia, validez, eficacia, interpretación, ejecución o resolución del presente Contrato, se tratará de resolver mediante trato directo, en base a las reglas de la buena fe y a la común intención de las partes. Para estos efectos, cualquiera de las Partes podrá notificar por escrito a la otra, para que en un plazo de quince (15) días 
calendario, contados a partir de la recepción de dicha notificación, se efectúe el trato directo entre los representantes de ambas Partes, con el objeto de resolver la controversia. Dicho plazo puede ser ampliado por acuerdo de las Partes.

Una vez vencido dicho plazo y no habiendo un acuerdo de las Partes, respecto de la controversia, cualquiera de ellas podrá iniciar el procedimiento de conciliación ante un Centro de Conciliación acreditado ante el Ministerio de Justicia y/o iniciar un arbitraje de derecho.

En caso de arbitraje, las Partes se someten a la organización y administración del Centro de Arbitraje de la Cámara de Comercio de Lima, y de acuerdo con su Reglamento y Estatuto que las Partes declaran conocer y aceptar incondicionalmente. El arbitraje será en idioma castellano y resuelto por un árbitro único designado por el Centro de Arbitraje de la Cámara de Comercio de Lima. La sede del arbitraje será en la ciudad de Lima.

El laudo arbitral emitido es vinculante para las Partes y pondrá fin al procedimiento de manera definitiva, siendo el laudo inapelable ante el Poder Judicial o ante cualquier instancia administrativa, salvo los casos taxativos previstos para el recurso de anulación de laudo contemplado en la Ley de Arbitraje.

\section{CLÁUSULA DÉCIMO SEXTA: SERVICIOS COMPLEMENTARIOS}

Las partes contratantes acuerdan que PETROPERÚ puede otorgar otros servicios complementarios al objeto del presente Contrato, los mismos que se implementarán a través de la suscripción de la adenda respectiva.

\section{CLÁUSULA DÉCIMO SÉPTIMA: DOMICILIO}

Las partes contratantes señalan como su domicilio el mencionado en la parte introductoria del presente contrato. El cambio de domicilio deberá ser puesto en conocimiento de la otra parte, debiendo comunicarlo por documento escrito remitido con cinco (5) días calendario de anticipación a la fecha en que se efectúe el cambio, salvo caso fortuito o fuerza mayor, en los que se notificará por escrito el cambio dentro de los cinco (5) días calendario posteriores a la fecha de producido el evento. 
En señal de conformidad y aceptación, las partes suscriben dos (2) ejemplares del presente Contrato, en la ciudad de Lima, a los [*] días del mes de [*] de 20[*].

Por PETROPERÚ:

Por EL CLIENTE:

$[*]$ 